\title{
Alcohol consumption as a risk factor for colorectal cancer : an epidemiological study on genetic susceptibility and molecular endpoints
}

Citation for published version (APA):

Bongaerts, B. W. C. (2008). Alcohol consumption as a risk factor for colorectal cancer : an epidemiological study on genetic susceptibility and molecular endpoints. [Doctoral Thesis, Maastricht University]. Datawyse / Universitaire Pers Maastricht. https://doi.org/10.26481/dis.20081016bb

Document status and date:

Published: 01/01/2008

DOI:

10.26481/dis.20081016bb

Document Version:

Publisher's PDF, also known as Version of record

Please check the document version of this publication:

- A submitted manuscript is the version of the article upon submission and before peer-review. There can be important differences between the submitted version and the official published version of record. People interested in the research are advised to contact the author for the final version of the publication, or visit the DOI to the publisher's website.

- The final author version and the galley proof are versions of the publication after peer review.

- The final published version features the final layout of the paper including the volume, issue and page numbers.

Link to publication

\footnotetext{
General rights rights.

- You may freely distribute the URL identifying the publication in the public portal. please follow below link for the End User Agreement:

www.umlib.nl/taverne-license

Take down policy

If you believe that this document breaches copyright please contact us at:

repository@maastrichtuniversity.nl

providing details and we will investigate your claim.
}

Copyright and moral rights for the publications made accessible in the public portal are retained by the authors and/or other copyright owners and it is a condition of accessing publications that users recognise and abide by the legal requirements associated with these

- Users may download and print one copy of any publication from the public portal for the purpose of private study or research.

- You may not further distribute the material or use it for any profit-making activity or commercial gain

If the publication is distributed under the terms of Article 25fa of the Dutch Copyright Act, indicated by the "Taverne" license above, 


\section{Alcohol consumption as a risk factor for colorectal cancer}

An epidemiological study on genetic susceptibility

and molecular endpoints 
Alcohol consumption as a risk factor for colorectal cancer

An epidemiological study on genetic susceptibility and molecular endpoints

B.W.C. Bongaerts

ISBN: 978-90-5278-754-1

Cover design: Ron Pollaart

Lay-out: Yvonne Jaegers-Leenders | Brenda Bongaerts

Printed by: Datawyse | Universitaire Pers Maastricht

(C) 2008, B.W.C. Bongaerts

All rights reserved. No part of this thesis may be reproduced or transmitted in any form or by any means, electronic or mechanical, including photocopying, recording or any information storage or retrieval system, without permission in writing from the author, or, when appropriate, from the publishers of the publications. 


\title{
Alcohol consumption as a risk factor for colorectal cancer
}

\author{
An epidemiological study on genetic susceptibility \\ and molecular endpoints
}

\section{PROEFSCHRIFT}

Ter verkrijging van de graad van doctor aan de Universiteit Maastricht, op gezag van de Rector Magnificus,

Prof. Mr. G.P.M.F. Mols, volgens het besluit van het College van Decanen, in het openbaar te verdedigen op donderdag 16 oktober 2008 om 12:00 uur door:

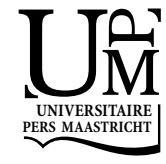




\section{Promotor}

Prof. dr. ir. P.A. van den Brandt

\section{Copromotores}

Dr. ir. M.P. Weijenberg

Dr. A.F.P.M. de Goeij

\section{Beoordelingscommissie}

Prof. dr. A.A.M. Masclee (voorzitter)

Prof. dr. R.A. Knibbe

Dr. T.M. de Kok

Prof. dr. J.H.J.M van Krieken (Radboud Universiteit, Nijmegen)

Prof. dr. ir. P. van 't Veer (Wageningen Universiteit)

The studies described in chapters 2, 3, 4 and 6 were funded by the European Research Advisory Board (ERAB).

The studies presented in this thesis were conducted at Maastricht University at the Department of Epidemiology and the Department of Pathology, Research Institute Growth and Development (GROW).

Financial support for printing of this thesis was provided by the European Research Advisory Board (ERAB), the Stichting Nationaal Fonds tegen Kanker and the Department of Epidemiology (Maastricht University). 
In the puzzle that is science, there are no straight-edged pieces.

(Thesis Daniela Ribeiro, University Wageningen 2007) 



\section{CONTENTS}

Chapter 1

Introduction

Chapter 2

Alcohol consumption, type of alcoholic beverage and risk of colorectal cancer at specific subsites

\section{Chapter 3}

Alcohol consumption, alcohol dehydrogenase $1 C$ ( $A D H 1 C)$ genotype and risk of colorectal cancer in the Netherlands Cohort Study on diet and cancer

Chapter 4

Alcohol consumption and distinct molecular pathways to colorectal cancer

Chapter 5

101

Associations of dietary methyl donor intake with $M L H 1$ promoter

hypermethylation and related molecular phenotypes in sporadic

colorectal cancer

Chapter 6

Alcohol and the risk of colon and rectal cancer with mutations in the KRAS gene

Chapter 7

General Discussion

Appendix

Summary

Samenvatting 183

Dankwoord 



\section{Introduction}



Today, alcohol is one of the major determinants of life style-related health. Whereas most people associate moderate alcohol intake with cardiovascular health benefits, not many are aware of the fact that it may also increase the risk of cancer and other chronic diseases. Being the topic of many epidemiological studies, alcohol has been related to a number diseases and conditions. This thesis focuses on alcohol consumption as a risk factor for colorectal cancer (CRC).

The current chapter will start by providing background information on alcohol including consumption levels in the Netherlands - the consequences of alcohol consumption for public and individual health and the alcohol metabolism. Next, an overview of the epidemiology of CRC will be given, followed by the current knowledge on the colorectal carcinogenic process. Subsequently, the possible mechanisms through which alcohol may contribute to CRC are addressed and the current epidemiological literature on associations between alcohol consumption and CRC risk will be evaluated. Finally, this chapter will conclude with the rationale and outline of this thesis.

\section{ALCOHOL}

\section{Consumption of alcohol}

The consumption of alcoholic beverages is culturally bound and consumption levels vary across and within countries and populations. According to estimates of the World Health Organization (WHO), about two billion people worldwide consume alcoholic drinks [1]. In 2000, the global level of alcohol consumption was estimated at approximately 5.8 liters of pure alcohol per capita per year. According to recent WHO data [2], the European Union can be indicated as the region with the highest consumption levels in the world (figure 1). Although the overall amount of alcohol consumption has declined after reaching a peak in the mid-70s, Europe's yearly per capita consumption equals 11 liters of pure alcohol, more than twice the world average [2]. 


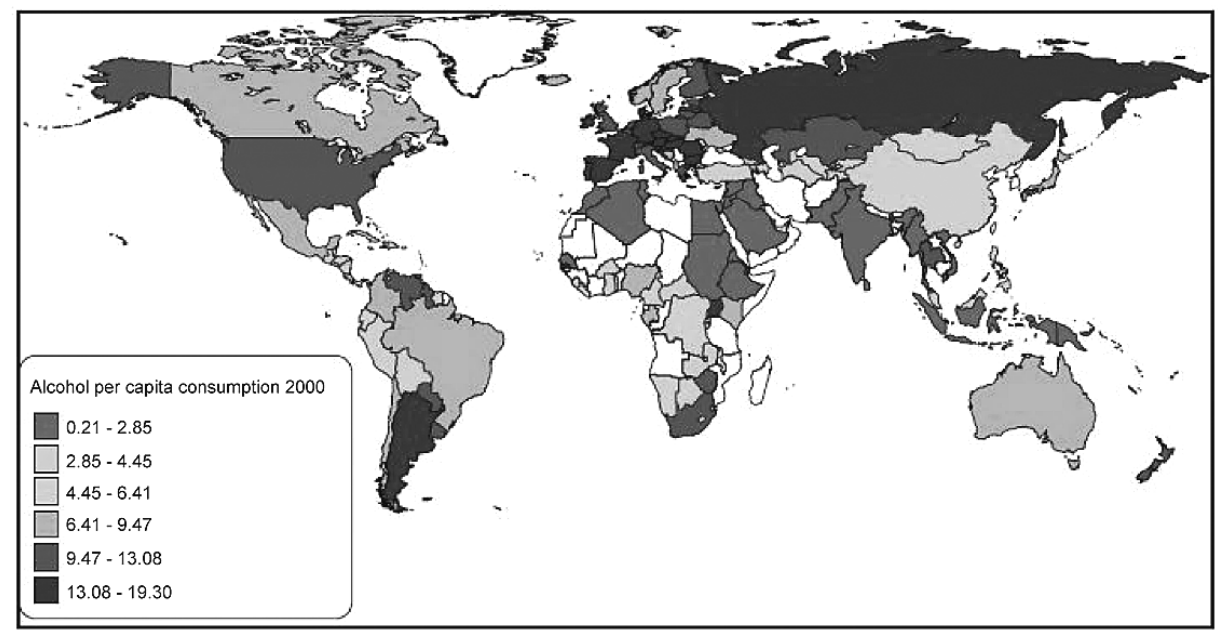

Figure 1: Adult per capita consumption of alcohol in Europe in 2000, measured in pure alcohol per capita per year. Source: Global status.report on alcohol (2004) [2]

In the Netherlands, consumption levels of total alcohol have increased since the 1960 s, to reach a peak around 1980. From that time on consumption decreased to the current level of approximately eight liters of pure alcohol per capita per year (figure 2).

In 2007, approximately $85 \%$ of the Dutch population of 12 years and older drank alcohol, the majority of which was male [3]. Among these male drinkers, $14 \%$ drank, on average, more than three alcoholic consumptions per day. For women this number was much lower and approximated $4 \%$. The percentage of abstainers among individuals aged 12 years and older, decreased from $20 \%$ to about $15 \%$ between 1995 and 2000, to increase again to almost 19\% in 2007 [3]. With regard to gender, the percentages abstainers amount to $14 \%$ in men and $23 \%$ in women.

Whereas the total amount of alcohol consumption in the Netherlands remained relatively stable over the last two decades, a shift occurred in the type of beverage that was consumed. Since 1975, wine consumption has doubled in favor of beer and liquor consumption (figure 2). A shift in drinking subgroups of the population was also seen. Since the beginning of the 1990s, the number of youngsters that have 
ever consumed alcohol has increased, particularly among boys and girls of 12 to 14 years $[4,5]$.

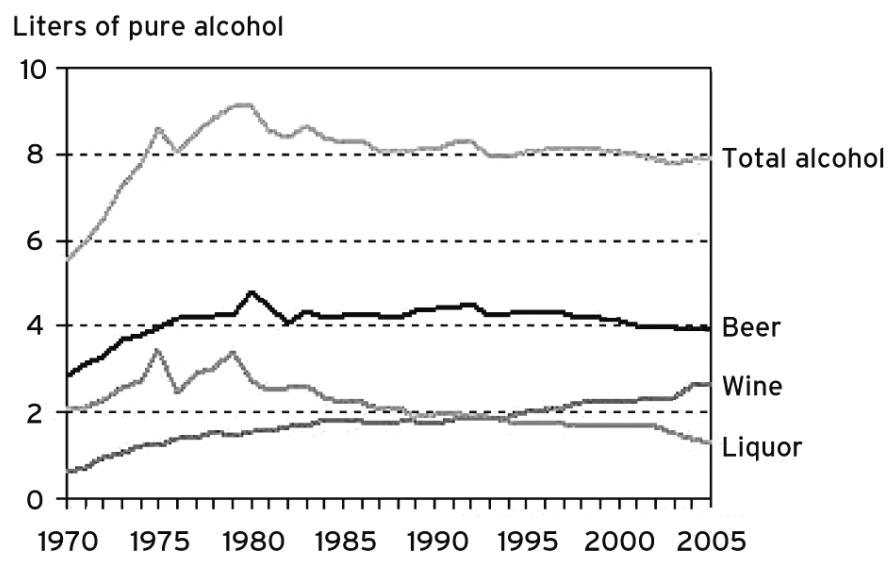

Figure 2: Trends in consumption of total alcohol and different alcoholic beverages in liters of pure alcohol per capita in the Netherlands. Source: www.euro. who.int/hfadb, accessed in January 2008.

\section{Public health impact of alcohol consumption}

The overall impact

Drinking has both immediate and long-term consequences for health and social life. The costs of alcohol-related harm to the European economy has been estimated at $1.3 \%$ of the gross domestic product (a measure expressing the value of goods and services produced in a year) [6]. These costs include expenses on crime and violence, traffic accidents, disease treatments and prevention.

With regard to public health, alcohol use is estimated to represent on average $4 \%$ of disease burden worldwide. In Western and Eastern Europe, alcohol is the third most important risk factor for disease burden after hypertension and smoking, which explain approximately $7 \%$ and $12 \%$ of disease burden, respectively $[2,7]$. In the Netherlands, alcohol consumption represents $7 \%$ of the total disease burden and is displaced by obesity from the top three of disease burdens to a fourth place [2]. 


\section{Effects on physical health}

Since long, it is known that alcohol contributes to an increased risk of illnesses and death. Alcohol has been related to more than 60 different medical conditions and diseases [7]. An overview of some important alcohol-related conditions is given below.

\section{Cardiovascular disease}

Compared to abstaining, chronic heavy drinking is a leading cause of several cardiovascular conditions and mortality, including cardiomyopathy, coronary heart disease, hypertension and arrhythmias [8]. Low to moderate drinking however, has been associated with a protective effect of cardiovascular diseases [9-13]. Mechanisms by which alcohol consumption may protect against cardiovascular diseases have been proposed and the most well-established one involves an increase in high-density lipoprotein cholesterol levels which clears fatty deposits in large blood vessels [14-16].

\section{Liver disease}

There is no question that alcohol abuse contributes significantly to liver-related morbidity and mortality $[17,18]$. The risk of liver disease is directly related to the amount of consumption [19-21]. Heavy alcohol intake is strongly associated with the development of cirrhosis, whereas the evidence for a direct carcinogenic effect of alcohol on the liver is limited [22].

\section{Diabetes mellitus type 2}

Alcohol consumption has been reported to be associated with type 2 diabetes in a Ushaped manner. Compared to both abstaining and heavy drinking, moderate levels of intake are related to a decreased risk of diabetes [23]. Several controlled trials have provided clues for the underlying mechanism $[24,25]$. Next to the total amount of consumption, drinking patterns also influence the risk of type 2 diabetes: a frequent, though low, pattern of consumption conveys the lowest risk [26].

\section{Bone conditions}

Epidemiologic studies have reported a significant dose-dependent association between alcohol consumption and risk of bone fracture and osteoporosis [27-29]. Some recent studies have suggested that moderate alcohol intakes may be associated with a decreased risk of fractures in postmenopausal women [30, 31]. 
Still, the effects of moderate consumption on bone health and risk of osteoporosis remain to be clarified [27].

\section{Brain disorders}

Alcoholism may affect the brain in several ways. Neurobehavioral conditions that are found in alcoholics seem to result from age, gender, family history of drinking and the individual's vulnerability to some forms of brain damage, in combination with a prolonged alcohol intake that impairs the way the brain normally works [32-34]. A well known neurobehavioral condition is the Wernicke-Korsakoff syndrome. The syndrome is caused by an alcohol-associated vitamin B1 deficiency, which affects a gross number of brain functions, such as memory, reasoning, language and problemsolving $[33,35,36]$.

\section{Cancer}

Alcohol has been linked to a number of cancers. For cancers of the head and neck (mouth, pharynx, larynx and esophagus) dose-dependent effects were shown in people who consumed $\geq 50 \mathrm{~g}$ of alcohol per day (approximately a half bottle of wine per day and more), when compared to non-drinkers [22, 37-39]. More than 100 epidemiological studies have consistently demonstrated a dose-dependent increase of the risk of breast cancer with chronic alcohol consumption [37, 40-43]. Alcohol is a probable cause of liver cancer [44]. A positive relationship between alcohol consumption and CRC is supported by several epidemiological studies [45-48]. To date, the exact alcohol-related mechanisms of carcinogenesis still largely remain unclear, however, seem closely related to the alcohol metabolism.

\section{The metabolism of alcohol}

After alcohol is ingested, it is absorbed from the small intestine and taken up into the blood. Alcohol is rapidly distributed over all organs and body fluids, reaching levels that equal those in the blood and the liver. Whereas only a minor percentage of the ingested alcohol $(<5 \%)$ will leave the body through breath and urine, most of it will be metabolized in the liver, the main organ for alcohol oxidation.

Alcohol is metabolized through several pathways and the most common route involves the two enzymes alcohol dehydrogenase (ADH) and aldehyde dehydrogenase (ALDH) [49]. ADH first oxidizes alcohol to acetaldehyde, a highly 
reactive, toxic and carcinogenic metabolite. In a second step, acetaldehyde is further oxidized by ALDH into acetate, a less active metabolite that subsequently will be degraded to water and carbon dioxide for easy elimination [49] (figure 3).

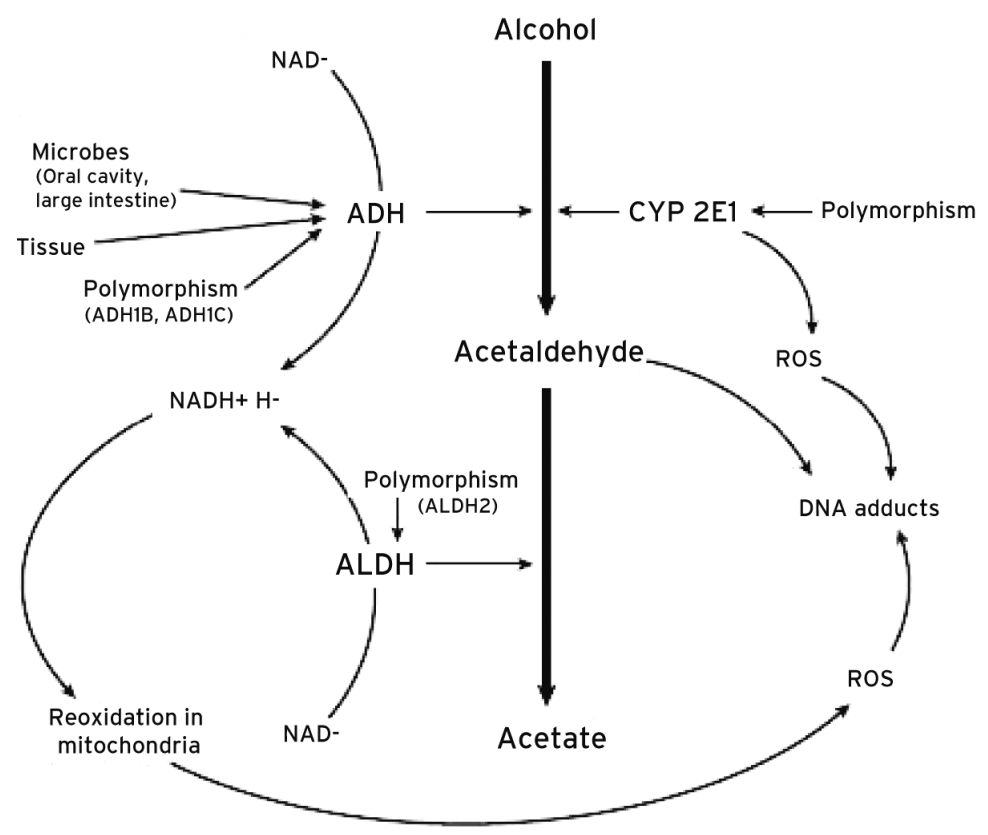

Figure 3: Pathways of alcohol metabolism.

Source: www.nature.com, accessed in March 2008.

Next to $A D H$ and ALDH, other enzymes contribute to the alcohol metabolism, such as cytochrome P450 2E1 (CYP 2E1) and, of secondary importance, catalase. CYP 2E1 is the key component of the microsomal ethanol oxidizing system (MEOS), an enzymatic system located in microsomes which metabolizes drugs and other substances [50,51]. The MEOS accounts for only a small proportion of the alcohol metabolism as the activity of CYP $2 E 1$ is induced after heavy chronic alcohol ingestion (more than $\mathbf{4 0} \mathrm{g}$ of alcohol per day for at least a week) and returns back to normal after a few days of abstention [52]. 
Whereas CYP 2E1 generates acetaldehyde from alcohol, the mechanism of production is very different from that by ADH enzymes. Acetaldehyde production through CYP $2 \mathrm{E} 1$ is associated with the generation of highly reactive oxygencontaining molecules, i.e. reactive oxygen species (ROS). ROS, such as superoxide anion $\left(\mathrm{O}^{2-}\right)$ and hydrogen peroxide $\left(\mathrm{H}_{2} \mathrm{O}_{2}\right)$, can damage proteins and DNA. Another way in which ROS can inflict harm is through peroxidation of lipids in the cell membrane. This interaction results in the generation of additional reactive molecules that are chemically related to acetaldehyde, and are thus capable of inducing DNA-adduct formation and mutations [53]. Such mechanisms of oxidative stress play an important role in cancer development, but also in inflammatory processes, aging and atherosclerosis [54].

\section{Genetic variations in alcohol metabolism}

The enzymes ADH and ALDH, which regulate the levels of acetaldehyde in the body, constitute a complex family of different enzyme classes based on kinetic and structural properties [55]. Genetic variants of some of the coding $A D H$ and $A L D H$ genes result in $A D H$ and $A L D H$ enzymes that differ in the rate at which they metabolize alcohol and acetaldehyde respectively [56].

The three class I ADH enzymes, which account for the largest part of the alcohol oxidation process, are encoded by $A D H 1 A, A D H 1 B$ and $A D H 1 C$ genes. As a result of single nucleotide polymorphisms (SNPs), three variant alleles exist for both $A D H 1 B$ $(A D H 1 B * 1, A D H 1 B * 2$ and $A D H 1 B * 3)$ and $A D H 1 C(A D H 1 C * 1, A D H 1 C * 2$ and $A D H 1 C * 3)$. ADH1B enzymes encoded by the $A D H 1 B * 2$ or $A D H 1 B * 3$ allele are 40 times more active than those encoded by the $A D H 1 B^{*} 1$ allele. Their presence is associated with a protection against alcoholism: carriers of these alleles are discouraged to drink due to a rapid production of large amounts of acetaldehyde which causes various unpleasant side effects. The frequencies of the $A D H 1 B * 2$ and $A D H 1 B * 3$ alleles are high in Asians (60-80\%), but low in Caucasian populations (0-10\%) [57]. ADH1C enzymes encoded by the $A D H 1 C^{* 1}$ allele convert alcohol approximately 2.5 times faster than enzymes encoded by the $A D H 1 C * 2$ allele. The frequency for both alleles in Caucasians is about $40-60 \%$ [56]. The $A D H 1 C * 3$ allele has only recently been described in native American populations and has not been studied in relation to alcohol yet [58] . 
The ALDH enzyme largely responsible for the conversion of acetaldehyde into acetate is ALDH2. A SNP converts the wild type $A L D H 2 * 1$ allele into the practically inactive $A L D H 2 * 2$ allele. Homozygotes for $A L D H 2 * 2$ are thus unable to oxidize acetaldehyde. As a consequence, the presence of even a single $A L D H 2 * 2$ allele is a strongly protective factor against alcoholism $[59,60]$. The allele is relatively common in Asian populations (40-50\%), yet essentially absent in European and African populations [57]. Other members of the $A L D H$ family are either not polymorphic ( $A L D H I)$ or have a low affinity to acetaldehyde and are therefore not involved in the alcohol metabolism [61].

Acetaldehyde levels, as found in the colorectum, are predominantly being produced by $\mathrm{ADH}$ activity of the colonic microflora and to a lesser extent by $\mathrm{ADH}$ activity of the intestine's mucosal cells. Both bacteria and mucosal cells are thus capable of metabolizing alcohol to acetaldehyde however, their ALDH activity is low [62-65]. In fact, this makes the colorectal mucosa, of all tissues in the body, the one containing the largest concentrations of acetaldehyde per gram of tissue following alcohol consumption [66].

Before we will further discuss the possible role of alcohol and the alcohol metabolism in CRC development, we will first address some general information on the epidemiology and development of CRC.

\section{COLORECTAL CANCER}

\section{The burden of colorectal cancer}

Worldwide, CRC accounts for about one million new cancers diagnosed each year, representing approximately $9 \%$ of the total cancer incidence [67]. CRC is a very common disease in industrialized parts of the world, such as Northern America, Western Europe, Australia and New Zealand, and is relatively uncommon in Africa and large parts of Asia. In the Netherlands in 2003, nearly 10,000 individuals have been diagnosed with the disease. CRC is therefore the third most common form of cancer in men and the second most common form in women in the Netherlands [68]. The risk of CRC, as of all cancers, increases with age. Among individuals of 50 years and older, the incidence rapidly increases. Life-time risk to develop a colorectal 
tumor before the age of 75 is slightly higher for men (4-6\%) than for women $(2-4 \%)$ [69]. Despite advances in diagnostic and therapeutic methods, the prognosis for patients with CRC is heavily dependent on disease stage at the time of diagnosis. In 2003 , approximately $45 \%$ of the CRC patients in the Netherlands have died.

The colorectal tract can grossly be divided into two sections, i.e. the colon, in which extraction of water and salts from the bowel content takes place, and the rectum, that functions as a temporary storage facility for feces. Whereas a distinction between colon and rectal cancer is usually made in studies that examine CRC, a more comprehensive distinction in anatomical subsites can be made, i.e. proximal (or right-sided) colon, distal (or left-sided) colon, rectosigmoid and rectum (figure 4). Based on data of the Netherlands Cancer Registry in 2003, the distribution of colorectal tumors over the distinct anatomical subsites was $31 \%, 27 \%, 9 \%$ and $27 \%$ for the proximal colon, distal colon, rectosigmoid and rectum, respectively [70].

\section{The colorectal carcinogenic process}

It is widely accepted that the carcinogenic process requires an accumulation of several molecular aberrations that alter the behavior of the cell, giving it a certain growth advantage. As such, normal growth may progressively convert to malignant behavior. This model of tumorigenesis has been confirmed by numerous molecular studies of various types of cancer [71-73].

The crypt-shaped colorectal mucosa (figure 4) is a rapidly proliferating tissue. The epithelial layer is continually being renewed. For this renewal process, several stem cells located at the bottom of each crypt are responsible. Epithelial cells are born as daughters of these stem cells; they differentiate into mature colonocytes within two to three days while migrating up the crypt to the mucosal surface $[74,75]$. When reaching the top of the crypt, the colonocytes will subsequently be shed into the gut lumen and undergo apoptosis [75]. The rate of cell replacement by the stem cells in the crypts must be in perfect equilibrium with the loss of colonocytes. A disruption of this balance in favor of hyperproliferation, may lie at the basis of a neoplastic transformation [74].

The 'classical' molecular model for the development of CRC was proposed by Fearon and Vogelstein in 1990, known as the adenoma-carcinoma sequence or the 
Vogelstein model (figure 5) [71]. T his model describes the pathway of events leading from normal mucosa via a premalignant adenoma to a carcinoma. It was assumed that an accumulation of genetic and molecular aberrations would exert their effect on the cell through a loss of control over cell growth and differentiation [76].

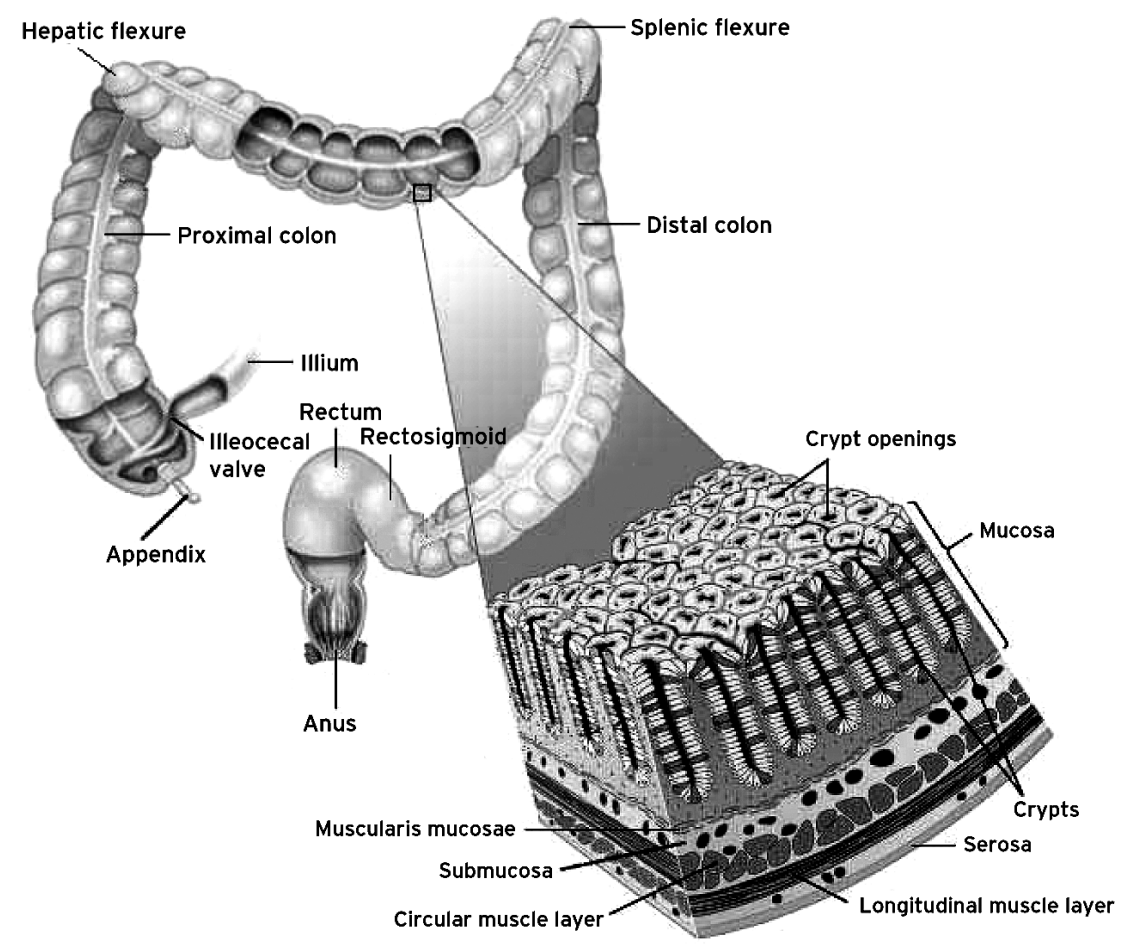

Figure 4: The anatomy of the colorectal tract, including a magnification of the crypt-shaped colorectal mucosa.

Source: http://www.britannica.com/eb/art-68639, accessed in March

According to the model, the colorectal carcinogenic process is initiated by the inactivation of the tumor suppressor gene $A P C$. The colorectal crypt in which the $A P C$-mutant cell is located will become dysplastic, as abnormal cells accumulate to slowly form a polyp or adenoma (figure 5) [77]. For an adenoma to increase in size additional mutations are required, such as KRAS oncogene mutations and SMAD2 
and SMAD4 tumor suppressor gene inactivation. Subsequently, $10-20 \%$ of these larger adenomas will progress to a carcinoma by acquiring further mutations in genes involved in the TP53 pathway and others [78].

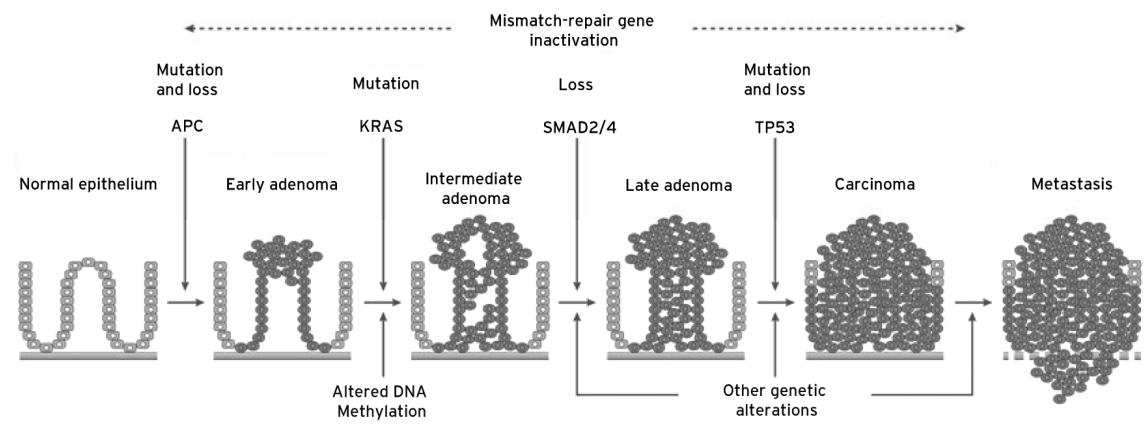

Figure 5: A multi-step model for colorectal cancer.

Source: www.nature.com, accessed in January 2008 .

The use of the laboratory technique of restriction fragment length polymorphism (RFLP) analysis, allowed Vogelstein and colleagues to compare colorectal tumor DNA from colonic tissue samples with adjacent normal DNA [79]. They discovered that allelic losses were a common and a random occurring event in most CRCs. Allelic losses appeared to be important in the progression from colorectal adenoma to carcinoma [80] and losses of specific chromosomal loci seemed meaningful for patient prognosis [81]. The process that Vogelstein and coworkers observed was called chromosomal instability (CIN) [82].

Research over the last 20 years however, has shown that the natural history of adenomas and carcinomas is extremely variable and that tumorigenesis is a much more complex and heterogeneous process than described in the Vogelstein model. In the early 1990s, a number of research groups developed novel approaches using the Polymerase Chain Reaction (PCR) technique to screen the genome for chromosomal losses or gains in order to find loci of novel tumor suppressor genes or oncogenes, respectively [83]. Unexpectedly however, it was discovered that certain 
short repetitive DNA sequences (microsatellites) in the cancer genome frequently presented deletions or insertions that did not occur in normal DNA. Consequently, a second pathway for CRC development was acknowledged and was named microsatellite instability (MSI) [84-86]. It was the discovery of this second route that triggered the idea that there might be more than one etiologic pathway to CRC. In addition, when the Vogelstein model was first presented, hypermethylation of gene promoter regions as a mechanism to inactivate tumor suppressor and DNA repair genes was not considered to be of importance. However, the discovery that the retinoblastoma and the Von Hippe/-Lindau tumor suppressor genes were both subject to a methylation-associated silencing made clear that promoter hypermethylation might be a broader issue in cancer [87]. This mechanism was termed CpG Island Methylator Phenotype (CIMP) [88] and nowadays, the phenomenon is considered to play a central role in tumorigenesis [89].

By examining the molecular and genetic characteristics of colorectal tumors, it has become clear that CRC is not a single disease and that several tumor subtypes exist based on their molecular features [90]. Molecular classifications of colorectal tumors may reflect their underlying etiologic pathway and are thus considered very important in CRC research. Here, three broad molecular classifications of CRC will be briefly discussed.

\section{Chromosomal Instability}

Approximately $85 \%$ of sporadic CRCs display a form of genetic instability that is characterized by an abnormal chromosomal content (aneuploidy). Aneuploidy in these cancers is the result of an accelerated rate of gains and losses of entire or large portions of chromosomes during cell division [91]. Loss of heterozygosity (LOH) for example, may be an evident mechanism by which CIN can contribute to inactivation of tumor suppressor genes. Also, CIN can provide mechanisms by which a cancer cell is able to adjust its growth characteristics in order to survive changes in environment related to metastasis and chemotherapy [78]. CIN tumors have been associated with a distal tumor localization, mutations in APC, KRAS and TP53 and a non-mucinous tumor differentiation. Many genetic mechanisms with a potential to cause CIN have been proposed $[82,90]$ and epigenetic events (events that involve changes in the DNA, other than mutational changes), such as methylation, may play a significant role as well [92]. The identification of key genes responsible for CIN is still in its infancy and whether the observed (epi)genetic changes are the cause, 
rather than the consequences of $\mathrm{CIN}$, remains an essential question for future research $[91,93]$.

\section{Microsatellite Instability}

About $10-15 \%$ of CRCs exhibit a form of genetic instability that is characterized by DNA mismatch repair deficiency [90]. Mismatch repair defects result in an accumulation of unrepaired mutations, largely present in short repetitive sequences in both coding and non-coding DNA, called microsatellites. The most common cause of $\mathrm{MSI}$ is identified as the functional loss of the $M L H 1$ mismatch repair gene through promoter methylation that results in silencing of the gene [94]. MSI can be assessed by analyzing a panel of five microsatellite markers, whereas additional markers are commonly tested to increase the accuracy [95]. Subsequently, a distinction can be made according to the degree of instability: tumors are considered highly instable (MSI-H) if over $30 \%$ of the investigated microsatellite loci demonstrate instability, whereas tumors are considered to have a low degree of instability (MSI-L) if less than $30 \%$ of the investigated loci demonstrate instability [96]. MSI tumors are linked to a mucinous tumor differentiation, KRAS mutations, wild type TP53 and localization in the proximal colon. Microsatellite instability may also be abbreviated as MIN.

\section{CpG Island Methylator Phenotype}

Methylation of DNA is an epigenetic means of regulating gene expression. As a distinct CRC phenotype, CIMP is characterized by the excessive methylation of CpGrich sequences in the DNA, called CpG islands. These islands are stretches of DNA that contain clusters of $C p G$ dinucleotides which are located in the promoter regions of almost half of all genes [90, 97]. In normal cells, CpG islands are mostly unmethylated. In virtually each type of human cancer however, CpG islands have been found to be hypermethylated, a condition that is associated with transcriptional silencing of the gene in question [98]. Whereas panels of methylation markers and the assessment of CIMP are not yet standardized, a distinction into CIMP-high (CIMP-H) and CIMP-low (CIMP-L) tumors is generally based on the number of methylated markers examined [90]. CIMP-H tumors are associated with a proximal tumor localization, female sex, poor tumor differentiation, MSI, a high frequency of BRAF mutations and low mutation rates of TP53 [97, 99-102]. The occurrence of CIMP-L tumors on the other hand, is associated with KRAS mutations and male sex, independent of MSI status [103]. 


\section{ALCOHOL AND CRC}

Knowledge of CRC development and the genes involved, is essential when studying the role of alcohol consumption in CRC. In this paragraph, several proposed mechanisms for alcohol-associated colorectal carcinogenesis are discussed followed by an overview of the available epidemiological literature.

\section{Alcohol-induced carcinogenesis}

The exact mechanisms by which alcohol invokes the carcinogenic process have not been clarified yet. As mentioned before, alcohol-related tumorigenesis seems closely related to the alcohol metabolism. The evidence has piled up against acetaldehyde as an important cancer-causing agent.

Acetaldehyde is a known carcinogen in animals [104]. For example, acetaldehyde induces inflammation and transformation of the cells lining the trachea. Acetaldehyde interferes with normal reproduction of cells and enhances cell injury of the gastrointestinal mucosa, linked to excessive cell growth [66]. One of the processes through which acetaldehyde may promote tumor formation is by interfering, with DNA-replication during cell division. In vitro studies have shown that acetaldehyde causes point mutations in certain genes, and induces sisterchromatid exchanges and gross chromosomal aberrations in human cells $[105,106]$. Moreover, acetaldehyde impairs the process through which naturally occurring damage to the DNA is repaired by inhibiting DNA repair enzymes, such as 06-methyl guanine methyltransferase, and important anti-oxidative peptides, such as glutathione [107, 108]. In addition to these mechanisms, acetaldehyde can interact with the DNA to form new molecules - DNA adducts - which have been found in chronic alcohol consumers $[109,110]$. These adducts may trigger replication errors and/or mutations in oncogenes or tumor suppressor genes [111]. The level of DNAadducts is influenced by several factors such as the activity of the anti-oxidative defense system, the DNA repair system and apoptosis. These factors in turn, may be directly or indirectly influenced by chronic alcohol consumption [112].

Acetaldehyde has also been shown to have accute toxic effects on the colorectal mucosa. Experimental studies in rats showed that chronic alcohol intake increased mucosal cell-regeneration in the rectum, suggested to be induced by mucosal cell 
injury as a principal result of acetaldehyde's toxicity [66, 113]. As known from studies in both experimental animals [114] and humans [115], such mucosal cellhyperregeneration, regardless of its underlying cause, predisposes to CRC development. The toxic effects of acetaldehyde on the colorectal mucosa have been confirmed in humans as well [49].

Another mechanism through which acetaldehyde may increase the risk of CRC involves folate, a B-vitamin that is important for overall cell regeneration and protection of the DNA. A growing body of epidemiological, clinical and animal studies have suggested that folate deficiency is an important factor in colorectal carcinogenesis [116]. In heavy abusers of alcohol (more than 10 alcoholic drinks per day) an inadequate dietary intake of folate is very common, together with deficiencies of many other micronutrients [117]. In addition, alcohol abusers have been shown to malabsorb folate $[118,119]$. Another mechanism by which alcohol may reduced folate availability, suggests that high acetaldehyde levels in the colorectum cleave the folate molecule into metabolic inactive components. Still, direct evidence for this concept is only provided by in vitro experiments [120]. Whereas insufficient intakes and malabsorption do not per definition apply to low and moderate drinkers, a diminished bioavailability of folate may occur in relatively low level drinkers as well. Both acute and chronic consumption may increase the loss of folate in the urine through a reduced tubular re-absorption [121, 122].

\section{Current epidemiological evidence}

\section{Alcohol consumption and risk of CRC}

The relationship between alcohol consumption and the risk of CRC has been investigated in numerous case-control and cohort studies. In general, these studies have reported positive associations. However, results have been relatively inconclusive with regard to the amount of alcohol that poses a risk and whether or not associations are dependent on the type of alcoholic beverage consumed, gender, and the anatomical tumor localization. These inconsistencies can be explained by several methodological aspects of the studies, including study design and sample size of the study population. Large meta-analyses $[47,48,123]$, pooled analyses [45] and multi-centre studies [124] may therefore provide more clarity on the relationship between alcohol and CRC. The findings of these large epidemiological studies are summarized in table 1. Overall, a positive association between alcohol 
consumption and risk of CRC has been observed: two alcoholic beverages per day are associated with an increase in risk of approximately 10\%. CRC risk increases with the amount of alcohol consumed. Associations do not seem to depend on beverage type, sex and anatomical tumor localization.

Table 1: Summary of the findings of large meta-analyses, pooled analyses and multi-centre studies with regard to the associations between alcohol consumption and risk of colorectal cancer in men and women

\begin{tabular}{|c|c|c|c|c|c|}
\hline Reference & $\begin{array}{l}\text { Contrast in } \\
\text { alcohol exposure }\end{array}$ & RR $(95 \% \mathrm{Cl})$ & $\begin{array}{c}\text { Beverage- } \\
\text { specific effect }\end{array}$ & $\begin{array}{c}\text { Sex-specific } \\
\text { effect }\end{array}$ & $\begin{array}{c}\text { Subsite-specific } \\
\text { effect }\end{array}$ \\
\hline \multicolumn{6}{|l|}{ Meta-analyses } \\
\hline $\begin{array}{l}\text { Longnecker et al. } 1990 \\
\text { [48] }\end{array}$ & $24 \mathrm{vs} 0 \mathrm{~g} / \mathrm{d}$ & $1.10(1.05-1.14)$ & N.S. & N.S. & N.S \\
\hline \multirow[t]{3}{*}{$\begin{array}{l}\text { Bagnardi et al. } 2001 \\
\text { [125] }\end{array}$} & $25 v s 0 \mathrm{~g} / \mathrm{d}$ & $1.08(1.06-1.10)$ & N.A. & N.A. & N.A. \\
\hline & $50 v s 0 \mathrm{~g} / \mathrm{d}$ & $1.18(1.14-1.22)$ & & & \\
\hline & $100 v \boldsymbol{s} 0 \mathrm{~g} / \mathrm{d}$ & $1.38(1.29-1.49)$ & & & \\
\hline \multicolumn{6}{|l|}{ Pooled analyses } \\
\hline \multirow[t]{3}{*}{ Cho et al. 2004 [45] } & $>15$ to $<30 v s 0 \mathrm{~g} / \mathrm{d}$ & $1.01(0.86-1.18)$ & N.S. & N.S. & N.S. \\
\hline & 30 to $<45 v s 0 \mathrm{~g} / \mathrm{d}$ & $1.16(0.99-1.36)$ & & & \\
\hline & $\geq 45$ vs $0 \mathrm{~g} / \mathrm{d}$ & $1.41(1.16-1.72)$ & & & \\
\hline \multicolumn{6}{|l|}{ Multi centre studies } \\
\hline \multirow[t]{2}{*}{ Ferrari et al. 2007 [124] } & 15 to $<30 v s 0 \mathrm{~g} / \mathrm{d}$ & $1.03(0.88-1.20)$ & N.S. & N.S. & N.S. \\
\hline & 30 to $<60 v s 0 \mathrm{~g} / \mathrm{d}$ & $1.26(1.06-1.49)$ & & & \\
\hline
\end{tabular}

RR: Incidence Risk Ratio; Cl: Confidence interval; N.S.: not statistically significant; N.A.: not available

\section{Alcohol consumption, ADH1C genotype and risk of CRC}

Another explanation for the inconsistent findings among the smaller individual studies on associations between alcohol consumption and risk of CRC may involve a genetic variation in the rate of alcohol metabolism, which consequently may result in a genetic susceptibility for alcohol-related CRC. The main alcohol metabolizing enzymes are $A D H$ and $A L D H$ and as explained in the first paragraph of this chapter. In Caucasian populations, the polymorphic $A D H 1 C$ gene is responsible for a variation in the rate at which acetaldehyde is produced from alcohol. The rate of acetaldehyde 
production in turn, may have its consequences for CRC development. Results from previous studies on alcohol, $A D H 1 C$ genotype and risk of colorectal neoplasias are summarized in table 2.

Chen et al. and Giovannucci et al. reported an increased risk of colorectal cancer and adenomas for drinkers in the highest consumption category with the $A D H 1 C * 2 / * 2$ genotype, compared to the reference group of drinkers in the lowest consumption category with the $A D H 1 C * 1 / * 1$ genotype, respectively $[126,127]$. Contradictory to these two studies, Tiemersma et al. considered low level drinkers with the $A D H 1 C^{*} 1 / 2$ and $A D H 1 C^{*} 2 /{ }^{*} 2$ genotypes combined as reference group. Compared to this reference group, the authors observed an increased risk of colorectal adenomas for high level drinkers with the $A D H 1 C^{* 1} 1{ }^{* 1}$ genotype [128]. In none of these three studies the interaction term between alcohol consumption and $A D H 1 C$ genotype reached statistical significance.

Table 2: Summary of the findings of the epidemiological studies on alcohol consumption, alcohol dehydrogenase $1 \mathrm{C}$ genotype and risk of colorectal neoplasias in men and women

\begin{tabular}{|c|c|c|c|}
\hline Reference & Endpoint & $\begin{array}{c}\text { Contrast in alcohol exposure and } \\
\text { ADHIC genotype }\end{array}$ & RR (95\% Cl) \\
\hline \multicolumn{4}{|c|}{ Nested case-control studies } \\
\hline \multirow[t]{3}{*}{ Chen et al. 2001 [126] } & Colorectal cancer & $\begin{array}{c}\geq 5 \text { drinks/week and } A D H 1 C^{* 1 / * 1} \text { vs } \\
<1 \text { drink/week and } A D H 1 C^{* 1} /{ }^{* 1}\end{array}$ & $1.31(0.73-2.35)$ \\
\hline & & $\begin{array}{c}\geq 5 \text { drinks/week and } A D H 1 C * 1 / * 2 \text { vs } \\
<1 \text { drink/week and } A D H 1 C * 1 / * 1\end{array}$ & $1.00(0.56-1.78)$ \\
\hline & & $\begin{array}{c}\geq 5 \text { drinks/week and } A D H 1 C^{*} 2 /{ }^{* 2} \text { vs } \\
<1 \text { drink/week and } A D H 1 C^{* 1} /{ }^{* 1}\end{array}$ & $1.63(0.77-3.45)$ \\
\hline \multirow[t]{3}{*}{$\begin{array}{l}\text { Giovannucci et al. } \\
2003 \text { [127] }\end{array}$} & Colorectal adenomas & $\begin{array}{l}\geq 30 \mathrm{~g} / \mathrm{d} \text { and } A D H 1 C^{* 1} /{ }^{* 1} \text { vs } \\
\leq 5 \mathrm{~g} / \mathrm{d} \text { and } A D H 1 C^{* 1} /{ }^{* 1}\end{array}$ & $1.27(0.63-2.53)$ \\
\hline & & $\begin{array}{c}\geq 30 \mathrm{~g} / \mathrm{d} \text { and } A D H 1 C * 1 / * 2 \text { vs } \\
\quad \leq 5 \mathrm{~g} / \mathrm{d} \text { and } A D H 1 C * 1 / * 1\end{array}$ & $1.83(1.03-3.26)$ \\
\hline & & $\begin{array}{l}\geq 30 \mathrm{~g} / \mathrm{d} \text { and } A D H 1 C * 2 / * 2 \mathrm{vs} \\
\quad \leq 5 \mathrm{~g} / \mathrm{d} \text { and } A D H 1 C * 1 / * 1\end{array}$ & $2.94(1.24-6.92)$ \\
\hline \multicolumn{4}{|l|}{ Case-control studies } \\
\hline \multirow[t]{2}{*}{$\begin{array}{l}\text { Tiemersma et al. } \\
2003[128]\end{array}$} & Colorectal adenomas & $\begin{array}{c}\geq 10 \text { drinks/week and } A D H 1 C * 1 /{ }^{* 1} \text { vs } \\
<1 \text { drink/week and } A D H 1 C * 1 / * 2 \text { and } A D H 1 C * 2 / * 2\end{array}$ & $1.76(1.00-3.11)$ \\
\hline & & $\begin{array}{c}\geq 10 \text { drinks/week and } A D H 1 C^{* 1} /{ }^{*} 2 \text { and } A D H 1 C^{*} 2 /{ }^{*} 2 \text { vs } \\
<1 \text { drink/week and } A D H 1 C^{* 1} /{ }^{*} 2 \text { and } A D H 1 C^{*} 2 /{ }^{*} 2\end{array}$ & $1.15(0.70-1.90)$ \\
\hline
\end{tabular}

ADH1C: Alcohol dehydrogenase 1C; RR: Incidence Risk Ratio; Cl: Confidence interval 
Alcohol consumption and risk of CRC according to specific genetic aberrations Next to studying genetic susceptibility to alcohol-related CRC, the evaluation of molecular cancer endpoints may provide further insights into associations between alcohol and CRC. A distinction can be made into studies that have examined alcohol in relation to single molecular CRC aberrations, and those that have examined alcohol in relation to specific molecular CRC subgroups. The results of the first, all case-control studies, are summarized in table 3.

Table 3: Summary of the findings of epidemiological studies on alcohol consumption and risk of colon cancer and colorectal cancer overall in men and women, harboring molecular aberrations; case-control studies only

\begin{tabular}{|c|c|c|c|}
\hline Reference & Molecular endpoint & Contrast in alcohol exposure & RR $(95 \% \mathrm{Cl})$ \\
\hline \multicolumn{4}{|l|}{$A P C$} \\
\hline \multirow{4}{*}{$\begin{array}{l}\text { Diergaarde et al. } 2003 \\
\text { [133] }\end{array}$} & Colorectal cancer; wild type $A P C$ & 3.8 to $12.9 v s<3.8 \mathrm{~g} / \mathrm{d}$ & $0.9(0.5-1.6)$ \\
\hline & & $>12.9$ vs $<3.8 \mathrm{~g} / \mathrm{d}$ & $1.7(1.0-3.0)$ \\
\hline & Colorectal cancer; $A P C$ mutation & 3.8 to $12.9 v s<3.8 \mathrm{~g} / \mathrm{d}$ & $0.6(0.3-1.2)$ \\
\hline & & $>12.9$ vs $<3.8 \mathrm{~g} / \mathrm{d}$ & $0.5(0.3-1.1)$ \\
\hline \multicolumn{4}{|l|}{ BRAF } \\
\hline \multirow[t]{4}{*}{$\begin{array}{l}\text { Slattery et al. } 2007 \\
\text { [131] }\end{array}$} & MSI colorectal cancer; wild type $B R A F$ & Moderate drinking vs none & $1.2(0.7-2.0)$ \\
\hline & & high drinking vs none & $2.2(1.2-3.7)$ \\
\hline & MSI colorectal cancer; $B R A F$ mutation & Moderate drinking $\boldsymbol{v s}$ none & $1.0(0.5-1.8)$ \\
\hline & & high drinking vs none & $1.1(0.6-2.3)$ \\
\hline \multicolumn{4}{|l|}{ KRAS } \\
\hline \multirow[t]{4}{*}{$\begin{array}{l}\text { Slattery } \\
\text { [134] }\end{array}$} & Colon cancer; wild type KRAS & $\leq 10$ vs $0 \mathrm{~g} / \mathrm{d}$ & $0.9(0.8-1.2)$ \\
\hline & & $>10 v s 0 \mathrm{~g} / \mathrm{d}$ & $1.0(0.8-1.2)$ \\
\hline & Colon cancer; KRAS mutation & $\leq 10$ vs $0 \mathrm{~g} / \mathrm{d}$ & $0.8(0.6-1.0)$ \\
\hline & & $>10$ vs $0 \mathrm{~g} / \mathrm{d}$ & $0.8(0.6-1.0)$ \\
\hline \multicolumn{4}{|l|}{ TP53 } \\
\hline \multirow[t]{2}{*}{$\begin{array}{l}\text { Fredrikson et al. } 1996 \\
\text { [135] }\end{array}$} & $\begin{array}{r}\text { Colorectal cancer; no TP53 protein } \\
\text { overexpression }\end{array}$ & highest vs lowest category & $0.6(0.3-1.2)$ \\
\hline & $\begin{array}{r}\text { Colorectal cancer; TP53 protein } \\
\text { overexpression }\end{array}$ & highest vs lowest category & $3.4(1.1-10)$ \\
\hline \multirow[t]{4}{*}{$\begin{array}{l}\text { Voskuil et al. } 1999 \\
\text { [136] }\end{array}$} & $\begin{array}{r}\text { Colorectal cancer; no TP53 protein } \\
\text { overexpression }\end{array}$ & Per quartile range of $18.2 \mathrm{~g} / \mathrm{d}$ & $1.15(0.86-1.56)$ \\
\hline & $\begin{array}{r}\text { Colorectal cancer; TP53 protein } \\
\text { overexpression }\end{array}$ & Per quartile range of $18.2 \mathrm{~g} / \mathrm{d}$ & $0.99(0.72-1.36)$ \\
\hline & Colorectal cancer; wild type TP53 & Per quartile range of $18.2 \mathrm{~g} / \mathrm{d}$ & $1.13(0.86-1.48)$ \\
\hline & Colorectal cancer; TP53 mutation & Per quartile range of $18.2 \mathrm{~g} / \mathrm{d}$ & $0.98(0.67-1.41)$ \\
\hline
\end{tabular}

RR: Incidence Risk Ratio; Cl: Confidence interval; MSI: Microsatellite instability 
Positive associations with a high versus a low alcohol intake have been described for colorectal tumors harboring wild type $A P C$ [133] and TP53 protein overexpression [135], and for a subgroup of MSI tumors that harbored wild type BRAF [131]. Alcohol consumption was not clearly related to colorectal tumors with $A P C$ mutations [133], tumors with and without KRAS mutations [134] and tumors with TP53 mutations [134, 136]. Voskuil et al. examined diet-cancer associations according to TP53 abnormalities in the tumor, whereas alcohol did not appear to be differently related to colorectal tumors with and without TP53 mutations and to those with or without overexpression of TP53. [136].

Findings for associations between alcohol consumption and molecular subgroups of CRC are presented in table 4. To date, studies that have examined associations between alcohol consumption and molecular subgroups of CRC are rare and are limited to the molecular subclassifications of MSI and CIMP. With regard to MSI, a high versus a low alcohol intake seemed to be related to an increased risk of microsatellite instable colon cancers, however, statistical significance was not reached $[129,130]$. Alcohol consumers in the highest category of intake compared to those in the lowest category, were associated with a higher risk of CIMP-H colon cancers [131]. Moreover, Curtin et al. examined interactions between long term alcohol intake and polymorphisms in genes relevant to the folate metabolism (methylenetetrahydrofolate reductase (MTHFR)) and to the alcohol metabolism $(A D H 1 C)$, in association with CIMP status in colon cancer [132]. No statistically significant interactions were observed with the exception of the interaction between long term alcohol consumption and the MTHFR $1298 \mathrm{~A}>\mathrm{C}$ polymorphism in CIMP+ tumors. 


\section{| Chapter 1}

Table 4: Summary of the findings of epidemiological studies on alcohol consumption and risk of colon cancer in men and women, according to molecular subgroups; case-control studies only

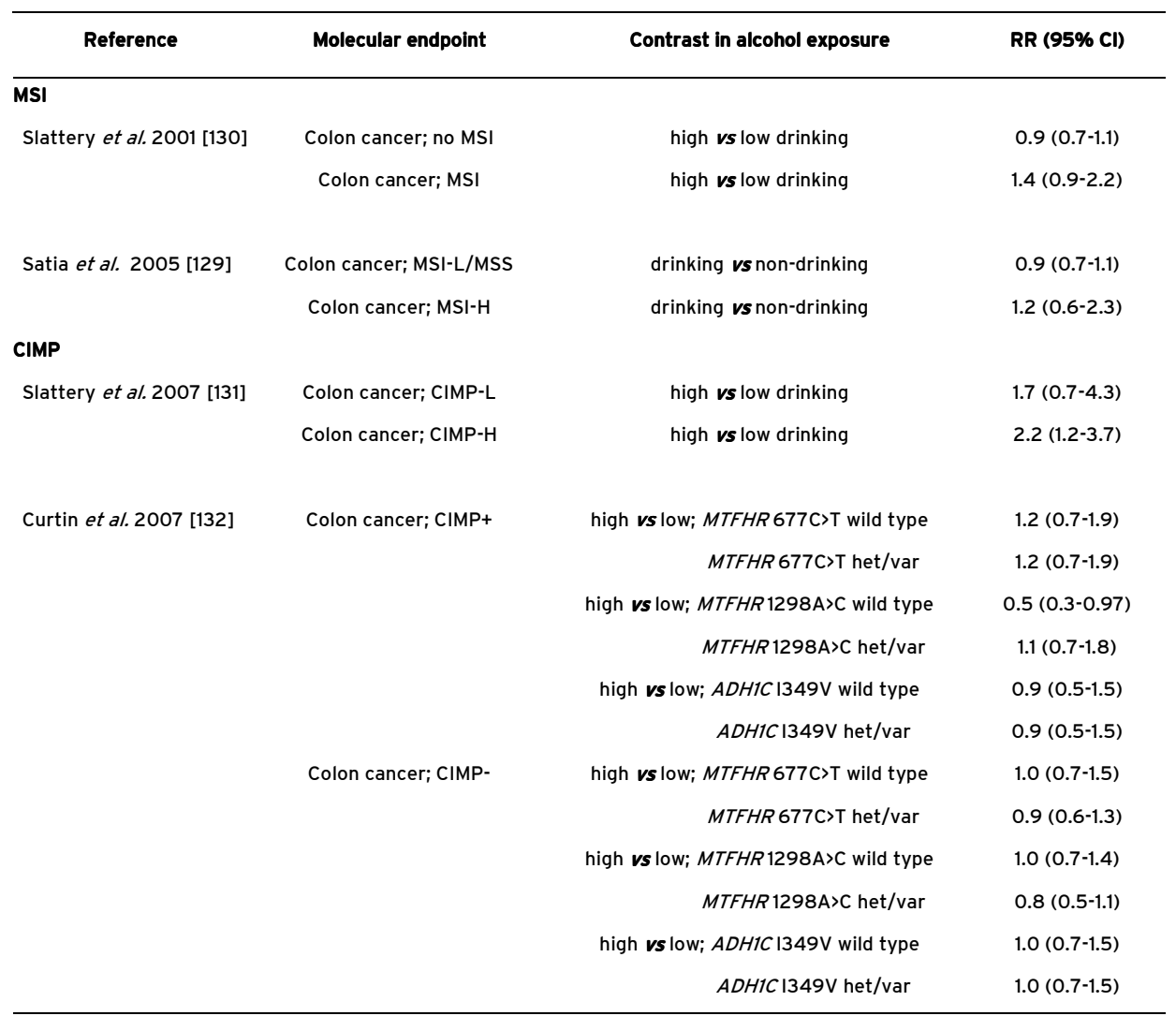

RR: Incidence Risk Ratio; Cl: Confidence interval; MSI: Microsatellite Instability; MSI-L: Microsatellite instability-low; MSS: Microsatellite stable; MSI-H: Microsatellite instability-high; CIMP-L: CpG island methylator phenotype-low; CIMP-H: CpG island methylator phenotype-high ; MTHFR: Methylenetetrahydrofolate reductase; ADH1C: Alcohol dehydrogenase $1 C$ 


\section{RATIONALE AND OUTLINE OF THE THESIS}

\section{Rationale}

As illustrated in the previous paragraph, the epidemiological data suggests that alcohol consumption is a risk factor for the development of CRC. The precise nature of this relationship however, still remains unclear. For example, risk differences between the anatomical CRC sublocalisations and the potential role of the polymorphic alcohol dehydrogenase $1 C$ (ADH1C) gene in the etiology of alcoholrelated CRC are still to be clarified. The promise of molecular epidemiology to provide clues for the underlying etiologic mechanisms of tumor development still stands, but to date, molecular results are limited. In an attempt to further elucidate the controversial aspects that encompass the association between alcohol consumption and the risk of CRC and to contribute to current molecular epidemiological findings, we have studied the role of alcohol in CRC within the Netherlands Cohort Study on diet and cancer (NLCS).

The NLCS was initiated in September 1986 [137]. A total of 120,852 men and women returned a self-administered questionnaire on dietary habits, life style and other risk factors for cancer. According to a case-cohort approach [138], data are processed and analyzed only for a random sample of the cohort (a subcohort, existing of 5,000 men and women at baseline) plus all incident cancer cases arising each year. Whereas only the subcohort is being followed-up for vital status and migration to estimate the accumulating person time, the entire cohort is being followed-up for cancer occurrence. In August 1999, tumor blocks from CRC cases diagnosed within the first 7.3 years of follow-up, were collected from Dutch pathology laboratories to be used for molecular characterization. In December 2000, members of the subcohort were contacted for the collection of mouth swabs. DNA isolated from these swabs was to be used for genetic analyses, in order to study geneenvironment interactions.

\section{Outline}

The aim of this thesis was to evaluate several aspect of the association between alcohol consumption and CRC and to contribute to the molecular epidemiological literature on alcohol and CRC. The studies we undertook focused on a number of general and detailed research questions, as illustrated in figure 6. 
Accordingly, we investigated the various aspects of alcohol consumption, such as different levels of intake and consumption of specific types of alcoholic beverages, together with detailed information on tumor localization throughout the colorectal tract, enabling us to comprehensively study associations between alcohol and CRC. We stated the following general research questions:

- Is a daily habitual alcohol consumption associated with the risk of CRC?

- Is the association dependent on sex, beverage type and anatomical tumor localization? (chapter 2)

To investigate the possibility of a genetic susceptibility to alcohol-related CRC according to genetic variations of the $A D H 1 C$ gene, we studied associations between alcohol and CRC according to the different genotypes of the polymorphic $A D H 1 C$ gene:

- Is the association between alcohol consumption and risk of CRC dependent of the $A D H 1 C$ genotype? (chapter 3)

Next, we incorporated molecular endpoints into our analyses to find clues for the alcohol-related pathogenesis of CRC. Since tumors with similar molecular characteristics are likely to share similar etiologic pathways, we studied associations between alcohol consumption and molecular subgroups of colorectal tumors according to the following research question:

- Is alcohol consumption related to distinct molecular subgroups of CRC? (chapter 4)

In addition to genetic aberrations, CRC development may be characterized by epigenetic events. Also, alcohol may contribute to CRC through involvement in the folate metabolism:

- Is a daily habitual alcohol consumption associated with CRC harboring $M L H 1$ promoter hypermethylation, and its related phenotypes, i.e. absent MLH1 protein expression, MSI and BRAF oncogene mutations?

- Does alcohol consumption modify the associations between methyl donors folate and methionine and risk of CRC? (chapter 5)

The first metabolite of alcohol, acetaldehyde, is known to have mutagenic properties. To investigate if alcohol (through acetaldehyde) may lead to CRC 
through inducing mutations in specific genes, we studied associations between alcohol consumption and tumors with and without mutations in one of the key genes involved in CRC:

- Is alcohol consumption associated with CRCs harboring KRAS oncogene mutations? (chapter 6)
Alcohol variables
Colorectal cancer endpoints

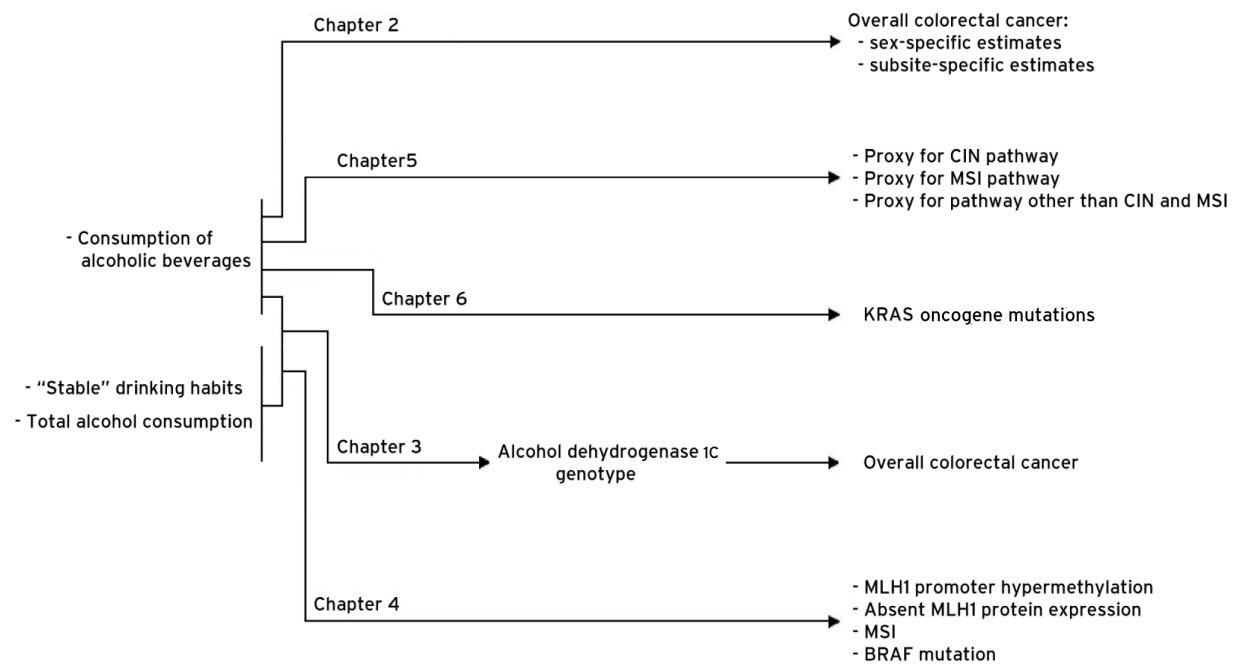

Figure 6: Schematic overview of the main associations examined in studies described in this thesis 


\section{REFERENCES}

1. World Health Organisation. Alcohol policy in the WHO European Region: current status and the way forward. Copenhagen: World Health Organisation Regional Office for Europe, 2005.

2. WHO Global Status Report on Alcohol 2004. Geneva: Department of Mental Health and Substance Abuse, World Health Organisation, 2004.

3. Zelfgerapporteerde medische consumptie, gezondheid en leefstijl. http://statline.cbs.nl/StatWeb, 18 maart 2008 edition. Voorburg/Heerlen: Centraal Bureau voor de Statistiek, 2008.

4. van Dorsselaer, S., Zeijl, E., van den Eeckhout, S., ter Bogt, T., and Vollebergh, W. Gezondheid en welzijn van jongeren in Nederland. HBSC 2005. Utrecht: Trimbosinstituut, 2007.

5. Monshouwer, K., Van Dorsselaer, S., Gorter, A., Verdurmen, J., and Vollebergh, W. Jeugd en riskant gedrag. Kerngegevens uit het Peilstationsonderzoek 2003. Utrecht: Trimbos-instituut, 2004.

6. Anderson, P. and Baumberg, B. Alcohol in Europe. London: Institute of Alcohol Studies, 2006.

7. Room, R., Babor, T., and Rehm, J. Alcohol and public health. Lancet, 365: 519-530, 2005.

8. Medical consequences of alcohol abuse. Alcohol Res Health, 24: 27-31, 2000.

9. Keil, U., Chambless, L. E., Doring, A., Filipiak, B., and Stieber, J. The relation of alcohol intake to coronary heart disease and all-cause mortality in a beer-drinking population. Epidemiology, 8: 150-156, 1997.

10. Kitamura, A., Iso, H., Sankai, T., Naito, Y., Sato, S., Kiyama, M., et al. Alcohol intake and premature coronary heart disease in urban Japanese men. Am J Epidemiol, 147: 59-65, 1998.

11. Doll, R., Peto, R., Hall, E., Wheatley, K., and Gray, R. Mortality in relation to consumption of alcohol: 13 years' observations on male British doctors. BMJ, 309: 911-918, 1994.

12. Fuchs, C. S., Stampfer, M. J., Colditz, G. A., Giovannucci, E. L., Manson, J. E., Kawachi, I., et al. Alcohol consumption and mortality among women. N Engl J Med, 332:1245-1250, 1995.

13. Rehm, J. T., Bondy, S. J., Sempos, C. T., and Vuong, C. V. Alcohol consumption and coronary heart disease morbidity and mortality. Am J Epidemiol, 146: 495-501, 1997.

14. Gaziano, J. M., Buring, J. E., Breslow, J. L., Goldhaber, S. Z., Rosner, B., VanDenburgh, M., et al. Moderate alcohol intake, increased levels of high-density lipoprotein and its subfractions, and decreased risk of myocardial infarction. N Engl J Med, 329: 1829$1834,1993$.

15. Klatsky, A. L. Epidemiology of coronary heart disease--influence of alcohol. Alcohol Clin Exp Res, 18: 88-96, 1994. 
16. Suh, I., Shaten, B. J., Cutler, J. A., and Kuller, L. H. Alcohol use and mortality from coronary heart disease: the role of high-density lipoprotein cholesterol. The Multiple Risk Factor Intervention Trial Research Group. Ann Intern Med, 116: 881-887, 1992.

17. Marrero, J. A., Fontana, R. J., Fu, S., Conjeevaram, H. S., Su, G. L., and Lok, A. S. Alcohol, tobacco and obesity are synergistic risk factors for hepatocellular carcinoma. J Hepatol, 42: 218-224, 2005.

18. Mann, R. E., Smart, R. G., and Govoni, R. The epidemiology of alcoholic liver disease. Alcohol Res Health, 27: 209-219, 2003.

19. Becker, U., Deis, A., Sørensen, T. I., Grønbæk, M., Borch-Johnsen, K., Muller, C. F., et al. Prediction of risk of liver disease by alcohol intake, sex, and age: a prospective population study. Hepatology, 23: 1025-1029, 1996.

20. Corrao, G., Bagnardi, V., Zambon, A., and Arico, S. Exploring the dose-response relationship between alcohol consumption and the risk of several alcohol-related conditions: a meta-analysis. Addiction, 94: 1551-1573, 1999.

21. Kamper-Jorgensen, M., Grønbæk, M., Tolstrup, J., and Becker, U. Alcohol and cirrhosis: dose--response or threshold effect? J Hepatol, 41: 25-30, 2004.

22. Corrao, G., Bagnardi, V., Zambon, A., and La Vecchia, C. A meta-analysis of alcohol consumption and the risk of 15 diseases. Prev Med, 38: 613-619, 2004.

23. Koppes, L. L., Dekker, J. M., Hendriks, H. F., Bouter, L. M., and Heine, R. J. Moderate alcohol consumption lowers the risk of type 2 diabetes: a meta-analysis of prospective observational studies. Diabetes Care, 28: 719-725, 2005.

24. Davies, M. J., Baer, D. J., Judd, J. T., Brown, E. D., Campbell, W. S., and Taylor, P. R. Effects of moderate alcohol intake on fasting insulin and glucose concentrations and insulin sensitivity in postmenopausal women: a randomized controlled trial. Jama, 287: 2559-2562, 2002.

25. Sierksma, A., Patel, H., Ouchi, N., Kihara, S., Funahashi, T., Heine, R. J., et al. Effect of moderate alcohol consumption on adiponectin, tumor necrosis factor-alpha, and insulin sensitivity. Diabetes Care, 27: 184-189, 2004.

26. Conigrave, K. M., Hu, B. F., Camargo, C. A., Jr., Stampfer, M. J., Willett, W. C., and Rimm, E. B. A prospective study of drinking patterns in relation to risk of type 2 diabetes among men. Diabetes, 50: 2390-2395, 2001.

27. Sampson, H. W. Alcohol and other factors affecting osteoporosis risk in women. Alcohol Res Health, 26: 292-298, 2002.

28. Chakkalakal, D. A. Alcohol-induced bone loss and deficient bone repair. Alcohol Clin Exp Res, 29: 2077-2090, 2005.

29. Hannan, M. T., Felson, D. T., Dawson-Hughes, B., Tucker, K. L., Cupples, L. A., Wilson, P. W., et al. Risk factors for longitudinal bone loss in elderly men and women: the Framingham Osteoporosis Study. J Bone Miner Res, 15: 710-720, 2000. 
30. Naves Diaz, M., O'Neill, T. W., and Silman, A. J. The influence of alcohol consumption on the risk of vertebral deformity. European Vertebral Osteoporosis Study Group. Osteoporos Int, 7: 65-71, 1997.

31. Felson, D. T., Zhang, Y., Hannan, M. T., Kannel, W. B., and Kiel, D. P. Alcohol intake and bone mineral density in elderly men and women. The Framingham Study. Am J Epidemiol, 142: 485-492, 1995.

32. Petrakis, I. L., Gonzalez, G., Rosenheck, R., and Krystal, J. H. Comorbidity of alcoholism and psychiatric disorders - An overview. Alcohol Research \& Health, 26: 81-89, 2002.

33. Lishman, W. A. Alcohol and the Brain. British Journal of Psychiatry, 156: 635-644, 1990.

34. Oscar-Berman, M. and Marinkovic, K. Alcohol: Effects on neurobehavioral functions and the brain. Neuropsychology Review, 17: 239-257, 2007.

35. Moselhy, H. F., Georgiou, G., and Kahn, A. Frontal lobe changes in alcoholism: A review of the literature. Alcohol and Alcoholism, 36: 357-368, 2001.

36. Oscar-Berman, M. and Marinkovic, K. Alcoholism and the brain: An overview. Alcohol Research \& Health, 27:125-133, 2003.

37. Baan, R., Straif, K., Grosse, Y., Secretan, B., El Ghissassi, F., Bouvard, V., et al. Carcinogenicity of alcoholic beverages. Lancet Oncol, 8: 292-293, 2007.

38. Boffetta, P. and Hashibe, M. Alcohol and cancer. Lancet Oncol, 7: 149-156, 2006.

39. Grønbæk, M., Becker, U., Johansen, D., Tonnesen, H., Jensen, G., and Sørensen, T. I. Population based cohort study of the association between alcohol intake and cancer of the upper digestive tract. BMJ, 317: 844-847, 1998.

40. Longnecker, M. P. Alcoholic beverage consumption in relation to risk of breast cancer: meta-analysis and review. Cancer Causes Control, 5: 73-82, 1994.

41. Smith-Warner, S. A., Spiegelman, D., Yaun, S. S., van den Brandt, P. A., Folsom, A. R., Goldbohm, R. A., et al. Alcohol and breast cancer in women - A pooled analysis of cohort studies. Jama-Journal of the American Medical Association, 279: 535-540, 1998.

42. Van den brandt, P. A., Goldbohm, R. A., and Vantveer, P. Alcohol and Breast-Cancer Results from the Netherlands Cohort Study. American Journal of Epidemiology, 141: 907-915, 1995.

43. Tjonneland, A., Christensen, J., Olsen, A., Stripp, C., Thomsen, B. L., Overvad, K., et al. Alcohol intake and breast cancer risk: the European Prospective Investigation into Cancer and Nutrition (EPIC). Cancer Causes \& Control, 18: 361-373, 2007.

44. Food, Nutrition, Physical activity, and the Prevention of Cancer: a Global Perspective. Washington DC: AICR, 2007.

45. Cho, E., Smith-Warner, S. A., Ritz, J., van den Brandt , P. A., Colditz, G. A., Folsom, A. R., et al. Alcohol intake and colorectal cancer: a pooled analysis of 8 cohort studies. Ann Intern Med, 140: 603-613, 2004. 
46. Ferraroni, M., Negri, E., LaVecchia, C., D'avanzo, B., and Franchesci, S. Socioeconomic indicators, tobacco and alcohol in the aethiology of digestive tract neoplasms. Int $J$ Epidemiol, 18: 556-562, 1989.

47. Moskal, A., Norat, T., Ferrari, P., and Riboli, E. Alcohol intake and colorectal cancer risk: A dose-response meta-analysis of published cohort studies. Int J Cancer, 120: 664-671, 2006.

48. Longnecker, M. P., Orza, M. J., Adams, M. E., Vioque, J., and Chalmers, T. C. A metaanalysis of alcoholic beverage consumption in relation to risk of colorectal cancer. Cancer causes control, 1: 59-68, 1990.

49. Simanowski, U. A., Homann, N., Knuhl, M., Arce, L., Waldherr, R., Conradt, C., et al. Increased rectal cell proliferation following alcohol abuse. Gut, 49: 418-422, 2001.

50. Lieber, C. S. The discovery of the microsomal ethanol oxidizing system and its physiologic and pathologic role. Drug Metab Rev, 36: 511-529, 2004.

51. Guengerich, F. P. Cytochromes P450, drugs, and diseases. Mol Interv, 3: 194-204, 2003.

52. Oneta, C. M., Lieber, C. S., Li, J., Ruttimann, S., Schmid, B., Lattmann, J., et al. Dynamics of cytochrome P4502E1 activity in man: induction by ethanol and disappearance during withdrawal phase. J Hepatol, 36: 47-52, 2002.

53. Seitz, H. K. and Stickel, F. Risk factors and mechanisms of hepatocarcinogenesis with special emphasis on alcohol and oxidative stress. Biol Chem, 387: 349-360, 2006.

54. Wu, D. and Cederbaum, A. I. Alcohol, oxidative stress, and free radical damage. Alcohol Res Health, 27: 277-284, 2003.

55. Bosron, W. F. and Li, T. K. Catalytic properties of human liver alcohol dehydrogenase isoenzymes. Enzyme, 37: 19-28, 1987.

56. Bosron, W. F. and Li, T. K. Genetic polymorphism of human liver alcohol and aldehyde dehydrogenases, and their relationship to alcohol metabolism and alcoholism. Hepatology, 6: 502-510, 1986.

57. Goedde, H. W., Agarwal, D. P., Fritze, G., Meier-Tackmann, D., Singh, S., Beckmann, G., et al. Distribution of $A D H 2$ and $A L D H 2$ genotypes in different populations. Hum Genet, 88: 344-346, 1992.

58. Osier, M. V., Pakstis, A. J., Goldman, D., Edenberg, H. J., Kidd, J. R., and Kidd, K. K. A proline-threonine substitution in codon 351 of $A D H 1 C$ is common in Native Americans. Alcohol Clin Exp Res, 26: 1759-1763, 2002.

59. Chen, C. C., Lu, R. B., Chen, Y. C., Wang, M. F., Chang, Y. C., Li, T. K., et al. Interaction between the functional polymorphisms of the alcohol-metabolism genes in protection against alcoholism. Am J Hum Genet, 65: 795-807, 1999.

60. Luczak, S. E., Glatt, S. J., and Wall, T. L. Meta-analyses of ALDH2 and ADH1B with alcohol dependence in Asians. Psychol Bull, 132: 607-621, 2006. 
61. Crabb, D. W., Matsumoto, M., Chang, D., and You, M. Overview of the role of alcohol dehydrogenase and aldehyde dehydrogenase and their variants in the genesis of alcohol-related pathology. Proceedings of the Nutrition Society, 63: 49-63, 2004.

62. Jokelainen, K., Roine, R. P., Vaananen, H., Farkkila, M., and Salaspuro, M. In vitro acetaldehyde formation by human colonic bacteria. Gut, 35: 1271-1274, 1994.

63. Jokelainen, K., Siitonen, A., Jousimies-Somer, H., Nosova, T., Heine, R., and Salaspuro, M. In vitro alcohol dehydrogenase-mediated acetaldehyde production by aerobic bacteria representing the normal colonic flora in man. Alcohol Clin Exp Res, 20: 967$972,1996$.

64. Salaspuro, M. Bacteriocolonic pathway for ethanol oxidation: characteristics and implications. Ann Med, 28: 195-200, 1996.

65. Visapää, J. P., Tillonen, J., and Salaspuro, M. Microbes and mucosa in the regulation of intracolonic acetaldehyde concentration during ethanol challenge. Alcohol and Alcoholism, 37: 322-326, 2002.

66. Seitz, H. K., Simanowski, U. A., Garzon, F. T., Rideout, J. M., Peters, T. J., Koch, A., et al. Possible Role of Acetaldehyde in Ethanol-Related Rectal Cocarcinogenesis in the Rat. Gastroenterology, 98: 406-413, 1990.

67. Curado, M. P., Edwards, B., Storm, H., Ferlay, J., Heanue, M., and Boyle, P. Cancer incidence in five continents, Vol. Vol. IX. Lyon, IARC: IARC Scientific Publications No 160, 2007.

68. Website Association of Comprehensive Cancer Centers The Netherlands: www.ikcnet.nl. Accesses March 21st 2008.

69. Faivre, J., Bouvier, A.-M., and Bonithon-Kopp, C. Epidemiology and screening of colorectal cancer. Best Practice \& Research Clinical Gasteroentology, 16: 187-199, 2002

70. Website Association of Comprehensive Cancer Centers The Netherlands: www.ikcnet.nl. Accessed March 21st 2008.

71. Fearon, E. R. and Vogelstein, B. A genetic model for colorectal tumorigenesis. Cell, 61: 759-767, 1990.

72. Lijovic, M. and Frauman, A. G. Toward an understanding of the molecular genetics of prostate cancer progression. J Environ Pathol Toxicol Oncol, 22: 1-15, 2003.

73. Morales, C. P., Souza, R. F., and Spechler, S. J. Hallmarks of cancer progression in Barrett's oesophagus. Lancet, 360: 1587-1589, 2002.

74. White, R. L. Colon polyps: a damaged developmental system and a precursor to cancer. Cytogenet Cell Genet, 86: 95-98, 1999.

75. Bach, S. P., Renehan, A. G., and Potten, C. S. Stem cells: the intestinal stem cell as a paradigm. Carcinogenesis, 21: 469-476, 2000.

76. Vogelstein, B., Fearon, E. R., Hamilton, S. R., Kern, S. E., Preisinger, A. C., Leppert, M., et al. Genetic alterations during colorectal-tumor development. N Engl J Med, 319: 525$532,1988$. 
77. Luebeck, E. G. and Moolgavkar, S. H. Multistage carcinogenesis and the incidence of colorectal cancer. Proc Natl Acad Sci U S A, 99: 15095-15100, 2002.

78. Rajagopalan, H., Nowak, M. A., Vogelstein, B., and Lengauer, C. The significance of unstable chromosomes in colorectal cancer. Nature Reviews Cancer, 3: 695-701, 2003.

79. Vogelstein, B., Fearon, E. R., Kern, S. E., Hamilton, S. R., Preisinger, A. C., Nakamura, Y., et al. Allelotype of colorectal carcinomas. Science, 244: 207-211, 1989.

80. Boland, C. R., Sato, J., Appelman, H. D., Bresalier, R. S., and Feinberg, A. P. Microallelotyping defines the sequence and tempo of allelic losses at tumour suppressor gene loci during colorectal cancer progression. Nat Med, 1: 902-909, 1995.

81. Kern, S. E., Fearon, E. R., Tersmette, K. W., Enterline, J. P., Leppert, M., Nakamura, Y., et al. Clinical and pathological associations with allelic loss in colorectal carcinoma [corrected]. Jama, 261: 3099-3103, 1989.

82. Lengauer, C., Kinzler, K. W., and Vogelstein, B. Genetic instabilities in human cancers. Nature, 396: 643-649, 1998.

83. Peinado, M. A., Malkhosyan, S., Velazquez, A., and Perucho, M. Isolation and characterization of allelic losses and gains in colorectal tumors by arbitrarily primed polymerase chain reaction. Proc Natl Acad Sci U S A, 89: 10065-10069, 1992.

84. Ionov, Y., Peinado, M. A., Malkhosyan, S., Shibata, D., and Perucho, M. Ubiquitous somatic mutations in simple repeated sequences reveal a new mechanism for colonic carcinogenesis. Nature, 363: 558-561, 1993.

85. Aaltonen, L. A., Peltomaki, P., Leach, F. S., Sistonen, P., Pylkkanen, L., Mecklin, J. P., et al. Clues to the pathogenesis of familial colorectal cancer. Science, 260: 812-816, 1993.

86. Thibodeau, S. N., Bren, G., and Schaid, D. Microsatellite instability in cancer of the proximal colon. Science, 260: 816-819, 1993.

87. Herman, J. G., Latif, F., Weng, Y., Lerman, M. I., Zbar, B., Liu, S., et al. Silencing of the VHL tumor-suppressor gene by DNA methylation in renal carcinoma. Proc Natl Acad Sci U S A, 91: 9700-9704, 1994.

88. Toyota, M. and Issa, J. P. CpG island methylator phenotypes in aging and cancer. Semin Cancer Biol, 9: 349-357, 1999.

89. Esteller, M. Aberrant DNA methylation as a cancer-inducing mechanism. Annu Rev Pharmacol Toxicol, 45: 629-656, 2005.

90. Ogino, S. and Goel, A. Molecular Classification and Correlates in Colorectal Cancer. J Mol Diagn, 10: 13-27, 2008.

91. Sieber, O. M., Heinimann, K., and Tomlinson, I. P. Genomic instability--the engine of tumorigenesis? Nat Rev Cancer, 3: 701-708, 2003.

92. Nigg, E. A. Centrosome aberrations: cause or consequence of cancer progression? Nat Rev Cancer, 2: 815-825, 2002.

93. Rajagopalan, H. and Lengauer, C. CIN-ful cancers. Cancer Chemotherapy and Pharmacology, 54: S65-S68, 2004. 
94. Deng, G., Chen, A., Hong, J., Chae, H. S., and Kim, Y. S. Methylation of CpG in a small region of the $h M L H 1$ promoter invariably correlates with the absence of gene expression. Cancer Res, 59: 2029-2033, 1999.

95. Boland, C. R., Thibodeau, S. N., Hamilton, S. R., Sidransky, D., Eshleman, J. R., Burt, R. W., et al. A National Cancer Institute Workshop on Microsatellite Instability for cancer detection and familial predisposition: development of international criteria for the determination of microsatellite instability in colorectal cancer. Cancer Res, 58: 5248$5257,1998$.

96. Boland, C. R. and Goel, A. Somatic evolution of cancer cells. Seminars in Cancer Biology, 15: 436-450, 2005.

97. Toyota, M., Ohe-Toyota, M., Ahuja, N., and Issa, J. P. Distinct genetic profiles in colorectal tumors with or without the $\mathrm{CpG}$ island methylator phenotype. Proc Natl Acad Sci U S A, 97: 710-715, 2000.

98. Baylin, S. B. and Herman, J. G. DNA hypermethylation in tumorigenesis: epigenetics joins genetics. Trends Genet, 16:168-174, 2000.

99. van Rijnsoever, M., Grieu, F., Elsaleh, H., Joseph, D., and lacopetta, B. Characterisation of colorectal cancers showing hypermethylation at multiple CpG islands. Gut, 51: 797802, 2002.

100. Whitehall, V. L. J., Wynter, C. V. A., Walsh, M. D., Simms, L. A., Purdie, D., Pandeya, N., et al. Morphological and molecular heterogeneity within nonmicrosatellite instability-high colorectal cancer. Cancer Research, 62: 6011-6014, 2002.

101. Hawkins, N., Norrie, M., Cheong, K., Mokany, E., Ku, S. L., Meagher, A., et al. CpG island methylation in sporadic colorectal cancers and its relationship to microsatellite instability. Gastroenterology, 122: 1376-1387, 2002.

102. Samowitz, W. S., Albertsen, H., Herrick, J., Levin, T. R., Sweeney, C., Murtaugh, M. A., et al. Evaluation of a large, population-based sample supports a $\mathrm{CpG}$ island methylator phenotype in colon cancer. Gastroenterology, 129: 837-845, 2005.

103. Ogino, S., Kawasaki, T., Kirkner, G. J., Loda, M., and Fuchs, C. S. CpG island methylator phenotype-low (CIMP-low) in colorectal cancer: possible associations with male sex and KRAS mutations. J Mol Diagn, 8: 582-588, 2006.

104. International Agency for Research on Cancer (IARC) Re-evaluation of some organic chemicals, hydrazine and hydrogen peroxide. IARC Monographs on the evaluation of the carcinogenic risk of chemicals to humans, 71: 319-325, 1999.

105. Maffei, F., Forti, G. C., Castelli, E., Stefanini, G. F., Mattioli, S., and Hrelia, P. Biomarkers to assess the genetic damage induced by alcohol abuse in human lymphocytes. Mutat Res, 514: 49-58, 2002.

106. Helander, A. and Lindahl-Kiessling, K. Increased frequency of acetaldehyde-induced sister-chromatid exchanges in human lymphocytes treated with an aldehyde dehydrogenase inhibitor. Mutat Res, 264: 103-107, 1991. 
107. Garro, A. J. and Lieber, C. S. Alcohol and cancer. Annu Rev Pharmacol Toxicol, 30: 219249, 1990.

108. Homann, N., Stickel, F., Konig, I. R., Jacobs, A., Junghanns, K., Benesova, M., et al. Alcohol dehydrogenase $1 C^{*} 1$ allele is a genetic marker for alcohol-associated cancer in heavy drinkers. International Journal of Cancer, 118: 1998-2002, 2006.

109. Wang, M., McIntee, E. J., Cheng, G., Shi, Y., Villalta, P. W., and Hecht, S. S. Identification of DNA adducts of acetaldehyde. Chem Res Toxicol, 13: 1149-1157, 2000.

110. Stein, S., Lao, Y., Yang, I. Y., Hecht, S. S., and Moriya, M. Genotoxicity of acetaldehydeand crotonaldehyde-induced 1,N2-propanodeoxyguanosine DNA adducts in human cells. Mutat Res, 608: 1-7, 2006.

111. Badger, T. M., Ronis, M. J., Seitz, H. K., Albano, E., Ingelman-Sundberg, M., and Lieber, C. S. Alcohol metabolism: role in toxicity and carcinogenesis. Alcohol Clin Exp Res, 27: 336-347, 2003.

112. Seitz, H. K., Egerer, G., Oneta, C., Kramer, S., Sieg, A., Klee, F., et al. Alcohol dehydrogenase in the human colon and rectum. Digestion, 57: 105-108, 1996.

113. Simanowski, U. A., Seitz, H. K., Baier, B., Kommerell, B., Schmidt-Gayk, H., and Wright, N. A. Chronic ethanol consumption selectively stimulates rectal cell proliferation in the rat. Gut, 27: 278-282, 1986.

114. Deschner, E. E., Long, F. C., Hakissian, M., and Cupo, S. H. Differential susceptibility of inbred mouse strains forecast by acute colonic proliferative response to methylazoxymethanol. J Natl Cancer Inst, 72: 195-198, 1984.

115. Eastwood, G. L. and Trier, J. S. Epithelial cell renewal in cultured rectal biopsies in ulcerative colitis. Gastroenterology, 64: 383-390, 1973.

116. Kim, Y. I. Folate and carcinogenesis: Evidence, mechanisms, and implications. Journal of Nutritional Biochemistry, 10: 66-88, 1999.

117. Manari, A. P., Preedy, V. R., and Peters, T. J. Nutritional intake of hazardous drinkers and dependent alcoholics in the UK. Addict Biol, 8: 201-210, 2003.

118. Halsted, C. H., Robles, E. A., and Mezey, E. Intestinal malabsorption in folate-deficient alcoholics. Gastroenterology, 64: 526-532, 1973.

119. Halsted, C. H., Robles, E. A., and Mezey, E. Decreased jejunal uptake of labeled folic acid ( 3 H-PGA) in alcoholic patients: roles of alcohol and nutrition. $N$ Engl J Med, 285: 701$706,1971$.

120. Shaw, S., Jayatilleke, E., Herbert, V., and Colman, N. Cleavage of folates during ethanol metabolism. Role of acetaldehyde/xanthine oxidase-generated superoxide. Biochem $\mathrm{J}$, 257: 277-280, 1989.

121. McMartin, K. E., Collins, T. D., Shiao, C. Q., Vidrine, L., and Redetzki, H. M. Study of dosedependence and urinary folate excretion produced by ethanol in humans and rats. Alcohol Clin Exp Res, 10: 419-424, 1986. 
122. Russell, R. M., Rosenberg, I. H., Wilson, P. D., Iber, F. L., Oaks, E. B., Giovetti, A. C., et al. Increased urinary excretion and prolonged turnover time of folic acid during ethanol ingestion. Am J Clin Nutr, 38: 64-70, 1983.

123. Bagnardi, V., Blangiardo, M., La Vecchia, C., and Corrao, G. Alcohol consumption and the risk of cancer - A meta-analysis. Alcohol Research \& Health, 25: 263-270, 2001.

124. Ferrari, P., Jenab, M., Norat, T., Moskal, A., Slimani, N., Olsen, A., et al. Lifetime and baseline alcohol intake and risk of colon and rectal cancers in the European prospective investigation into cancer and nutrition (EPIC). Int J Cancer, 121: 2065-2072, 2007.

125. Bagnardi, V., Blangiardo, M., La Vecchia, C., and Corrao, G. A meta-analysis of alcohol drinking and cancer risk. Br J Cancer, 85: 1700-1705, 2001.

126. Chen, J., Ma, J., Stampfer, M. J., Hines, L. M., Selhub, J., and Hunter, D. J. Alcohol dehydrogenase 3 genotype is not predictive for risk of colorectal cancer. Cancer Epidemiology Biomarkers \& Prevention, 10: 1303-1304, 2001.

127. Giovannucci, E., Chen, J., Smith-Warner, S. A., Rimm, E. B., Fuchs, C. S., Palomeque, C., et al. Methylenetetrahydrofolate reductase, alcohol dehydrogenase, diet, and risk of colorectal adenomas. Cancer Epidemiol Biomarkers Prev, 12: 970-979, 2003.

128. Tiemersma, E. W., Wark, P. A., Ocke, M. C., Bunschoten, A., Otten, M. H., Kok, F. J., et al. Alcohol consumption, alcohol dehydrogenase 3 polymorphism, and colorectal adenomas. Cancer Epidemiology Biomarkers \& Prevention, 12: 419-425, 2003.

129. Satia, J. A., Keku, T., Galanko, J. A., Martin, C., Doctolero, R. T., Tajima, A., et al. Diet, lifestyle, and genomic instability in the North Carolina colon cancer study. Cancer Epidemiology Biomarkers \& Prevention, 14: 429-436, 2005.

130. Slattery, M. L., Anderson, K., Curtin, K., Ma, K., Schaffer, D., and Samowitz, W. Dietary intake and microsatellite instability in colon tumors. Int J Cancer, 93: 601-607, 2001.

131. Slattery, M. L., Curtin, K., Sweeney, C., Levin, T. R., Potter, J., Wolff, R. K., et al. Diet and lifestyle factor associations with $\mathrm{CpG}$ island methylator phenotype and $B R A F$ mutations in colon cancer. Int J Cancer, 120: 656-663, 2007.

132. Curtin, K., Slattery, M. L., Ulrich, C. M., Bigler, J., Levin, T. R., Wolff, R. K., et al. Genetic polymorphisms in one-carbon metabolism: associations with $\mathrm{CpG}$ island methylator phenotype (CIMP) in colon cancer and the modifying effects of diet. Carcinogenesis, 28: 1672-1679, 2007.

133. Diergaarde, B., Geloof van, W. L., Muijen van, G. N. P., Kok, F. J., and Kampman, E. Dietary factors and the occurence of truncating $A P C$ mutations in sporadic colon carcinomas: a Dutch population-based study. Carcinogenesis, 24: 283-290, 2003.

134. Slattery, M. L., Curtin, K., Anderson, K., Ma, K. N., Edwards, S., Leppert, M., et al. Associations between dietary intake and $\mathrm{Ki}$-ras mutations in colon tumors: a population-based study. Cancer Res, 60: 6935-6941, 2000.

135. Fredrikson, M., Axelson, O., Sun, X. F., Arbman, G., Nilsson, E., Nordenskjold, B., et al. A pilot study on risk factors and $p 53$ gene expression in colorectal cancer. $\mathrm{Br} \mathrm{J}$ Cancer, 73: 1428-1430, 1996. 
Introduction |

136. Voskuil, D. W., Kampman, E., van Kraats, A. A., Balder, H. F., van Muijen, G. N. P., Goldbohm, R. A., et al. p53 over-expression and p53 mutations in colon carcinomas: Relation to dietary risk factors. International Journal of Cancer, 81: 675-681, 1999.

137. van den Brandt, P. A., Goldbohm, R. A., van 't Veer, P., Volovics, A., Hermus, R. J., and Sturmans, F. A large-scale prospective cohort study on diet and cancer in The Netherlands. J Clin Epidemiol, 43: 285-295, 1990.

138. Miettinen, O. S. Theoretical Epidemiology. Principles of Occurrence Research in Medicine. New York: Wiley, 1985. 



\section{Alcohol consumption, type of alcoholic beverage and risk of}

colorectal cancer at specific subsites

Brenda W.C. Bongaerts Piet A. van den Brandt R. Alexandra Goldbohm Anton F.P.M. de Goeij Matty P. Weijenberg

International Journal of Cancer, 2008. In press 


\begin{abstract}
Within the Netherlands Cohort Study on diet and cancer, we investigated associations between total alcohol consumption, specific alcoholic beverage consumption and risk of colorectal cancer (CRC) according to anatomical subsite.
\end{abstract}

Hazard Ratios (HR) and 95\% confidence intervals $(\mathrm{Cl})$ were estimated using Cox proportional hazards models. Analyses were performed on 2,323 CRC cases, available after 13.3 years of follow-up.

Compared to abstaining, alcohol consumption of $\geq 30.0 \mathrm{~g} / \mathrm{d}$ (approximately three alcoholic drinks) was positively associated with the risk of CRC (HR: $1.32,95 \% \mathrm{Cl}$ : 1.06-1.65). Analyses restricted to subjects who reported to have consumed equal amounts of alcohol five years before baseline compared to baseline, showed higher risk estimates for consumers of $\geq 30.0 \mathrm{~g}$ of total alcohol per day (HR: $1.53,95 \% \mathrm{Cl}$ : 1.16-2.01). Suggestive of a subsite-specific effect, cancer risk seemed to increase from proximal colon through rectum; HR: 1.29, 95\% Cl: 0.85-1.96 for proximal colon cancer, HR: 1.41, 95\% Cl: 0.94-2.11 for distal colon cancer, HR: 2.07, 95\% Cl: 1.034.18 for rectosigmoid cancer and HR: $1.69,95 \% \mathrm{Cl}: 1.08-2.64$ for rectal cancer. No associations were observed between consumption of alcoholic beverages and CRC risk when compared to the non-drinkers of the specific beverage and after adjustment for total alcohol intake. No evidence was found for sex-specific effects of alcohol and alcoholic beverages.

Our data showed a positive association between alcohol consumption and risk of CRC, which seemed to be mainly explained by the alcoholic content of alcoholic beverages, rather than other constituents. Also, cancer risk may vary according to anatomical subsite. 


\section{INTRODUCTION}

Consumption of alcohol is known to be associated with an increased risk of cancer in various organs $[1,2]$ and in general, the risk increases with the average amount of alcohol intake [3]. This also seems to be the case for colorectal cancer (CRC), as shown by a pooled analysis of data of eight large prospective studies on alcohol consumption and risk of CRC (the Pooling Project) [4]. The Pooling Project suggested a threshold in alcohol consumption of 30 grams per day (approximately three alcoholic consumptions per day) above which the risk of CRC would increase significantly. Conversely, a large meta-analysis of prospective studies only [5], showed statistically significantly elevated CRC risks for consumption levels below 30 grams of alcohol per day, e.g. levels ranging from 3.6 to $14.0 \mathrm{~g} / \mathrm{d}$. As can be learned from the Pooling Project, but also from large meta-analyses [5-7] and the study of the EPIC cohort [8], associations between alcohol consumption and CRC risk are expected to be relatively modest, ranging from risk increases of $10-20 \%$ for 14-30 grams of alcohol per day relative to abstaining. Nevertheless, alcohol should not be overlooked as an important determinant of CRC [9]. This disease is a very common form of cancer in the Western world ànd alcohol is consumed by the majority of the population. Alcohol consumption may therefore contribute to a number of CRC patients population-wide.

Whereas total alcohol consumption is an established risk factor for CRC, findings that relate to consumption of specific alcoholic beverages, different tumor subsites within the large bowel and risk differences between men and women are much less clear. With respect to specific alcoholic beverages, epidemiological studies have reported inconsistent associations with regard to CRC [10-12], cancer risk for the anatomical subsites [11, 13-16] and sex-specific risk estimates [15, 16]. Alcoholic beverages contain many other substances apart from alcohol that may affect CRC risk. For example, associations between beer consumption and rectal cancer in men were speculated to be caused by the volatile nitrosamines that were present in beer more than twenty-five years ago [10, 17-20].

When considering the anatomical subsites of the colorectum, many investigators have debated the issue whether the proximal and distal colon and the rectum should be considered as a single entity, or as distinct ones. Many differences between these anatomical subsites have been described, ranging from different embryological 
origin and vascular supply to different genetic make-up and varying cancerincidence according to sex [21-25]. Different carcinogenic mechanisms may therefore exist [26, 27]. Hence, risk factors could have different etiological significance according to tumor subsite and as such, should be studied accordingly.

As for the CRC subsites, there are plausible reasons to stratify analyses on alcohol and CRC for sex as well. Apart from a sex-specific distribution of colon and rectal tumors, men and women display different drinking habits and patterns. Also, the rate of alcohol metabolism is dependent on sex. Compared to men, alcohol is broken down more slowly in women [28], which may cause associations with CRC to differ.

In an attempt to further investigate the relationship between alcohol consumption and CRC, we studied associations between total alcohol consumption, specific alcoholic beverage consumption, and the risk of CRC according to anatomical subsite and sex.

\section{MATERIALS AND METHODS}

\section{Study population}

In September 1986, the Netherlands Cohort Study on diet and cancer (NLCS) was initiated, as has been described in detail elsewhere [29]. Briefly, the cohort includes 58,279 men and 62,573 women, aged 55-69 years at baseline and originating from 204 municipal population registries throughout the Netherlands. All cohort members completed an extensive self-administered questionnaire on daily dietary habits during the year preceding the start of the study, life style factors and other risk factors for cancer. Newly diagnosed cancer cases in the entire cohort were identified through annual record linkage to the Netherlands Cancer Registry (NCR, comprising nine cancer registries in the Netherlands) and to PALGA, a nationwide database of histo- and cytopathology reports [30]. Cancer cases were classified according to anatomical subsite: colon cancers comprised tumors of the caecum through transverse colon (proximal colon cancers, ICD-O codes C18.0 through C18.4) and tumors of the splenic flexure through sigmoid colon (distal colon cancers, ICD-O codes C18.5 through C18.7), as well as colon tumors overlapping subsites and unspecified tumors (ICD-O codes $\mathrm{C} 18.8$ and $\mathrm{C} 18.9$ ); rectosigmoid cancers (ICD-O 
code $\mathrm{C19}$ ) and rectal cancers (ICD-O code C20). CRC cancers comprised all cancers of the colon, the rectosigmoid and the rectum.

The NLCS followed the case-cohort approach [31, 32] in which data are processed and analyzed only for a random sample of the cohort plus all incident cancer cases arising each year. Cases were identified for the entire cohort, while a random sample of the cohort, i.e. the subcohort, was used to estimate person years at risk accumulating in the cohort (from the date of entry into the cohort until the date of a colorectal cancer diagnosis, death from any cause, leaving the study area or the end of the studied follow-up period). The subcohort, consisting of 5,000 men and women, was followed-up biennially to assess information on vital status and migration in order to calculate accumulated person time in the cohort. Prevalent cancer cases other than non-melanoma skin cancer were excluded from the subcohort, resulting in 4,774 subcohort members.

\section{Assessment of exposure}

Information on daily dietary habits was obtained through a 150-item semiquantitative food frequency questionnaire. Alcohol consumption was measured by six items: (a) beer; (b) red wine; (c) white wine; (d) sherry and other fortified wines; (e) liqueur types containing on average $16 \%$ alcohol and (f) (Dutch) gin, brandy and whiskey. Participants were asked about their usual frequency of consumption and the number of glasses consumed at each drinking occasion. Mean daily alcohol consumption was calculated using the computerized Dutch food-composition table [33]. Together with the alcoholic content of the various beverages, the total amount of daily alcohol consumption $(\mathrm{g} / \mathrm{d})$ was calculated.

We defined low alcohol consumption as drinking $>0$ to $\leq 10$ grams of alcohol per day (approximately $>0$ to $\leq 1$ glass of alcohol per day); moderate consumption as drinking $>10$ to $<30$ grams per day (approximately $>1$ to $<3$ glasses per day); and high alcohol consumption as drinking 30 or more grams of alcohol per day (approximately $\geq 3$ glasses of alcohol per day).

Unfortunately, both the questionnaire and the respondents in our study provided too little information to establish specific drinking patterns. One question in the questionnaire however, provided limited information on the subjects' drinking habits 
five years before baseline. For "beer" and "other alcoholic beverages" participants could indicate whether five years ago, they drunk (a) more than; (b) equal amounts of; or (c) less than today. The fourth answering option was (d) I never use this. This information enabled for example, a selection of subjects that reported to have consumed equal amounts of alcohol five years before baseline, compared to baseline drinking habits.

The questionnaire has been validated against a 9-day diet record [34]. The Spearman correlation coefficient between mean daily alcohol intake assessed by the questionnaire and estimated from the 9-day diet record was 0.89 for all subjects and 0.85 for users of alcoholic beverages. The absolute amount of alcohol reported in the questionnaire by users of alcoholic beverages was, on average, $86 \%$ of that reported in the 9-day diet record.

Besides the dietary section, the questionnaire comprised a section on lifestyle and other risk factors for cancer. Information on for instance family history of CRC, sex, age at baseline, and smoking were retrieved from this section.

\section{Data analyses}

Data analyses were carried out over a 13.3-year period of follow-up and were based on subcohort members and cases with complete information on alcohol consumption and confounding variables, e.g. 4,118 subcohort members $(49,497$ person-years) and 2,323 CRC cases. Hazard Ratios (HR) and corresponding 95\% confidence intervals (CI) were estimated using Cox proportional hazards models. The proportional hazards assumption was tested using the scaled Schoenfeld residuals [35]. Standard errors were estimated using the robust Huber-White sandwich estimator to account for additional variance introduced by sampling from the cohort.

Age at baseline (years), sex, family history of CRC (yes/no), body mass index (BMI) $\left(\mathrm{kg} / \mathrm{m}^{2}\right)$, smoking (never, ex, current), non-occupational physical activity (min/d), $\beta$ caroteen intake $(\mu \mathrm{g} / \mathrm{d})$, folate intake $(\mu \mathrm{g} / \mathrm{d})$, energy intake $(\mathrm{kJ} / \mathrm{d})$ and energyadjusted intakes of fiber $(\mathrm{g} / \mathrm{d})$, fat $(\mathrm{g} / \mathrm{d})$, meat $(\mathrm{g} / \mathrm{d})$ and calcium $(\mathrm{mg} / \mathrm{d})$ were evaluated for their effect on the relationship between alcohol consumption and CRC risk. Those variables that altered the estimate for the exposure coefficient between statistical models with and without the potential confounder by more than $10 \%$, or 
those that were found to statistically significantly contribute to the multivariable model for CRC were included in the analyses.

The risk of CRC was estimated for categories of total alcohol consumption relative to abstaining. Since preclinical disease or other health problems may cause subjects to quit drinking or to continue their drinking on a lower level, baseline measurement of alcohol intake alone will categorize these drinkers as abstainer or low-level drinker. This will result in underestimated disease risks. In additional sensitivity analyses we evaluated the relationship between alcohol and $\mathrm{CRC}$, by restricting the analyses to the alcohol drinkers that reported to have consumed equal amounts of alcohol five years before baseline, compared to baseline drinking habits, using the abstainers that reported to have abstained from alcohol five years before baseline as reference category.

Tests for heterogeneity were performed to evaluate differences in HRs for cancers of the proximal colon, distal colon, rectosigmoid and rectum, based on a bootstrapping method that was developed for the case-cohort design [36]. The observed differences in HRs for the above mentioned anatomical subsites were obtained from replicated statistics; 1,000 in total.

Besides total alcohol consumption, three types of alcoholic beverages (categorical variables) were examined, i.e. beer, wine (red wine, white wine, sherry and other fortified wines combined) and liqueur (liquors containing on average $16 \%$ alcohol, gin, brandy and whiskey combined), relative to the non-drinkers of beer, wine and liquor respectively. A glass of beer $(200 \mathrm{ml})$, wine $(105 \mathrm{ml})$ and liquor $(45 \mathrm{ml})$ was assumed to contain 8,10 and $13 \mathrm{~g}$ of alcohol, respectively. When analyzing the specific beverages, each beverage type was additionally adjusted for the cumulative intake of the remaining two types. When analyzing the effects of consumption of specific beverages however, total alcohol intake should be taken into account because associations may also occur because of the alcohol in the beverage. A Danish study [37] evaluated four methods - introduced by Willett to solve similar issues regarding nutrient intake and total energy intake [38] - for their applicability in alcohol analyses. According to their findings, we further evaluated the alcoholic beverages taking total alcohol intake into account, through adjustment of the analyses for total alcohol consumption (categorical: $0,<30.0$ and $\geq 30.0 \mathrm{~g} / \mathrm{d}$, in line 
with the results of The Pooling Project suggesting a threshold in alcohol consumption above which CRC risk is increased [4]).

In additional analyses red and white wine were evaluated separately, but since their results were not different from one another or from total wine, they will not be further discussed or presented. Sensitivity analyses evaluated the relationship between the three alcoholic beverages and risk of CRC by restricting the analyses to alcohol drinkers that indicated to have consumed equal amounts of total alcohol five years before baseline, compared to baseline.

We performed additional analyses on beer consumption and rectal cancer risk in men only, as the number of beer-drinking women was very small. In 1980, the relatively large amounts of nitrosamines present in beer and implicated in the etiology of rectal cancer in men, were drastically lowered by a change in the brewing process [17]. The levels that were present in beer before 1980 however, were speculated to still influence cancer risk for up to ten more years [17]. To examine a hypothetical attenuation in rectal cancer risk over time, we performed analyses on beer consumption (categorical variable) compared to no-beer drinking and adjusted for total alcohol intake, and rectal cancer for the first 3.3 years of follow-up (19861990 , e.g. within the first ten years after lowering of the nitrosamines levels), as well as for the subsequent 10 years of follow-up (1990-1999).

As we found no statistically significant interaction $(p=0.100)$ between alcohol consumption $(0,<30.0$ and $\geq 30.0 \mathrm{~g} / \mathrm{d})$ and sex, and since stratification by sex resulted in small subgroups, all described models were conducted for men and women combined. However, since sex-specific results in literature have been inconsistent [4, 25, 39-41], we additionally examined associations between alcohol intake ( $0<30.0$ and $\geq 30.0 \mathrm{~g} / \mathrm{d}$ ) and cancer risk of the colorectum overall and anatomical subsites for men and women separately. Interactions between total alcohol $(0,<30.0$ and $\geq 30.0 \mathrm{~g} / \mathrm{d}$ ) and folate intake (low and high intakes as based on the sex-specific median folate intakes) were tested, as well as interactions between total alcohol $(0,<30.0$ and $\geq 30.0 \mathrm{~g} / \mathrm{d})$ and smoking (never, ex, current). All $p$-values were two-sided. 
To evaluate the possible influence of subclinical disease symptoms on exposure status in early diagnosed cases, all analyses were repeated after exclusion of the first 2.3 years of follow-up.

\section{RESULTS}

After a 13.3-year period of follow-up of the NLCS cohort, a total of 1,573 colon cancers -760 in the proximal colon, 750 in the distal colon -, 218 rectosigmoid cancers and 532 rectal cancers were diagnosed. At baseline, $79 \%$ of the CRC cases consumed alcohol. Rectosigmoid and rectal cancer cases seemed to consume a higher amount of total alcohol per day, compared to proximal and distal colon cancer cases (table 1). Yet, the percentage of men amongst these cases was higher as well. There were no differences between cases with regard to other baseline characteristics.

A daily alcohol consumption of $\geq 30.0 \mathrm{~g} / \mathrm{d}$, when compared to abstaining, was associated with an increased risk of overall CRC (HR: 1.32, 95\% Cl: 1.06-1.65, table 2). With exception of the proximal colon, the increased cancer risk was seen for all anatomical subsites, most prominent and statistically significant in the rectum (HR: 1.50, 95\% Cl: 1.05-2.16). Bootstrap analyses showed that the HRs for the proximal colon, distal colon, rectosigmoid and rectum differed statistically significantly from one another $(p=0.017)$. When restricting the analyses to drinkers that reported to have consumed equal amounts of alcohol five years before baseline compared to baseline habits, the increased CRC risk as seen for baseline consumption levels of $\geq 30.0 \mathrm{~g} / \mathrm{d}$, increased even further when compared to abstainers that indicated to have abstained from alcohol five years before baseline also (HR: 1.53, 95\% Cl: 1.162.01). Risk was also increased for the various colorectal subsites, with statistically significant estimates for colon, rectosigmoid and rectal cancers. Moreover, bootstrap analyses suggested that the HRs for the distinct anatomical subsites differed borderline statistically significantly $(p=0.056)$. 
| Chapter 2

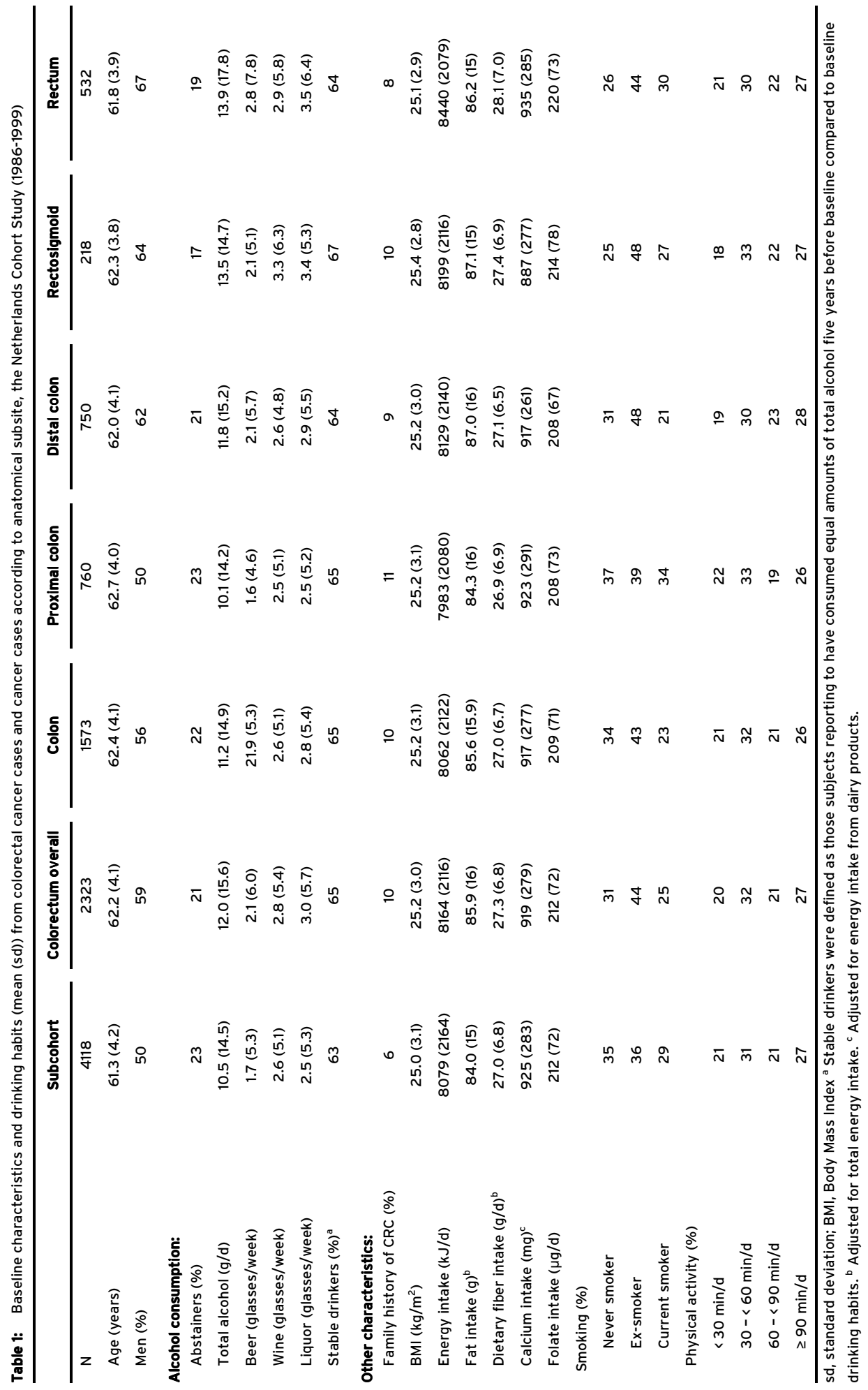




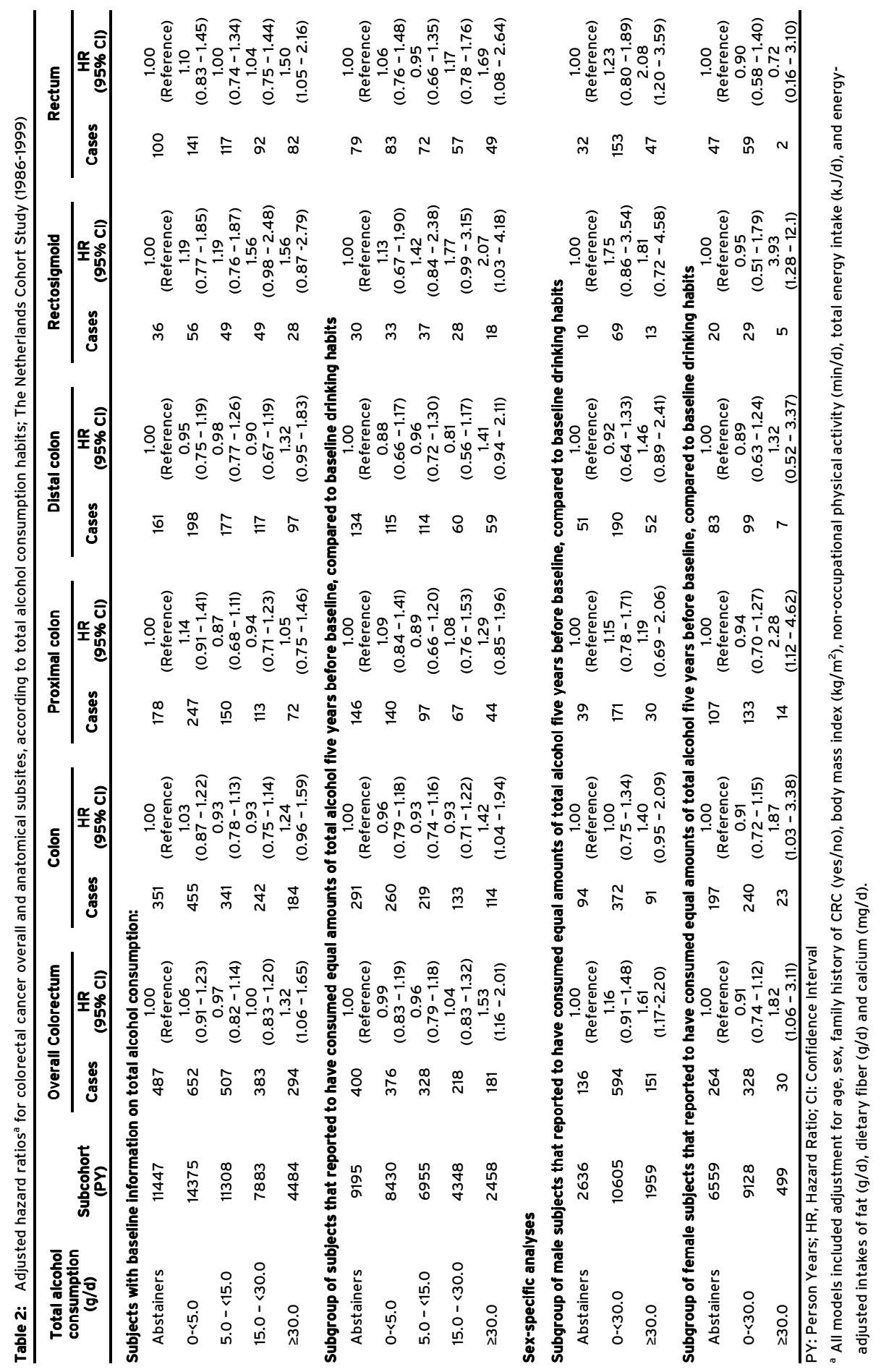


Stratification by sex showed similar results; in both men and women alcohol consumption of $\geq 30.0 \mathrm{~g} / \mathrm{d}$ was associated with an increased risk of CRC. In men, the highest risk was observed for the rectum (HR: 2.08, 95\% Cl: 1.20-3.59). In women risk of proximal colon cancer (HR: $2.28,95 \% \mathrm{Cl}: 1.12-4.62$ ) was evident, whereas the amount of cases in the highest alcohol consumption category for all other cancer subsites was too small for adequate interpretation of the results. In both men and women, the difference in HRs for the distinct anatomical subsites according to bootstrap analyses, did not reach statistical significance ( $p=0.160$ in men, $p=0.998$ in women)

No clear associations were observed between consumption levels of beer, wine and liquor and the risk of CRC overall, compared to the non-drinkers of of the specific beverage and additionally adjusted for cumulative consumption of the remaining beverage types (HR: 1.16, 95\% Cl: 0.98-1.39 for consumers of $>5$ glasses of beer/week; HR: $1.05,95 \% \mathrm{Cl}$ : 0.90-1.23 for consumers of $>5$ glasses of wine/week; and HR: 1.10, 95\% Cl: 0.94-1.28) for consumers of $>5$ glasses of liquor/week. Taking total alcohol consumption into account by adjusting the analyses for total alcohol consumption, instead of the cumulative intake of the remaining beverages types, the risk estimates for the highest categories of beverage-consumption slightly decreased towards 1.00 (table 3 ). Similar findings were observed for the different colorectal subsites. Restriction of these analyses to subjects that reported to have consumed equal amounts of alcohol five years before baseline as compared to baseline, did not provide different results (results not shown). The examined interactions between total alcohol consumption and folate intake $(p=0.207)$ and between total alcohol intake and smoking $(p=0.873)$ did not reach statistical significance. Also, exclusion of the first 2.3 years of follow-up did not change the results.

Associations between beer consumption and rectal cancer in men within the NLCS were studied further according to different periods of follow-up (results not shown). For the first 3.3 years of follow-up, each level of beer consumption, adjusted for total alcohol intake and compared to nobeer drinking, was not associated with the risk of rectal cancer in men. For the period from 3.3 until 13.3 years of follow-up, results similar to those of the first 3.3 years were observed. Restriction of the analyses to drinkers that reported to have consumed equal amounts of total alcohol five years before baseline as compared to baseline habits, did not alter the results 


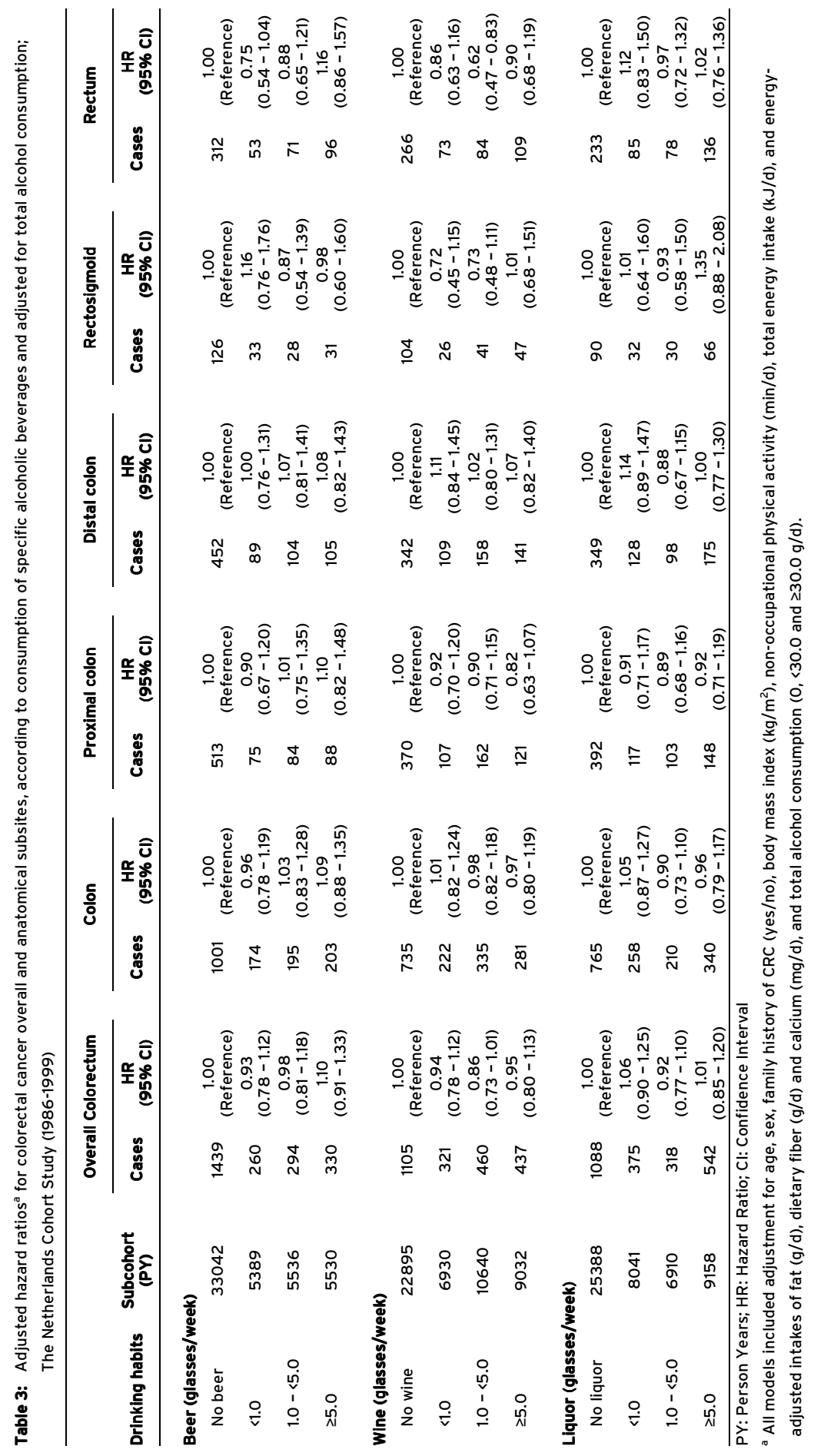


for the first 3.3 years of follow-up. For the subsequent ten years of follow-up however, consumption $\geq 5.0$ glasses of beer per week among these drinkers was associated with an increased risk of rectal cancer (HR: 1.56, 95\% Cl: 1.01-2.42), when adjusted for total alcohol consumption and compared to the non-beer drinking men.

\section{DISCUSSION}

In the current prospective study on a large sample of the general population we investigated associations between total alcohol consumption, consumption of specific types of alcoholic beverages, and the risk of CRC overall as for the anatomical subsites. For total alcohol consumption $\geq 30.0 \mathrm{~g} / \mathrm{d}$, compared to abstaining, we observed an increased risk of CRC. Sensitivity analyses, restricted to drinkers that reported to have consumed equal amounts of total alcohol five years before baseline compared to baseline drinking, showed slightly higher risk estimates for consumers of $\geq 30.0 \mathrm{~g}$ of total alcohol per day. In addition, positive associations between the individual CRC subsites and the specific consumption level became stronger as well. Cancer risk seemed to increase from proximal colon through rectum, suggestive of a subsite-specific effect with the highest risk in the rectosigmoid.

The relationship between alcohol consumption and CRC has often been studied. The majority of individual case-control $[10-12,39,41-45]$ and cohort studies $[14-16,18$, $25,40,46-49$ ] have shown rather inconsistent results, which in part can be explained by differing (methodological) aspects of these studies and lack of statistical power. To the best of our knowledge, our study is currently the largest single prospective study that has investigated associations between alcohol consumption and CRC. Our results confirm the reported consumption level of 30.0 $\mathrm{g} / \mathrm{d}$ above which an effect on CRC was apparent, in agreement with results of the Pooling Project [4], the EPIC study [8] and the meta-analyses on alcohol consumption and risk of CRC $[5-7,50]$. The meta-analysis of Moskal et al. [5], was unique in the sense of showing statistically significantly increased risks of CRC at even very low levels of alcohol intake. Risk estimates ranged from 3-4\% for 3.6 grams of alcohol per day to $15 \%$ for $14 \mathrm{~g} / \mathrm{d}$. In the present study, we were not able to reproduce these results. 
Alcohol is likely to be a long-term risk factor, and drinking habits over a longer time period may reflect alcohol exposure more accurately than information on baseline drinking habits alone. Yet, results of the EPIC cohort showed that associations between average lifetime alcohol intake and CRC risk were similar to those for baseline consumption and CRC risk [8]. Another issue concerning baseline drinking habits is that associations between alcohol and CRC may be affected by subjects included in the abstainer category, who quitted drinking because of preclinical disease symptoms or other health problems. These subjects have a relatively high risk of alcohol-related conditions as a result of their former high consumption levels, and inclusion in the reference category may result in underestimation of disease risk. Studies with information on ex-drinkers usually try to avoid the issue by excluding the ex-drinkers from the abstainer group. Yet, health issues may also urge subjects to reduce their intake levels. As such, underestimation of disease risk will not be overcome by excluding the ex-drinkers from the analyses. In the current study, information on drinking habits five years before baseline enabled us to select subjects that consumed equal amounts of alcohol five years before baseline compared to baseline drinking. We could thus exclude both ex-drinkers and drinkers with changed habits from our analyses. For the high alcohol consumers, these sensitivity analyses showed stronger risk estimates for both CRC overall and the different tumor subsites. The results suggested that the use of baseline information on alcohol consumption alone is subject to a certain degree of misclassification of former (heavy) drinkers. Data on alcohol use in the recent past for more and shorter time intervals, or repeated measurements of alcohol consumption would lead to an even more accurate measurement of drinking exposure over time that would probably result in even higher risk estimates.

Results in the literature on consumption of different alcoholic beverages and risk of CRC are far from consistent [10-12, 14, 47, 49]. The meta-analysis by Longnecker et al. [7], the Pooling Project [4] and the EPIC study [8] could not provide conclusive evidence for beverage-specificity also. Whereas most epidemiological studies have controlled their analyses on alcoholic beverages for the cumulative consumption of the remaining types of alcoholic beverages, we would like to separate the effect of the beverage's alcoholic content from the effect of its remaining constituents. Namely, associations between beverage types and CRC may simply occur because of the alcohol in the beverages. Willett proposed four methods for a similar issue in nutritional epidemiology with regard to nutrient intake and total energy intake [38]. 
Yet to apply these methods to alcohol research, requires careful considerations as alcoholic beverage intake is highly correlated to total alcohol intake (in our study: 0.53, 0.57 and 0.72 for beer, wine and liquor respectively). Moreover, for most people, total alcohol intake is determined predominantly by one type of beverage which will increase the correlation with total alcohol. Johansen et al. evaluated the applicability of Willett's methods to alcohol analyses [37]. According to their findings, we accounted for total alcohol intake by additionally adjusting the beverage type analyses for total alcohol consumption. Whether or not restricted to the drinkers that reported to have consumed equal amounts of alcohol five years before baseline as compared to baseline, no clear associations were observed suggesting that the observed association between overall alcohol consumption and CRC risk were mainly explained by the alcoholic content of the beverages used.

Despite the inconsistent results for the different alcoholic beverages among the epidemiological studies, beer consumption has more consistently been related to rectal cancer in men $[10,11,15,16,18,20,39,41,45,46]$. The data collection of these studies dates back to the 1960s until the 1980s, when in 1978 it was discovered that beer contained large amounts of the carcinogenic $\mathrm{N}$ nitrosodimethylamines (NDMAs) [51-53]. To reduce the NDMA concentrations in beer, an effective change in the brewing process was implemented during the following year. NDMA concentrations present in beer before 1979, were speculated to influence cancer risk for up to ten years later $[17,54]$. Our data showed no clear relationship between different levels of beer intake and risk of rectal cancer in men for both the 3.3 years and the 3.3-13.3 years of follow-up, when adjusted for total alcohol consumption and compared to no-beer drinking. When restricted to alcohol drinkers that indicated to have consumed equal amounts of total alcohol five years before baseline as compared to baseline, a positive association emerged between consumption of $\geq 5$.0 glasses of beer per week and rectal cancer risk for the 3.3-13.3 year-period of follow-up, as well as for the complete 13.3 years of follow-up. Of all the cases that drank $\geq 5.0$ glasses of beer per week, $45 \%$ simultaneously consumed a total of $\geq 30.0 \mathrm{~g}$ of alcohol per day, compared to $5 \%$ and $12 \%$ among the non-beer drinkers for both follow-up periods respectively. As described before, it is impossible to completely separate the effect of the alcoholic content of a specific beverage from the effect of its remaining constituents. Also, an analysis of a range of beers (138) from over 42 countries worldwide and purchased in 2003, showed that an overwhelming majority of the samples (79\%) do not contain detectable NDMA 
concentrations $(<0.1 \mu \mathrm{g} /$ litre) [55]. We therefore suggest that both estimates of increased rectal cancer risk for consumption of $\geq 5$ glasses of beer per week do not reflect an effect of specific ingredients in beer (NDMAs) other than alcohol, but reflect the (inseparable) effect of simultaneous high total alcohol consumption.

The large number of CRC cases enabled us to study associations between alcohol and $\mathrm{CRC}$, according to anatomical subsite. When restricting our analyses to the alcohol drinkers that reported to have consumed equal amounts of alcohol five years before baseline as compared to baseline, the estimates more clearly indicated increasing risks advancing from the proximal colon to the rectum, suggestive of a subsite-specific effect. This was strengthened by the bootstrap analyses that we performed. From literature, it is evident that colon and rectal tumors have different characteristics [21-25] and previous studies on alcohol and CRC have usually reported somewhat higher risk estimates for the rectum [11, 15, 16, 19, 25, 41]. Similarly, most epidemiological studies report stronger associations between alcohol and CRC for men compared to women [15, 19, 39, 41]. Our data however, showed no interaction between alcohol consumption and sex, and an additional stratification of our analyses showed similar results for men and women. In addition to the large meta-analyses [5-7, 50], the Pooling Project [4] and the EPIC study [8], we did not observe any evidence for sex-specificity.

In conclusion, this study showed that compared to abstaining, a daily alcohol consumption of $\geq 30.0 \mathrm{~g}$ was positively associated with CRC. CRC risk was more likely to be affected by the alcoholic content of the different beverage types as opposed to other beverage constituents. Although we found no evidence of sexspecificity, there may be a colorectal subsite-specific effect of total alcohol consumption. Furthermore, additional information on alcohol consumption over a longer period of time and specifically, stability of this behavior, is useful in minimizing misclassification of former drinkers and in obtaining more accurate risk estimates. 


\section{REFERENCES}

1. Boffetta, P. and Hashibe, M. Alcohol and cancer. Lancet Oncol, 7: 149-156, 2006.

2. Poschl, G., Stickel, F., Wang, X. D., and Seitz, H. K. Alcohol and cancer: genetic and nutritional aspects. Proc Nutr Soc, 63: 65-71, 2004.

3. Rehm, J., Room, R., Graham, K., Monteiro, M., Gmel, G., and Sempos, C. T. The relationship of average volume of alcohol consumption and patterns of drinking to burden of disease: an overview. Addiction, 98: 1209-1228, 2003.

4. Cho, E., Smith-Warner, S. A., Ritz, J., van den Brandt , P. A., Colditz, G. A., Folsom, A. R., et al. Alcohol intake and colorectal cancer: a pooled analysis of 8 cohort studies. Ann Intern Med, 140: 603-613, 2004.

5. Moskal, A., Norat, T., Ferrari, P., and Riboli, E. Alcohol intake and colorectal cancer risk: A dose-response meta-analysis of published cohort studies. Int J Cancer, 120: 664-671, 2006.

6. Corrao, G., Bagnardi, V., Zambon, A., and La Vecchia, C. A meta-analysis of alcohol consumption and the risk of 15 diseases. Prev Med, 38: 613-619, 2004.

7. Longnecker, M. P., Orza, M. J., Adams, M. E., Vioque, J., and Chalmers, T. C. A metaanalysis of alcoholic beverage consumption in relation to risk of colorectal cancer. Cancer causes control, 1: 59-68, 1990.

8. Ferrari, P., Jenab, M., Norat, T., Moskal, A., Slimani, N., Olsen, A., et al. Lifetime and baseline alcohol intake and risk of colon and rectal cancers in the European prospective investigation into cancer and nutrition (EPIC). Int J Cancer, 121: 2065-2072, 2007.

9. Food, Nutrition, Physical activity, and the Prevention of Cancer: a Global Perspective. Washington DC: AICR, 2007.

10. Newcomb, P. A., Storer, B. E., and Marcus, P. M. Cancer of the large bowel in women in relation to alcohol consumption: a case-control study in Wisconsin (United States). Cancer Causes Control, 4: 405-411, 1993.

11. Sharpe, C. R., Siemiatycki, J., and Rachet, B. Effects of alcohol consumption on the risk of colorectal cancer among men by anatomical subsite (Canada). Cancer Causes Control, 13: 483-491, 2002.

12. Tavani, A., Ferraroni, M., Mezzetti, M., Franchesci, S., Lo Re, A., and La Vecchia, C. Alcohol intake and risk of cancers of the colon and rectum. Nutr Cancer, 30: 213-219, 1998.

13. Barra, S., Negri, E., Franchesci, S., Guarneri, S., and La Vecchia, C. Alcohol and colorectal cancer: a case-control study from northern Italy. Cancer Causes Control, 3: 153-159, 1992.

14. Glynn, S. A., Albanes, D., Pietinen, P., Brown, C. C., Rautalahti, M., and Tangrea, J. A. Alcohol consumption and risk of colorectal cancer in a cohort of Finnish men. Cancer Causes Control, 7: 214-223, 1996. 
15. Goldbohm, R. A., van den Brandt, P. A., van 't Veer, P., Dorant, E., Sturmans, F., and Hermus, R. J. Prospective study on alcohol consumption and the risk of cancer of the colon and rectum in the Netherlands. Cancer Causes Control, 5: 95-104, 1994.

16. Pedersen, A., Johansen, C., and Grønbæk, M. Relations between amount and type of alcohol and colon and rectal cancer in a Danish population based cohort study. Gut, 52: 861-867, 2002.

17. Preussmann, R. Occurence and exposure to $n$-nitroso compounds and precursors. In: 0 . N. IK., V. B. RC., and M. CT. (eds.), N-Nitroso compounds: occurrence, biological effects and relevance to human cancer. Vol. 57, pp. 3-15. Lyon, France: IARC Sci Pub, 1984.

18. Hsing, A. W., McLaughlin, J. K., Chow, W. H., Schuman, K. L., Co Cien, H. T., Gridley, G., et al. Risk factors for colorectal cancer in a prospective study among U.S. white men. Int J Cancer, 77: 549-553, 1998.

19. Kune, G. A. and Vitetta, L. Alcohol consumption and the etiology of colorectal cancer: a review of the scientific evidence from 1957 to 1991. Nutr Cancer, 18: 97-111, 1992.

20. Stemmermann, G. N., Nomura, A. M., Chyou, P. H., and Yoshizawa, C. Prospective study of alcohol intake and large bowel cancer. Dig Dis Sci, 35: 1414-1420, 1990.

21. Birkenkamp-Demtroder, K., Olesen, S. H., Sørensen, F. B., Laurberg, S., Laiho, P., and $\emptyset$ rntoft, T. F. Differential gene expression in colon cancer of the caecum versus the sigmoid and rectosigmoid. Gut, 54: 374-384, 2005.

22. Frattini, M., Balestra, D., Suardi, S., Oggionni, M., Alberici, P., Radice, P., et al. Different genetic features associated with colon and rectal carcinogenesis. Clin Cancer Res, 10: 4015-4021, 2004.

23. Kapiteijn, E., Liefers, G. J., Los, L. C., Klein Kranenbarg, E., Hermans, J., Tollenaar, R. A. E. M., et al. Mechanisms of oncogenesis in colon versus rectal cancer. J Pathol, 195: 171178, 2001.

24. Konishi, K., Fujii, T., Boku, N., Koba, I., Ohtsu, A., Tajiri, H., et al. Clinicopathological differences between colonic and rectal carcinomas: are they based on the same mechanism of carcinogenesis? Gut, 45: 818-821, 1999.

25. Wei, E. K., Giovannucci, E., Wu, K., Rosner, B., Fuchs, C. S., Willet, W. C., et al. Comparison of risk factors for colon and rectal cancer. Int J Cancer, 108: 433-442, 2004.

26. Glebov, O. K., Rodriguez, L. M., Nakahara, K., Jenkins, J., Cliatt, J., Humbyrd, C. J., et al. Distinguishing right from left colon by the pattern of gene expression. Cancer Epidemiol Biomarkers Prev, 12: 755-762, 2003.

27. lacopetta, B. Are there two sides to colorectal cancer? Int J Cancer, 101: 403-408, 2002.

28. Frezza, M., di Padova, C., Pozzato, G., Terpin, M., Baraona, E., and Lieber, C. S. High blood alcohol levels in women. The role of decreased gastric alcohol dehydrogenase activity and first-pass metabolism. N Engl J Med, 322: 95-99, 1990. 
29. Van den Brandt, P. A., Goldbohm, R. A., van 't Veer, P., Volovics, A., Hermus, R. J., and Sturmans, F. A large-scale prospective cohort study on diet and cancer in The Netherlands. J Clin Epidemiol, 43: 285-295, 1990.

30. Casparie, M., Tiebosch, A. T., Burger, G., Blauwgeers, H., van de Pol, A., van Krieken, J. $\mathrm{H}$., et al. Pathology databanking and biobanking in The Netherlands, a central role for PALGA, the nationwide histopathology and cytopathology data network and archive. Cell Oncol, 29: 19-24, 2007.

31. Miettinen, O. S. Theoretical Epidemiology. Principles of Occurrence Research in Medicine. New York: Wiley, 1985.

32. Prentice, R. L. A case-cohort design for epidemiologic cohort studies and disease prevention trails. Biometrika, 73: 1-12, 1985.

33. NEVO-table, Dutch food composition table 1986-1987. The Hague, Netherlands: Voorlichtingsbureau voor de voeding. 1986.

34. Goldbohm, R. A., van den Brandt, P. A., Brants, H. A., van't Veer, P., Al, M., Sturmans, F., et al. Validation of a dietary questionnaire used in a large-scale prospective cohort study on diet and cancer. Eur J Clin Nutr, 48: 253-265, 1994.

35. Schoenfeld, D. Partial residuals for the proportional hazards regression model. Biometrika, 69: 239-241, 1982.

36. Wacholder, S., Gail, M., Pee, D., and Brookmeyer, R. Alternative variance and efficiency calculations for the case-cohort design. Biometrika, 76: 117-123, 1989.

37. Johansen, D., Andersen, P. K., Overvad, K., Jensen, G., Schnohr, P., Sørensen, T. I., et al. Energy adjustment methods applied to alcohol analyses. Alcohol, 31: 11-17, 2003.

38. Willett, W. C. Implications of total energy intake for epidemioligic analyses. In: W. C. Willett and M. Stampfer (eds.), Nutritional Epidemiology, pp. 273-301. Oxford: Oxford University Press, 1990.

39. Freudenheim, J. L., Graham, S., Marshall, J. R., Haughey, B. P., and Wilkinson, G. Lifetime alcohol intake and risk of rectal cancer in Western New York. Nutr Cancer, 13: 101-109, 1990.

40. Gapstur, S. M., Potter, J. D., and Folsom, A. R. Alcohol consumption and colon and rectal cancer in postmenopausal woman. Int J Epidemiol, 23: 50-57, 1994.

41. Riboli, E., Cornee, J., Macquart-Moulin, G., Kaaks, R., Casagrande, C., and Guyader, M. Cancer and polyps of the colorectum and lifetime consumption of beer and other alcoholic beverages. Am J Epidemiol, 134: 157-166, 1991.

42. Bardou, M., Montembault, S., Giraud, V., Balian, A., Borotto, E., Houdayer, C., et al. Excessive alcohol consumption favours high risk polyp or colorectal cancer occurence among patients with adenomas: a case-control study. Gut, 50: 38-42, 2005.

43. Erhardt, J. G., Kreichgauer, H. P., Meisner, C., Bode, J. C., and Bode, C. Alcohol, cigarette smoking, dietary factors and the risk of colorectal adenomas and hyperplastic polyps--a case control study. Eur J Nutr, 41: 35-43, 2002. 
44. Boyapati, S. M., Bostick, R. M., McGlynn, K. A., Fina, M. F., Roufail, W. M., Geisinger, K. R., et al. Folate intake, MTHFR C677T polymorphism, alcohol consumption, and risk for sporadic colorectal adenoma (United States). Cancer Causes \& Control, 15: 493-501, 2004.

45. Longnecker, M. P. A case-control study of alcoholic beverage consumption in relation to risk of cancer of the right colon and rectum in men. Cancer Causes Control, 1: 5-14, 1990.

46. Pollack, E. S. Prospective study of alcohol consumption and cancer. N Engl J Med, 310: 617-621, 1984.

47. Su, L. J. and Arab, L. Alcohol consumption and risk of colon cancer: evidence from the national health and nutrition examination survey I epidemiologic follow-up study. Nutr Cancer, 50: 111-119, 2004.

48. Lieberman, D. A., Prindiville, S., Weiss, D. G., Willett, W., and 380, V. C. S. G. Risk factors for advanced colonic neoplasia and hyperplastic polyps in asymptomatic individuals. Jama-Journal of the American Medical Association, 290: 2959-2967, 2003.

49. Giovannucci, E., Rimm, E. B., Ascherio, A., Stampfer, M. J., Colditz, G. A., and Willet, W. C. Alcohol, low-methionine-low-folate diets, and risk of colon cancer in men. J Natl Cancer Inst, 87: 265-273, 1995.

50. Bagnardi, V., Blangiardo, M., La Vecchia, C., and Corrao, G. A meta-analysis of alcohol drinking and cancer risk. $\mathrm{Br} \mathrm{J}$ Cancer, 85: 1700-1705, 2001.

51. Goff, E. U. and Fine, D. H. Analysis of volatile N-nitrosamines in alcoholic beverages. Food Cosmet Toxicol, 17: 569-573, 1979.

52. Knekt, P., Jarvinen, R., Dich, J., and Hakulinen, T. Risk of colorectal and other gastrointestinal cancers after exposure to nitrate, nitrite and N-nitroso compounds: a followup study. Int J Cancer, 80: 852-856, 1999.

53. Nelson, R. L., Persky, V., and Turyk, M. Determination of factors responsible for the declining incidence of colorectal cancer. Dis Colon Rectum, 42: 741-752, 1999.

54. Goldbohm, R. A., van den Brandt, P. A., van 't Veer, P., Dorant, E., Sturmans, F., and Hermus, R. J. J. Prospective study on alcohol consumption and the risk of cancer of the colon and rectum. Cancer causes control, 5: 95-104, 1994.

55. Baxter, E. D., Slaiding, I. R., and Travers, V. Current incidence of Nnitrosodimethylamine in beers worldwide. Food Addit Contam, 24: 807-811, 2007. 



\title{
Alcohol consumption, alcohol dehydrogenase $1 C$ ( ADH1C) genotype and risk of colorectal cancer in the Netherlands Cohort Study on diet and cancer
}

\author{
Brenda W.C. Bongaerts \\ Anton F.P.M. de Goeij \\ Kim A.D. Wouters \\ Manon van Engeland \\ Ralph W.H. Gottschalk \\ Frederik J. Van Schooten \\ R. Alexandra Goldbohm \\ Piet A. van den Brandt \\ Matty P. Weijenberg
}

Submitted for publication 


\begin{abstract}
The alcohol dehydrogenase $1 C$ ( $A D H 1 C)$ gene codes for the ADH1C enzyme, which determines the rate of acetaldehyde formation from alcohol. We examined the modifying effect of the $A D H 1 C$ polymorphism on the association between alcohol consumption and CRC risk within the Netherlands Cohort Study (NLCS).
\end{abstract}

Using a case-cohort approach, adjusted incidence rate ratios (RR) and 95\% confidence intervals $(\mathrm{Cl})$ for $\mathrm{CRC}$ were estimated using Cox proportional hazards models. After a follow-up period of 7.3 years, 594 CRC cases with complete information on $A D H 1 C$ genotype and alcohol consumption were available for analyses.

Whereas the $A D H 1 C$ genotype was not related with the level of alcohol intake, the $A D H 1 C * 2 / * 2$ genotype was related with a higher risk of CRC relative to the $A D H 1 C^{*} /{ }^{* 1}$ genotype. Associations between baseline alcohol consumption, and risk of CRC stratified by $A D H 1 C$ genotype, were not apparent. Next, we restricted the analyses to subjects that reported to have consumed equal amounts of total alcohol five years preceding baseline as compared to baseline. Alcohol consumers of $\geq 30.0$ $\mathrm{g} / \mathrm{d}$ with the $A D H 1 C * 2 / * 2$ genotype were associated with a non-significant increased risk of CRC, compared to abstainers with the $A D H 1 C^{*} 1{ }^{*} 1$ genotype (RR: $1.91,95 \% \mathrm{Cl}$ : 0.68-5.34). Further restriction to drinkers only showed even higher, though nonsignificant, risk estimates for consumers of $\geq 30.0 \mathrm{~g} / \mathrm{d}$ with the $A D H 1 C^{*} 2 /{ }^{*} 2$ genotype relative to consumers of $>0-<5.0 \mathrm{~g} / \mathrm{d}$ with the $A D H 1 C^{*} 1 /{ }^{* 1}$ genotype (RR: 2.60, 95\% Cl: 0.84-7.42).

In conclusion, the $A D H 1 C$ genotype modified the association between alcohol consumption and risk of $\mathrm{CRC}$, with the highest risk conferred to the $A D H 1 C^{*} 2 /{ }^{* 2}$ genotype. 


\section{INTRODUCTION}

Alcohol consumption is an important risk factor for the development of several types of cancer, including cancers of the upper aerodigestive tract, liver and breast [1]. Also a considerable proportion of colorectal cancers (CRC) may arise as a result of (excessive) alcohol intake [1,2]. Pooled results from eight large cohort studies [3], data from meta-analyses [4-6] and results from the EPIC cohort [7] demonstrated increased risks of colon and rectal cancer for alcohol consumption levels from 30.0 up to $100.0 \mathrm{~g} / \mathrm{d}$, relative to abstinence. Even small amounts of daily alcohol consumption with levels ranging from 3.6 to $14.0 \mathrm{~g} / \mathrm{d}$ already increase the risk of CRC, as was shown in a large recently published meta-analysis [8].

According to current knowledge, mechanisms of alcohol-associated tumorigenesis are closely related to the alcohol metabolism in which acetaldehyde is identified as important carcinogen [9]. Alcohol is mainly metabolized in the liver and involves oxidation of alcohol to acetaldehyde by alcohol dehydrogenase (ADH) enzymes. Acetaldehyde is then rapidly oxidized to acetate by aldehyde dehydrogenase (ALDH) [10]. Both enzymes occur in several isoforms. For the isoforms $A D H 1 B, A D H 1 C$ and $A L D H 2$, single nucleotide polymorphisms (SNPs) have been described, coding for enzymes with different enzymatic properties [11,12]. In contrast to polymorphisms in $A D H 1 B$ and $A L D H 2$, polymorphisms in $A D H 1 C$ are highly frequent in Caucasian populations $[12,13]$. For this gene, one functional SNP has been identified and in Caucasians the two allelic variants are present in approximately equal frequency. Homozygotes for the $A D H 1 C^{* 1}$ allele metabolize alcohol 2.5 times faster than homozygotes for the $A D H 1 C * 2$ allele [10]. As such, subjects with the $A D H 1 C * 1 / * 1$, $A D H 1 C^{*} 1 /{ }^{*} 2$ and $A D H 1 C * 2 / * 2$ genotype are classified as fast, intermediate and slow metabolizers respectively. Because of the different kinetic properties of the enzymes, the $A D H 1 C$ polymorphism is speculated to underlie a genetic susceptibility to alcohol-associated cancers. In literature, studies have reported an interaction between alcohol consumption, $A D H 1 C$ genotype and risk of upper aerodigestive tract (UADT) cancer [14, 15], breast cancer [16-18], hepatitis cirrhosis and chronic pancreatitis [19], as well as colorectal neoplasia [20-22]. These studies all suggested the fast metabolizing $A D H 1 C{ }^{*} 1 /{ }^{*} 1$ genotype to be the high risk genotype, except for two studies on colorectal adenomas and carcinomas that reported $A D H 1 C * 2 * 2$ to be the high risk genotype. 
Therefore, we examined associations between alcohol consumption, ADH1C polymorphism and risk of CRC in a large prospective cohort study. Opposite to the results for UADT cancer and breast cancer, we hypothesized that for CRC the slowmetabolizing $A D H 1 C * 2 / 2$ genotype would confer a higher risk of alcohol-associated carcinogenesis. The elimination of alcohol is largely dependent on the oxidative metabolism in the liver through $A D H$ and ALDH. In case of the slow-metabolizing $A D H 1 C * 2 / * 2$ genotype, blood- and tissue-alcohol concentrations will decline less fast than in case of the fast-metabolizing genotype $A D H 1 C^{*} 1 / * 1$. As such all organs, including the colon and rectum, are exposed for a relatively longer period of time to circulating alcohol. ADH activity from the colorectal mucosa and perhaps even more important, ADH activity from colonic bacteria, may thus lead to higher amounts of locally formed acetaldehyde in de colorectum [23-26]. As such, the $A D H 1 C^{*} 2 /{ }^{* 2}$ genotype may confer a higher risk of CRC compared to the $A D H 1 C^{* 1} 1{ }^{* 1}$ genotype, through higher levels of locally formed acetaldehyde.

\section{SUBJECTS AND METHODS}

\section{Study population}

In September 1986, the Netherlands Cohort Study on diet and cancer (NLCS) was initiated, as described in detail elsewhere [27]. Briefly, the cohort includes 58,279 men and 62,573 women, aged 55-69 years at baseline and originating from 204 municipal population registries throughout the Netherlands. All cohort members completed an extensive self-administered questionnaire on dietary habits during the year preceding the start of the study, life style factors and other risk factors for cancer. The entire cohort is followed-up for cancer occurrence through annual record linkage to the Netherlands Cancer Registry (NCR, comprising nine cancer registries in the Netherlands) and to PALGA, a nationwide database of histo- and cytopathology reports $[28,29]$. The NLCS followed the case-cohort approach in which data are processed and analyzed only for a random sample of the cohort plus all incident cancer cases arising each year $[30,31]$. Cases were identified for the entire cohort, while a random sample of the cohort, i.e. the subcohort, was used to estimate person years at risk accumulating in the cohort (from the date of entry into the cohort until the date of a colorectal cancer diagnosis, death from any cause, leaving the study area or the end of the studied follow-up period). The subcohort, 
consisting of 5,000 men and women, was followed-up biennially to assess information on vital status and migration in order to calculate accumulated person time in the cohort. Prevalent cancer cases, other than non-melanoma skin cancer, were excluded from the subcohort, resulting in 4,774 subcohort members.

Cancer cases were classified according to anatomical subsite: colon cancers, comprising tumors of the caecum through sigmoid colon (ICD-O codes $C 18.0$ through C18.7) as well as colon tumors overlapping subsites and unspecified tumors (ICD-O codes C18.8 and C18.9); rectosigmoid cancers (ICD-O code C19) and rectal cancers (ICD-O code C20). Colorectal cancers comprised all cancers of the colon, the rectosigmoid and the rectum.

\section{Assessment of exposure}

Information on dietary habits was obtained through a 150-item semi-quantitative food frequency questionnaire. Information on daily dietary habits was obtained through a 150-item semi-quantitative food frequency questionnaire. Alcohol consumption was measured by six items: (a) beer; (b) red wine; (c) white wine; (d) sherry and other fortified wines; (e) liquor types containing on average $16 \%$ alcohol and (f) (Dutch) gin, brandy and whiskey. Participants were asked about their usual frequency of consumption and the number of glasses consumed at each drinking occasion. Together with the alcoholic content of the various beverages, the total amount of mean daily alcohol consumption ( $\mathrm{g} / \mathrm{d}$ ) was calculated [32]. In addition, for "beer" and "other alcoholic beverages" participants could indicate whether five years ago, they drank (a) more than, (b) equal amounts of, or (c) less than today. The fourth answering option was (d) I never use this. This information enabled for example, a selection of subjects that reported to have consumed equal amounts of total alcohol five years before baseline, compared to baseline drinking habits.

The questionnaire has been validated against a 9-day diet record [33]. The Spearman correlation coefficient between mean daily alcohol intake assessed by the questionnaire and estimated from the 9-day diet record was 0.89 for all subjects and 0.85 for users of alcoholic beverages. The absolute amount of alcohol reported in the questionnaire by users of alcoholic beverages was, on average, 86 percent of that reported in the 9-day diet record. 
Besides the dietary section, the questionnaire comprised a section on lifestyle and other risk factors for cancer. Information on for instance family history of CRC, sex, age at baseline, and smoking were retrieved from this section.

\section{Tissue sample collection and DNA extraction}

In August 1999, collection of tumor tissue specimens was started after approval by the Ethical Review board of University Maastricht, PALGA and the NCR. Tumor blocks from CRC cases that were diagnosed within the first 7.3 years of follow-up were collected, using PALGA to identify and locate the tissue samples in Dutch pathology laboratories. Since full coverage of the included municipalities by PALGA was not reached until the end of 1988, the first 2.3 years of follow-up were excluded from collection to avoid selection bias as a result of this incomplete coverage. As such, from the 925 CRC cases diagnosed between January 1989 and January 1994, 815 tissue samples could be linked to a PALGA report of the lesion of which 734 (90\%) could be retrieved from the pathology laboratories. Genomic DNA was extracted from macrodissected tumor tissue, as described in detail elsewhere [34], which we used to establish the $A D H 1 C$ genotype of the CRC cases. As opposed to using normal healthy tissue, one could argue whether the ADH1C genotype as derived from tumor tissue, may or may not be affected by tumor changes. Yet, we consider it unlikely that these changes would involve a specific single point mutation in the gene.

In December 2000, all available members of the subcohort who were still alive at that time point $(n=3,579)$ were contacted and asked to collect mouth swabs. Four cotton swabs in a small non-woven polyethylene envelope were mailed to each subject, including a simple protocol on how to use the swabs for the left cheek, the right cheek, the inside of the upper lip and gums of the upper jaw, and the inside of the lower lip and gums of the lower jaw. Shortly after receipt of the envelopes with the air-dried mouth swabs, the swabs were placed in a falcon tube with $2.0 \mathrm{ml}$ buffer solution (100mM NaCl, $10 \mathrm{mM}$ EDTA, $10 \mathrm{mM}$ Tris, Ph 8 with $0.2 \mathrm{mg} / \mathrm{ml}$ proteinase $\mathrm{K}$ and $0.5 \% \mathrm{w} / \mathrm{v}$ SDS). The lysed solution was kept stored at room temperature in the dark. In total, 1,929 subcohort members (54\%) returned the mouth swabs with the informed consent in 2000. Corresponding with data from literature [35], the average DNA yield per cotton swab was 0.1-10 $\mu \mathrm{g}$, from which we determined the ADH1C genotype of subcohort members. 


\section{ADH1C genotyping}

$A D H 1 C$ was amplified using 50 ng of genomic DNA, 1 x PRC buffer (Invitrogen, Breda, The Netherlands), $1.75 \mathrm{mM} \mathrm{MgCl}_{2}$ (Invitrogen), $0.4 \mu \mathrm{mol} / \mathrm{L}$ dNTPs (Amersham Bioscience, Buckinghamshire, England), 100 ฤM of each primer (Eurogentec, Maastricht, The Netherlands) and $0.25 \mathrm{U}$ Platinum Taq (Invitrogen) in a final volume of $10 \mu \mathrm{l}$. The following PCR primers were used: F5'-CTT GTG GCT GAC TTT ATG GCT A-3' and R5'-CTC TTT CCA GAG CGA AGC AG-3'. PCR conditions comprised three minutes at $94^{\circ} \mathrm{C}, 35 \mathrm{cycles}$ of $30 \mathrm{sec}$ at $94^{\circ} \mathrm{C}, 30 \mathrm{sec}$ at $62^{\circ} \mathrm{C}, 30 \mathrm{sec}$ at $72^{\circ} \mathrm{C}$, a final extension for five minutes at $72^{\circ} \mathrm{C}$ and four minutes at $20^{\circ} \mathrm{C}$. To degrade excess PCR primers and dNTPs, $5 \mu$ multiplex PRC product was incubated with $2 \mu \mathrm{l}$ EXO-SAP IT (Amersham Bioscience) at $37^{\circ} \mathrm{C}$ for 45 minutes, followed by $80^{\circ} \mathrm{C}$ for 15 minutes to deactivate the enzyme.

Genotyping was performed using the Multiplex SNaPShot single base extension (SBE) reaction (Applied Biosystems, Foster City, CA U.S.A.) as described previously [36]. The SBE primers were designed to anneal immediately adjacent 5 ' to the SNP of interest - i.e. rs698 A1047G - with a template specific part of 20 to $33 \mathrm{bp}$ and a Tm of $60^{\circ} \mathrm{C}$ (for ADH1C: TTTTCACTGGATGCATTAATAACA- AAT). During thermal cycling, the primers were extended at the 3 '-end with a single dideoxyribonucleoside triphosphate, labelled with a distinct fluorophore for the ADH1C genotype. SBE was performed using 25 cycles of $96^{\circ} \mathrm{C}$ for $10 \mathrm{sec}$ and $60^{\circ} \mathrm{C}$ for $30 \mathrm{sec}$. Following cycling, one unit Shrimp Alkaline Phosphatase (Amersham Bioscience) was added at $37^{\circ} \mathrm{C}$ for one hour to degrade the unincorporated dideoxynucleotide triphosphates, followed by enzyme deactivation at $75^{\circ} \mathrm{C}$ for 15 minutes. One $\mu$ SBE product was added to $13 \mu \mathrm{l}$ of $\mathrm{Hi}-\mathrm{Di}$ formamide (Applied Biosystems) and $0.4 \mu \mathrm{l}$ of Genescan-120 size standard (Applied Biosystems) and denatured at $95^{\circ} \mathrm{C}$ for five minutes and subsequently analyzed on an ABI Prism 3100 genetic analyzer using Genmapper Analysis Software (version 4).

\section{Data analyses}

Data analyses were based on subcohort members and cases for which information on $A D H 1 C$ genotype and complete information on alcohol consumption and confounding variables was present; i.e. 1,649 subcohort members and 594 CRC cases. For all subcohort members who were also CRC case $(n=19)$, the $A D H 1 C$ genotype derived from tumor tissue matched the outcome of their mouth swab. 
Since the mouth swab collection for SNP analyses took place 14 years after baseline, there may have occurred a selection of subcohort members on characteristics related to survival. This selection may be associated with a certain genetic constitution and/or with environmental exposures, such as diet. We have therefore compared the subcohort members that provided mouth swabs with the subcohort members that had not. We tested for differences in alcohol consumption and confounders used in our analyses, using $t$-tests and $x^{2}$ tests where appropriate. Also, there may have been selective loss to follow-up affecting the $A D H 1 C$ genotype frequency in the subcohort. To preclude this we applied ANOVA to compare the mean age from subcohort members across the different $A D H 1 C$ genotypes.

To verify that the level of alcohol consumption was independent of $A D H 1 C$ genotype, we used the $\mathrm{x}^{2}$ test to test for differences in $A D H 1 C$ genotype frequencies across categories of alcohol intake $(0,<30.0, \geq 30.0 \mathrm{~g} / \mathrm{d})$ among subcohort members. The categories of alcohol intake used in the data analyses were based on a previous study on alcohol consumption and CRC within this population which showed increased CRC risk for drinkers of $\geq 30.0 \mathrm{~g} / \mathrm{d}$ relative to abstainers, consistent with results in literature $[3,7]$.

Cox proportional hazards models were used to estimate incidence rate ratios (RR) and corresponding 95 percent confidence intervals $(\mathrm{Cl})$ for the main effects of the ADH1C genotype on CRC risk, as well as cancer risk for the colon, rectosigmoid and rectum. The proportional hazards assumption was tested using the scaled Schoenfeld residuals [37]. Standard errors were estimated using the robust HuberWhite sandwich estimator to account for additional variance introduced by sampling from the cohort. According to our hypothesis, the fast-metabolizing $A D H 1 C * 1 /{ }^{*}$ was considered as the low risk genotype for CRC and thus served as reference group. Subsequently, the modifying effect of the ADH1C polymorphism on the association between alcohol consumption and risk of CRC was evaluated in three ways. Firstly, to be able to compare our findings with most other studies on alcohol and CRC, we used baseline alcohol consumption as exposure variable and we considered the abstainers with the $A D H 1 C^{*} 1 /{ }^{*} 1$ genotype as reference group. Secondly, the analyses were restricted to the alcohol drinkers that reported to have consumed equal amounts of alcohol five years before baseline as compared to baseline. Abstainers with the $A D H 1 C^{*} 1 /{ }^{* 1}$ genotype, who reported to have abstained from alcohol five years before baseline as well, now served as reference group. These sensitivity 
analyses attempted to minimize the possible misclassification of former (heavy) drinkers as abstainer or low-level drinker. And thirdly, since alcohol is the only substrate for the ADH1C enzyme, we excluded the abstainers from the analyses and considered consumers of $>0-<5.0 \mathrm{~g}$ of alcohol per day with the $A D H 1 C^{*} 1 /{ }^{*} 1$ genotype as reference category. All three analyses were performed for overall CRC only, since small numbers of cases did not allow separate analyses for the anatomical subsites.

Confounding effects of age at baseline (years), family history of CRC (yes/no), body mass index $(\mathrm{BMI})\left(\mathrm{kg} / \mathrm{m}^{2}\right)$, smoking (never, ex, current), non-occupational physical activity $(\mathrm{min} / \mathrm{d})$, energy intake $(\mathrm{kJ} / \mathrm{d})$, folate intake $(\mu \mathrm{g} / \mathrm{d})$, meat intake $(\mathrm{g} / \mathrm{d})$, calcium intake $(\mathrm{mg} / \mathrm{d})$ adjusted for energy-intake from dairy products and energyadjusted intakes of $\mathrm{fat}(\mathrm{g} / \mathrm{d})$ and fiber $(\mathrm{g} / \mathrm{d})$ were evaluated for their effect on the relationship between alcohol consumption and CRC risk. Those variables that altered the estimate for the exposure coefficient between statistical models with and without the potential confounder by more than 10 percent, or those that were found to statistically significantly contribute to the multivariable model for CRC were included in the analyses. When assessing the main effects of the $A D H 1 C$ genotype on risk of $C R C$, additional adjustment was made for total alcohol intake (categorical; 0 , $<30.0$ and $\geq 30.0 \mathrm{~g} / \mathrm{d}$ ).

Because stratification by gender would result in small subgroups, statistical analyses were performed for men and women combined. We tested for interactions between total alcohol consumption and gender, as well as for interactions between total alcohol consumption and $A D H 1 C$ genotype, alcohol and folate intake and total alcohol and smoking. To test these interactions, we computed a cross-product term using a three-category ordinal value for $A D H 1 C$, for alcohol (based on intakes of 0 , $<30$ and $\geq 30 \mathrm{~g} / \mathrm{d}$ ) and for smoking (based on never-, ex- and current smoking), and a two-category ordinal value for gender, and folate intake (based on median folate intake in the subcohort). $P$ for interaction was based on the Wald test for this crossproduct term added to the model. P-values were two-sided and all statistical analyses were performed with the STATA Statistical Software Package (version 9). 


\section{RESULTS}

The current analyses were based on 7.3-years of follow-up of the NLCS cohort, i.e. a total of 11,992 person years accumulated in the subcohort and 594 CRC cases (403 colon cancers, 62 rectosigmoid cancers and 129 rectal cancers). At baseline, $76 \%$ of the CRC cases drank alcohol (table 1). Among the cancer cases, rectal cancer cases seemed to drink more alcohol on a daily basis yet, the percentage of men amongst these cases was higher. Cancer cases did not differ with respect to genotype variants and other baseline characteristics.

There were no differences in mean daily alcohol consumption and confounding variables between subcohort members that provided mouth swabs and those that did not, except for age. As expected, subcohort members without mouth swabs were, on average, two years older $(p=0.00)$ (results not shown). The mean age of subcohort members did not differ statistically significantly across the different $A D H 1 C$ genotypes ( $p=0.708$, results not shown).

With respect to allele and genotype frequencies in the subcohort, no deviation from Hardy-Weinberg equilibrium was observed ( $p=0.316)$. Among subcohort members, frequencies of the $A D H 1 C$ genotype variants were similar within the different categories of alcohol intake ( $p>0.05$ ) (table 2).

An association was observed between $A D H 1 C$ genotype and risk of CRC. Compared to the fast-activity genotype $A D H 1 C^{*} 1 / * 1$, the $A D H 1 C * 2 /{ }^{*} 2$ genotype was associated with a statistically significant $44 \%$ increase in risk of overall CRC, a $39 \%$ increase in risk of colon cancer, a borderline statistically significant $95 \%$ increase in risk of rectosigmoid cancer, and a non-significant $38 \%$ increase in rectal cancer risk (table 3). These analyses were adjusted for confounding variables as well as for total mean daily alcohol consumption. The crude associations - whether or not adjusted for total alcohol consumption - were equally strong (results not shown). 
Table 1: Baseline characteristics and mean dietary intakes (sd) for male and female subcohort members and male and female CRC cases according to anatomical subsite, the Netherlands Cohort Study (1986-1993)

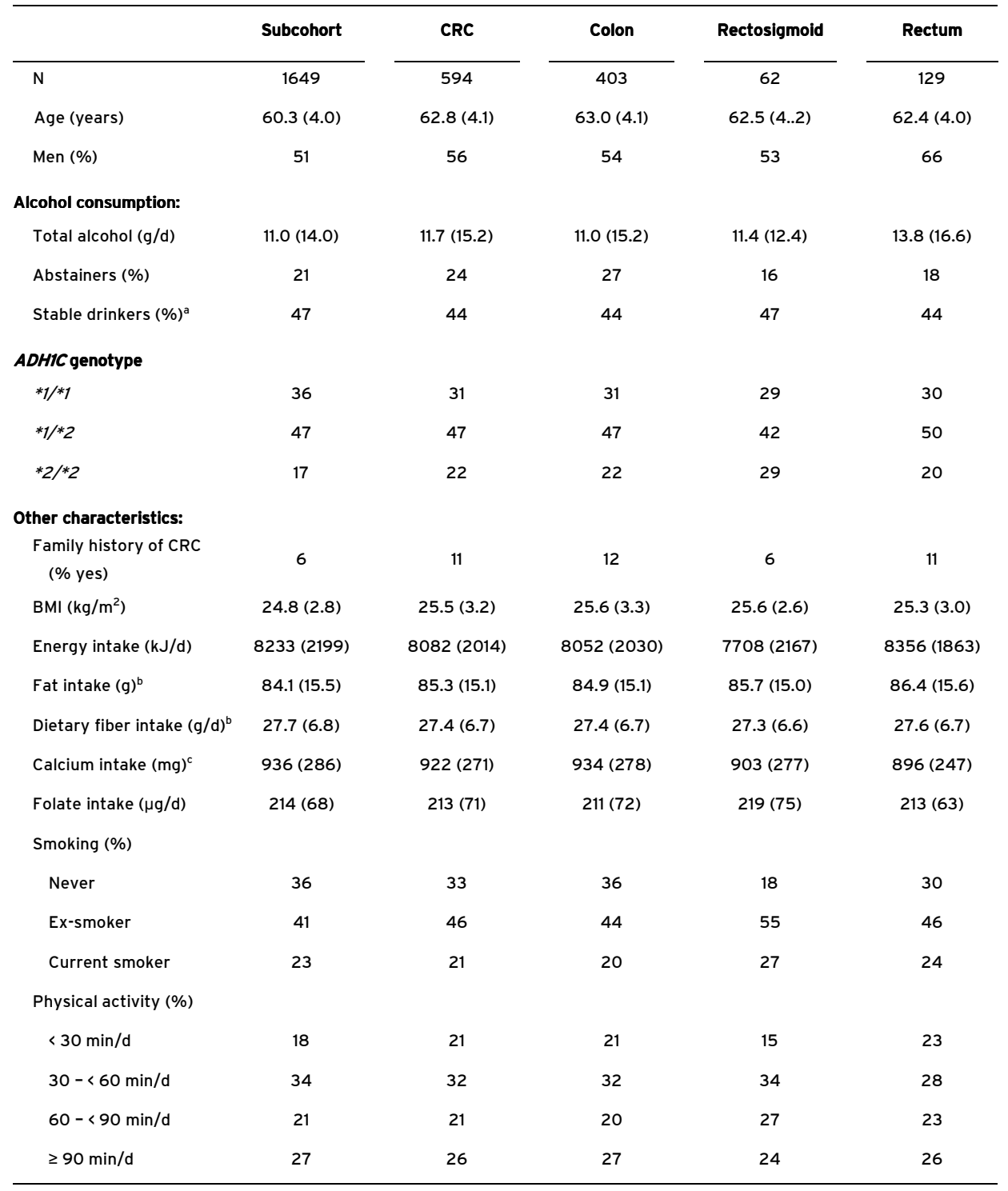

a Stable drinkers are those subjects that reported to have consumed equal amounts of total alcohol five years before baseline, compared to baseline drinking habits.

${ }^{b}$ Adjusted for total energy intake.

${ }^{c}$ Adjusted for energy intake from dairy products. 


\section{| Chapter 3}

Table 2: Alcohol dehydrogenase $1 C$ ( $A D H 1 C)$ genotype variants and allele frequencies across categories of total average alcohol intake in male and female subcohort members; The Netherlands Cohort Study (1986-1993)

\begin{tabular}{lccc}
\hline & \multicolumn{3}{c}{ Alcohol consumption } \\
\cline { 2 - 4 } & Abstainer & $<30.0 \mathrm{~g} / \mathrm{d}$ & $230.0 \mathrm{~g} / \mathbf{d}$ \\
\hline ADHIC genotype & & & \\
$* 1 / * 1(\%)(\mathrm{N}=587)$ & $129(22 \%)$ & $393(67 \%)$ & $65(11 \%)$ \\
$* 1 / * 2(\%)(\mathrm{N}=775)$ & $163(21 \%)$ & $542(70 \%)$ & $70(9 \%)$ \\
$* 2 / *^{2}(\%)(\mathrm{N}=287)$ & $54(19 \%)$ & $201(70 \%)$ & $32(11 \%)$ \\
& & $x^{2}(p$-value $)=0.585$ & $60 \%$ \\
Allele frequency & & & $40 \%$ \\
$* 1$ & $61 \%$ & $58 \%$ & $42 \%$ \\
\hline
\end{tabular}

Table3: Adjusted incidence rate ratios ${ }^{a}$ for colorectal cancer according to alcohol dehydrogenase 1C (ADH1C) genotype in men and women; The Netherlands Cohort Study (1986-1993)

\begin{tabular}{|c|c|c|c|c|c|c|c|c|c|}
\hline & \multirow[b]{2}{*}{$\begin{array}{c}\text { Subcohort } \\
\text { (PY) }\end{array}$} & \multicolumn{2}{|c|}{ Overall Colorectum } & \multicolumn{2}{|r|}{ Colon } & \multicolumn{2}{|c|}{ Rectosigmoid } & \multicolumn{2}{|c|}{ Rectum } \\
\hline & & Cases & $\begin{array}{c}\mathbf{R R} \\
(95 \% \mathrm{Cl})\end{array}$ & Cases & $\begin{array}{c}\text { RR } \\
(95 \% \mathrm{Cl})\end{array}$ & Cases & $\begin{array}{c}\text { RR } \\
(95 \% \mathrm{Cl})\end{array}$ & Cases & $\begin{array}{c}\text { RR } \\
(95 \% \mathrm{Cl})\end{array}$ \\
\hline \multicolumn{10}{|c|}{ ADHIC genotype } \\
\hline$* 1 / * 1$ & 4266 & 183 & $\begin{array}{c}1.00 \\
\text { (Reference) }\end{array}$ & 126 & $\begin{array}{c}1.00 \\
\text { (Reference) }\end{array}$ & 18 & $\begin{array}{c}1.00 \\
\text { (Reference) }\end{array}$ & 39 & $\begin{array}{c}1.00 \\
\text { (Reference) }\end{array}$ \\
\hline$* 1 / * 2$ & 5636 & 278 & $\begin{array}{c}1.11 \\
(0.88-1.40)\end{array}$ & 188 & $\begin{array}{c}1.08 \\
(0.83-1.42)\end{array}$ & 26 & $\begin{array}{c}1.06 \\
(0.56-2.01)\end{array}$ & 64 & $\begin{array}{c}1.22 \\
(0.80-1.88)\end{array}$ \\
\hline$* 2 / * 2$ & 2090 & 133 & $\begin{array}{c}1.44 \\
(1.08-1.92)\end{array}$ & 89 & $\begin{array}{c}1.39 \\
(1.00-1.93)\end{array}$ & 18 & $\begin{array}{c}1.95 \\
(0.99-3.85)\end{array}$ & 26 & $\begin{array}{c}1.38 \\
(0.80-2.37)\end{array}$ \\
\hline$p$-trend & & & 0.022 & & 0.082 & & 0.088 & & 0.213 \\
\hline
\end{tabular}

PY : Person Years ; RR: Incidence Rate Ratio; Cl: Confidence Interval

a Adjusted for age, gender, family history of CRC (yes/no), body mass index $\left(\mathrm{kg} / \mathrm{m}^{2}\right)$, non-occupational physical activity $(\mathrm{min} / \mathrm{d})$, total energy intake $(\mathrm{kJ} / \mathrm{d})$, and energy-adjusted intakes of fat $(\mathrm{g} / \mathrm{d})$, dietary fiber $(\mathrm{g} / \mathrm{d})$ and calcium $(\mathrm{mg} / \mathrm{d})$ and total alcohol intake $(0,<30.0 \geq 30.0 \mathrm{~g} / \mathrm{d})$. 
Associations between alcohol consumption and risk of $\mathrm{CRC}$, stratified by $A D H 1 C$ genotype are presented in table 4 . No relationship between alcohol consumption and CRC was observed when using information on baseline alcohol consumption. Furthermore, there was no apparent modifying effect from ADH1C genotype. When the analyses were restricted to drinkers that reported to have consumed equal amounts of alcohol five years before baseline as compared to baseline, a daily alcohol consumption of $\geq 30.0 \mathrm{~g} / \mathrm{d}$ was positively associated with the risk of CRC. Statistical significance was not reached, probably due to small numbers of cases in this consumption category, but all risk estimates pointed towards an increased CRC risk, with the highest risk conferred to the slow metabolizing $A D H 1 C * 2 / * 2$ genotype relative to abstainers with the $A D H 1 C^{*} 1{ }^{*}$ 1 genotype (RR: 1,27, 95\% Cl: 0.55-2.91 for $A D H 1 C * 1 / * 1$, RR: $1.85,95 \% \mathrm{Cl}: 0.85-3.99$ for $A D H 1 C * 1 / * 2$ and RR: 1.91, 95\% Cl: 0.685.34 for $A D H 1 C^{*} 2 * 2$ ). Also, CRC risk was increased, yet not statistically significant, for abstainers and consumers of $<30.0 \mathrm{~g}$ of alcohol per day with the $A D H 1 C^{*} 2{ }^{*} 2$ genotype when compared to the reference group. An interaction between alcohol consumption and $A D H 1 C$ genotype was not evident ( $p>0.05$ ).

Assuming that substrate for the ADH1C enzyme is needed in order to observe an effect of the genotypic variants, the analyses were further restricted to drinkers only. Compared to consumers of $>0-<5.0 \mathrm{~g}$ of alcohol per day with the $A D H 1 C^{*} 1 /{ }^{* 1}$ genotype, the risk estimates for consumers of $\geq 30.0 \mathrm{~g} / \mathrm{d}$ indicated a further increased risk, regardless of $A D H 1 C$ genotype (RR: $1.71,95 \% \mathrm{Cl}: 0.68-4.27$ for $A D H 1 C^{* 1} /{ }^{* 1}$, RR: $2.38,95 \% \mathrm{Cl}: 1.02-5.54$ for $A D H 1 C^{*} 1 /{ }^{* 2}$ and RR: $2.50,95 \% \mathrm{Cl}$ : 0.84-7.42 for the $A D H 1 C * 2 / * 2$ genotype). Again, the highest risk was observed for drinkers with the $A D H 1 C^{*} 2{ }^{*} 2$ genotype in the highest consumption category. The test for interaction did not reach statistical significance, however.

Interactions between alcohol intake and gender, alcohol and folate intake and between alcohol intake and smoking were not statistically significant ( $p>0.05$ ). 


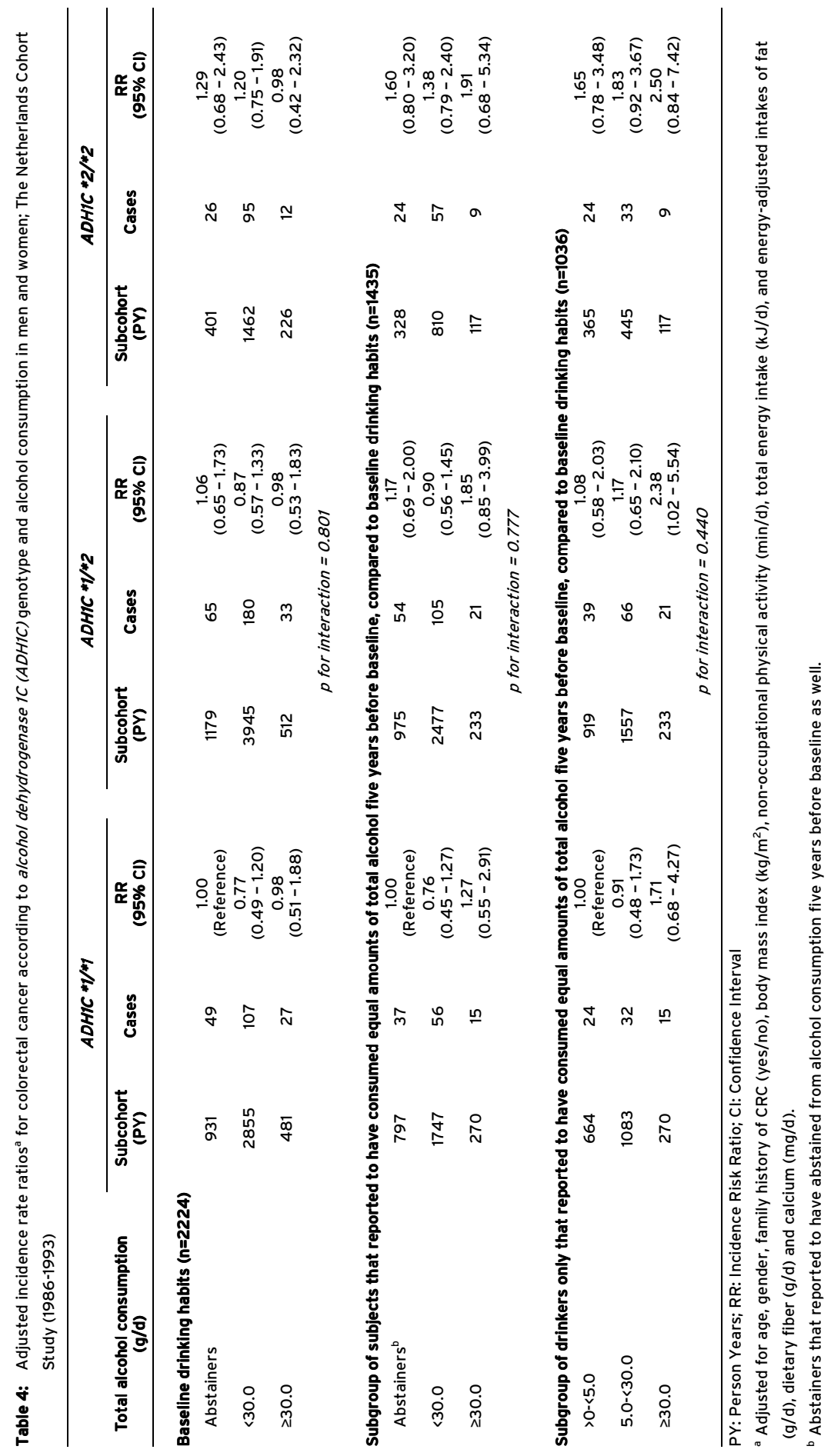




\section{DISCUSSION}

In the current prospective study on a large sample of the Dutch general population we investigated associations between total alcohol consumption, ADH1C genotype and the risk of CRC. An association was observed between ADH1C and risk of CRC, both crude and adjusted for confounders including total alcohol intake. In subjects that reported to have consumed equal amounts of total alcohol five years before baseline as compared to baseline habits, the $A D H 1 C$ genotype appeared to modify the association between alcohol consumption and CRC although the interaction term did not reach statistical significance. The highest risk estimate was seen for alcohol drinkers of $\geq 30.0 \mathrm{~g} / \mathrm{d}$ with the $A D H 1 C * 2 / * 2$ genotype, compared to abstainers with the $A D H 1 C^{*} 1{ }^{* 1}$ genotype. By excluding abstainers and considering the drinkers of $>0-<5.0 \mathrm{~g}$ alcohol per day with the $A D H 1 C * 1 /{ }^{*} 1$ genotype as reference group, CRC risk estimates increased further and particularly for consumers of $\geq 30.0 \mathrm{~g} / \mathrm{d}$.

Only a limited number of studies have investigated the relationship between alcohol consumption, the ADH1C polymorphism and risk of colorectal neoplasia, and their results have been inconsistent. In line with the present results, a nested casecontrol study on colorectal adenomas, performed within the Health Professional's Follow-Up Study, demonstrated a nearly threefold increase in adenoma risk for subjects with the $A D H 1 C * 2 / 2$ genotype consuming $>30.0 \mathrm{~g}$ of alcohol per day, relative to consumers of $\leq 5.0 \mathrm{~g} / \mathrm{d}$ with the $A D H 1 C * 1 /{ }^{*} 1$ genotype (RR: $2.94,95 \% \mathrm{Cl}$ : 1.24-6.92) [21]. The test for interaction was not statistically significant, however. Another nested case-control study, performed within the Physicians' Health Study on colorectal carcinomas, showed similar results [20]. Whereas both alcohol drinkers with the $A D H 1 C^{*} 1 /{ }^{*} 1$ and the $A D H 1 C * 2 /{ }^{*} 2$ genotype were associated with an increased risk of CRC relative to consumers of $\leq 1 \mathrm{drink} /$ week with the $A D H 1 C^{*} 1 /{ }^{* 1}$ genotype, the highest risk was seen for subjects with the $A D H 1 C * 2 / 2$ genotype within the highest consumption category ( $\geq 5.0$ drinks/week) (RR: 1.63, 95\% Cl: $0.77-$ 3.45). In contrast to the present results and to those of the two nested case-control studies, are the results from a Dutch case-control study on colorectal adenomas [22]. The authors proposed the $A D H 1 C * 1 /{ }^{* 1}$ genotype as the high risk genotype and consequently composed their reference group of subjects with the $A D H 1 C * 1 / * 2$ and $A D H 1 C^{*} 2 /{ }^{*} 2$ genotype drinking $<1$ drink/week. Compared to this reference group, subjects with the $A D H 1 C^{*} 1{ }^{* 1}$ genotype within the highest consumption category of 
$\geq 10$ drinks/week, were associated with an increased risk of colorectal adenomas (RR: $1.76,95 \% \mathrm{Cl}: 1.00-3.11)$. The test for interaction was not statistically significant.

In alcohol-induced colorectal carcinogenesis, acetaldehyde - a well-known mutagen and carcinogen - is believed to be the important cancer-causing agent. Most acetaldehyde in the body originates from the alcohol metabolism for which the main pathway is the one involving the oxidative metabolism through $A D H$. The liver is the most important organ in which this route of metabolism takes place, yet $A D H$ genes are expressed in a variety of extra-hepatic tissues as well, albeit at a lower level than in the liver. In addition to colorectal mucosal ADH [23, 38, 39], it has been shown that the colonic mircoflora exhibits $A D H$ activity also and that intestinal acetaldehyde levels are generated, at least in part, through bacterial alcohol oxidation $[25,26,40]$. The significant contribution of the microflora to locally produced acetaldehyde in the large intestine may explain the higher risk of CRC that we observed for subjects with the $A D H 1 C * 1 / * 2$ and $A D H 1 C * 2 / * 2$ genotype compared to subjects with the $A D H 1 C * 1 /{ }^{* 1}$ genotype. In slow metabolizers with the $A D H 1 C * 2 / 2$ genotype, all organs including the large intestine, will be exposed to systemic levels for a relatively longer period of time as compared to fastmetabolizers. Consequently, the local acetaldehyde production and accumulation in the large intestine may be higher, implying a higher risk of carcinogenicity.

In addition to microbial acetaldehyde formation, certain colonic microbes are capable of producing alcohol through alcoholic fermentation of glucose [41]. This endogenous source of alcohol has only been demonstrated in subjects with specific gastro-intestinal abnormalities and overgrowth of Candida albicans [42] which makes it unlikely that this process may contribute to the incidence of CRC in the general population.

As alcohol is a substrate for the ADH1C enzyme, we had not expected an association between genotype and risk of CRC, adjusted for total alcohol intake (table 3) and one that pointed towards an increased, yet not statistically significant, risk of CRC in abstainers with the $A D H 1 C^{*} 2 / * 2$ genotype (table 4 ). According to the concept of Mendelian randomization [43], the $A D H 1 C$ genotypic variants might account as a proxy for lifetime differences in alcohol consumption levels, and may thus explain the observed associations. Yet, within the different alcohol consumption categories the three genetic variants of the ADH1C enzyme occurred at equal frequencies, 
arguing against this concept with respect to $A D H 1 C$. Another possible explanation for the observed association with $A D H 1 C$ genotype in abstainers that reported to have abstained from alcohol five years before baseline also, may be related to the measurement of alcohol consumption. Alcohol is likely to be a long-term risk factor for chronic diseases such as cancer and apparently drinking habits that go back for five years do not suffice to reflect an accurate alcohol exposure of subjects. As there is some evidence that recalled alcohol intake 5 - and even 10 years - back in the past is generally reliable $[44,45]$, this time span may not be long enough to account for the relevant alcohol exposure in our analyses.

In studies on alcohol consumption and disease, in which only baseline drinking habits are measured and used, a certain degree of misclassification of former (heavy) alcohol drinkers may exist. Drinking habits at baseline do not necessarily reflect drinking habits of the past. Measuring baseline habits only will not reveal former heavy drinkers who quitted drinking because of preclinical disease symptoms or other health problems, and as such are likely to have a higher risk of alcohol-related conditions. Inclusion of these subjects in the reference category will result in underestimated disease risks. We have previously shown that associations between baseline alcohol consumption and CRC risk became stronger if we restricted these analyses to subjects that reported to have consumed equal amounts of alcohol five years before baseline as compared to baseline [B.W.C. Bongaerts, P.A. van den Brandt, R.A. Goldbohm, A.F.P.M. de Goeij, M.P. Weijenberg, 2008]. That stable drinking habits reflect alcohol exposure of subjects more accurately and may thus help to minimize misclassification of former drinkers was also suggested by the present results. Whereas there was no relationship apparent between baseline alcohol consumption, ADH1C genotype and CRC, restriction of these analyses to subjects that reported to have consumed equal amounts of alcohol five years before baseline as compared to baseline, elucidated the associations. An even more accurate determination of long term exposure to alcohol, involving measurement of alcohol use in the recent past for more and shorter time intervals or repeated measurements over time, could result in even higher risk estimates for CRC.

In conclusion, in alcohol drinkers the $A D H 1 C$ genotype is likely to modify the association between alcohol consumption and risk of $\mathrm{CRC}$, with the highest risk conferred to drinkers with $A D H 1 C * 2 * 2$ genotype. Also, independent of alcohol consumption and when compared to the $A D H 1 C * 1 /{ }^{* 1}$ genotype, the $A D H 1 C * 2 / * 2$ 


\section{| Chapter 3}

genotype was positively related to CRC risk. This observation emphasizes the importance of an accurate measurement of long-term alcohol exposure.

More research within this field is needed to lend support to the current findings

concerning the modifying effect of $A D H 1 C$ genotype. Attention should be paid to measurement of alcohol consumption in the past, in addition to baseline drinking habits. 


\section{REFERENCES}

1. Food, Nutrition, Physical activity, and the Prevention of Cancer: a Global Perspective. Washington DC: AICR, 2007.

2. Boffetta, P. and Hashibe, M. Alcohol and cancer. Lancet Oncol, 7: 149-156, 2006.

3. Cho, E., Smith-Warner, S. A., Ritz, J., van den Brandt , P. A., Colditz, G. A., Folsom, A. R., et al. Alcohol intake and colorectal cancer: a pooled analysis of 8 cohort studies. Ann Intern Med, 140: 603-613, 2004.

4. Bagnardi, V., Blangiardo, M., La Vecchia, C., and Corrao, G. A meta-analysis of alcohol drinking and cancer risk. Br J Cancer, 85: 1700-1705, 2001.

5. Corrao, G., Bagnardi, V., Zambon, A., and La Vecchia, C. A meta-analysis of alcohol consumption and the risk of 15 diseases. Prev Med, 38: 613-619, 2004.

6. Longnecker, M. P., Orza, M. J., Adams, M. E., Vioque, J., and Chalmers, T. C. A metaanalysis of alcoholic beverage consumption in relation to risk of colorectal cancer. Cancer causes control, 1: 59-68, 1990.

7. Ferrari, P., Jenab, M., Norat, T., Moskal, A., Slimani, N., Olsen, A., et al. Lifetime and baseline alcohol intake and risk of colon and rectal cancers in the European prospective investigation into cancer and nutrition (EPIC). Int J Cancer, 121: 2065-2072, 2007.

8. Moskal, A., Norat, T., Ferrari, P., and Riboli, E. Alcohol intake and colorectal cancer risk: A dose-response meta-analysis of published cohort studies. Int J Cancer, 120: 664-671, 2006.

9. Seitz, H. K. and Stickel, F. Molecular mechanisms of alcohol-mediated carcinogenesis. Nat Rev Cancer, 7: 599-612, 2007.

10. Bosron, W. F. and Li, T. K. Genetic polymorphism of human liver alcohol and aldehyde dehydrogenases, and their relationship to alcohol metabolism and alcoholism. Hepatology, 6: 502-510, 1986.

11. Bosron, W. F. and Li, T. K. Catalytic properties of human liver alcohol dehydrogenase isoenzymes. Enzyme, 37: 19-28, 1987.

12. Goedde, H. W., Agarwal, D. P., Fritze, G., Meier-Tackmann, D., Singh, S., Beckmann, G., et al. Distribution of $A D H 2$ and $A L D H 2$ genotypes in different populations. Hum Genet, 88: 344-346, 1992.

13. Borras, E., Coutelle, C., Rosell, A., Fernandez-Muixi, F., Broch, M., Crosas, B., et al. Genetic polymorphism of alcohol dehydrogenase in europeans: the $A D H 2 * 2$ allele decreases the risk for alcoholism and is associated with ADH3*1. Hepatology, 31: 984989, 2000.

14. Coutelle, C., Ward, P. J., Fleury, B., Quattrocchi, P., Chambrin, H., Iron, A., et al. Laryngeal and oropharyngeal cancer, and alcohol dehydrogenase 3 and glutathione Stransferase M1 polymorphisms. Hum Genet, 99: 319-325, 1997. 
15. Harty, L. C., Caporaso, N. E., Hayes, R. B., Winn, D. M., Bravo-Otero, E., Blot, W. J., et al. Alcohol dehydrogenase 3 genotype and risk of oral cavity and pharyngeal cancers. J Natl Cancer Inst, 89: 1698-1705, 1997.

16. Terry, M. B., Gammon, M. D., Zhang, F. F., Knight, J. A., Wang, Q., Britton, J. A., et al. $A D H 3$ genotype, alcohol intake and breast cancer risk. Carcinogenesis, 27: 840-847, 2006.

17. Coutelle, C., Hohn, B., Benesova, M., Oneta, C. M., Quattrochi, P., Roth, H. J., et al. Risk factors in alcohol associated breast cancer: alcohol dehydrogenase polymorphism and estrogens. Int J Oncol, 25: 1127-1132, 2004.

18. Freudenheim, J. L., Ambrosone, C. B., Moysich, K. B., Vena, J. E., Graham, S., Marshall, J. R., et al. Alcohol dehydrogenase 3 genotype modification of the association of alcohol consumption with breast cancer risk. Cancer Causes Control, 10: 369-377, 1999.

19. Day, C. P., Bashir, R., James, O. F., Bassendine, M. F., Crabb, D. W., Thomasson, H. R., et al. Investigation of the role of polymorphisms at the alcohol and aldehyde dehydrogenase loci in genetic predisposition to alcohol-related end-organ damage. Hepatology, 14: 798-801, 1991.

20. Chen, J., Ma, J., Stampfer, M. J., Hines, L. M., Selhub, J., and Hunter, D. J. Alcohol dehydrogenase 3 genotype is not predictive for risk of colorectal cancer. Cancer Epidemiology Biomarkers \& Prevention, 10: 1303-1304, 2001.

21. Giovannucci, E., Chen, J., Smith-Warner, S. A., Rimm, E. B., Fuchs, C. S., Palomeque, C., et al. Methylenetetrahydrofolate reductase, alcohol dehydrogenase, diet, and risk of colorectal adenomas. Cancer Epidemiol Biomarkers Prev, 12: 970-979, 2003.

22. Tiemersma, E. W., Wark, P. A., Ocke, M. C., Bunschoten, A., Otten, M. H., Kok, F. J., et al. Alcohol consumption, alcohol dehydrogenase 3 polymorphism, and colorectal adenomas. Cancer Epidemiology Biomarkers \& Prevention, 12: 419-425, 2003.

23. Pestalozzi, D. M., Buhler, R., von Wartburg, J. P., and Hess, M. Immunohistochemical localization of alcohol dehydrogenase in the human gastrointestinal tract. Gastroenterology, 85: 1011-1016, 1983.

24. Seitz, H. K., Egerer, G., Oneta, C., Kramer, S., Sieg, A., Klee, F., et al. Alcohol dehydrogenase in the human colon and rectum. Digestion, 57: 105-108, 1996.

25. Jokelainen, K., Roine, R. P., Vaananen, H., Farkkila, M., and Salaspuro, M. In vitro acetaldehyde formation by human colonic bacteria. Gut, 35: 1271-1274, 1994.

26. Jokelainen, K., Siitonen, A., Jousimies-Somer, H., Nosova, T., Heine, R., and Salaspuro, $M$. In vitro alcohol dehydrogenase-mediated acetaldehyde production by aerobic bacteria representing the normal colonic flora in man. Alcohol Clin Exp Res, 20: 967972, 1996.

27. Van den Brandt, P. A., Goldbohm, R. A., van 't Veer, P., Volovics, A., Hermus, R. J., and Sturmans, F. A large-scale prospective cohort study on diet and cancer in The Netherlands. J Clin Epidemiol, 43: 285-295, 1990. 
28. Van den Brandt, P. A., Schouten, L. J., Goldbohm, R. A., Dorant, E., and Hunen, P. M. Development of a record linkage protocol for use in the Ducth Cancer Registry for Epidemiological Research. Int J Epidemiol, 19: 553-558, 1990.

29. Casparie, M., Tiebosch, A. T., Burger, G., Blauwgeers, H., van de Pol, A., van Krieken, J. $\mathrm{H}$., et al. Pathology databanking and biobanking in The Netherlands, a central role for PALGA, the nationwide histopathology and cytopathology data network and archive. Cell Oncol, 29: 19-24, 2007.

30. Miettinen, O. S. Theoretical Epidemiology. Principles of Occurrence Research in Medicine. New York: Wiley, 1985.

31. Prentice, R. L. A case-cohort design for epidemiologic cohort studies and disease prevention trails. Biometrika, 73: 1-12, 1985.

32. NEVO-table, Dutch food composition table 1986-1987. The Hague, Netherlands: Voorlichtingsbureau voor de voeding. 1986.

33. Goldbohm, R. A., van den Brandt, P. A., Brants, H. A., van't Veer, P., Al, M., Sturmans, F., et al. Validation of a dietary questionnaire used in a large-scale prospective cohort study on diet and cancer. Eur J Clin Nutr, 48: 253-265, 1994.

34. Brink, M., de Goeij, A. F., Weijenberg, M. P., Roemen, G. M., Lentjes, M. H., Pachen, M. M., et al. K-ras oncogene mutations in sporadic colorectal cancer in The Netherlands Cohort Study. Carcinogenesis, 24: 703-710, 2003.

35. Meulenbelt, I., Droog, S., Trommelen, G. J., Boomsma, D. I., and Slagboom, P. E. Highyield noninvasive human genomic DNA isolation method for genetic studies in geographically dispersed families and populations. Am J Hum Genet, 57: 1252-1254, 1995.

36. Knaapen, A. M., Ketelslegers, H. B., Gottschalk, R. W., Janssen, R. G., Paulussen, A. D., Smeets, H. J., et al. Simultaneous genotyping of nine polymorphisms in xenobioticmetabolizing enzymes by multiplex PCR amplification and single base extension. Clin Chem, 50: 1664-1668, 2004.

37. Schoenfeld, D. Partial residuals for the proportional hazards regression model. Biometrika, 69: 239-241, 1982.

38. Yin, S. J., Liao, C. S., Lee, Y. C., Wu, C. W., and Jao, S. W. Genetic polymorphism and activities of human colon alcohol and aldehyde dehydrogenases: no gender and age differences. Alcohol Clin Exp Res, 18: 1256-1260, 1994.

39. Estonius, M., Svensson, S., and Hoog, J. O. Alcohol dehydrogenase in human tissues: localisation of transcripts coding for five classes of the enzyme. FEBS Lett, 397: 338$342,1996$.

40. Seitz, H. K., Simanowski, U. A., Garzon, F. T., Rideout, J. M., Peters, T. J., Koch, A., et al. Possible Role of Acetaldehyde in Ethanol-Related Rectal Cocarcinogenesis in the Rat. Gastroenterology, 98: 406-413, 1990.

41. Zeikus, J. G. Chemical and fuel production by anaerobic bacteria. Annu Rev Microbiol, 34: 423-464, 1980. 


\section{| Chapter 3}

42. Salaspuro, M. P. Acetaldehyde, microbes, and cancer of the digestive tract. Critical Reviews in Clinical Laboratory Sciences, 40: 183-208, 2003.

43. Davey Smith, G. and Ebrahim, S. What can mendelian randomisation tell us about modifiable behavioural and environmental exposures? BMJ, 330: 1076-1079, 2005.

44. Czarnecki, D. M., Russell, M., Cooper, M. L., and Salter, D. Five-year reliability of selfreported alcohol consumption. J Stud Alcohol, 51: 68-76, 1990.

45. Liu, S., Serdula, M. K., Byers, T., Williamson, D. F., Mokdad, A. H., and Flanders, W. D. Reliability of alcohol intake as recalled from 10 years in the past. Am J Epidemiol, 143: 177-186, 1996. 


\section{Alcohol consumption and distinct molecular pathways to colorectal cancer}

Brenda W.C. Bongaerts Anton F.P.M. de Goeij Stefan de Vogel Piet A. van den Brandt

R. Alexandra Goldbohm Matty P. Weijenberg

British Journal of Nutrition, 97: 430-434, 2007 


\section{ABSTRACT}

High alcohol consumption is related to colorectal cancer (CRC). Our objective was to study associations between alcohol consumption and risk of CRC according to characteristics of etiologic pathways; the chromosomal instability (CIN) and the microsatellite instability (MSI) pathway. We classified $\mathrm{CIN}+$ tumors (tumors with either a truncating $A P C$ mutation, an activating $K R A S$ mutation or overexpression of TP53), MSI+ tumors (tumors lacking MLH1 expression) and CIN-/MSI- tumors (tumors without these defects).

In the Netherlands Cohort Study on diet and cancer, 120,852 men and women, aged 55-69 years, completed a questionnaire on risk factors for cancer at baseline (1986). Case-cohort analyses were conducted using 573 CRC cases with complete data after 7.3 years of follow-up, excluding the first 2.3 years. Adjusted incidence rate ratios (RR) and $95 \%$ confidence intervals $(\mathrm{Cl})$ were estimated.

Compared to abstaining, alcohol consumption of $30 \mathrm{~g} / \mathrm{d}$ and more, was positively associated with the risk of CRC irrespective of genetic or molecular aberrations present, although statistical significance was not reached (RR: 1.35 (95\% Cl: 0.92.0) for the CIN+ tumors, RR: 1.59 (95\% CI: 0.4-5.8) for the MSI+ tumors and RR: 1.15 (95\% Cl: 0.5-2.7) for the CIN-/MSI- tumors). Beer, wine and liquor consumption were, independent of their alcoholic content, not consistently associated with the risk of CRC within the defined subgroups.

In conclusion, our results indicate that a daily alcohol consumption of 30 grams and more is associated with an increase in risk of $C R C$, independent of the presence or absence of the studied characteristics of different etiologic pathways. 


\section{INTRODUCTION}

Colorectal cancer (CRC) is characterized by multiple chromosomal abnormalities. It is one of the best studied models representing the multistep nature of tumorigenesis. Sporadic CRC may develop through at least two independent pathways: i.e. the chromosomal instability (CIN) and the microsatellite instability (MSI) pathway. The CIN pathway is characterized by aneuploidy/polyploidy and mutations in $A P C, K R A S, T P 53$ and DCC genes, and occasionally in SMAD2 and $S M A D 4$ genes. The MSI pathway on the other hand, is characterized by alterations in small stretches of short repetitive DNA sequences (microsatellites), and deficiency in DNA mismatch repair (MMR) which is often caused by promoter methylation of the MMR gene $M L H 1[1,2]$. Colorectal carcinomas that evolve through the CIN or MSI pathways differ in several pathological features such as tumor sub-localization, tumor differentiation and patient survival [3-6]. This indicates that various environmental risk factors, such as dietary habits and life style factors, may play a different role in the etiology of CIN and MSI colorectal tumors.

The association between alcohol consumption and CRC has long been debated. Although alcohol itself is not carcinogenic, alcohol's first metabolite, acetaldehyde, is emerging as an important malefactor being able to form stable DNA adducts, trigger mutations in tumor suppressor and oncogenes and interfere with DNA repair [7].

Several epidemiological studies have investigated associations between alcohol consumption and single genetic events involved in CRC, such as mutations in $A P C$ and KRAS genes, microsatellite instability and overexpression of TP53. [5, 8-13]. Although these studies focused merely on a single gene and their results are not consistent, all positive associations that were found linked alcohol consumption to colorectal carcinomas harboring the mutated version of the studied gene, but not the wild type version. What needs further elucidation are the etiologic pathway(s) by which alcohol consumption may contribute to colorectal tumorigenesis.

Our aim was to study the associations between alcohol consumption and the risk of CRC in subgroups of tumors, according to their genetic and molecular aberrations. We defined $\mathrm{CIN}+$ tumors as colorectal tumors with either a truncating $A P C$ mutation, an activating KRAS mutation or overexpression of TP53, since these genes can be 
considered as key genes of the CIN pathway. MSI+ tumors were defined according to a key feature of the MSI pathway, i.e. lack of MLH1 expression. A third group of colorectal tumors was identified as CIN-/MSI-, i.e. tumors without the genetic and molecular aberrations characteristic for the $\mathrm{CIN}+$ and $\mathrm{MSI}+$ tumors.

The current study was conducted within the ongoing Netherlands Cohort Study on diet and cancer (NLCS), and is the first to study alcohol consumption and subgroups of colorectal tumors, based on independent etiologic pathways of disease.

\section{MATERIALS AND METHODS}

\section{Study population}

In September 1986, the Netherlands Cohort Study on diet and cancer (NLCS) was initiated [14]. Briefly, 120,852 men and women, aged 55-69 years and originating from 204 municipal population registries throughout the country, completed an extensive self-administered questionnaire on daily dietary habits, life style and other risk factors for cancer. Newly diagnosed cancer cases were identified through annual record linkage to the Netherlands Cancer Registry (NCR) and to PALGA, a nationwide database of histo- and cytopathology reports [15].

The present analyses were carried out over a 7.3-year period of follow-up, excluding the first 2.3 years. Hence, 925 histologically confirmed CRC cases were identified between January 1989 and January 1994, of whom 815 could be linked to a PALGA report of the lesion.

Data processing and analysis was done according to the case-cohort approach: cases were identified in the entire cohort, while a random sample of the cohort (subcohort) was used to estimate person years at risk accumulating in the cohort. A subcohort of 5,000 men and women was followed-up biennially to assess information on vital status and migration. Prevalent cancer cases, other than nonmelanoma skin cancer, were excluded from the subcohort as well as subjects who deceased or were diagnosed with cancer during the first 2.3 years of follow-up. This left 4,673 subcohort members for analyses. 


\section{Assessment of exposure}

Information on alcohol consumption was obtained from the baseline questionnaire, which comprised a 150-item semi-quantitative food frequency questionnaire. This questionnaire has been validated against a 9-day diet record [16]. The Spearman correlation coefficient between mean daily alcohol consumption assessed by the questionnaire and estimated from the 9-day diet record was 0.89 for all subjects and 0.85 for users of alcoholic beverages. The absolute amount of alcohol consumption reported in the questionnaire by users of alcoholic beverages was, on average, $86 \%$ of that reported in the 9 -day diet record.

\section{Tissue samples and molecular analyses}

Of the 815 eligible CRC cases, 771 formalin-fixed, paraffin-embedded tissue blocks could be retrieved from Dutch pathology archives. Samples that did not contain carcinoma tissue were excluded. As previously described, tissue samples of 734 CRC cases were available for molecular analyses of KRAS [17] and APC [18] genes, and immunohistochemical staining of MLH1 [3] and TP53.

Immunohistochemical staining for TP53 was performed on archival adeno-carcinoma specimens of all 734 CRC cases according to the avidin-biotin-peroxidase complex method, using the DO-7 mouse monoclonal antibody (DAKO A/S, Denmark). Immunostained slides and negative controls were evaluated semiquantitatively and independently by two observers without knowledge of clinical parameters. We defined cases positive for overexpression of TP53 if $20 \%$ or more of the tumor cell nuclei showed positive staining with the antibody.

\section{Statistical analysis}

All subjects with complete information on alcohol consumption and confounding variables derived from the baseline questionnaire, and CRC cases for whom information on $A P C, K R A S$, TP53 and MLH1 status was also known, were included in the statistical analysis (4,076 subcohort members and 573 CRC cases).

Incidence risk ratios (RR) and corresponding 95\% confidence intervals $(\mathrm{Cl})$ were estimated using Cox proportional hazards models. Total alcohol consumption was divided into three categories: $0,<30.0$ and $\geq 30.0 \mathrm{~g} / \mathrm{d}$, in line with the results of a 
recent pooled analysis that suggested a threshold in alcohol consumption above which the risk of CRC increases [19]. Consumption of beer, wine and liquor were considered dichotomously. Analyses were adjusted for age at baseline (years), sex, body mass index (BMI) $\left(\mathrm{kg} / \mathrm{m}^{2}\right)$, family history of CRC (yes versus no), daily intakes of total energy ( $\mathrm{kJ} / \mathrm{d})$ linoleic acid $(\mathrm{g} / \mathrm{d})$ and calcium $(\mathrm{mg} / \mathrm{d})$, and smoking (never, ex, current smoker). The analyses of the alcoholic beverages were additionally adjusted for total alcohol intake (categorized as $0,<30.0$ and $\geq 30.0 \mathrm{~g} / \mathrm{d}$ ), to evaluate the role of the specific beverage independent of its alcoholic content. The analyses were performed using the STATA statistical software package (version 9.1).

\section{RESULTS}

Table 1 shows drinking habits and baseline characteristics of the subcohort and CRC cases classified according to the studied genetic and molecular defects. Of the 471 CIN+ colorectal tumors, 38 (8\%) tumors only had a truncating APC mutation, 46 (9\%) only had an activating KRAS mutation and 168 (36\%) tumors only showed overexpression of TP53. In addition, 174 (37\%) of the CIN+ tumors had two of the described aberrations and 45 (10\%) had all three aberrations. Compared to the CIN+ cases, the MSI+ cases comprised significantly more female cases, had less liquor consumers and a lower daily intake of total energy. No differences in drinking habits or baseline characteristics between the $\mathrm{CIN}$-/MSI- cases and both $\mathrm{CIN}+$ and $\mathrm{MSI}+$ cases were observed.

Table 2 reports the RRs and 95\% Cls for total alcohol consumption and different types of alcoholic beverages, and the risk of CRC according to the presence or absence of specific genetic and molecular aberrations. Compared to abstaining, consumption levels of total alcohol above $30 \mathrm{~g} / \mathrm{d}$ were associated with an increased risk of CRC irrespective of genetic or molecular aberrations present, although statistical significance was not reached (RR: 1.35 (95\% Cl: 0.9-2.0) for the CIN+ tumors, RR: 1.59 (95\% Cl: 0.4-5.8) for the MSI+ tumors and RR: 1.15 (95\% Cl: 0.52.7) for the CIN-/MSI- tumors). Beer, wine and liquor consumption, after adjustment for total alcohol intake, showed no clear relationship with $\mathrm{CIN}+, \mathrm{MSI}+$ and $\mathrm{CIN}-/ \mathrm{MSI}-$ tumors. 
Table 1: Drinking habits and baseline characteristics (mean (sd)) of the subcohort members and subgroups of colorectal cancer characterized by specific genetic and molecular aberrations, the Netherlands Cohort Study (1986-1993)

\begin{tabular}{|c|c|c|c|c|}
\hline & Subcohort & $\mathrm{CIN}+$ tumors $^{\mathrm{a}}$ & MSI+ tumors ${ }^{b}$ & CIN-/MSI- tumors ${ }^{c}$ \\
\hline $\mathrm{N}$ & 4076 & 471 & 32 & 87 \\
\hline Age $(y)$ & $61.3(4.2)$ & $62.6(4.1)$ & $63.5(4.4)$ & $63.4(3.7)$ \\
\hline Sex (\% male) & 50 & 59 & 41 & 52 \\
\hline \multicolumn{5}{|l|}{ Alcohol consumption: } \\
\hline Total alcohol (g/d) & $10.4(14.4)$ & $11.8(15.3)$ & $10.9(14.8)$ & $10.8(13.0)$ \\
\hline Beer (glasses/week) & $1.7(5.3)$ & $1.8(4.7)$ & $2.0(7.3)$ & $1.8(5.9)$ \\
\hline Wine (glasses/week & $2.6(5.0)$ & $2.8(5.5)$ & $3.9(7.4)$ & $2.5(4.8)$ \\
\hline Liquor (glasses/week) & $2.5(5.2)$ & $3.0(5.6)$ & $1.5(3.4)$ & $2.9(5.7)$ \\
\hline \multicolumn{5}{|l|}{ Molecular characteristics ${ }^{d}$} \\
\hline Truncating $A P C$ mutation & - & 201 & 0 & 0 \\
\hline Activating KRAS mutation & - & 194 & 0 & 0 \\
\hline Overexpression of TP53 & - & 340 & 0 & 0 \\
\hline Lack of MLH1 expression & - & 0 & 32 & 0 \\
\hline \multicolumn{5}{|l|}{ Other lifestyle factors: } \\
\hline Family history CRC (\% yes) & 6 & 10 & 13 & 15 \\
\hline BMI $\left(\mathrm{kg} / \mathrm{m}^{2}\right)$ & $25.0(3.1)$ & $25.5(3.0)$ & $25.5(3.4)$ & $25.4(3.7)$ \\
\hline Energy intake $(\mathrm{kJ} / \mathrm{d})$ & $8074(2160)$ & $8162(2060)$ & 7294 (1713) & $7990(2041)$ \\
\hline Linoleic acid intake $(\mathrm{g} / \mathrm{d})^{\mathrm{e}}$ & $14.4(7.5)$ & $15.1(7.7)$ & $14.2(5.7)$ & $14.8(8.1)$ \\
\hline Calcium intake $(\mathrm{mg} / \mathrm{d})^{f}$ & $925(282)$ & $932(270)$ & 888 (219) & $934(271)$ \\
\hline \multicolumn{5}{|l|}{ Smoking (\%) } \\
\hline Never smoker & 36 & 32 & 28 & 33 \\
\hline Ex-smoker & 36 & 46 & 41 & 50 \\
\hline Current smoker & 28 & 22 & 31 & 17 \\
\hline
\end{tabular}

${ }^{a}$ Defined as colorectal tumors presenting either a truncating APC mutation, an activating KRAS mutation or overexpression of TP53.

${ }^{\mathrm{b}}$ Defined as colorectal tumors presenting lack of MLH1 expression only.

${ }^{\mathrm{C}}$ Defined as colorectal tumors presenting no truncating $A P C$ mutation, nor an activating KRAS mutation, overexpression of TP53 or lack of MLH1 expression.

${ }^{d}$ Of the CIN+ tumors, 38 harboured a truncating APC mutation only, 46 an activating KRAS mutation only and 168 only showed over-expression of TP53. In addition, $174 \mathrm{CIN}+$ tumors harbored two of these aberrations and 45 harboured all three aberrations.

${ }^{e}$ Adjusted for total energy intake.

${ }^{f}$ Adjusted for energy intake from dairy products. 
Table 2: Incidence rate ratios for subgroups of colorectal cancer characterized by specific genetic and molecular aberrations, according to drinking habits, adjusted for confounders ${ }^{a}$, the Netherlands Cohort Study (1986-1993)

\begin{tabular}{|c|c|c|c|c|c|c|c|}
\hline \multirow{2}{*}{ Drinking habits } & \multirow[b]{2}{*}{$\begin{array}{c}\text { Subcohort } \\
\text { (PY) }\end{array}$} & \multicolumn{2}{|c|}{ CIN+ tumors ${ }^{b}$} & \multicolumn{2}{|c|}{ MSI+ tumors ${ }^{c}$} & \multicolumn{2}{|c|}{ CIN-/MSI- tumors ${ }^{d}$} \\
\hline & & Cases & RR $(95 \% \mathrm{Cl})$ & Cases & RR $(95 \% \mathrm{Cl})$ & Cases & RR (95\% Cl) \\
\hline \multicolumn{8}{|l|}{ Total alcohol (g/d) } \\
\hline No alcohol & 6762 & 103 & 1.00 & 9 & 1.00 & 22 & 1.00 \\
\hline$<30.0$ & 19656 & 308 & $0.97(0.8-1.2)$ & 19 & $0.81(0.4-1.9)$ & 56 & $0.87(0.5-1.5)$ \\
\hline$\geq 30.0$ & 2624 & 60 & $1.35(0.9-2.0)$ & 4 & $1.59(0.4-5.8)$ & 9 & $1.15(0.5-2.7)$ \\
\hline \multicolumn{8}{|l|}{ Beer $^{e}$} \\
\hline No beer & 19320 & 307 & 1.00 & 25 & 1.00 & 61 & 1.00 \\
\hline Beer drinker & 9722 & 164 & $0.82(0.6-1.1)$ & 7 & $0.60(0.2-1.7)$ & 26 & $0.85(0.5-1.5)$ \\
\hline \multicolumn{8}{|l|}{ Wine $e^{e}$} \\
\hline No wine & 13601 & 224 & 1.00 & 16 & 1.00 & 43 & 1.00 \\
\hline Wine drinker & 15441 & 247 & $0.97(0.8-1.2)$ & 16 & $0.89(0.3-2.3)$ & 44 & $0.83(0.5-1.5)$ \\
\hline \multicolumn{8}{|l|}{ Liquor $^{e}$} \\
\hline No liquor & 14883 & 211 & 1.00 & 19 & 1.00 & 43 & 1.00 \\
\hline Liquor drinker & 14159 & 260 & $1.15(0.9-1.5)$ & 13 & $0.73(0.3-1.9)$ & 44 & $1.13(0.7-1.9)$ \\
\hline
\end{tabular}

PY: Person Years; RR: Incidence Risk Ratio; Cl: Confidence Interval

${ }^{a}$ Adjusted for age (years), sex, BMI $\left(\mathrm{kg} / \mathrm{m}^{2}\right.$ ), family history of colorectal cancer (yes/no), daily energy intake $(\mathrm{kJ} / \mathrm{d})$, daily linoleic acid intake (g/d), daily calcium intake (mg/d), and smoking (never, ex current).

${ }^{b}$ Defined as colorectal tumors presenting either a truncating $A P C$ mutation, an activating KRAS mutation or overexpression of TP53.

${ }^{\mathrm{C}}$ Defined as colorectal tumors presenting lack of MLH1 expression only.

'Defined as colorectal tumors presenting no truncating APC mutation, nor an activating KRAS mutation, overexpression of TP53 or lack of MLH1 expression.

${ }^{e}$ Additionally adjusted for categories of total alcohol consumption $(0,<30.0, \geq 30.0 \mathrm{~g} / \mathrm{d})$.

\section{DISCUSSION}

We investigated associations between alcohol consumption and the risk of CRC by involvement of the CIN and MSI etiologic pathways in a large prospective study. In this study we defined $\mathrm{CIN}+$ tumors as tumors harboring either a truncating $A P C$ mutation, an activating KRAS mutation or overexpression of TP53, and the MSI+ tumors as tumors lacking expression of MLH1. A third group of colorectal tumors did not harbor any of these defects and was defined as CIN-/MSI-. Our results indicate that, compared to abstaining, alcohol consumption levels equal to or exceeding 30 $\mathrm{g} / \mathrm{d}$ were associated with an increased risk of $\mathrm{CRC}$, which was observed in all three 
subgroups although statistical significance was not reached. Within all three subgroups, no associations were observed between different alcoholic beverages adjusted for total alcohol consumption, and the risk of CRC.

In line with the present results, positive associations between alcohol consumption and CRC with single genetic or molecular aberrations have been reported for colorectal tumors that showed overexpression of TP53 and colon tumors with MSI [5, 9-11], but not for colon tumors harboring mutations in the APC and KRAS genes $[12,13]$. We performed additional analyses for alcohol consumption and the risk of CRC in which we considered each genetic or molecular aberration independent of any other simultaneously present genetic or molecular aberration(s), but the results of these analyses did not alter our present conclusions.

The pathological effects of alcohol consumption on the colorectal tract have been extensively investigated but still remain largely unclear. Evidence exists for the involvement of acetaldehyde [20], but also other mechanisms have been linked to $C R C$, e.g. the induction of reactive oxygen species through the induction of cytochrome P-450 2E [21-23]. Other molecular changes seen in CRC, involve alterations in DNA methylation e.g. induction of expression of oncogenes and silencing of tumor suppressor genes. Choi et al. [24] demonstrated that chronic alcohol consumption causes genomic DNA hypomethyation in rats, whereas no effect was seen on the methylation status of tumor suppressor gene TP53. Next to effects at genomic level, alcohol may also affect the colorectal mucosa. As shown in experimental studies, decreasing cell numbers in the functional compartment of the colonic crypt through acetaldehyde, trigger compensatory hyperregeneration with increased crypt cell production rates and extension of the proliferative compartment towards the lumen of the crypt $[25,26]$. Mucosal hyperregeneration, regardless of the underlying cause, is strongly associated with CRC risk. Many of the above described processes have been observed in heavy or chronic alcohol consumers. The amount of damage related to alcohol tends to follow a doseresponse relationship and as such, (very) high levels of daily alcohol intake may be needed for genetic mutations to occur. Moderate consumption levels as in our study population, might thus not be able to increase CRC risk trough causing specific genetic or molecular aberrations. In addition, besides adverse effects of alcohol consumption the entire nutritional status in heavy drinkers may be impaired due to malnutrition and intestinal absorption, increasing the cancer risk even more. 
The strengths of our study include a population based and prospective design. In addition, the high completeness of follow-up of cancer incidence and subcohort members precluded minimal recall and selection biases. Although the CIN and MSI pathways also involve aberrations other than the ones that were included in the current study, $A P C, K R A S$ and TP53 are key genes of the CIN pathway, as $M L H 1$ is a key gene of the MSI pathway. Our study is currently the first prospective study that investigated the association between alcohol consumption and distinct CRC subgroups. Nevertheless, it should be noted that the numbers of CRC cases in certain subgroups are small and results should be interpreted with caution.

In conclusion, our results indicate that a daily alcohol consumption of $30 \mathrm{~g}$ and more is positively associated with the risk of CRC. This increase in risk was observed independent of the presence or absence of the genetic and molecular aberrations we studied to distinguish between etiologic pathways. 


\section{REFERENCES}

1. Rashid, A., Zahurak, M., Goodman, S. N., and Hamilton, S. R. Genetic epidemiology of mutated $K$-ras proto-oncogene, altered suppressor genes, and microsatellite instability in colorectal adenomas. Gut, 44: 826-833, 1999.

2. Arnold, C. N., Goel, A., Compton, C., Marcus, V., Niedzwiecki, D., Dowell, J. M., et al. Evaluation of microsatellite instability, $h M L H 1$ expression and $h M L H 1$ promoter hypermethylation in defining the MSI phenotype of colorectal cancer. Cancer Biol Ther, 3: 73-78, 2004.

3. Lüchtenborg, M., Weijenberg, M. P., Wark, P. A., Saritas, A. M., Roemen, G. M. J. M., van Muijen, G. N. P., et al. Mutations in $A P C$, CTNNBI and K-ras genes and expression of hMLHI in sporadic colorectal carcinomas from the Netherlands Cohort Study. Bmc Cancer, 5: -, 2005.

4. Salahshor, S., Kressner, U., Púhlman, L., Glimelius, B., Lindmark, G., and Lindblom, A. Colorectal cancer with and without microsatellite instability involves different genes. Genes Chromosomes Cancer, 26: 247-252, 1999.

5. Samowitz, W. S., Holden, J. A., Curtin, K., Edwards, S. L., Walker, A. R., Lin, H. A., et al. Inverse relationship between microsatellite instability and K-ras and TP53 gene alterations in colon cancer. Am J Pathol, 158: 1517-1524, 2001.

6. Giaretti, W., Venesio, T., Prevosto, C., Lombardo, F., Ceccarelli, J., Molinu, S., et al. Chromosomal instability and $A P C$ gene mutations in human sporadic colorectal adenomas. Journal of Pathology, 204: 193-199, 2004.

7. Poschl, G., Stickel, F., Wang, X. D., and Seitz, H. K. Alcohol and cancer: genetic and nutritional aspects. Proc Nutr Soc, 63: 65-71, 2004.

8. Voskuil, D. W., Kampman, E., van Kraats, A. A., Balder, H. F., van Muijen, G. N. P., Goldbohm, R. A., et al. TP53 over-expression and TP53 mutations in colon carcinomas: Relation to dietary risk factors. International Journal of Cancer, 81: 675-681, 1999.

9. Terry, M. B., Neugut, A. I., Mansukhani, M., Waye, J., Harpaz, N., and Hibshoosh, H. Tobacco, alcohol, and TP53 overexpression in early colorectal neoplasia. BMC Cancer, 3, 2003.

10. Fredrikson, M., Axelson, O., Sun, X. F., Arbman, G., Nilsson, E., Nordenskjold, B., et al. A pilot study on risk factors and TP53 gene expression in colorectal cancer. $\mathrm{Br} \mathrm{J}$ Cancer, 73: 1428-1430, 1996.

11. Diergaarde, B., Braam, H., van Muijen, G. N., Ligtenberg, M. J., Kok, F. J., and Kampman, E. Dietary factors and microsatellite instability in sporadic colon carcinomas. Cancer Epidemiol Biomarkers Prev, 12: 1130-1136, 2003.

12. Diergaarde, B., van Geloof, W. L., van Muijen, G. N., Kok, F. J., and Kampman, E. Dietary factors and the occurrence of truncating $A P C$ mutations in sporadic colon carcinomas: a Dutch population-based study. Carcinogenesis, 24: 283-290, 2003. 
13. Slattery, M. L., Curtin, K., Anderson, K., Ma, K. N., Edwards, S., Leppert, M., et al. Associations between dietary intake and Ki-ras mutations in colon tumors: a population-based study. Cancer Res, 60: 6935-6941, 2000.

14. Van den Brandt, P. A., Goldbohm, R. A., van 't Veer, P., Volovics, A., Hermus, R. J., and Sturmans, F. A large-scale prospective cohort study on diet and cancer in The Netherlands. J Clin Epidemiol, 43: 285-295, 1990.

15. Van den Brandt, P. A., Schouten, L. J., Goldbohm, R. A., Dorant, E., and Hunen, P. M. Development of a record linkage protocol for use in the Ducth Cancer Registry for Epidemiological Research. Int J Epidemiol, 19: 553-558, 1990.

16. Goldbohm, R. A., van den Brandt, P. A., Brants, H. A., van't Veer, P., Al, M., Sturmans, F., et al. Validation of a dietary questionnaire used in a large-scale prospective cohort study on diet and cancer. Eur J Clin Nutr, 48: 253-265, 1994.

17. Brink, M., de Goeij, A. F., Weijenberg, M. P., Roemen, G. M., Lentjes, M. H., Pachen, M. M., et al. K-ras oncogene mutations in sporadic colorectal cancer in The Netherlands Cohort Study. Carcinogenesis, 24: 703-710, 2003.

18. Lüchtenborg, M., Weijenberg, M. P., Roemen, G. M. J. M., Bruine de, A. P., van den Brandt, P. A., Lentjes, M. H. F. M., et al. APC mutations in sporadic colorectal carcinomas from The Netherlands Cohort Study. Carcinogenesis, 25: 1219-1226, 2004.

19. Cho, E., Smith-Warner, S. A., Ritz, J., van den Brandt , P. A., Colditz, G. A., Folsom, A. R., et al. Alcohol intake and colorectal cancer: a pooled analysis of 8 cohort studies. Ann Intern Med, 140: 603-613, 2004.

20. Taylor, B. and Rehm, J. Moderate alcohol consumption and diseases of the gastrointestinal system: a review of pathophysiological processes. Dig Dis, 23: 177-180, 2005.

21. Badger, T. M., Ronis, M. J., Seitz, H. K., Albano, E., Ingelman-Sundberg, M., and Lieber, C. S. Alcohol metabolism: role in toxicity and carcinogenesis. Alcohol Clin Exp Res, 27: 336-347, 2003.

22. Boffetta, P. and Hashibe, M. Alcohol and cancer. Lancet Oncol, 7: 149-156, 2006.

23. Seitz, H. K., Maurer, B., and Stickel, F. Alcohol consumption and cancer of the gastrointestinal tract. Digestive Diseases, 23: 297-303, 2005.

24. Choi, S. W., Stickel, F., Baik, H. W., Kim, Y. I., Seitz, H. K., and Mason, J. B. Chronic alcohol consumption induces genomic but not TP53-specific DNA hypomethylation in rat colon. Journal of Nutrition, 129: 1945-1950, 1999.

25. Seitz, H. K., Simanowski, U. A., Garzon, F. T., Rideout, J. M., Peters, T. J., Koch, A., et al. Possible Role of Acetaldehyde in Ethanol-Related Rectal Cocarcinogenesis in the Rat. Gastroenterology, 98: 406-413, 1990.

26. Simanowski, U. A., Homann, N., Knuhl, M., Arce, L., Waldherr, R., Conradt, C., et al. Increased rectal cell proliferation following alcohol abuse. Gut, 49: 418-422, 2001. 


\title{
Associations of dietary methyl donor
}

\author{
intake with $M L H 1$ promoter \\ hypermethylation and related \\ molecular phenotypes in sporadic \\ colorectal cancer
}

Stefan de Vogel

Brenda W.C. Bongaerts

Kim A.D. Wouters Arnold D.M. Kester Leo J. Schouten Anton F.P.M. de Goeij Adriaan P. De Bruine R. Alexandra Goldbohm Piet A. van den Brandt Manon van Engeland Matty P. Weijenberg 


\begin{abstract}
Intake of dietary factors that serve as methyl group donors may influence promoter hypermethylation in colorectal carcinogenesis. We investigated whether dietary folate, vitamins B2 and B6, methionine and the antagonist alcohol were associated with $M L H 1$ hypermethylation, and the related molecular phenotypes of MLH1 protein expression, microsatellite instability $(\mathrm{MSI})$ and $B R A F$ mutations in patients with colorectal carcinomas.
\end{abstract}

Within the Netherlands Cohort Study on diet and cancer $(n=120,852), 648$ cases and 4,059 subcohort members were available for data analyses from a follow-up period between 2.3 and 7.3 years after baseline. Gender-specific adjusted incidence rate ratios (RR) were calculated over categories of dietary intake in case-cohort analyses.

The intakes of folate, vitamin B2, methionine and alcohol were not associated with risk of tumors showing $M L H 1$ hypermethylation, those lacking MLH1 protein expression, or with MSI. Among men, we observed strong positive associations between folate and BRAF-mutated tumors (RR: 3.04, for the highest versus lowest tertile of intake, $p$-trend=0.03), and between vitamin B6 and tumors showing $M L H 1$ hypermethylation (highest vs. lowest tertile: RR: 3.23, p-trend=0.03). Among women, the relative risks of tumors with $B R A F$ mutations or $M L H 1$ hypermethylation were also increased in the highest tertiles of folate and vitamin B6 intake respectively, but these did not reach statistical significance.

The positive associations between folate intake and tumors harboring $B R A F$ mutations and between vitamin $\mathrm{B} 6$ intake and those showing $M L H 1$ hypermethylation were most pronounced among men, and may indicate that these vitamins enhance $C R C$ risk through genetic as well as epigenetic aberrations. 


\section{INTRODUCTION}

It has been hypothesized that two forms of genetic instability may contribute to the carcinogenesis of sporadic colorectal cancer (CRC). While microsatellite instability (MSI) occurs in approximately $15 \%$ of the sporadic CRCs, chromosomal instability (CIN) would account for the remaining 85\% [1]. Sporadic tumors with MSI present a distinct molecular phenotype and may develop predominantly as a consequence of hypermethylation of the mismatch repair gene Mut-L Homologue 1 (MLHI) [2-4]. Furthermore, mutations in the $B R A F$ oncogene are strongly associated with $M L H 1$ promoter methylation and MSI [5], and are an additional type of molecular alteration characterizing this phenotype.

Dietary factors that serve as methyl group donors, such as folate and methionine, potentially have an effect at the level of DNA methylation. A low folate status may decrease genomic DNA methylation, which in turn presumably contributes to the process of carcinogenesis [6]. A specific form of aberrant methylation that is frequently observed in carcinogenesis involves $\mathrm{CpG}$ island promoter hypermethylation of for example DNA repair genes [7]. It may be hypothesized that deficient status or low intake of methyl donors could also lead to increased frequencies of this type of aberrant DNA methylation. In this respect, in a pilot study ( $n=122$ patients), we previously observed a weak association between relatively low folate intake in combination with high alcohol consumption, and increased promoter hypermethylation of at least one out of six of the studied colorectal cancer genes [8]. Conversely, it was recently suggested that folate supplementation in combination with vitamin B12 during 6 months may be associated with increased levels of promoter hypermethylation in colorectal mucosa, although this association was borderline significant [9]. These results seem contradictive and it is obviously important to further study the potential effect of relatively high methyl donor intake on the occurrence of promoter hypermethylation.

Other dietary factors, such as vitamins B2 and B6, are also involved in the folatemediated one-carbon metabolism (figure 1). These vitamins may therefore modulate the bioavailability of methyl groups and thereby DNA methylation as well [10]. Flavin adenine dinucleotide (FAD), a metabolite of vitamin B2, is the cofactor for methylene-tetrahydrofolate reductase (MTHFR), the enzyme that converts 5,10methylene-tetrahydrofolate into 5-methyl-tetrahydrofolate and thereby enhances 
DNA methylation. Low vitamin B2 status was previously observed to be associated with increased total homocysteine concentration, which possibly results in lower availability of methyl groups needed for DNA methylation [11]. Interestingly, it was suggested that patients with the MTHFR C677T and A1298C polymorphisms, that are associated with lower activity of this enzyme, tended to have a higher level of $M L H 1$ promoter methylation in colon carcinomas [12]. Subjects with the homozygous MTHFR 677TT variant also had lower serum folate levels [13], and may be at increased risk of developing tumors harboring MSI $[13,14]$. Vitamin B6 is involved in the conversion of tetrahydrofolate into 5,10-methylenetetrahydrofolate, which is one of the steps of the folate cycle and therefore essential for the subsequent supply of methyl groups. Conversely, high alcohol intake reduces the bioavailability of folate and such a disruption of the one-carbon metabolism may affect DNA methylation in for example the colonic mucosa [15, 16]. Long term alcohol consumption may also result in an increased risk of tumors harboring MSI [17, 18].

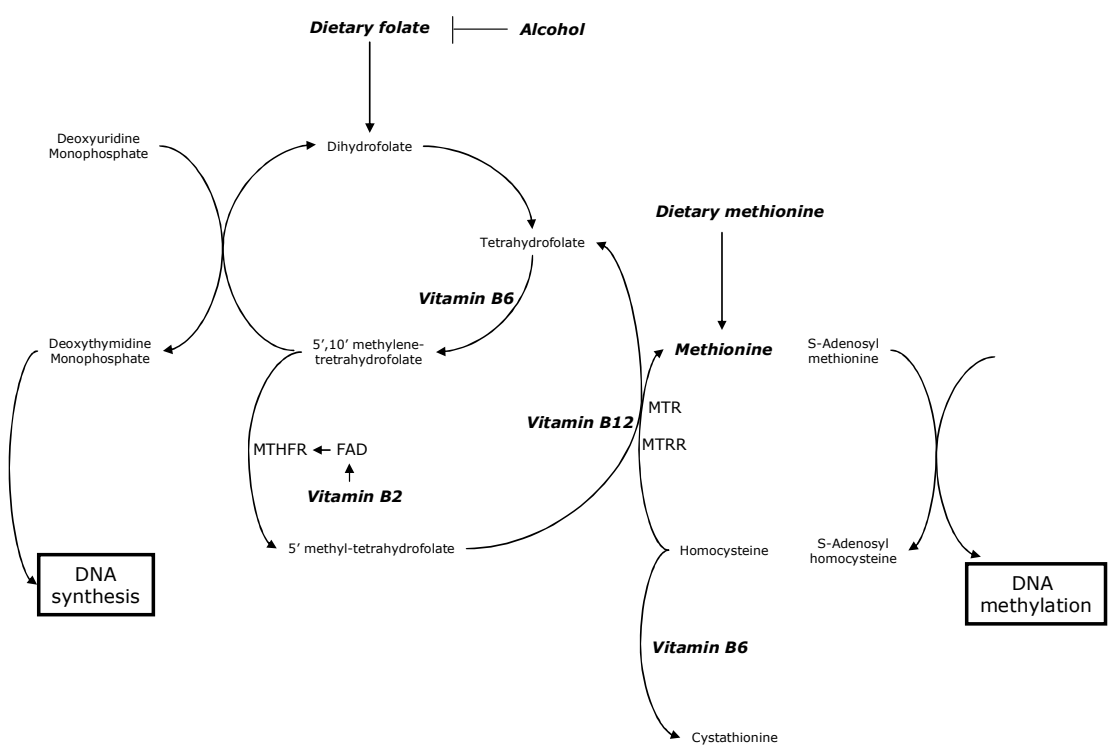

Figure 1: The role of folate, methionine, vitamins B2 and B6, and alcohol in the synthesis an methylation of DNA. Dietary factors are displayed in Italics. Methyl donors are folate and methionine; factors that may modulate the bioavailability of methyl groups are $v$ itamin B2, vitamin B6 and alcohol. FAD: flavine adenine dinucleotide, MTHFR: methylene tetrahydrofo late reductase, MTR: methionine synthase; MTRR: methionine synthase reductase. 
Since folate plays an important role in both DNA synthesis and -methylation, one would expect that adequate folate status or sufficient folate intake can also reduce the risk of tumors harboring gene mutations. Opposite to this however, we have previously observed that relatively high folate intake may increase the risk of CRCs with truncating $A P C$ mutations in men [19]. The relation between diet and $B R A F$ mutations has been studied, but no associations were observed with folate, vitamins B6 and B12, and methionine [20].

Here, we investigate associations between dietary folate, vitamin B2, vitamin B6, methionine and alcohol in relation to $M L H 1$ promoter methylation and the associated molecular characteristics of absence of MLH1 protein expression, MSI and BRAF mutations in CRCs. This allows us to establish which of these endpoints is associated with the MSI phenotype is most sensitive to dietary exposure, and whether the effect of methyl donor intake through folate and methionine may be modulated by vitamins $B 2$ and B6, or alcohol. We also describe the occurrence and overlap between $M L H 1$ promoter methylation, MLH1 protein expression, MSI and BRAF mutations. This study is carried out within the Netherlands Cohort Study on diet and cancer (NLCS), among a large group of unselected CRC patients.

\section{SUBJECTS AND METHODS}

\section{Study population}

The participants in this study are incident colon and rectal cancer patients and subcohort members from the Netherlands Cohort Study (NLCS), which has been described in detail elsewhere [21]. Briefly, the study was initiated in 1986 and includes 58,279 men and 62,573 women aged 55-69 years at baseline, who originated from 204 Dutch municipalities with computerized population registers. At baseline, participants completed a self-administered food-frequency questionnaire that also provided information about age, sex and other risk factors for cancer. The entire cohort is being monitored for cancer occurrence by annual record linkage to the Netherlands Cancer Registry (NCR, nine cancer registries in The Netherlands) and to PALGA, a nationwide network and registry of histopathology and cytopathology reports [22]. Accumulation of person-time in the cohort has been 
estimated through biennial vital status follow-up of a subcohort of 5,000 men and women who were randomly selected after baseline exposure measurement.

Cases with prevalent cancer other than non-melanoma skin cancer were excluded from this subcohort, which left 4,774 men and women eligible for analysis.

In 1986, the PALGA registry was not yet implemented in some of the municipalities included in the study, but reached full coverage by the end of 1988 . Incomplete coverage may introduce selection bias, and in addition, possible preclinical disease may have affected exposure status. For these reasons we excluded the first 2.3 years of follow-up from the analyses. A total of 101 subcohort members were either deceased or diagnosed with cancer other than non-melanoma skin cancer within this period, leaving 4,673 men and women for analysis. From 1989 to 1994, 925 incident cases were identified with histologically confirmed CRC of whom 815 could also be linked to a PALGA report of the lesion. The PALGA database was used to identify and locate tumor tissue in Dutch pathology laboratories. CRC was classified according to disease site as follows: colon, i.e. proximal colon (ICD-0-1 codes 153.0, $153.1,153.4,153.5,153.6)$ and distal colon $(153.2,153.3,153.7)$, rectosigmoid (154.0), rectum (154.1), or ICD-0-1 codes 153.8 and 153.9 if information of the disease site was not available.

\section{Tissue samples}

Tumor material of the colorectal cancer patients was collected after approval by the ethical review boards of Maastricht University, the NCR and PALGA [23]. In addition, all pathology laboratories in the Netherlands agreed to make relevant tissue samples available from PALGA upon request. Of the 815 tissue samples that were scattered over 54 pathology laboratories in the Netherlands, 734 samples (90\%) could be traced and were retrieved between August 1999 and December 2001 [23].

\section{MLH1 promoter methylation}

DNA methylation in the CpG islands of the $M L H 1$ gene was determined by chemical modification of genomic DNA with sodium bisulfite and subsequent Methylation Specific PCR (MSP, described in detail elsewhere [24]). In brief, 500 ng of DNA was denatured by $\mathrm{NaOH}$ and modified by sodium bisulfite. DNA samples were then purified using Wizard DNA purification resin (Promega), again treated with $\mathrm{NaOH}$, 
precipitated with ethanol and resuspended in $\mathrm{H}_{2} \mathrm{O}$. To facilitate MSP analysis on DNA retrieved from formalin-fixed, paraffin-embedded tissue, DNA was first amplified with flanking PCR primers (described in ref [8]) that amplify bisulfite modified DNA but do not preferentially amplify methylated or unmethylated DNA. The resulting fragment was used as a template for the MSP-reaction $[8,25]$.

All PCRs were performed with controls for unmethylated alleles (DNA from normal lymphocytes), methylated alleles (normal lymphocyte DNA treated in vitro with SssI methyltransferase (New England Biolabs)) and a control without DNA. Ten $\mu$ l of each MSP reaction was directly loaded onto nondenaturing $6 \%$ polyacrylamide gels, stained with ethidium bromide and visualized under UV illumination. MSP analyses of $M L H 1$ were successfully performed for 686 (93\%) out of 734 patients.

\section{MLH1 protein expression status}

Immunohistochemical analyses were performed and scored on $4 \mu \mathrm{m}$ sections of formalin-fixed, paraffin-embedded cancer tissue and adjacent normal tissue using a monoclonal antibody against MLH1, as previously described [17]. Two investigators reviewed the immunohistochemical staining profiles independently and discrepancies were re-examined and discussed with a pathologist until consensus was reached. MLH1 protein expression status was determined successfully in 721 $(98 \%)$ of the 734 patients.

\section{Microsatellite instability}

Microsatellite instability (MSI) was determined by a pentaplex PCR, using the MSI markers BAT-26, BAT-25, NR-21, NR-22 and NR-24, as described in detail by Suraweera et al [26]. MSI analyses were successful on $662(90 \%)$ out of the 734 available samples.

\section{BRAF mutations}

The common V600E BRAF mutation in exon 15 was analyzed by a semi-nested PCR and subsequent RFLP analyses as previously described [27]. BRAF mutation status could be analyzed successfully in 697 (95\%) out of 734 tissue samples. 


\section{Food frequency questionnaire}

The self-administered questionnaire was a 150-item semi-quantitative food frequency questionnaire, which concentrated on habitual consumption of food and beverages during the year preceding the start of the study, and also contained questions about body weight and -length, smoking status, physical activity, and family history of colorectal cancer. Daily mean nutrient intakes were calculated as the cumulated product of the frequencies and portion sizes of all food items and their tabulated nutrient contents from the Dutch Food Composition Table (NEVO table, 1986 [28]).

The questionnaire was validated through comparison with a 9-day diet record [29]. Questionnaire data were key-entered twice for all incident cases in the cohort and for all subcohort members in a blinded manner with respect to case/subcohort status. This was done in order to minimize observer bias in coding and interpretation of the data.

Folate data were derived from a validated liquid chromatography trienzyme method [30] used to analyze the 125 most important Dutch foods contributing to folate intake [31]. Mean daily intakes of all other relevant nutrients were calculated using the computerized Dutch Food Composition Table [28]. Dietary supplement data were also obtained via the food frequency questionnaire. However, the use of Bvitamins and/or multivitamin supplements was low ( $7 \%$ and $4 \%$ respectively), and folic acid was generally not included in supplements in the Netherlands in the late 1980s. Therefore, folic acid supplement use most likely plays a very minor role in our study population, and dietary supplement use was not further accounted for in the analyses.

\section{Statistical analyses}

The occurrence and relative overlap of $M L H 1$ hypermethylation with any of the three other characteristics - absence of MLH1 protein expression, MSI, and BRAF mutations - were calculated and tested with Chi-square tests. Dietary factors and other baseline characteristics were summarized for men and women separately, for subcohort members and colorectal cancer cases by calculating means and standard deviations for continuous variables and distributions of the categorical variables. Differences in dietary folate, vitamins B2 and B6, methionine and alcohol intake 
were tested between CRC cases and the non-cases in the subcohort using Student $\mathrm{t}$ tests or Chi-square tests where appropriate. This comparison was also made for the four other molecular characteristics.

Cox proportional hazards regression models were used to estimate multivariateadjusted incidence rate ratios (RR) and corresponding $95 \%$ confidence intervals $(\mathrm{Cl})$ over tertiles of folate intake, vitamin B2, vitamin B6 and methionine, and over categories of alcohol intake, using the lowest intake categories as reference. Standard errors (SE) of the RRs were estimated using the robust Huber-White sandwich estimator to account for additional variance introduced by sampling from the cohort [32]. The proportional hazards assumption was tested using the scaled Schoenfeld residuals [33]. Tests for dose response trends over the different categories of intake were estimated by fitting the ordinal exposure variables as continuous variables and evaluated using the Wald test.

For each endpoint, a model was used that included all of these five dietary variables. Folate, vitamins B2 and B6, and methionine were adjusted for total energy intake by calculating nutrient residuals from the regression of nutrient intake on total energy intake, as described by Willet et al. [34]. These nutrient residuals are uncorrelated with total energy intake, and the effect of the variation in nutrient intake can subsequently be estimated independently of a potential effect of energy intake. The RRs were calculated for all colorectal tumors, for tumors with $M L H 1$ hypermethylation, absence of MLH1 protein expression, MSI, or BRAF mutations. Because tumors presenting MSI usually occur more frequently among women, and may have a different etiology than in men, we have chosen to present genderspecific results. In addition to these analyses, we also performed overall analyses for men and women combined in order to create larger subgroups and thereby to reduce the probability of reporting chance findings.

Tests for heterogeneity were performed to evaluate differences between subtypes of tumors (e.g. MLH1 methylated versus unmethylated), using the competing risks procedure in Stata. However, the SE for the difference of the log HRs from this procedure assumes independence of both estimated HRs, which would underestimate that $\mathrm{SE}$ and thus overestimate the $p$-values for their difference. Therefore, these $p$-values and the associated confidence intervals were estimated based on a bootstrapping method that was developed for the case-cohort design 
[35]. For each bootstrap sample, $X$ subcohort members were randomly drawn from the subcohort of $X$ subjects and $Y$ cases from the total of $Y$ cases outside the subcohort, both with replacement, out of the dataset of $X+Y$ observations. The log HRs were obtained from this sample using Stata's competing risks procedure and recalculated for each bootstrap-replication. The confidence interval and $p$-value of the differences in hazard ratio of the subtypes were then calculated from the replicated statistics. Each bootstrap analysis was based on 1,000 replications.

The covariates included in the multivariate analyses were those found to influence the RR by more than 10 percent, or those observed to be associated with CRC in previous studies. This applied for the variables age, family history of CRC, smoking, Body Mass Index (BMI), and dietary intakes of energy, meat, fat, fiber, vitamin C, iron and calcium. After excluding subjects with missing information on these covariates or subjects who only partly filled out the questionnaire, 4,059 subcohort members remained for statistical analyses as well as 648 CRC cases, irrespective of the available molecular analyses.

We determined possible interactions between dietary intakes of methyl donors (folate and methionine) and the potentially "modulating" factors vitamin B2, vitamin B6 and alcohol, for each of the individual endpoints. This was done by first testing, in separate models, the gender-specific interaction terms between folate and methionine, with vitamin B2, vitamin B6 and alcohol, i.e. folate*methionine, folate*B2, folate*B6, folate*alcohol, methionine*B2, methionine*B6 and methionine*alcohol. The Cox proportional hazard analyses without the interaction terms were subsequently stratified by low or high intake of folate, vitamins B2 and B6, and methionine using the median intakes as cut-off values to define both strata within each variable. The strata used for alcohol intake were 1: abstainers, 2: subjects with intake $<30 \mathrm{~g} / \mathrm{d}$, and 3 : subjects who consumed $\geq 30 \mathrm{~g} / \mathrm{d}$. All statistical analyses were performed with the Stata statistical software package (version 9.1). 


\section{RESULTS}

Among the colorectal cancer patients in our study, we first assessed the occurrence of $M L H 1$ hypermethylation, MLH1 protein expression, MSI, and $B R A F$ mutations. The frequencies and percentages, as well as the overlap between these molecular phenotypes are shown in table 1 and figure 2 . In $152(22.1 \%)$ of the patients with successful MLH1 MSP analyses promoter methylation of this gene was found. The percentages of tumors that lacked the MLH1 protein, those with MSI as determined by the MSI pentaplex assay, or those harboring $B R A F$ mutations were $8.5 \%, 12.7 \%$ and $16.1 \%$ respectively. Although the associations between $M L H 1$ hypermethylation and the three other aberrations individually were highly significant (all Chi-square tests had $p$-values $<0.001$ ), the overlap between the four molecular phenotypes, which was based on patients with all molecular analyses available, was not complete.

Table 1: Frequencies of molecular phenotypes and overlap of $M L H 1$ promoter methylation with MLH1 expression, MSI and BRAF mutations

\begin{tabular}{|c|c|c|c|c|c|c|c|}
\hline & \multirow{2}{*}{\multicolumn{2}{|c|}{$\begin{array}{c}\text { Frequency of molecular } \\
\text { phenotype }\end{array}$}} & \multicolumn{4}{|c|}{ MLH1 promoter methylation } & \multirow[b]{3}{*}{$p$-value } \\
\hline & & & \multicolumn{2}{|c|}{ Methylated } & \multicolumn{2}{|c|}{ Unmethylated } & \\
\hline & $\mathbf{N}$ & (\%) & $\mathbf{N}^{\mathrm{a}}$ & $(\%)^{a}$ & $\mathbf{N}^{\mathrm{a}}$ & $(\%)^{a}$ & \\
\hline \multicolumn{8}{|l|}{$M L H 1$ methylation } \\
\hline Methylated & 152 & (22.1\%) & - & - & - & - & \\
\hline Unmethylated & 534 & (77.9\%) & - & - & - & - & - \\
\hline MLH1 expression & & & 41 & $(74.6 \%)$ & 14 & $(25.4 \%)$ & \\
\hline No & 61 & $(8.5 \%)$ & 97 & $(17.3 \%)$ & 463 & $(82.7 \%)$ & $<0.001$ \\
\hline Yes & 660 & (91.5\%) & & & & & \\
\hline MSI & & & 50 & $(65.8 \%)$ & 26 & $(34.2 \%)$ & \\
\hline Present & 84 & $(12.7 \%)$ & 88 & $(16.3 \%)$ & 452 & $(83.7 \%)$ & $<0.001$ \\
\hline Absent & 578 & $(87.3 \%)$ & & & & & \\
\hline \multicolumn{8}{|l|}{ BRAF } \\
\hline Mutation & 112 & $(16.1 \%)$ & 48 & $(47.5 \%)$ & 53 & $(52.5 \%)$ & \\
\hline Wild Type & 585 & $(83.9 \%)$ & 90 & $(17.5 \%)$ & 425 & $(82.5 \%)$ & $<0.001$ \\
\hline
\end{tabular}


The highest relative overlap was observed with MLH1 protein expression since out of the 55 tumors lacking the MLH1 protein, 41 (74.6\%) also showed $M L H 1$ hypermethylation. The overlap between MSI and $M L H 1$ hypermethylation was lower, with $50(65.8 \%)$ out of 76 tumors harboring MSI also having $M L H 1$ hypermethylation. The lowest percentage of overlap was observed between $B R A F$ mutations and $M L H 1$ hypermethylation, as 48 (47.5\%) out of 101 BRAF-mutated tumors had a hypermethylated $M L H 1$ gene.

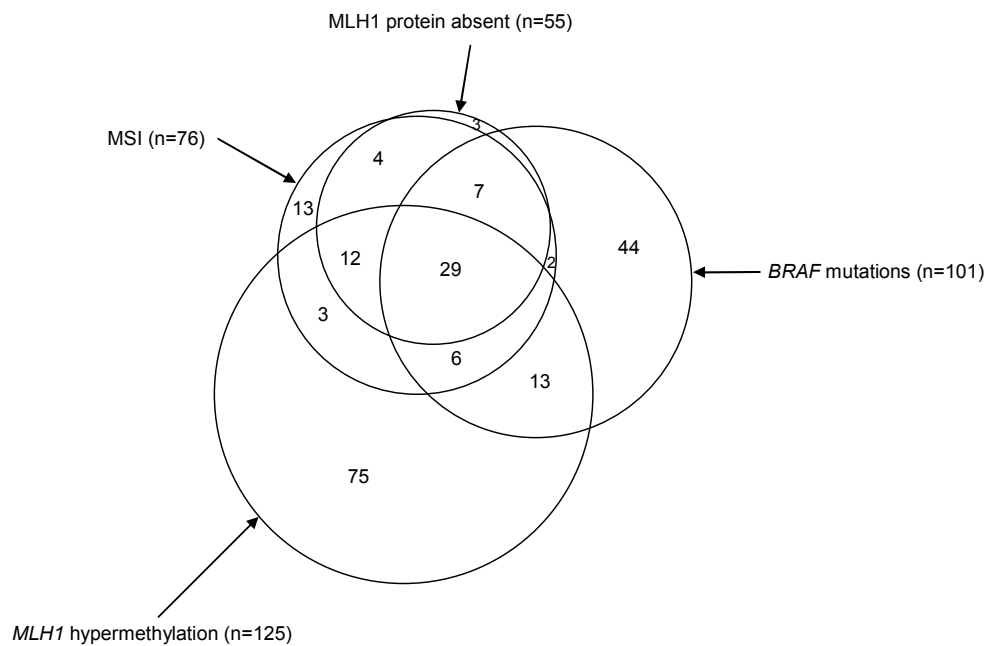

Figure 2: Overlap between MLH1 hypermethylation, absence of $M L H 1$ protein expression, MSI and BRAF in tumors showing at least one of these four aberrations.

In total, there were $\mathrm{n}=\mathbf{2 3 8}$ tumors harboring at least one aberration. Numbers are based on tumors with complete analyses of all four molecular characteristics. The sizes of the different areas in this figure do not exactly reflect the numbers of the applicable subsets.

We then explored dietary intakes and other baseline characteristics of subcohort members and cancer cases with $M L H 1$ promoter methylation, absence of MLH1 protein expression, MSI, or BRAF mutations among men and women (table 2). 


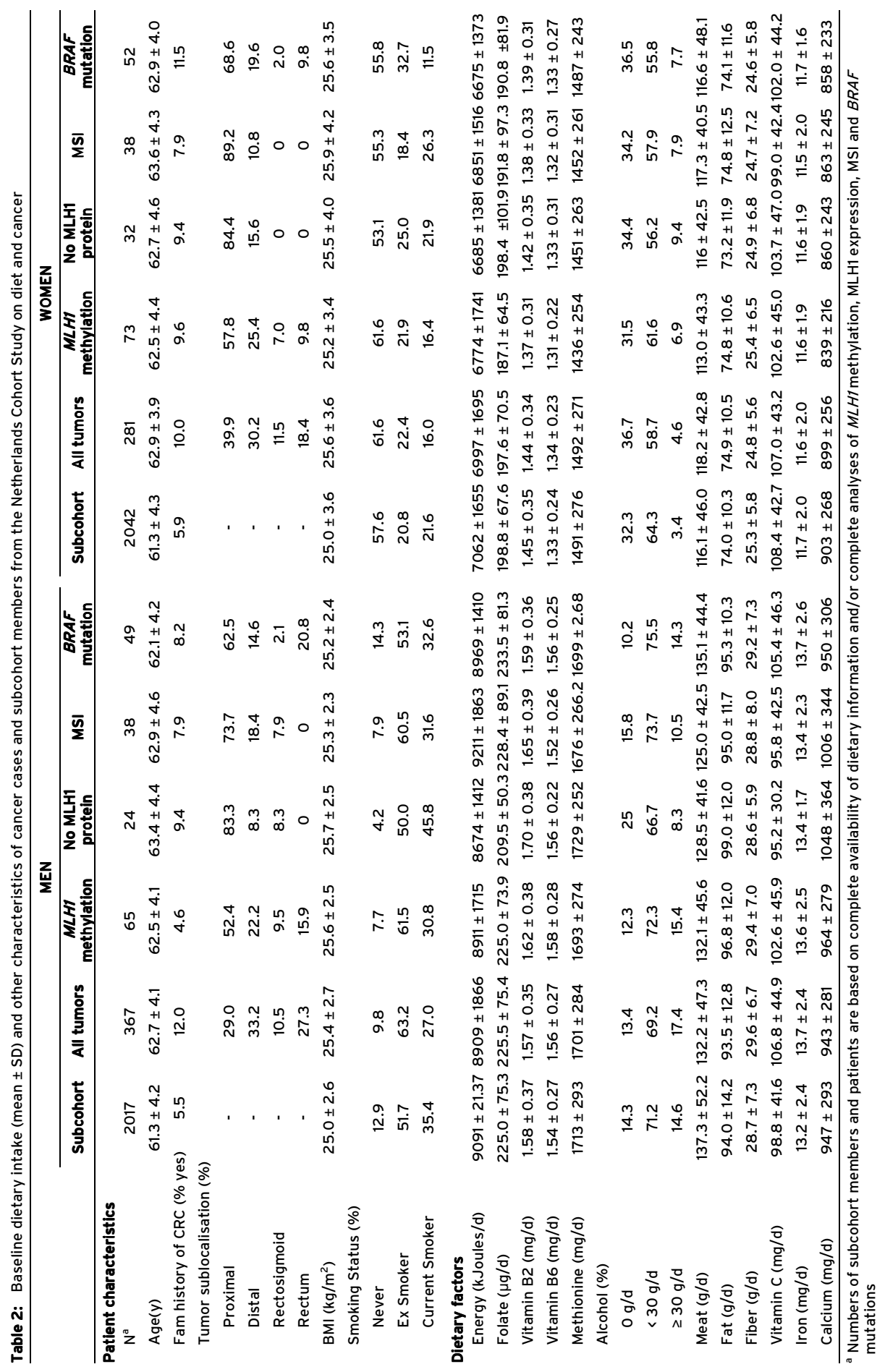


The percentage of male patients with a family history of colorectal cancer was substantially lower among men with a hypermethylated $M L H 1$ gene, as compared to all CRC tumors combined in men. It was also clear that tumors with $M L H 1$ hypermethylation, without MLH1 protein expression, with MSI or BRAF mutations all occurred more often in the proximal colon if compared to the total group of tumors in both men and women. The intakes of folate, vitamin B2, vitamin B6, methionine and alcohol were similar among cases in the different subgroups compared to subcohort members.

We subsequently estimated the associations between intakes of folate, vitamins B2 and B6, methionine and alcohol on the one hand, with colorectal carcinoma risk with or without $M L H 1$ hypermethylation, absence of MLH1 protein expression, MSI or $B R A F$ mutations on the other. Among men, folate intake was not associated with overall colorectal cancer, with tumors showing $M L H 1$ hypermethylation, lacking MLH1 protein expression or with MSI. However, it was positively associated with colorectal tumors harboring $B R A F$ mutations in men (RR: $3.04,95 \% \mathrm{Cl}: 1.13-8.20, p-$ trend=0.03 for the highest versus the lowest tertile of intake, table 3 ). Conversely, there was an inverse association between methionine intake and risk of $B R A F$ mutated tumors (highest vs. lowest tertile: RR: $0.28,95 \% \mathrm{Cl}: 0.09-0.86, p-$ trend=0.02). Both vitamin B2 and alcohol were not associated with any of the endpoints studied in men. However, dietary intake of vitamin B6 was positively associated with overall colorectal cancer in men (RR: 1.54, 95\% Cl: 1.01-2.36, $p$ trend=0.06 for the highest versus the lowest tertile of intake). The association between vitamin $\mathrm{B} 6$ and tumors with $M L H 1$ hypermethylation in men was even stronger (RR: $3.23,95 \% \mathrm{Cl}: 1.15-9.06, p$-trend=0.03).

Among women, dietary intakes of folate, vitamin B2, vitamin B6, methionine and alcohol were not associated with overall colorectal cancer or any of the endpoints studied (table 4). Although the RRs of tumors with BRAF mutations and those with $M L H 1$ hypermethylation were also increased in the highest tertiles of folate and vitamin B6 intake respectively, these associations were not statistically significant among women. Increased relative risks could be observed in the highest category of alcohol intake for most of the endpoints, however, trends were not statistically significant and the numbers of cases in the highest category were low for both men and women. 


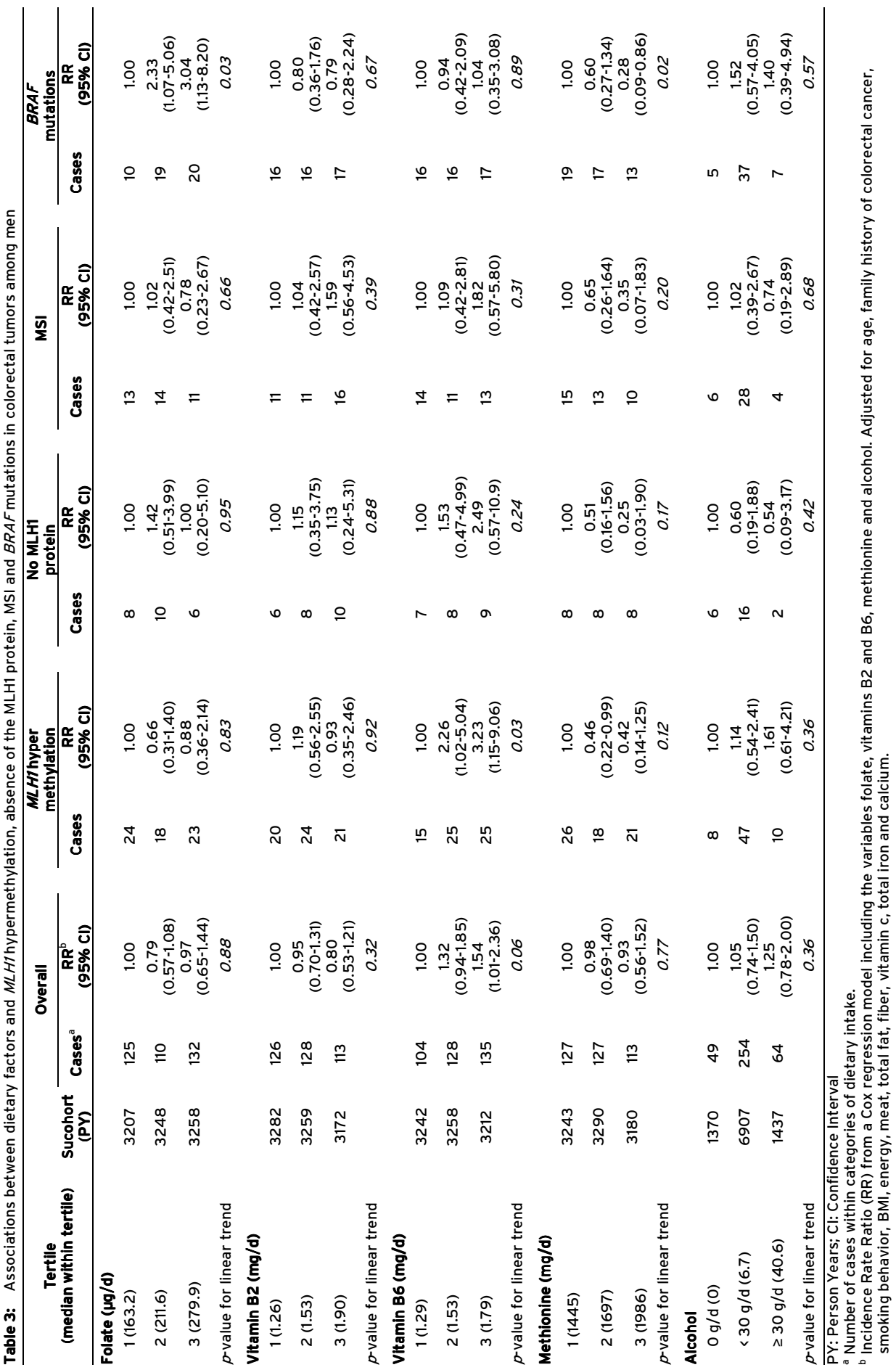




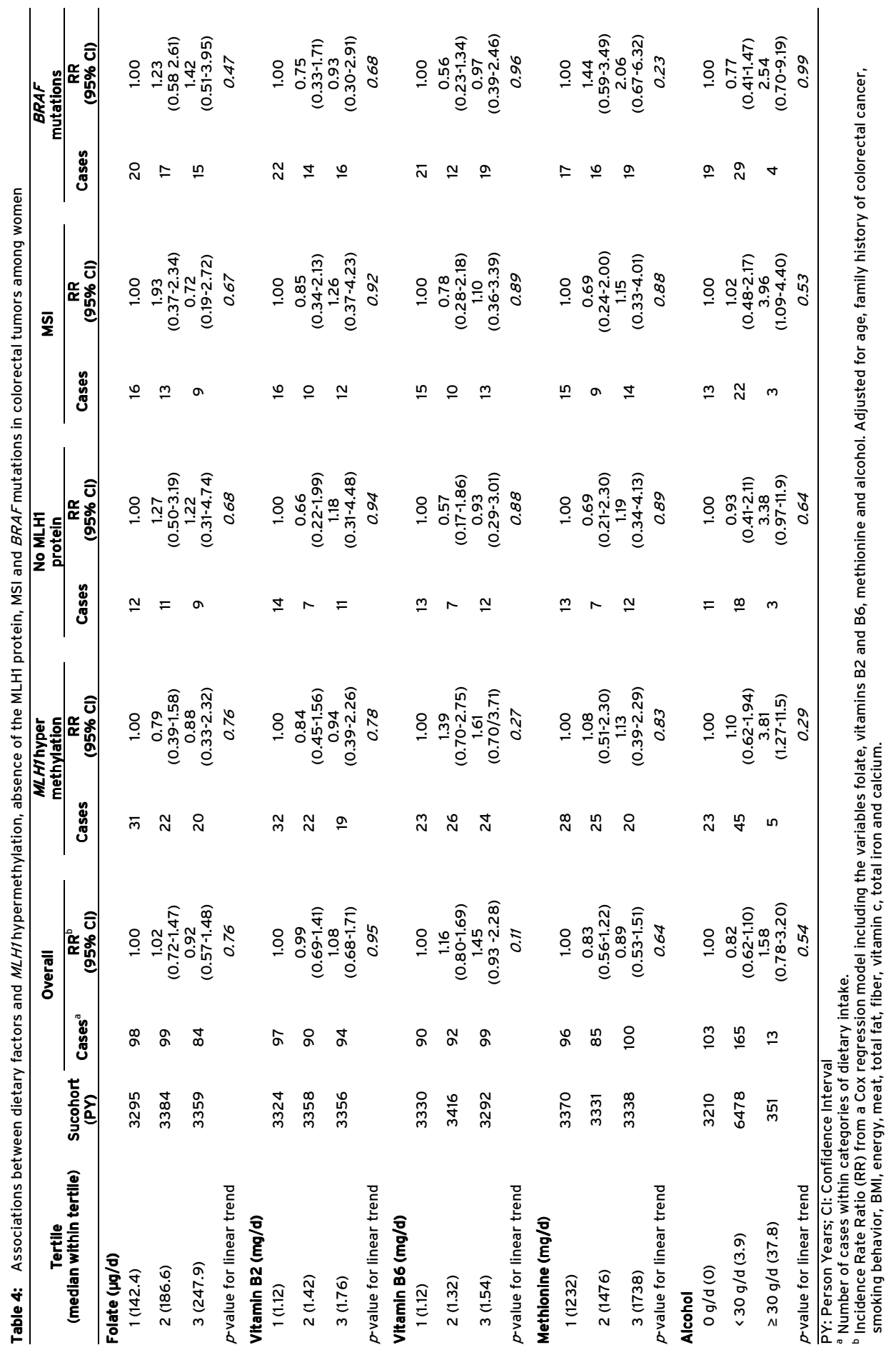


When performing overall analyses for men and women together (data not shown), we observed that, although borderline significant, the highest tertile of folate intake was associated with colorectal tumors harboring $B R A F$ mutations (RR: $1.85,95 \% \mathrm{Cl}$ : 0.92-3.73, $p$-trend=0.08). There clearly were positive associations between vitamin B6 intake and overall CRC (RR: 1.51, 95\% Cl: 1.11-2.04, $p$-trend=0.01) and risk of tumors with $M L H 1$ promoter methylation (RR: $2.32,95 \% \mathrm{Cl}: 1.21-4.43, p$-trend=0.01). The tests for heterogeneity did not show significant differences between tumors with or without $M L H 1$ hypermethylation, MLH1 protein expression, MSI or BRAF mutations (data not shown).

After testing potential interactions, it appeared that there was no interaction between folate and methionine, vitamin B2 or alcohol in either men or women. However, among men we observed an interaction between folate and vitamin B6 for overall CRC. In this respect, stratified analyses revealed that relatively high vitamin B6 intake was associated with an increased risk of overall CRC among men who had a folate intake in the category above the median (RR: 1.96, 95\% Cl: 1.06-3.60, $p$ trend=0.02 for the highest vs. lowest tertile of B6 intake, data not shown), whereas the RR was not increased among subjects with folate intake below the median of the distribution ( $p$-interaction=0.06). Similarly, men having tumors with $M L H 1$ hypermethylation also had higher RRs in the 3rd tertile of vitamin B6 intake in the subgroup of high folate intake (RR: $3.36,95 \% \mathrm{Cl}$ : $0.81-13.93, p$-trend=0.08, data not shown), which was not observed among men with low folate intake. However, the interaction term for this endpoint was not statistically significant. Among women, an interaction between vitamin B6 and folate was not observed, neither did we observe interactions between methionine and any of the other dietary variables under study.

\section{DISCUSSION}

In this study we investigated the associations between dietary folate, vitamins B2 and B6, methionine, alcohol and colorectal cancer risk while accounting for $M L H 1$ promoter methylation, MLH1 protein expression, MSI and $B R A F$ mutations. It was observed that the highest tertiles of folate, vitamins B2, B6 and methionine, and low alcohol intake were not associated with decreased colorectal cancer risk, irrespective of the presence of $M L H 1$ hypermethylation, the MLH1 protein or MSI. On 
the other hand, we observed a positive association between dietary folate and $B R A F$ mutations in men. Moreover, vitamin B6 increased overall CRC risk, and especially $M L H 1$-hypermethylated tumors among men.

We studied four different aberrations that have previously been suggested to be associated with the MSI pathway. Despite the strong and statistically significant correlations between these characteristics, they were not always concurrently present in tumors. Whereas the percentages of overlap between absence of MLH1 protein expression and $M L H 1$ methylation, and between MSI and $M L H 1$ methylation were relatively high $(74.6 \%$ and $65.8 \%$ respectively), less than half of the tumors with $B R A F$ mutations (47.5\%) appeared to have $M L H 1$ methylation. In this respect, it is appreciated that individual techniques were used for each endpoint, each having specific sensitivities, which may partly account for the observed incomplete overlap. However, an additional, even more obvious reason may lie in potential differences in tumor biology. For example, within the subset of sporadic CRCs showing MSI, there may be differences in the frequency of $M L H 1$ hypermethylation depending on the localization of the tumor. In this respect, $M L H 1$ hypermethylation was observed less frequently in distal sporadic CRCs with MSI compared to proximal MSI cancers, suggesting that an epigenetic pathway has played a smaller role in the development of distal MSI cancers [36]. Next to $M L H 1$ hypermethylation, $M L H 1$ mutations may result in loss of the MLH1 protein as well. Although such mutations are mainly observed in tumors of HNPCC patients with MSI [37], it has been suggested that they may also occur in sporadic colorectal carcinomas, and that MSI may be present concurrently [38].

The occurrence of $M L H 1$ hypermethylation, lack of MLH1 protein expression or BRAF mutations may apparently differ among tumors that develop through the MSI pathway. In addition to the observed incomplete overlap in our study, this is an important reason to study these molecular phenotypes separately in relation to methyl donor intake. From our results, it appeared that the endpoint of MSI is least related to the intake of the studied methyl donors, but that there rather may be an effect on methylation and mutations which are associated with MSI. Moreover, the relation between folate intake and $\mathrm{MSI}$ in colorectal cancer was previously investigated [18], but no association was observed in that particular study. 
Promoter hypermethylation and global hypomethylation are alternative types of aberrant methylation, and it has been suggested that both of these patterns may contribute separately to the process of colorectal carcinogenesis [39, 40]. Moreover, they may also specifically affect DNA stability, given the observed strong associations between promoter hypermethylation and $\mathrm{MSI}$ and between global hypomethylation and CIN in colorectal carcinomas [5, 41]. However, the relative contribution of methyl donor intake to either hypermethylation or hypomethylation is unknown. Promoter hypermethylation may occur in normal colorectal mucosa of patients with hyperplastic polyposis [42] or colorectal cancer [43], suggesting that dietary methyl donors may play a role in the prevention or initiation of neoplastic formation. Moreover, folic acid supplementation may decrease global hypomethylation in the normal-appearing colonic mucosa of patients with adenomas [44]. Furthermore, in a pilot study we previously observed an indication for an inverse association between relatively high folate intake in combination with low alcohol intake and promoter methylation in colorectal tumors [8]. However, this association was only weak, and the conclusion in this study was based on an outcome measure defined as hypermethylation of at least one out of six genes. Others observed positive associations between high alcohol consumption and risk of MSI-H tumors [17, 18, 20], indicating that disruption of the folate metabolism may lead to colorectal cancer, possibly partly through increasing promoter hypermethylation.

Although the above suggests a protective effect of adequate folate status or intake on aberrant methylation, it has been hypothesized that its actual influence may also differ depending on the stage of tumor development in colorectal carcinogenesis. Whereas folate deficiency might increase the risk of neoplastic transformation of normal tissue by inducing genomic hypomethylation, it may have an inhibitory effect on progression of neoplasms to cancer. Conversely, folate supplementation may prevent aberrant DNA methylation in normal tissue, but could promote established lesions by increasing promoter hypermethylation [45]. Results of a recent study suggest that folic acid and vitamin B12 supplementation in subjects with a history of colorectal adenoma may indeed increase promoter hypermethylation, although this association was statistically borderline significant [9].

One might also wonder whether intake of dietary folate has a similar effect as supplementation with folic acid. Interestingly, in a prospective case-control study it 
was recently observed that high plasma folate levels measured at baseline may increase CRC risk [46]. Our data revealed the strongest increased risk among patients in the highest tertile of vitamin B6 intake of tumors with $M L H 1$ hypermethylation, suggesting that vitamin B6 may have had a tumor-promoting effect by increasing promoter methylation. We also observed that the increased RRs in the highest tertiles of vitamin B6 of overall CRC and tumors harboring $M L H 1$ hypermethylation were present only among men who also had a relatively high folate intake. The latter association suggests that the transfer of methyl donors provided by folate may at least partly depend on the availability of vitamin B6 as a "modulating" factor, and that the combination of relatively high vitamin B6 and folate intake may increase promoter methylation and thereby enhance the development of tumors with a methylation-associated phenotype. Our results therefore contribute to the hypothesis that relatively high methyl donor intake potentially increases aberrant promoter hypermethylation rather than preventing it. Several other studies showed inverse associations between vitamin B6 intake and CRC risk. However, in these studies, the levels of vitamin B6 intake were generally higher, and the distributions sometimes even lie largely above the median intake of the highest tertile of the Dutch population included in our study [47-50]. This may have been a reason why we did not observe a protective effect of vitamin $B 6$. However, this difference may be due to other factors as well, since vitamin B6 was also associated with decreased CRC risk in a recent study in a Japanese population, in which intake of vitamin B6 was comparable to that in the study population of the NLCS [51]. There is one study that has previously demonstrated a positive association between vitamin B6 intake and CRC risk, among women who had a much higher vitamin B6 intake than in our study population [52]. Apparently, a potential positive association between vitamin $\mathrm{B} 6$ and colorectal cancer should be taken into account and obviously needs further attention in future studies.

Another remarkable finding in our study is the positive association between dietary folate and BRAF mutations among men, which was not expected considering the importance of folate for nucleotide synthesis. We have previously observed that folate may increase the risk of tumors harboring truncating $A P C$ mutations in men [19]. BRAF and $A P C$ mutations are inversely correlated in this study population, which was also the case in a previous study [53], indicating that relatively high folate intake may give a growth advantage to mutated tumors independent of the 
type of mutation. Moreover, folate was not associated with $M L H 1$ hypermethylation in men, suggesting that it exerts a specific effect on tumors with gene mutations.

To account for potential gender-specific differences in tumor etiology, we presented data for men and women individually. However, disadvantages of such stratified analyses are the resulting smaller numbers of patients in subgroups and, consequently, less precise estimations. Therefore, we also conducted analyses for men and women combined to reduce the potential danger of reporting chance findings. Interestingly, the positive associations of folate with $B R A F$ mutations, and of vitamin B6 with $M L H 1$ hypermethylation were then observed as well. Since similar, but not statistically significant increased RRs were present among women, and thus caution is warranted in drawing conclusions, this might indicate that folate and vitamin B6 had similar tumor promoting effects in both men and women.

In this Dutch population, relatively high intakes of folate, vitamins B2 and B6 and methionine, or low alcohol intake were not associated with a decreased risk of CRC, or with tumors harboring $M L H 1$ hypermethylation, lack of MLH1 protein expression or with MSI. The occurrence of MSI does not seem to be sensitive to methyl donor intake; however, folate increased the risk of BRAF mutations whereas vitamin $B 6$ increased the risk of tumors with $M L H 1$ hypermethylation among men. This may indicate that dietary folate and vitamin B6 have different effects, but may both enhance colorectal carcinogenesis by exerting an effect on genetic or epigenetic alterations. 


\section{REFERENCES}

1. Rajagopalan, H. and Lengauer, C. CIN-ful cancers. Cancer Chemother Pharmacol, 54 Suppl 1: S65-68, 2004.

2. Arnold, C. N., Goel, A., Compton, C., Marcus, V., Niedzwiecki, D., Dowell, J. M., et al. Evaluation of microsatellite instability, $h M L H 1$ expression and $h M L H 1$ promoter hypermethylation in defining the MSI phenotype of colorectal cancer. Cancer Biol Ther, 3: 73-78, 2004.

3. Herman, J. G., Umar, A., Polyak, K., Graff, J. R., Ahuja, N., Issa, J. P., et al. Incidence and functional consequences of $h M L H 1$ promoter hypermethylation in colorectal carcinoma. Proc Natl Acad Sci U S A, 95: 6870-6875, 1998.

4. Kuismanen, S. A., Holmberg, M. T., Salovaara, R., de la Chapelle, A., and Peltomaki, P. Genetic and epigenetic modification of $M L H 1$ accounts for a major share of microsatellite-unstable colorectal cancers. American Journal of Pathology, 156: 1773$1779,2000$.

5. Deng, G., Chen, A., Hong, J., Chae, H. S., and Kim, Y. S. Methylation of CpG in a small region of the $h M L H 1$ promoter invariably correlates with the absence of gene expression. Cancer Res, 59: 2029-2033, 1999.

6. Kim, Y. I. Folate and DNA methylation: a mechanistic link between folate deficiency and colorectal cancer? Cancer Epidemiol Biomarkers Prev, 13: 511-519, 2004.

7. Herman, J. G. and Baylin, S. B. Mechanisms of disease: Gene silencing in cancer in association with promoter hypermethylation. New England Journal of Medicine, 349: 2042-2054, 2003.

8. Van Engeland, M., Weijenberg, M. P., Roemen, G. M., Brink, M., de Bruine, A. P., Goldbohm, R. A., et al. Effects of dietary folate and alcohol intake on promoter methylation in sporadic colorectal cancer: the Netherlands cohort study on diet and cancer. Cancer Res, 63: 3133-3137, 2003.

9. Van den Donk, M., van Engeland, M., Pellis, L., Witteman, B. J., Kok, F. J., Keijer, J., et al. Dietary folate intake in combination with MTHFR C677T genotype and promoter methylation of tumor suppressor and DNA repair genes in sporadic colorectal adenomas. Cancer Epidemiol Biomarkers Prev, 16: 327-333, 2007.

10. Ulrich, C. M. Nutrigenetics in cancer research--folate metabolism and colorectal cancer. J Nutr, 135: 2698-2702, 2005.

11. Rimm, E. B. and Moats, C. Alcohol and coronary heart disease: Drinking patterns and mediators of effect. Annals of Epidemiology, 17: S3-S7, 2007.

12. Oyama, K., Kawakami, K., Maeda, K., Ishiguro, K., and Watanabe, G. The association between methylenetetrahydrofolate reductase polymorphism and promoter methylation in proximal colon cancer. Anticancer Res, 24: 649-654, 2004. 
13. Tjonneland, A., Christensen, J., Olsen, A., Stripp, C., Thomsen, B. L., Overvad, K., et al. Alcohol intake and breast cancer risk: the European Prospective Investigation into Cancer and Nutrition (EPIC). Cancer Causes \& Control, 18: 361-373, 2007.

14. Hubner, R. A., Lubbe, S., Chandler, I., and Houlston, R. S. MTHFR C677T has differential influence on risk of MSI and MSS colorectal cancer. Hum Mol Genet, 2007.

15. Giovannucci, E. Alcohol, one-carbon metabolism, and colorectal cancer: recent insights from molecular studies. J Nutr, 134: 2475S-2481S, 2004.

16. Mason, J. B. and Choi, S. W. Effects of alcohol on folate metabolism: implications for carcinogenesis. Alcohol, 35: 235-241, 2005.

17. Diergaarde, B., Braam, H., van Muijen, G. N., Ligtenberg, M. J., Kok, F. J., and Kampman, E. Dietary factors and microsatellite instability in sporadic colon carcinomas. Cancer Epidemiol Biomarkers Prev, 12: 1130-1136, 2003.

18. Slattery, M. L., Anderson, K., Curtin, K., Ma, K. N., Schaffer, D., and Samowitz, W. Dietary intake and microsatellite instability in colon tumors. Int $J$ Cancer, 93: 601-607, 2001.

19. De Vogel, S., van Engeland, M., Lüchtenborg, M., de Bruine, A. P., Roemen, G. M., Lentjes, M. H., et al. Dietary folate and $A P C$ mutations in sporadic colorectal cancer. J Nutr, 136: 3015-3021, 2006.

20. Slattery, M. L., Curtin, K., Sweeney, C., Levin, T. R., Potter, J., Wolff, R. K., et al. Diet and lifestyle factor associations with $\mathrm{CpG}$ island methylator phenotype and $B R A F$ mutations in colon cancer. Int J Cancer, 120: 656-663, 2007.

21. Van den Brandt, P. A., Goldbohm, R. A., van 't Veer, P., Volovics, A., Hermus, R. J., and Sturmans, F. A large-scale prospective cohort study on diet and cancer in The Netherlands. J Clin Epidemiol, 43: 285-295, 1990.

22. Casparie, M., Tiebosch, A. T., Burger, G., Blauwgeers, H., van de Pol, A., van Krieken, J. $\mathrm{H}$., et al. Pathology databanking and biobanking in The Netherlands, a central role for PALGA, the nationwide histopathology and cytopathology data network and archive. Cell Oncol, 29: 19-24, 2007.

23. Brink, M., de Goeij, A. F., Weijenberg, M. P., Roemen, G. M., Lentjes, M. H., Pachen, M. M., et al. K-ras oncogene mutations in sporadic colorectal cancer in The Netherlands Cohort Study. Carcinogenesis, 24: 703-710, 2003.

24. Herman, J. G., Graff, J. R., Myohanen, S., Nelkin, B. D., and Baylin, S. B. Methylationspecific PCR: a novel PCR assay for methylation status of CpG islands. Proc Natl Acad Sci U S A, 93: 9821-9826, 1996.

25. Derks, S., Lentjes, M. H., Hellebrekers, D. M., de Bruine, A. P., Herman, J. G., and van Engeland, M. Methylation-specific PCR unraveled. Cell Oncol, 26: 291-299, 2004.

26. Suraweera, N., Duval, A., Reperant, M., Vaury, C., Furlan, D., Leroy, K., et al. Evaluation of tumor microsatellite instability using five quasimonomorphic mononucleotide repeats and pentaplex PCR. Gastroenterology, 123: 1804-1811, 2002. 
27. Sieben, N. L., Roemen, G. M., Oosting, J., Fleuren, G. J., van Engeland, M., and Prat, J. Clonal analysis favours a monoclonal origin for serous borderline tumours with peritoneal implants. J Pathol, 210: 405-411, 2006.

28. Nevo table Dutch food composition table 1986-1987. 1986.

29. Goldbohm, R. A., van den Brandt, P. A., Brants, H. A., van't Veer, P., Al, M., Sturmans, F., et al. Validation of a dietary questionnaire used in a large-scale prospective cohort study on diet and cancer. Eur J Clin Nutr, 48: 253-265, 1994.

30. Konings, E. J. A validated liquid chromatographic method for determining folates in vegetables, milk powder, liver, and flour. J AOAC Int, 82: 119-127, 1999.

31. Konings, E. J., Roomans, H. H., Dorant, E., Goldbohm, R. A., Saris, W. H., and van den Brandt, P. A. Folate intake of the Dutch population according to newly established liquid chromatography data for foods. Am J Clin Nutr, 73: 765-776, 2001.

32. Lin DY, W. L. The robust inference for the Cox Proportional Hazards Model. JASA, 84: 1074-1078, 1989.

33. Schoenfeld, D. Partial residuals for the proportional hazards regression model. Biometrika, 69: 239-241, 1982.

34. Willett, W. and Stampfer, M. J. Total energy intake: implications for epidemiologic analyses. Am J Epidemiol, 124: 17-27, 1986.

35. Wacholder, S., Gail, M., Pee, D., and Brookmeyer, R. Alternative variance and efficiency calculations for the case-cohort design. Biometrika, 76: 117-123, 1989.

36. Watanabe, T., Kobunai, T., Toda, E., Yamamoto, Y., Kanazawa, T., Kazama, Y., et al. Distal colorectal cancers with microsatellite instability (MSI) display distinct gene expression profiles that are different from proximal MSI cancers. Cancer Res, 66: 9804-9808, 2006.

37. Peltomaki, P. and Vasen, H. Mutations associated with HNPCC predisposition -- Update of ICG-HNPCC/INSiGHT mutation database. Dis Markers, 20: 269-276, 2004.

38. Chaksangchaichot, P., Punyarit, P., and Petmitr, S. Novel hMSH2, hMSH6 and $h M L H 1$ gene mutations and microsatellite instability in sporadic colorectal cancer. J Cancer Res Clin Oncol, 133: 65-70, 2007.

39. Bariol, C., Suter, C., Cheong, K., Ku, S. L., Meagher, A., Hawkins, N., et al. The relationship between hypomethylation and $\mathrm{CpG}$ island methylation in colorectal neoplasia. American Journal of Pathology, 162: 1361-1371, 2003.

40. Frigola, J., Sole, X., Paz, M. F., Moreno, V., Esteller, M., Capella, G., et al. Differential DNA hypermethylation and hypomethylation signatures in colorectal cancer. Human Molecular Genetics, 14: 319-326, 2005.

41. Rodriguez, J., Frigola, J., Vendrell, E., Risques, R. A., Fraga, M. F., Morales, C., et al. Chromosomal Instability Correlates with Genome-wide DNA Demethylation in Human Primary Colorectal Cancers. Cancer Res, 66: 8462-9468, 2006. 
42. Minoo, P., Baker, K., Goswami, R., Chong, G., Foulkes, W. D., Ruszkiewicz, A. R., et al. Extensive DNA methylation in normal colorectal mucosa in hyperplastic polyposis. Gut, 55: 1467-1474, 2006.

43. Kawakami, K., Ruszkiewicz, A., Bennett, G., Moore, J., Grieu, F., Watanabe, G., et al. DNA hypermethylation in the normal colonic mucosa of patients with colorectal cancer. $\mathrm{Br} \mathrm{J}$ Cancer, 94: 593-598, 2006.

44. Pufulete, M., Emery, P. W., and Sanders, T. A. B. Folate, DNA methylation and colorectal cancer. Proceedings of the Nutrition Society, 62: 437-445, 2003.

45. Kim, Y. I. Folate and colorectal cancer: An evidence-based critical review. Mol Nutr Food Res, 51: 267-292, 2007.

46. Pischon, T., Lahmann, P. H., Boeing, H., Friedenreich, C., Norat, T., Tjonneland, A., et al. Body size and risk of colon and rectal cancer in the European prospective investigation into cancer and nutrition (EPIC). Journal of the National Cancer Institute, 98: 920-931, 2006.

47. Kune, G. and Watson, L. Colorectal cancer protective effects and the dietary micronutrients folate, methionine, vitamins B6, B12, C, E, selenium, and lycopene. Nutr Cancer, 56: 11-21, 2006.

48. Larsson, S. C., Giovannucci, E., and Wolk, A. Vitamin B-6 intake, alcohol consumption, and colorectal cancer: A longitudinal population-based cohort of women. Gastroenterology, 128: 1830-1837, 2005.

49. Wei, E. K., Giovannucci, E., Selhub, J., Fuchs, C. S., Hankinson, S. E., and Ma, J. Plasma vitamin B6 and the risk of colorectal cancer and adenoma in women. J Natl Cancer Inst, 97: 684-692, 2005.

50. Terry, M. B., Gammon, M. D., Zhang, F. F., Knight, J. A., Wang, Q., Britton, J. A., et al. ADH3 genotype, alcohol intake and breast cancer risk. Carcinogenesis, 27: 840-847, 2006.

51. Otani, T., Iwasaki, M., Hanaoka, T., Kobayashi, M., Ishihara, J., Natsukawa, S., et al. Folate, vitamin B6, vitamin B12, and vitamin B2 intake, genetic polymorphisms of related enzymes, and risk of colorectal cancer in a hospital-based case-control study in Japan. Nutr Cancer, 53: 42-50, 2005.

52. Harnack, L., Jacobs, D. R., Nicodemus, K., Lazovich, D., Anderson, K., and Folsom, A. R. Relationship of folate, vitamin B-6, vitamin B-12, and methionine intake to incidence of colorectal cancers. Nutrition and Cancer-an International Journal, 43: 152-158, 2002.

53. Samowitz, W. S., Slattery, M. L., Sweeney, C., Herrick, J., Wolff, R. K., and Albertsen, H. $A P C$ mutations and other genetic and epigenetic changes in colon cancer. Mol Cancer Res, 5: 165-170, 2007. 



\section{Alcohol and the risk of colon and rectal cancer with mutations in the KRAS gene}

Brenda W.C. Bongaerts Anton F.P.M. de Goeij Piet A. van den Brandt Matty P. Weijenberg 


\section{ABSTRACT}

The first metabolite of alcohol, acetaldehyde, may trigger replication errors and mutations in DNA which may predispose to developing colorectal cancer (CRC). In a prospective study on colon and rectal cancer, we investigated the following hypotheses: alcohol consumption is associated with an increased risk of mutations in the KRAS oncogene, and beer consumption is associated with an increased risk of G>A mutations in this gene. Therefore, we studied the associations between consumption of alcohol and alcoholic beverages and the risk of CRC without or with specific KRAS gene mutations.

In 1986, 120,852 men and women, aged 55-69 years, completed a questionnaire on risk factors for cancer. The case-cohort approach was used for data processing and analyses. After 7.3 years of follow-up, excluding the first 2.3 years, complete data from 4,076 subcohort members, 428 colon and 150 rectal cancer patients, were available for data analyses. Incidence rate ratios (RR) and corresponding 95\% confidence intervals $(\mathrm{Cl})$ were estimated using Cox proportional hazards models.

Compared to abstaining, a total alcohol consumption of $30.0 \mathrm{~g} / \mathrm{d}$ and more was associated with the risk of colon and rectal cancer with and without a KRAS mutation in both men and women. Independent from alcohol intake, liquor consumption when compared to no-liquor consumption, was associated with an increased risk of rectal cancer with a wild type KRAS in men (RR: 2.25, 95\% Cl: 1.05.0). Beer consumption was not clearly associated with the risk of colon and rectal tumors harboring G>A mutations in the KRAS gene in men. This association could not be assessed in women because of sparse beer consumption.

In conclusion, alcohol does not seem to be involved in predisposing to CRC through mutations in the KRAS gene, and specifically beer consumption is not associated with colon and rectal tumors harboring a $\mathrm{G}>\mathrm{A}$ mutation. 


\section{INTRODUCTION}

Consumption of alcohol is well known to be associated with several malignant and non-malignant diseases. Although alcohol itself is not carcinogenic, there is increasing evidence that acetaldehyde, a cytotoxic, mutagenic and carcinogenic metabolite of alcohol, rather than alcohol itself, is responsible for tumor enhancing effects [1, 2]. Acetaldehyde can bind to cellular proteins and DNA, and the additional formation of stable DNA-adducts could trigger replication errors and mutations in tumor suppressor genes or oncogenes. Acetaldehyde may also interfere with DNArepair by inhibiting enzymes important to the repair of adducts caused by alkylating agents [1-3]. Regarding these mechanisms, it is plausible to consider alcohol consumption as a possible risk factor for developing colorectal cancer (CRC).

Development of CRC is a multistep process, characterized by an accumulation of several genetic alterations driving normal colorectal mucosa to transform into highly malignant derivatives $[4,5]$. An early event in colorectal tumorigenesis is often an activating mutation in the KRAS oncogene. KRAS mutations occur in 30-60 $\%$ of colorectal carcinomas and are involved in the progression of small adenomas to the more clinically relevant larger adenomas. Therefore, KRAS mutations may be an important contributor CRC development. Most KRAS mutations are G>A transitions and G>T transversions $[4,6]$. Several studies have shown that patients with these types of KRAS point mutations have a poor prognosis and a high risk of recurrence of the disease [7-9]. Knowledge of the etiology of KRAS mutations arising in colorectal tumors may provide valuable clues for prevention strategies.

The association between alcohol consumption and CRC was long debated, and according to a recently published pooled analysis of eight prospective cohort studies, CRC risk is only increased when daily alcohol consumption levels exceed 30.0 grams [10]. This suggests that there may be a threshold in alcohol consumption above which the risk of CRC is increased. The role of different types of alcoholic beverages on the risk of CRC is less clear, although beer consumption has more consistently been implicated in the etiology of rectal cancer. In the past, beer in the Netherlands as well as in other European countries was contaminated with relatively large amounts of $\mathrm{N}$-nitrosodimethylamine (NDMA) (mean $1.2 \mu \mathrm{g} / \mathrm{kg}$ ) [11]; [12]. As such, beer drinking accounted for $90 \%$ of the NDMA intake in beer drinkers, whose total NDMA intake was as much as 10 times higher than that of non-beer drinkers. 
Jacoby et al. [13] have shown that nitrosamines have mutagenic properties and are able to induce mutations, especially $G>A$ transitions in the KRAS gene in rodents. However, since 1979, changes in the beer brewing process have greatly decreased the NDMA contaminations in beers [14]. Yet it is likely that the adverse effects of NDMA still influences the risk of (rectal) cancer for up to 10 years later, and that this declines in the years thereafter.

Taking into account the mutagenic and carcinogenic potentials of acetaldehyde mentioned above, we hypothesized that alcohol consumption is associated with an increased risk of mutations in the KRAS oncogene involved in CRC. Hence, we examined the associations between consumption of alcohol and various alcoholic beverages and the risk of colon and rectal cancer with and without KRAS gene mutations. In a second hypothesis we stated that beer consumption is associated with $\mathrm{G}>\mathrm{A}$ mutations in the KRAS gene involved in CRC. To answer this hypothesis we examined the associations between beer consumption and this specific type of KRAS mutation among the colon and rectal cancer cases in our study population.

\section{MATERIALS AND METHODS}

\section{Study population}

In September 1986, the Netherlands Cohort Study on diet and cancer (NLCS) was initiated. The study design has been described in detail elsewhere [15]. Briefly, the cohort included 58,279 men and 62,573 women, aged 55-69 years at baseline and originating from 204 municipal population registries throughout the country. All cohort members completed an extensive self-administered questionnaire on daily dietary habits during the year preceding the start of the study, life style factors and other risk factors for cancer. Newly diagnosed cancer cases in the entire cohort were identified through annual record linkage to The Netherlands Cancer Registry (NCR, comprising nine cancer registries in the Netherlands) and to PALGA, a nationwide database of histo- and cytopathology reports, used for identification and location of tumor tissue from eligible colorectal cancer cases stored in 54 Dutch Pathology laboratories. 
The present analyses were carried out over the 7.3-year period of follow-up since September 1986. The first 2.3 years of follow- up were excluded, due to incomplete coverage of PALGA in some of the municipalities included and since subclinical symptoms may have influenced the exposure status in cases diagnosed during these 2.3 years. Using updated information from the NCR in 2004, 925 cases with histologically confirmed CRC were identified with an incidence date between January 1989 and January 1994, of who 815 could be linked to a PALGA report of the lesion. CRC was classified according to site as follows: colon: cecum through sigmoid colon (ICD-O codes 153.0, 153.1, 153.2, 153.3, 153.4, 153.5, 153.6, 153.7, $153.8,153.9)$; rectosigmoid colon (ICD-O codes 154.0) and rectum (ICD-O code 154.1).

Processing and analysis of data were done according to the case-cohort approach: cases were identified for the entire cohort, while a random sample of the cohort (subcohort) was used to estimate person years at risk accumulating in the cohort (from the date of entry into the cohort until the date of a colorectal cancer diagnosis, death from any cause, leaving the study area or the end of the 7.3 year follow-up period). This subcohort of 5,000 men and women was followed-up biennially to assess information on vital status and migration in order to calculate accumulated person time in the cohort. Prevalent cancer cases, other than nonmelanoma skin cancer were excluded from the subcohort, resulting in 4,748 subcohort members. During the first 2.3 years of follow-up, $101(2 \%)$ subcohort members deceased or were diagnosed with cancer other than non-melanoma skin cancer, leaving 4,647 subcohort members for analysis.

\section{Assessment of exposure}

Information on daily dietary habits was obtained by a 150 -item semi-quantitative food frequency questionnaire. Alcohol consumption was measured by six items: (a) beer, (b) red wine, (c) white wine, (d) sherry and other fortified wines, (e) liqueur (containing 16\% alcohol) and (f) (Dutch) gin, brandy and whiskey, which are presumed to cover all types of consumed alcoholic beverages. Participants were asked about their usual frequency of consumption (never/less than once per month, once per month, 2-3 times per month, once per week, 2-3 times per week, 4-5 times per week, 6-7 times per week) and the number of glasses consumed at each drinking occasion. The total amount of alcohol per day $(\mathrm{g} / \mathrm{d}$ ) was calculated by using the 
reported frequency of consumption, the quantity consumed and the alcohol content of the consumed beverage.

The questionnaire has been validated against a 9-day diet record [16]. The Spearman correlation coefficient between mean daily alcohol intake assessed by the questionnaire and estimated from the 9-day diet record was 0.89 for all subjects and 0.85 for users of alcoholic beverages. The absolute amount of alcohol reported in the questionnaire by users of alcoholic beverages was, on average, $86 \%$ of that reported in the 9-day diet record.

Next to the dietary section, the questionnaire comprised a section on lifestyle and other risk factors for cancer. Information on for instance family history of CRC, sex, age at baseline, smoking and body mass index (BMI) were retrieved from this section.

\section{Tissue samples and molecular analyses}

Tumor material of colorectal cancer cases, identified in the entire cohort, was collected after approval of the Ethical Review Boards of University Maastricht, the NCR and PALGA. From 44 (5\%) of the eligible 815 colorectal cancer cases, tissue samples could not be retrieved. Of the retrieved 771 tissue samples, $37(5 \%)$ contained only healthy colorectal mucosa, did not yield sufficient DNA for molecular analyses or were revised as a benign adenoma instead of a carcinoma by a pathologist. Hence, tumor tissue of 734 colorectal cancer cases was available for molecular analyses.

Mutation analysis of the exon 1 fragment of the KRAS oncogene, spanning codons 829, was performed on archived adenocarcinoma specimens of all 734 colorectal cancer patients [6].

\section{Data analyses}

Data analyses were based on subcohort members and cases for whom information on alcohol consumption and confounding variables were complete, i.e. 4,076 subcohort members, 428 colon cancer cases and 150 rectal cancer cases. Since the rectosigmoid can be considered as a clinically applied term rather than an 
anatomically defined transitional zone between the colon and the rectum, cases with a rectosigmoid tumor $(n=70)$ were excluded from data analyses. Moreover, the group of cases with a rectosigmoid tumor was too small for adequate stratified analyses. Incidence rate ratios (RR) and corresponding $95 \%$ confidence intervals (CI) were estimated using Cox proportional hazards models. The proportional hazards assumption was tested using the scaled Schoenfeld residuals [17]. Standard errors were estimated using the robust Huber-White sandwich estimator to account for additional variance introduced by sampling from the cohort.

Next to considering total amount of alcohol consumption, we examined three types of alcoholic beverages, i.e. beer, wine (red wine, white wine, sherry and other fortified wines), and liquor (liqueur, gin, brandy and whiskey). An extensive categorization of the alcohol variables was not possible due to small numbers of cases per category. Only total alcohol consumption was divided into three categories: $0,<30.0$ and $\geq 30.0 \mathrm{~g} / \mathrm{d}$. The threshold value of $30.0 \mathrm{~g} / \mathrm{d}$ was chosen in line with the results of the pooled analysis by Cho et al. [10]. Data analysis was conducted separately for male and female colon and rectal cancer with and without a KRAS mutation, described here as KRAS+ (tumors harboring a KRAS mutation) and KRAS- (tumors harboring a wild type KRAS gene). However, since several cells comprised less than ten cancer cases and some reference groups comprised relatively small numbers of cases, analyses were also conducted for all male plus female colorectal cancer cases with and without a KRAS mutation. In the overall analyses only, the rectosigmoid cancer cases were included. In the light of our second hypothesis, tumors with a KRAS mutation were further examined for associations between beer consumption and the risk of colon and rectal cancer harboring a G>A mutation in the KRAS gene.

Age at baseline (years), BMI $\left(\mathrm{kg} / \mathrm{m}^{2}\right)$, family history of CRC (yes versus no), daily intake of total energy $(\mathrm{kJ} / \mathrm{d})$, daily folate intake $(\mu \mathrm{g} / \mathrm{d})$, daily intake of linoleic acid ( $\mathrm{g} / \mathrm{d})$ and calcium (mg/d), physical activity (min/d) and smoking (never, ex, current) were considered as potential confounders. Those variables that changed the regression coefficient for alcohol by more than $10 \%$, or those that were found to statistically significantly contribute to the multivariable model for colon and rectal cancer were included in the analyses. Analyses for beer, wine and liquor were additionally adjusted for total alcohol consumption (as a categorical variable), to evaluate the effect of the beverage on the risk of colon and rectal cancer 
independent of the beverages' alcoholic content. Interactions between sex and alcohol consumption were investigated as well as interactions between smoking and alcohol, and folate intake and alcohol, but none of the tested interactions were found to be statistically significant. P-values $<0.05$ were considered statistically significant. All analyses were performed with the STATA statistical software package.

\section{RESULTS}

Alcohol intake and baseline characteristics of the study population are presented in table 1. Overall, both male and female colon and rectal cancer patients tended to be older than subcohort members. For female colon cancer cases, cases with a KRAS+ tumor were older than cases with a KRAS- tumor ( $p<0.05)$. Furthermore, for both men and women, there were no significant differences in alcohol consumption or lifestyle characteristics when comparing the KRAS- colon tumors with the KRAS+ colon tumors or when comparing the KRAS- rectal tumors with the KRAS+ rectal tumors.

Associations between drinking habits in men and the risk of KRAS- and KRAS+ colon and rectal tumors are presented in table 2. Consumption equal to or exceeding 30.0 grams of alcohol per day, compared to abstaining was associated with an increased risk of colon cancer with and without a KRAS mutation, although none of these results reached statistical significance. For rectal cancer, both with and without KRAS mutations, the reference group as well as the group of cases who consumed $30.0 \mathrm{~g}$ of alcohol per day or more was very small, making it difficult to interpret the results correctly. Most of the associations with the different beverage types adjusted for total alcohol consumption were not consistent, suggesting that in general no clear associations with KRAS- and KRAS+ colon and rectal tumors existed. Compared to non-liquor consumers, liquor consumption was associated with an increased risk of a KRAS- rectal tumor, independent of the consumed alcohol (RR: 2.25, 95\% Cl: 1.0-5.0). 


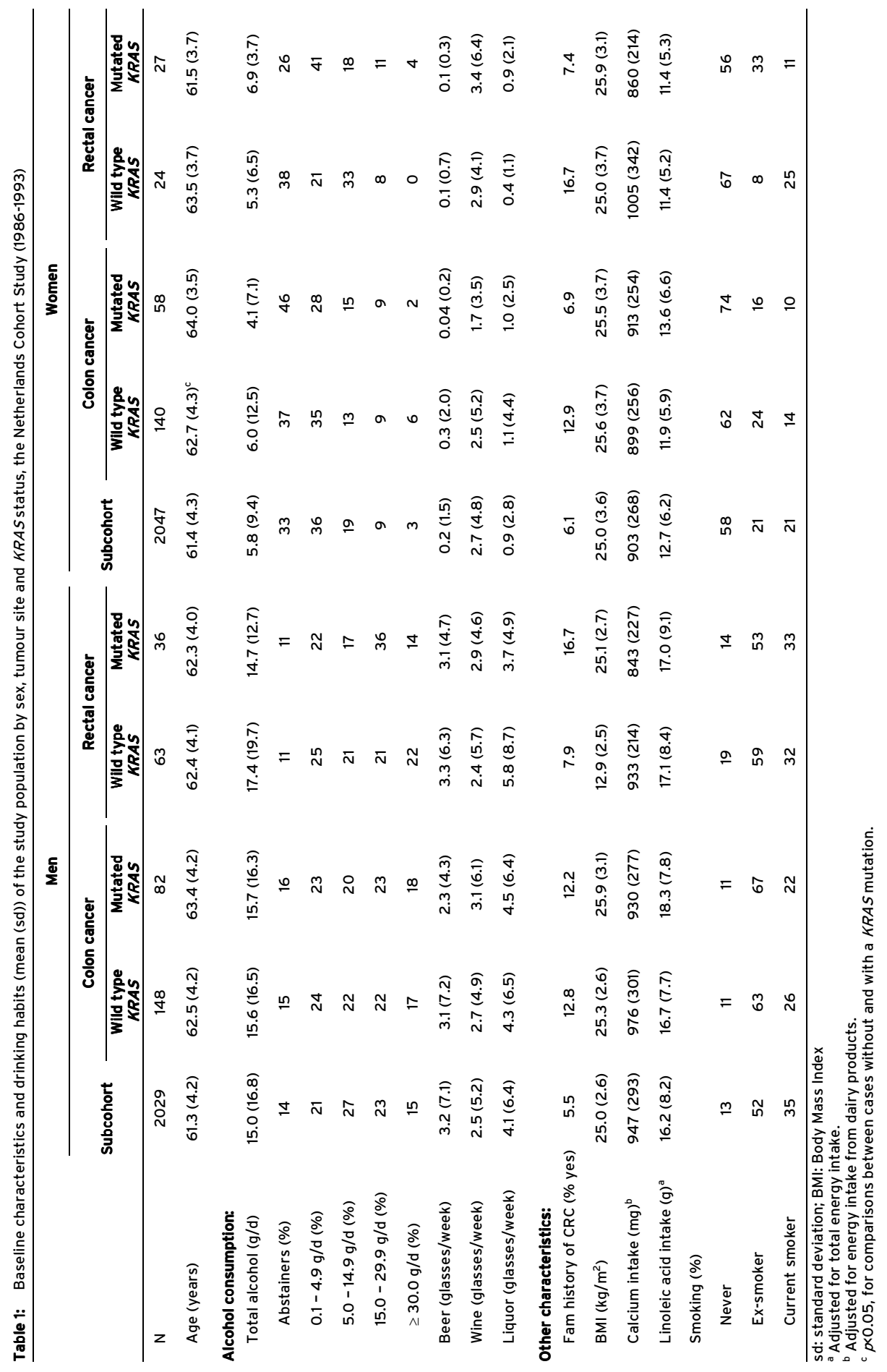


Table 2: Incidence rate ratios ${ }^{\mathrm{a}}$ for male colon and rectal cancer cases with a wild type or a mutated $K R A S$ gene according to drinking habits, adjusted for confounders, the Netherlands Cohort Study (1986-1993)

\begin{tabular}{|c|c|c|c|c|c|c|c|c|c|}
\hline \multirow{3}{*}{$\begin{array}{c}\text { Drinking } \\
\text { habits }\end{array}$} & \multirow{3}{*}{$\begin{array}{c}\text { Subcohort } \\
\text { (PY) }\end{array}$} & \multicolumn{4}{|c|}{ Colon cancer } & \multicolumn{4}{|c|}{ Rectal cancer } \\
\hline & & \multicolumn{2}{|c|}{ Wild type KRAS } & \multicolumn{2}{|c|}{ Mutated KRAS } & \multicolumn{2}{|c|}{ Wild type $K R A S$} & \multicolumn{2}{|c|}{ Mutated KRAS } \\
\hline & & Cases & $\begin{array}{c}\text { RR } \\
(95 \% \mathrm{Cl})\end{array}$ & Cases & $\begin{array}{c}\text { RR } \\
(95 \% \mathrm{Cl})\end{array}$ & Cases & $\begin{array}{c}\text { RR } \\
(95 \% \mathrm{Cl})\end{array}$ & Cases & $\begin{array}{c}\text { RR } \\
(95 \% \mathrm{Cl})\end{array}$ \\
\hline \multicolumn{10}{|c|}{ Total alcohol (g/d) } \\
\hline No alcohol & 2035 & 22 & 1.00 & 13 & 1.00 & 7 & 1.00 & 4 & 1.00 \\
\hline$<30.0$ & 10190 & 100 & $\begin{array}{c}0.95 \\
(0.6-1.6)\end{array}$ & 54 & $\begin{array}{c}0.84 \\
(0.4-1.6)\end{array}$ & 42 & $\begin{array}{c}1.23 \\
(0.5-2.8)\end{array}$ & 27 & $\begin{array}{c}1.30 \\
(0.4-4.0)\end{array}$ \\
\hline$\geq 30.0$ & 2121 & 26 & $\begin{array}{c}1.24 \\
(0.7-2.3)\end{array}$ & 15 & $\begin{array}{c}1.15 \\
(0.5-2.6)\end{array}$ & 14 & $\begin{array}{c}2.00 \\
(0.8-5.3)\end{array}$ & 5 & $\begin{array}{c}0.98 \\
(0.2-4.0)\end{array}$ \\
\hline
\end{tabular}

Beer $^{\mathrm{b}}$

$\begin{array}{lccccccccc}\text { No beer } & 6082 & 69 & 1.00 & 40 & 1.00 & 30 & 1.00 & 14 & 1.00 \\ \text { Beer drinker } & 8264 & 79 & 0.84 & & 0.78 & & 0.68 & 22 & 1.09 \\ & & & & (0.6-1.2) & 42 & (0.5-1.3) & 33 & (0.4-1.2) & \end{array}$

Wine $^{\text {b }}$

$\begin{array}{lccccccccc}\text { No wine } & 7094 & 69 & 1.00 & 43 & 1.00 & 32 & 1.00 & 18 & 1.00 \\ \text { Wine drinker } & 7252 & 79 & 1.11 & & 0.85 & & 0.79 & 18 & 0.92 \\ & & & (0.7-1.7) & 39 & (0.5-1.4) & 31 & (0.4-1.4) & \end{array}$

Liquor $^{\mathrm{b}}$

$\begin{array}{lccccccccc}\text { No liquor } & 5234 & 51 & 1.00 & 29 & 1.00 & 14 & 1.00 & 11 & 1.00 \\ \text { Liquor drinker } & 9112 & 97 & 1.08 & & 0.97 & & 2.25 & 25 & 1.15 \\ & & & (0.7-1.7) & 53 & (0.5-1.7) & 49 & (1.0-5.0) & & (0.5-2.7)\end{array}$

PY: Person Years; RR: Incidence Risk Ratio; Cl: Confidence Interval

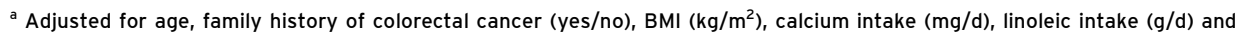
smoking (never/ex/current).

${ }^{\mathrm{b}}$ Additionally adjusted for total alcohol consumption $(0,<30.0, \geq 30.0 \mathrm{~g} / \mathrm{d})$.

Table 3 shows the associations between drinking habits in women and the risk of KRAS- and KRAS+ colon and rectal tumors. When compared to abstaining, consumption of $30 \mathrm{~g}$ of alcohol per day and more was positively associated with KRAS+ colon tumors. The KRAS+ colon cancer subgroup and both rectal cancer subgroups comprised too few cases to adequately interpret the results for total alcohol consumption. The results for the different beverage types independent of alcohol content, suggested that there were no clear associations with the risk of colon and rectal cancer with and without a KRAS mutation. 
Table 3: Incidence rate ratios ${ }^{a}$ for female colon and rectal cancer cases with a wild type or a mutated KRAS gene according to drinking habits, adjusted for confounders, the Netherlands Cohort Study (1986-1993)

\begin{tabular}{|c|c|c|c|c|c|c|c|c|c|}
\hline \multirow[b]{3}{*}{ Drinking habits } & \multirow{3}{*}{$\begin{array}{c}\text { Subcohort } \\
\text { (PY) }\end{array}$} & \multicolumn{4}{|c|}{ Colon cancer } & \multicolumn{4}{|c|}{ Rectal cancer } \\
\hline & & \multicolumn{2}{|c|}{ Wild type KRAS } & \multicolumn{2}{|c|}{ Mutated KRAS } & \multicolumn{2}{|c|}{ Wild type KRAS } & \multicolumn{2}{|c|}{ Mutated KRAS } \\
\hline & & Cases & $\begin{array}{c}\text { RR } \\
(95 \% \mathrm{Cl})\end{array}$ & Cases & $\begin{array}{c}\text { RR } \\
(95 \% \mathrm{Cl})\end{array}$ & Cases & $\begin{array}{c}\text { RR } \\
(95 \% \mathrm{Cl})\end{array}$ & Cases & $\begin{array}{c}\text { RR } \\
(95 \% \mathrm{Cl})\end{array}$ \\
\hline \multicolumn{10}{|l|}{ Total alcohol (g/d) } \\
\hline No alcohol & 4727 & 52 & 1.00 & 27 & 1.00 & 9 & 1.00 & 7 & 1.00 \\
\hline$<30.0$ & 9467 & 80 & $\begin{array}{c}0.78 \\
(0.5-1.1)\end{array}$ & 30 & $\begin{array}{c}0.62 \\
(0.4-1.1)\end{array}$ & 15 & $\begin{array}{c}0.98 \\
(0.4-2.2)\end{array}$ & 19 & $\begin{array}{c}1.28 \\
(0.5-3.2)\end{array}$ \\
\hline$\geq 30.0$ & 503 & 8 & $\begin{array}{c}1.83 \\
(0.8-4.1)\end{array}$ & 1 & $\begin{array}{c}0.65 \\
(0.1-5.5)\end{array}$ & 0 & - & 1 & $\begin{array}{c}1.25 \\
(0.1-11.7)\end{array}$ \\
\hline \multicolumn{10}{|l|}{ Beer $^{b}$} \\
\hline No beer & 13239 & 129 & 1.00 & 55 & 1.00 & 22 & 1.00 & 24 & 1.00 \\
\hline Beer drinker & 1458 & 11 & $\begin{array}{c}0.74 \\
(0.4-1.5)\end{array}$ & 3 & $\begin{array}{c}0.80 \\
(0.2-2.8)\end{array}$ & 2 & $\begin{array}{c}1.22 \\
(0.3-6.0)\end{array}$ & 3 & $\begin{array}{c}0.88 \\
(0.2-3.4)\end{array}$ \\
\hline \multicolumn{10}{|l|}{ Wine $^{b}$} \\
\hline No wine & 6507 & 71 & 1.00 & 33 & 1.00 & 10 & 1.00 & 11 & 1.00 \\
\hline Wine drinker & 8190 & 69 & $\begin{array}{c}0.79 \\
(0.5-1.3)\end{array}$ & 25 & $\begin{array}{c}1.05 \\
(0.4-2.6)\end{array}$ & 14 & $\begin{array}{c}3.80 \\
(0.5-30.0)\end{array}$ & 16 & $\begin{array}{c}0.88 \\
(0.3-2.8)\end{array}$ \\
\hline \multicolumn{10}{|l|}{ Liquor $^{\mathrm{b}}$} \\
\hline No liquor & 9649 & 90 & 1.00 & 40 & 1.00 & 18 & 1.00 & 14 & 1.00 \\
\hline Liquor drinker & 5048 & 50 & $\begin{array}{c}1.16 \\
(0.7-1.8)\end{array}$ & 18 & $\begin{array}{c}1.20 \\
(0.6-2.5)\end{array}$ & 6 & $\begin{array}{c}0.56 \\
(0.2-1.7)\end{array}$ & 13 & $\begin{array}{c}1.72 \\
(0.7-4.4)\end{array}$ \\
\hline
\end{tabular}

For the overall analyses (table 4), combining all male plus female colorectal cancer cases (including rectosigmoid cancer cases), results pointed in the same direction as the results for the stratified analyses presented in tables 2 and 3. Compared to abstainers, an increased risk was observed for KRAS- and KRAS+ colorectal tumors for cases whose daily consumption exceeded $30 \mathrm{~g}$ of alcohol. Independent of consumed alcohol, only liquor consumption was positively associated with the risk of KRAS- colorectal tumors, although statistical significance was not reached (RR: $1.22,95 \% \mathrm{Cl}: 0.9-1.6)$. 
Table 4: Incidence rate ratios ${ }^{a}$ for male and female colorectal cancer cases (including the rectosigmoid cancer cases) with a wild type or a mutated KRAS gene according to drinking habits, adjusted for confounders, the Netherlands Cohort Study (1986-1993)

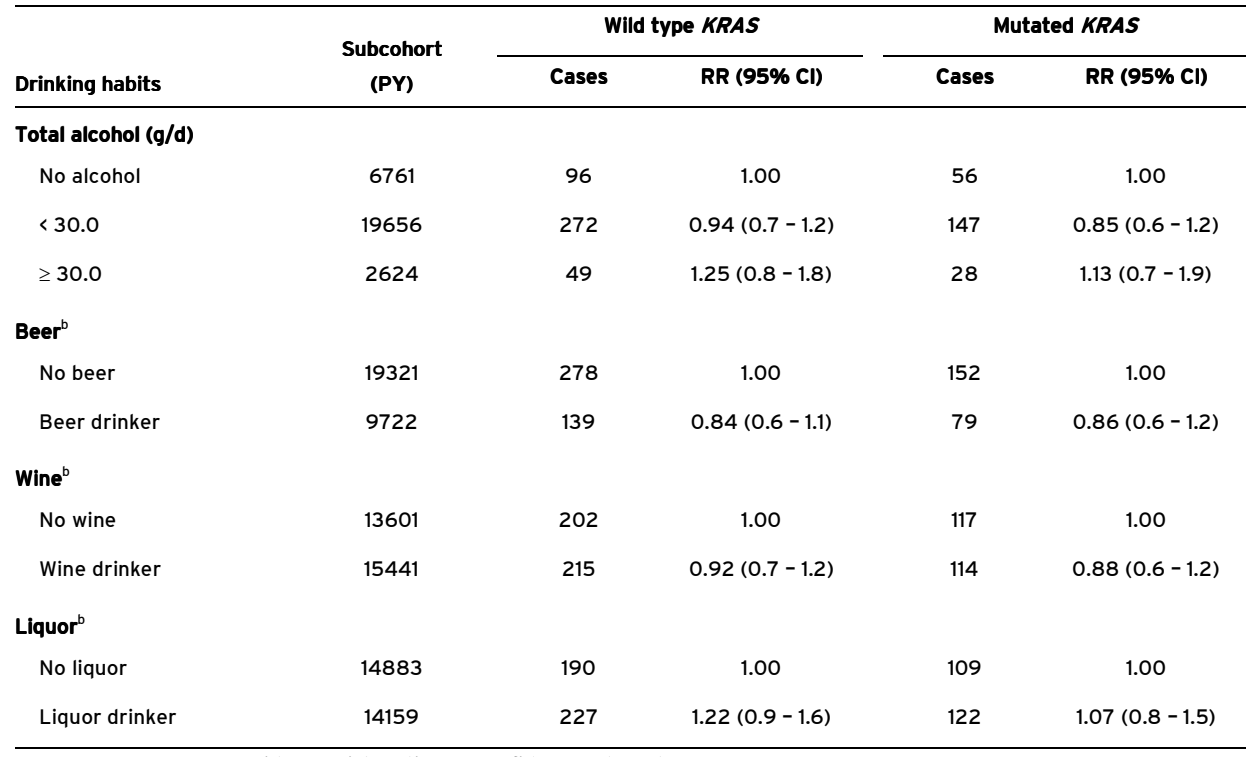

PY: Person Years; RR: Incidence Risk Ratio; Cl: Confidence Interval

${ }^{a}$ Adjusted for age, family history of colorectal cancer (yes/no), BMI ( $\mathrm{kg} / \mathrm{m}^{2}$ ), calcium intake (mg/d), linoleic intake (g/d) and smoking (never/ex/current).

${ }^{\mathrm{b}}$ Additionally adjusted for total alcohol consumption $(0,<30.0, \geq 30.0 \mathrm{~g} / \mathrm{d})$.

In order to examine the hypothesis that beer consumption is associated with G>A mutations in the KRAS gene, a further distinction of KRAS+ tumors was made into tumors with a $G>A$ transition (results not shown). There were 41 male and 29 female colon cancer cases with a G>A transition and 20 male and 9 female rectal cancer cases harboring this transition. When compared to the non-beer drinkers, consumption of beer was not associated with the risk of colon tumors harboring a G>A mutation in men, independent of the alcohol consumed. A positive association however, was observed between beer drinking, independent of the alcohol consumed, and the risk of rectal tumors harboring a G>A mutation (RR: 3.48 , 95\% $\mathrm{Cl}$ : 1.1-11.0). In women, these associations could not be assessed since there were only two female colon cancer cases and no female rectal cancer cases harboring a G>A mutation that consumed beer. Next to beer intake, we also considered associations between total alcohol, wine and liquor consumption and risk of colon and rectal tumors harboring $\mathrm{G}>\mathrm{A}$ mutations, but no significant relationships were found. 


\section{DISCUSSION}

\section{Alcohol, CRC and KRAS gene mutations}

In the current prospective study we have investigated associations between alcohol consumption and the risk of colon and rectal cancer with and without KRAS mutations, as our hypothesis implied a relationship between alcohol consumption and colorectal tumors harboring a KRAS mutation. When considering all male plus female colorectal tumors according to KRAS mutational status, our results showed that a daily alcohol consumption of $30.0 \mathrm{~g} / \mathrm{d}$ and more was associated with an increased risk of colorectal cancer, which is consistent with current literature [10]. However, in contradiction with our hypothesis this increase in risk was independent of the presence or absence of KRAS mutations. When stratifying by sex and tumor site this result was still observed for subgroups with sufficient numbers of cases. No clear associations were seen between alcohol intakes below $30.0 \mathrm{~g} / \mathrm{d}$ and the risk of KRAS- and KRAS+ colon and rectal tumors in both men and women. There is evidence that acetaldehyde is directly involved in CRC [18], but also other mechanisms have been linked to colorectal tumorigenesis, e.g. the induction of reactive oxygen species through the induction of cytochrome P-450 2E [19-21]. Many of these processes have been observed in heavy or chronic alcohol consumers. The amount of alcohol-related damage tends to follow a dose-response relationship and as such, higher levels of daily alcohol intakes may be needed for genetic mutations to occur as a result of alcohol consumption. Moderate consumption levels, as in our study population, might not be able to increase colorectal cancer risk through causing specific gene mutations. This may explain why we do not observe a differential association between alcohol consumption and KRAS- and KRAS+ tumors. Thus moderate drinking apparently involves a certain risk of developing colorectal tumors, possibly arising through mechanisms other than those causative of genetic aberrations.

Liquor consumption as opposed to non-liquor consumption, increased the risk of a KRAS- rectal tumor in men independent of the alcohol consumed. Although this finding was statistically significant, we must warrant caution not to overinterpret this result. We performed many analyses and therefore it is possible that this is merely a chance finding. Moreover, the reference group was relatively small compared to the number of liquor drinking KRAS- rectal cancer cases. Also, liquor was the most frequently consumed beverage type among the male cancer cases and 
as such, a statistically significant result is more likely to be found for liquor than for beer or wine.

To date, some studies have been performed on the effect of different life style factors on genetic alterations of the KRAS gene [22-25], of which only two considered alcohol consumption [22, 23]. Martinez et al. [22], who conducted crosssectional analyses among adenoma patients in a phase III trial, found no associations between total alcohol consumption and KRAS gene mutations in adenomas. Slattery et al. [23], used data collected as part of a large population-based case-control study on sporadic colon cancer. Without distinguishing between men and women, the authors found that levels of alcohol intake above $10 \mathrm{~g} / \mathrm{d}$ reduced the risk of KRAS mutations in colon tumors (OR: $0.7,95 \% \mathrm{Cl}: 0.5-1.0$ ). None of the above mentioned authors reported on the different types of alcoholic beverages.

\section{Alcohol, CRC and type of KRAS mutations}

Our data showed no association between beer consumption, independent from alcohol intake, and colon tumors with a G>A mutation in men, whereas a statistically significant increased risk was observed for rectal tumors with a G>A mutation. Again, caution is warranted not to overinterpret this result. The increased risk was based on merely thirteen male rectal cancer cases with a G>A mutation and a reference group of only seven cases. As mentioned in the Introduction, the adverse effects of elevated NDMA levels present in beer before 1979 might influence the risk of cancer for up to 10 years later. We checked the exact year of cancer diagnosis of the thirteen male rectal cancer cases that harbored a G>A mutation however, only one of these cases was diagnosed between January 1979 and January 1990, namely in 1989. Also, the results in table 2, based on 22 male KRAS+ rectal cancer cases and a reference group of 14 cases, indicated that beer, independent of consumed alcohol, was not associated with the risk of rectal tumors harboring a mutated KRAS gene. Unfortunately, we have not been able to gather information on the actual nitrosamine levels that were present in beer over the past few decades, or on whether these concentrations might vary across different types of beer and brands. We therefore will not emphasize the association we observed between beer consumption in men and rectal cancer harboring a $\mathrm{G}>\mathrm{A}$ mutation too much. 
To our knowledge, only one other study reported an association between total alcohol consumption, but not specific beverage types, and with different types of KRAS mutations [23]. In this study, the authors found that levels of alcohol above 10 $\mathrm{g} / \mathrm{d}$ were associated with a reduced risk of $\mathrm{G}>\mathrm{A}$ mutations in their population-based case-control study on sporadic colon cancer (OR: 0.7, 95\% Cl: 0.4-1.1).

\section{Strengths and limitations of the study}

The present prospective study was based on a large population. Due to record linkage to the NCR and to PALGA, losses to follow-up were minimized. The high completeness of follow-up of cancer incidence and of subcohort members also minimized selection and information bias. Exclusion of cases diagnosed during the first 2.3 years of follow-up, diminished the chance of information bias due to preclinical symptoms of CRC. Our study is currently the largest prospective study that has investigated associations between alcohol consumption and colon and rectal cancer with and without KRAS mutations. Nevertheless it should be noted that the number of colon and rectal cancer cases in certain subgroups are small.

\section{Conclusion}

The present study does not show a clear relationship between alcohol consumption and risk of colon and rectal tumors with a KRAS mutation, nor was a positive association apparent between beer consumption and the risk of colon and rectal tumors harboring $\mathrm{G}>\mathrm{A}$ transitions in the KRAS gene. Liquor consumption in men, seemed to be a potential risk factor for developing a KRAS- rectal tumor, independent of the alcohol consumed. We conclude that although daily alcohol consumption from a certain level of consumption on may be a risk factor for developing $\mathrm{CRC}$, alcohol consumption seems not involved in predisposing to CRC through (specific) mutations in the KRAS gene. 


\section{REFERENCES}

1. Salaspuro, M. P. Alcohol consumption and cancer of the gastrointestinal tract. Best Practice \& Research in Clinical Gastroenterology, 17: 679-694, 2003.

2. Seitz, H. K., Matsuzaki, S., Yokoyama, A., Homann, N., Vakevainen, S., and Wang, X. D. Alcohol and cancer. Alcohol Clin Exp Res, 25: 137S-143S, 2001.

3. Ahmed, F. E. Toxicological Effects of Ethanol on Human Health. Critical Reviews in Toxicology, 25: 347-367, 1995.

4. Fearon, E. R. and Vogelstein, B. A genetic model for colorectal tumorigenesis. Cell, 61: 759-767, 1990.

5. Vogelstein, B., Fearon, E. R., Hamilton, S. R., Kern, S. E., Preisinger, A. C., Leppert, M., et al. Genetic alterations during colorectal-tumor development. N Engl J Med, 319: 525$532,1988$.

6. Brink, M., de Goeij, A. F., Weijenberg, M. P., Roemen, G. M., Lentjes, M. H., Pachen, M. M., et al. K-ras oncogene mutations in sporadic colorectal cancer in The Netherlands Cohort Study. Carcinogenesis, 24: 703-710, 2003.

7. Cerottini, J. P., Caplin, S., Saraga, E., Givel, J. C., and Benhattar, J. The type of K-ras mutation determines prognosis in colorectal cancer. Am J Surg, 175: 198-202, 1998.

8. Span, M., Moerkerk, P. T., De Goeij, A. F., and Arends, J. W. A detailed analysis of K-ras point ion to tumor progression and survival in colorectal cancer patients. Int $\mathrm{J}$ Cancer, 69: 241-245, 1996.

9. Moerkerk, P., Arends, J. W., van Driel, M., de Bruine, A., de Goeij, A., and ten Kate, J. Type and number of Ki-ras point mutations relate to stage of human colorectal cancer. Cancer Res, 54: 3376-3378, 1994.

10. Cho, E., Smith-Warner, S. A., Ritz, J., van den Brandt, P. A., Colditz, G. A., Folsom, A. R., et al. Alcohol intake and colorectal cancer: a pooled analysis of 8 cohort studies. Ann Intern Med, 140: 603-613, 2004.

11. Spiegelhalder, B., Eisenbrand, G., and Preussmann, R. Contamination of beer with trace quantities of $\mathrm{N}$-nitrosodimethylamine. Food Cosmet Toxicol, 17: 29-31, 1979.

12. Stephany, R. W. and Schuller, P. L. Daily dietary intakes of nitrate, nitrite and volative $\mathrm{N}$-nitrosamines in the Netherlands using the duplicate portion sampling technique. Oncology, 37: 203-210, 1980.

13. Jacoby, R. F., Alexander, R. J., Raicht, R. F., and Brasitus, T. A. K-ras oncogene mutations in rat colon tumors induced by $\mathrm{N}$-methyl-N-nitrosourea. Carcinogenesis, 13: 45-49, 1992.

14. Ellen, G. and Schuller, P. L. N-nitrosamine investigations in the Netherlands: highlights from the last ten years. In: R. Preussmann (ed.), Das Nitrosamin-Problem, pp. 81-92. Weinheim Verlag, 1983. 
15. Van den Brandt, P. A., Goldbohm, R. A., van 't Veer, P., Volovics, A., Hermus, R. J., and Sturmans, F. A large-scale prospective cohort study on diet and cancer in The Netherlands. J Clin Epidemiol, 43: 285-295, 1990.

16. Goldbohm, R. A., van den Brandt, P. A., Brants, H. A., van't Veer, P., Al, M., Sturmans, F., et al. Validation of a dietary questionnaire used in a large-scale prospective cohort study on diet and cancer. Eur J Clin Nutr, 48: 253-265, 1994.

17. Schoenfeld, D. Partial residuals for the proportional hazards regression model. Biometrika, 69: 239-241, 1982.

18. Taylor, B. and Rehm, J. Moderate alcohol consumption and diseases of the gastrointestinal system: a review of pathophysiological processes. Dig Dis, 23: 177-180, 2005.

19. Boffetta, P. and Hashibe, M. Alcohol and cancer. Lancet Oncol, 7:149-156, 2006.

20. Badger, T. M., Ronis, M. J., Seitz, H. K., Albano, E., Ingelman-Sundberg, M., and Lieber, C. S. Alcohol metabolism: role in toxicity and carcinogenesis. Alcohol Clin Exp Res, 27: 336-347, 2003.

21. Seitz, H. K., Maurer, B., and Stickel, F. Alcohol consumption and cancer of the gastrointestinal tract. Dig Dis, 23: 297-303, 2005.

22. Martinez, M. E., Maltzman, T., Marshall, J. R., Einspahr, J., Reid, M. E., Sampliner, R., et al. Risk factors for Ki-ras mutation in sporadic colorectal adenomas. Cancer Res, 59: 5181-5185, 1999.

23. Slattery, M. L., Curtin, K., Anderson, K., Ma, K. N., Edwards, S., Leppert, M., et al. Associations between dietary intake and $\mathrm{Ki}$-ras mutations in colon tumors: a population-based study. Cancer Res, 60: 6935-6941, 2000.

24. Bautista, D., Obrador, A., Moreno, V., Cabeza, E., Canet, R., Benito, E., et al. Ki-ras mutation modifies the protective effect of dietary monounsaturated fat and calcium on sporadic colorectal cancer. Cancer Epidemiol Biomarkers Prev, 6: 57-61, 1997.

25. Slattery, M. L., Anderson, K., Curtin, K., Ma, K., Schaffer, D., Edwards, S., et al. Lifestyle factors and Ki-ras mutations in colon cancer tumors. Mutat Res, 483: 73-81, 2001. 

General discussion 

Alcohol consumption has consistently been shown to increase the risk of colorectal cancer ( $C R C)$. However, many aspects concerning this relationship still remain unclear, for example, potential risk differences between the anatomical tumor sublocalizations and the role of the polymorphic alcohol dehydrogenase $1 C$ ( $A D H 1 C)$ gene in the etiology of alcohol-related CRC. In this thesis, we have extensively studied associations between consumption of alcohol and risk of CRC within the Netherlands Cohort Study on diet and cancer (NLCS). We have examined whether associations differed according to alcoholic beverage type, gender and tumor subsite, we evaluated the role of the $A D H 1 C$ genotype and we studied associations between alcohol and molecular CRC endpoints. This final chapter will start with a summary of our main findings. Next, particular points of attention will be discussed with regard to measurement of alcohol exposure, followed by a paragraph on the assessment and analysis of molecular endpoints and their importance to CRC research. Subsequently the implications of our findings, and suggestions for future research will be addressed, followed by our concluding remarks.

\section{MAIN FINDINGS}

The main findings of the studies described in this thesis are summarized in table 1.

When compared to abstaining, we observed that a mean alcohol consumption of 30 $\mathrm{g} / \mathrm{d}$ (approximately three alcoholic consumptions per day) and more was associated with an increased risk of CRC (chapter 2). There seemed to be a gradient of increasing cancer risk from the proximal colon through the rectum. In addition, we performed the analyses for a subgroup of drinkers that reported to have consumed equal amounts of alcohol five years before baseline compared to baseline, relative to a reference group of baseline abstainers that reported to have abstained from alcohol five years before baseline as well. As a result, all risk estimates for consumers of $\geq 30.0 \mathrm{~g} / \mathrm{d}$ increased. CRC risk was likely to be attributable to the alcohol content of the consumed beverages, rather than to other beverage constituents. We did not observe statistically significant sex-specific, beveragespecific and subsite-specific associations. Overall, our conclusions on the relationship between alcohol consumption and CRC risk are consistent with the results from large meta-analyses [1-3], The Pooling Project of Prospective Studies of Diet and Cancer (from here on referred to as the Pooling Project) [4], and the 


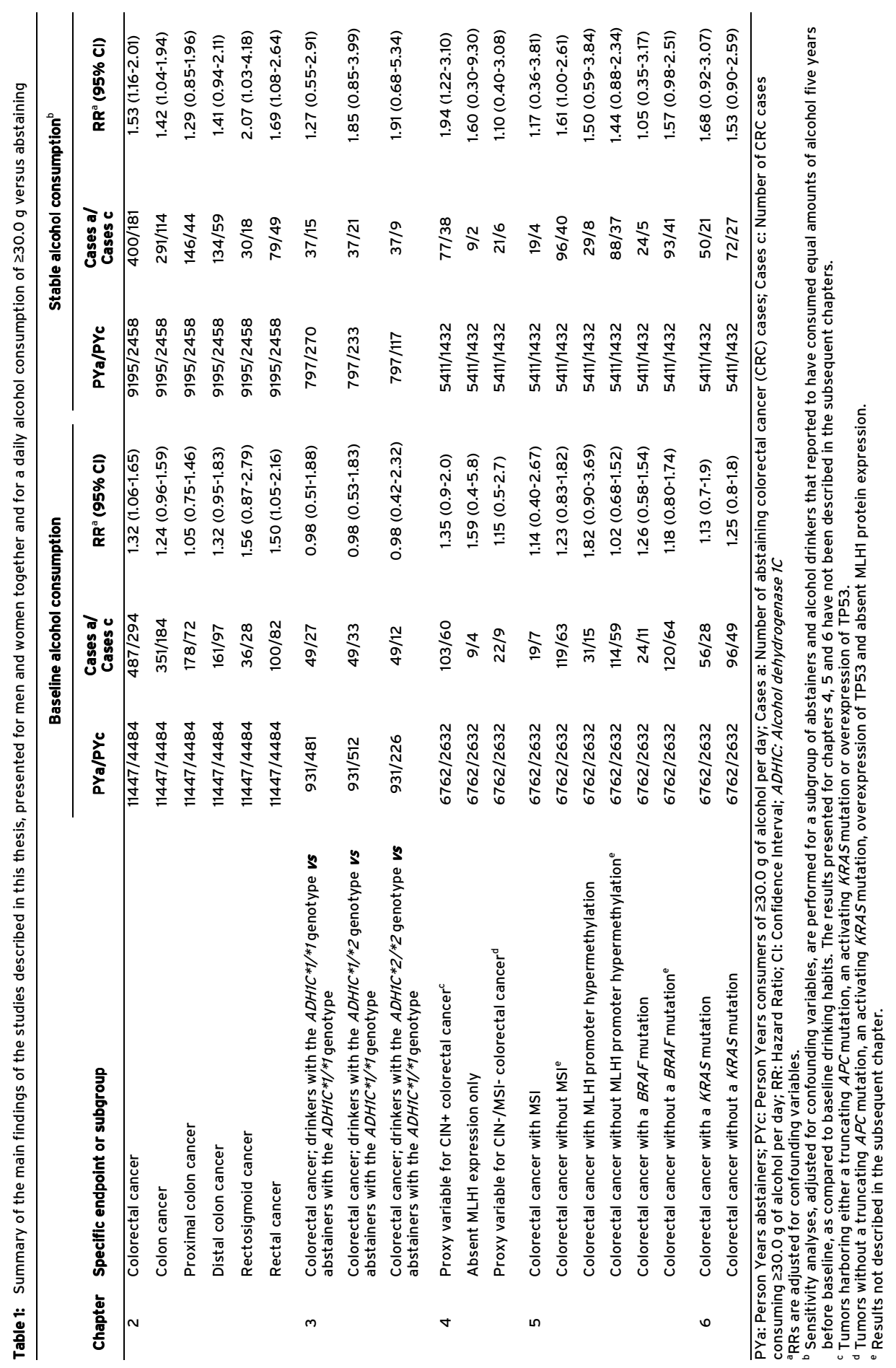


European Prospective Investigation into Cancer and Nutrition (EPIC) [5] (see chapter 1, table 1).

To examine the influence of the polymorphic $A D H 1 C$ gene with respect to genetic susceptibility to alcohol-associated $\mathrm{CRC}$, we stratified the analyses on $A D H 1 C$ genotype (chapter 3). Only for the subgroup of drinkers that reported to have consumed equal amounts of alcohol five years before baseline as compared to baseline, we observed that the risk of CRC was higher for alcohol consumers of $\geq 30.0 \mathrm{~g} / \mathrm{d}$ with the $A D H 1 C * 2 / * 2$ genotype than for those with the $A D H 1 C^{* 1} /{ }^{* 1}$ genotype. Yet, the interaction term between $A D H 1 C$ genotype and alcohol intake did not reach statistical significance. Our results were similar to two nested casecontrol studies on alcohol consumption, ADH1C genotype and risk colorectal adenomas and carcinomas $[6,7]$, but contradictory to the findings of a Dutch casecontrol study on colorectal adenomas [8] (chapter 1, table 2).

Next, we incorporated molecular endpoints into our analyses. We studied associations between alcohol intake and (a) molecular subgroups of colorectal tumors, representing proxies for distinct molecular pathways (chapter 4); (b) $M L H 1$ promoter hypermethylation and related phenotypes, representing epigenetic events (chapter 5); and (c) tumors with a KRAS mutation, representing single genetic aberrations (chapter 6). Our results indicated that a high alcohol consumption, compared to abstaining, was associated with the risk of the three studied tumor subgroups. However, alcohol intake did not seem to be involved in the development of a particular subgroup (chapter 4 ).

High alcohol consumption seemed to be related to tumors with $M L H 1$ hypermethylation and related phenotypes, i.e. tumors with microsatellite instability (MSI), tumors lacking MLH1 protein expression and tumors with BRAF mutations. Statistical significance was not reached, however. Also, alcohol intake did not modify the associations between the two methyl donors folate and methionine and risk of CRC (chapter 5).

Finally, our results pointed towards a positive association between high alcohol consumption and colorectal tumors, both with and without a KRAS mutation (chapter 6). Our findings regarding associations between alcohol consumption and several molecular CRC endpoints are largely consistent with those of other 
molecular studies on alcohol and CRC. Whereas previous studies often observed that alcohol was related to either tumors that did or did not harbor the studied molecular defect (chapter 1, table 3 and 4), we found rather similar associations between tumors with and without the molecular defect under study.

\section{ALCOHOL}

\section{Assessment of alcohol consumption}

An important goal of alcohol epidemiology is to link alcohol consumption to the disease of interest. Whereas each method to measure alcohol exposure has certain advantages and drawbacks, the method of assessment should be determined by the specific aim of the study [9]. Epidemiologic studies have routinely relied on individual recall through (self-administered) questionnaires or face-to-face interviews. The self-administered NLCS questionnaire comprised a 150-item food frequency questionnaire to assess dietary habits and life style factors during the year preceding the start of the study. Because the primary aim of the NLCS was to describe associations between dietary exposure and cancer, an adequate ranking of the study's respondents according to their habitual dietary intake was considered sufficient for ranking [10].

The reference period for the respondent's dietary habits comprised one year: the year preceding the start of the study. This coincided with the usually recommended time span of one year for assessing alcohol consumption in large populations of light to moderate, and potentially irregular, drinkers [11]. The NLCS questionnaire contained 8 questions on habitual alcohol consumption that we used in our analyses (see appendix).

In question block 28, frequency and quantity were inquired for six categories of alcoholic beverages that were presumed to cover all types of alcoholic beverages consumed (see appendix). Together with the alcohol content of these beverages, the reported consumption quantity and frequency were used to calculate the respondent's habitual mean daily alcohol intake; the variable on which all our main analyses were based. Quantity and frequency measurements like the questions in block 28 , have been reported to underestimate the volume of drinking and as such, 
may be less suitable to relate disease risk to the actual grams of alcohol consumed [12-14]. However, the principal aim of the NLCS was to elucidate associations between dietary exposure and cancer, for which a ranking of participants would suffice. Relating absolute levels of intake to disease risk was of secondary importance.

In question block 34 of the NLCS questionnaire, respondents were asked about their use of "beer" and "other alcoholic beverages" five years before the start of the study (see appendix). Respondents could indicate whether five years ago they drank more, less or as much as at baseline, or whether they never used the particular item. Together with the information on baseline consumption levels, this question gave us more insight into the respondents' "chronic" exposure to alcohol. A selection of those abstainers and drinkers that reported to have consumed as much alcohol five years before baseline as compared to baseline, would create a specific subgroup in which the "noise" attributable to individuals with changed drinking habits would be minimized. Alcohol consumption would thus more closely reflect the actual exposure to alcohol, which in turn should benefit the strength of the associations between alcohol and CRC risk. Our results confirmed this: compared to the results when using baseline alcohol consumption levels, CRC risk estimates were stronger for alcohol drinkers of $\geq 30.0 \mathrm{~g} / \mathrm{d}$ when the analyses were restricted to the subgroup of individuals that reported to have consumed equal amounts of alcohol five years before baseline, compared to baseline levels (also see chapters 2 and 3). Unlike chapters 2 and 3, these sensitivity analyses had not initially been performed for chapters 4, 5 and 6. However, the associations examined in these chapters became stronger as well when restricted to drinkers who indicated to have consumed equal amounts of alcohol five years before baseline as compared to baseline. These additional results are presented in table 1 of this chapter.

The advantage of the above mentioned subgroup is a reduction of individuals with (recently) changed drinking habits and a subsequent misclassification of their exposure to alcohol according to reported baseline consumption levels. The large proportion of epidemiological studies that has not taken former drinkers and drinkers with changed drinking habits into account may have underestimated associations between alcohol consumption and CRC to a certain degree, while in fact they may be stronger. 


\section{Validity and reproducibility of alcohol assessment}

As mentioned in the previous paragraph, a self-administered dietary questionnaire is often used for the assessment of dietary habits in large-scale epidemiological studies. Diet is difficult to assess and liable to recall bias. A major advantage of a cohort study is that recall bias will not be influenced by disease status, since the included participants are all disease-free at baseline. Over and underreporting of particular food items, whether unintentional or deliberate, cannot be avoided however. The food frequency questionnaire used in the NLCS has extensively been studied for its validity [15] and reproducibility [16].

\section{Validity}

As was described in the previous chapters, the dietary section of the questionnaire has been validated against a nine-day diet record. Of all nutrients, alcohol intake scored highest with a Spearman correlation coefficient between mean daily alcohol intake assessed by the questionnaire and that from the nine-day record of 0.89 for all subjects, and 0.85 for users of alcoholic beverages. For the remaining nutrients, some of which were included in our statistical models as confounding variables, the unadjusted correlation coefficients ranged from 0.40 for vitamin $B 1$ to 0.83 for polysaccharides [15].

The results of the validation study were consistent with what is usually reported in literature, i.e. correlations between FFQ and multiple-day diet records often range from 0.4 to 0.6 for nutrients [17] while correlations for alcohol consumption are much higher [18]. Being a conscious decision, alcohol is subject to a more accurate recall of intake. With regard to social desirability however, alcohol is liable to underreporting. A strong correlation between reported alcohol intakes from a FFQ and a diet-record is no guarantee for measuring the true alcohol exposure levels however, since underreporting of consumption may occur in both the FFQ and the diet-record. Nevertheless, the NLCS questionnaire can be considered as a valid method for ranking subjects according to both alcohol and nutrient intakes.

\section{Reproducibility}

The reproducibility of the $F F Q$ was evaluated by repeating the questionnaire administration annually during the first five years of follow-up among random independent samples of 400 cohort members (200 men and 200 women) [16]. The repeated questionnaires were mailed in the same month (September) as the baseline 
questionnaire. It was observed that mean intakes changed very little and correlations between two measurements decreased only slightly over time. This decrease may be attributable to intra-individual changes in dietary habits, i.e. participants who consciously changed their habits [16]. The average decline in correlation over all nutrients after five years amounted to only 0.07 , suggesting that the single baseline measurement by the FFQ had been a good indicator of nutrient intake over a period of at least five years.

\section{Assessment of $A D H 1 C$ genotype}

In December 2000, all available subcohort members who were still alive were contacted for the collection of buccal (mouth) swabs. For our study on genetic susceptibility to alcohol-related CRC (chapter 3 ), these mouth swabs were applied to determine the respondents' $A D H 1 C$ genotype according to the polymorphic $A D H 1 C$ gene.

The swabs were collected 14 years after baseline. Since a considerable part of the subcohort had died since the start of the study, the remaining cohort members may represent a selection of survivors with characteristics associated with certain genetic features and/or environmental exposures, such as diet. This in turn, may have had consequences for the genotype distribution among the subcohort members that provided buccal swabs, introducing selection bias into our study. To exclude this possibility, we compared subcohort members that provided buccal swabs with those that did not for a number of environmental variables collected at baseline and representative of genetic factors (age, body height and a family history of breast, colorectal and prostate cancer). Additionally, we compared the two groups for differences in alcohol consumption and confounding variables used in the analyses described in chapter 3. Apart from an expected difference in age (subcohort members who provided buccal swabs were two years younger; $p_{(x 2)}<0.01$ ), we found no differences in mean daily alcohol intake and in other (survival-related) characteristics tested. We thus concluded that the group providing buccal swabs did not represent a selective sample of the subcohort with specific (survival-related) characteristics. In addition, mean age did not differ across the different $A D H 1 C$ genotypes in the subcohort, suggesting that none of the $A D H 1 C$ genotypes was prone to a survival advantage either. 
Information on $A D H 1 C$ genotype for CRC cases was derived from tumor tissue samples, collected in August 1999. The use of tumor tissue instead of non-tumorous tissue for $A D H 1 C$ genotyping may be disputed as the gene in question may have been affected by tumor-specific changes. However, we consider it highly unlikely that in CRC cases without the ADH1C polymorphism, a single point mutation would occurr at the exact location of the single nucleotide polymorphism (SNP) under study. This was supported by the fully identical results of $A D H 1 C$ analyses from mouth swab and tumor tissue samples from 20 participants who were both subcohort member and CRC case.

To determine the reproducibility of the $A D H 1 C$ genotyping analyses, we analyzed 93 duplicate samples. Thirty one of these consisted of a random sample of CRC cases, whereas the remaining 62 samples consisted of a random sample of 31 male and 31 female subcohort members.

All duplicate samples matched the $A D H 1 C$ genotype as established from the first run, resulting in a $100 \%$ reproducibility of $A D H 1 C$ genotyping.

\section{Alcohol consumption in survival analyses}

Statistical analyses on alcohol consumption and disease need several aspects and decisions to be taken into account for correct interpretation of the results. The issues that were relevant to the studies described in this thesis are discussed in the following section.

\section{Abstainers as reference group}

An ongoing debate in epidemiological studies on alcohol consumption and disease is the selection of an appropriate comparison group. Abstainers are often chosen as a reference group, whereas there are indications that abstainers do not per definition enjoy a better health than drinkers [19-21]. A commonly mentioned drawback of the abstainer group is their potential heterogeneous composition. Consisting of life-time abstainers and former drinkers, the overall health status of the group may be negatively influenced by former drinkers who stopped drinking because of health problems (sick quitters) $[22,23]$. Whereas the NLCS-questionnaire made no specific inquiries into former drinking habits of abstainers, the questionnaire provided information on drinking habits five years before baseline for both abstainers and drinkers. As explained previously, this information enabled us to perform analyses 
for a subgroup of drinkers and abstainers that reported to have consumed equal amounts of alcohol five years before baseline, compared to baseline drinking habits. Apart from merely distinguishing former drinkers from life-time abstainers, our approach had the additional advantage of reducing "noise" introduced by drinkers with changed drinking habits, thereby improving the validityof assessing alcohol exposure.

\section{Different types of alcoholic beverages}

Epidemiologic studies have reported inconsistent results with regard to how beer, wine and liquor consumption relate to the risk of CRC. Apart from methodological issues, speculations to explain the different results for the alcoholic beverages include individual differences in sociological and psychological characteristics [19, $24,25]$. Another explanation may involve the specific substances in the beverages, other than alcohol. Wine for example, contains flavonoids and antioxidants which may reduce cancer risk $[26,27]$, whereas beer (before 1979) contained nitrosamines which may have enhanced cancer risk [28].

In the studies described in this thesis, we have attempted to address the question whether associations between consumption of alcoholic beverages and risk of CRC are more likely to be attributable to the alcohol content of the drink or to other substances in the beverages. However, there are no standard statistical models available to address the fore mentioned research question and we had no information on substance-specific levels present in the various beverages.

We have therefore studied four methods proposed by Willett, to address a similar problem in nutritional epidemiology with regard to nutrient intake (fat, carbohydrates and protein) and intake of total energy, i.e. the nutrient density model, the nutrient residual model, the energy partition model and the standard multivariate model $[9,29]$.

\section{The nutrient density model}

As a traditional method to account for total energy intake, the nutrient density method includes nutrient intake divided by total energy into the model. However, when total energy is related with the disease, the effects of nutrient intake will be confounded by total energy. The nutrient density variable - partly composed of the inverse of total energy - will then tend to be associated with the disease in a direction opposite to total energy, even if the nutrient itself is not related to the 
disease. In alcohol analyses, we would include the intake of a specific beverage type divided by total alcohol consumption in the model. However, because total alcohol intake is related to $C R C$, the nutrient density model will not be a good method to control the intakes of alcoholic beverages for the intake of total alcohol.

\section{The nutrient residual model}

The nutrient residual model calculates residuals of nutrient intake by using regression analyses to remove the variation caused by total energy intake. These residuals represent the differences between each individual's actual nutrient intake and their intake according to their total energy consumption. The residuals thus indicate whether the individual's nutrient intake is as expected at a given total energy intake. For alcohol beverages, the calculation of residuals is problematic. Because of the non-drinkers of a particular beverage type, a regression line will not be able to fit the data satisfactorily and will result in loss of information. Also, information of abstainers will be lost since the residual method depends on total alcohol consumption. As such, the residual model was considered unsuitable for our alcohol analyses.

\section{The energy-partition model}

In this model, the nutrient under study is included as one term and the remaining sources of energy are included as secondary terms. When, for example, beer consumption is included in the model as one term, wine and liquor intake will be included as a second and third term. The model calculates a difference in disease risk that is associated with the increase of one unit of beer, while the other sources of alcohol - wine and liquor - are kept constant. This implies that the difference in disease risk represents the effect of both the alcohol in one unit of beer and the non-alcoholic constituents in one unit of beer. Therefore, the energy partition model would not suitable to answer our research question.

\section{The standard multivariable model}

The final model that we evaluated was the standard multivariable model. This approach attempts to control for confounding by total energy intake to include this variable in the model along with the nutrient of interest. In terms of alcohol, total alcohol intake is included in the model along with the alcoholic beverage of interest. The standard multivariable model thus calculates a difference in disease risk represented by the increase of one unit of the beverage type of interest - suppose 
beer - while keeping total alcohol intake constant. Since an increase in one unit of beer would imply a subsequent increase in total alcohol, total alcohol intake can only be kept constant by substituting the alcohol content of one unit of beer by the same amount of alcohol from wine and/or liquor. Thus theoretically, a possible relationship between total alcohol consumption and disease should not influence the estimates for specific beverage types. This last model seemed the most suitable one to answer our question of whether beverage constituents may affect CRC risk, apart from alcohol.

The subsequent results for beer, wine and liquor consumption analyzed according to the standard multivariable model, showed no clear associations between consumption of the beverages and risk of CRC, when compared to the non-drinkers of the particular beverage types (chapter 2, 4 and 6). We therefore concluded that the alcohol content, rather than other beverage-constituents, was the factor of importance with regard to $\mathrm{CRC}$ risk.

Interpretation of results from a standard multivariable model applied in alcohol analyses may not be as straightforward as it may be in nutrient analyses, for which the model originally has been proposed. Total energy is always composed of the energy content of fat, carbohydrates, protein and alcohol whereas total alcohol intake is composed of usually one or two beverage types, dependent of individual taste preferences. The intake of an individual alcoholic beverage intake is then highly correlated to total alcohol intake. The higher the correlation between beverage type and total alcohol, the more difficult it will be to "separate" the effect of the remaining beverage constituents from the effect of total alcohol consumption. Results from the standard multivariable model should thus be interpreted with caution (also see chapter 2). To support our conclusions drawn from the standard multivariable models, we additionally applied the energy-partition model to analyse the alcoholic beverage types. If it indeed would be true that only the alcohol content of the beverages would affect CRC risk, the energy-partition model should yield comparable risk estimates for each beverage type. And indeed, for beer, wine and liquor intakes the risk estimates for drinkers in the highest category of consumption relative to the non-drinkers of the particular beverage type were comparable to one another, and supported our conclusion drawn from the standard multivariable models. 
In the Copenhagen City Heart Study, Johansen et al. have evaluated the applicability of the above mentioned as models proposed by Willett, to study the effects of different alcoholic beverage types on the risk of coronary heart disease. The authors concluded that the standard multivariable model was indeed useful in alcohol analyses and that it complemented traditional analyses in which all beverage types are included separately into the model (energy-partition model) [30].

\section{Relationship between time of exposure measurement and disease}

To be able to link a disease to the studied exposure, the exposure factor needs to be measured within a relevant time frame of the particular disease. The development of CRC is estimated to take approximately 10 to 30 years $[31,32]$, suggesting that the exposure to alcohol 10 to 30 years before diagnosis may have been relevant to the particular tumor. In the NLCS, alcohol exposure was measured in 1986. Still, this does not necessarily imply that the baseline alcohol measurement would be irrelevant for cases diagnosed after the relatively short follow-up period (7.3 years) in chapters 3 through 6 . With regard to the study's design, a relatively older cohort was recruited with the advantage of stabilized dietary habits [10]. The reproducibility study of the used food frequency questionnaire confirmed stability of dietary habits and suggested that baseline habits were representative of habits of the recent past [16]. In addition, compared to using baseline alcohol consumption, analyses that were restricted to abstainers and drinkers that reported to have consumed equal amounts of alcohol five years before baseline as compared to baseline pointed towards positive associations between alcohol and CRC as well. Finally, if alcohol would exclusively be involved in tumor initiation instead of tumor progression, the timing of exposure assessment would indeed need to be very strict. Besides the fact that the exact moment of tumor initiation is impossible to determine in epidemiological studies, it has never been established that alcohol consumption is solely implicated in tumor initiation. 


\section{ALCOHOL AND COLORECTAL CANCER}

\section{Cancer endpoints according to anatomical tumor localization}

An issue within the field of alcohol consumption and CRC risk that still remains unclear is whether or not the effect of alcohol on CRC risk is dependent on anatomical sublocalization. In literature several differences have been described for the colorectal subsites, including differences in cancer incidence among men and women (proximal colon cancer is seen more often in women, whereas rectal cancer is observed more frequently in men), and differences in physiologic function and vascular supplies [33-35]. As an example with respect to alcohol, Seitz et al. have observed higher levels of the toxic acetaldehyde in the distal colon and rectum as opposed to the proximal colon [36]. It is thus likely that risk factors for CRC - and possibly even carcinogenic mechanisms - may differ depending on anatomical subsite [37]. As such, research into differential associations between potential risk factors and colon and rectal cancer may provide valuable insights into CRC development.

The many individual epidemiological studies on alcohol consumption and CRC have reported rather inconsistent - and sometime contradictory - associations for colon and rectal cancer. Still, alcohol has relatively more often been associated with a higher risk of rectal cancer than colon cancer. The meta-analysis by Corrao et al. [38] and the Pooling Project [4] observed somewhat higher risk estimates for rectal cancer than for colon cancer, although the estimates did not differ statistically significantly from one another. In line with the results from EPIC [5], we observed a gradient of increasing associations from proximal to distal colon, followed by the rectosigmoid and rectum (chapter 2). In EPIC these subsite-specific risks were not found to differ from each other, whereas in our study risk estimates appeared to be statistically significantly heterogeneous.

Based on the available results in literature and the previously mentioned observation of higher acetaldehyde levels in the rectum than in the colon [39], alcohol may likely be more important to rectal cancer risk than to colon cancer risk. Nevertheless, in order to draw firm conclusions, additional large-scale studies with detailed information on tumor localization are needed. 


\section{Cancer endpoints according to molecular tumor characteristics}

Molecular epidemiology has the potential to provide more insight into carcinogenic mechanisms through studying associations between exposure factor and molecular tumor characteristics. The evaluation of mutations that a tumor has acquired during its development in combination with diet or other lifestyle factors, may provide clues on specific disease pathways and the biological behavior of the particular tumor. Nevertheless, it is important to realize that the assessment of tumor aberrations will only indicate the defects that are present in the tumor at that particular moment. Assessment at a later stage of the disease may reveal new abnormalities whereas earlier ones may be lost, for example due to chromosomal defects.

The choice for specific molecular endpoints to be incorporated in our studies was based on the current knowledge in literature about carcinogenic pathways to CRC. The genes that we examined are all key genes in CRC, i.e. APC, KRAS, BRAF, MLH1 and TP53 [40-42].

\section{Validity and reproducibility of molecular analyses}

For an efficient assessment of genetic aberrations, mutation analyses concentrated on only those regions of the gene in which the majority of mutations are known to occur, i.e. the mutation cluster region in exon 15 for $A P C[43,44]$, codons 8 through 29 for KRAS [45] and exon 15 for BRAF [46]. With regard to aberrations in TP53 and $M L H 1$, it appeared more efficient to test for surrogate markers instead of analyzing the genes for mutations, i.e. overexpression of the TP53 protein and absence of MLH1 protein expression, respectively. Furthermore, promoter hypermethylation of the $M L H 1$ gene, a common cause of MSI in sporadic CRC [4749], and MSI were assessed.

\section{Validity}

The validity of the mutation analyses was ascertained through the amplification and sequencing of DNA from CRC cell lines and from fresh CRC tissue specimens, which were each divided into two adjacent tumor blocks: one paraffin-embedded and one freshly frozen block. It appeared that the used techniques yielded the same mutations in the CRC cell lines as described in literature [46, 50, 51]. Nuclear staining of normal epithelial and stromal cells or lymphocytes served as internal positive controls for the immunohistochemical analyses of MLH1 and TP53. The 
Methylation Specific Polymerase Chain Reactions (MSP) to assess $M L H 1$ promoter methylation, were performed with internal controls for unmethylated and methylated alleles as with controls without DNA.

\section{Reproducibility}

The reproducibility of the mutation analyses, MSP reactions and MSI assessment was tested by subjecting a random number of tissue samples twice to the complete analysis procedure. This revealed a good reproducibility of $85 \%$ for $A P C, 88 \%$ for both KRAS and BRAF, $89 \%$ for MSP reactions and $100 \%$ for MSI analyses [46, 50, 51]. The immunohistochemical staining profiles of MLH1 and TP53 were independently reviewed by two evaluators. Disagreements were re-evaluated and discussed with a pathologist until consensus was reached.

Bias related to the losses to follow-up, tumor sample collection and success rate of the molecular analyses are difficult to assess. However, it is not likely that this bias, if present, has influenced our study results in a non-random fashion.

\section{Molecular subgroups of colorectal cancer}

To date, molecular classifications of CRC are still evolving. At least three broad subgroups have been identified, known as chromosomal instability (CIN), MSI and the CpG Island Methylator Phenotype (CIMP) as described in chapter 1. In the study described in chapter 4 in this thesis, we aimed to examine associations between alcohol consumption and distinct molecular subgroups of CRC, in order to gain more insight into the role of alcohol consumption in CRC development. Since we only had limited data on a number of molecular CRC aberrations, we created CRC subgroups according to similar molecular characteristics to represent proxies for distinct CRC pathways. Although some subgroups were small, the results all pointed towards a positive association with alcohol. This may suggest that alcohol consumption is not associated with a specific molecular subgroup of CRC, and that the effect of alcohol on CRC development may not involve very specific genetic and molecular aberrations. It may thus be that alcohol exerts an effect on a much broader level (chapter 4).

In a later stage of our research, information associated with the epigenetic subgroup of CIMP became available, i.e. data on $M L H 1$ promoter hypermethylation, MSI status and $B R A F$ mutations $[47,52-55]$ (chapter 5 ). The combined results for men and 
women, as presented in table 1 of this chapter, indicate positive associations between alcohol intakes of $\geq 30.0 \mathrm{~g} / \mathrm{d}$, relative to abstaining, and colorectal tumors harboring methylation-related aberrations. This was also true for tumors without the studied aberrations (table 1). Whereas the subgroups were relatively small and caution is warranted when interpreting the results, the findings suggest - in line with those from chapter 4 - that alcohol may be more likely to affect CRC development through mechanisms other than to inflict aberrations at very specific locations in genes.

\section{Single molecular endpoints}

Whereas the study of molecular tumor subgroups according to global cellular events, such as CIN and MSI, may reveal clues of disease mechanisms, the studying of single molecular events should not be disregarded. Their usefulness has been proven in response prediction to therapies targeted against single molecules [56-58]. Moreover, single molecular endpoints may be useful to test very specific hypotheses related to the effect of an exposure factor.

In chapter 6 we have examined associations between alcohol consumption and CRCs with and without a KRAS mutation. Based on observations in experimental studies [59], we tested the hypothesis that beer consumption, as a proxy variable for nitrosamine exposure, was associated with CRCs harboring a G>A mutation. No clear associations were observed, however. Another hypothesis that was tested in chapter 6 stated that the intake of alcohol, as a proxy variable for acetaldehyde exposure, was related to tumors with a KRAS mutation. We eventually had to reject this hypothesis since we observed no differential associations between alcohol and colorectal tumors with and without a KRAS mutation. Next to KRAS, the same was true for tumors with and without an $A P C$ mutation, with and without absence of MLH1 expression, with and without overexpression of the TP53 protein (all mentioned in chapter 4 ) and tumors with and without a BRAF mutation (table 1). It thus seemed unlikely that alcohol consumption would contribute to CRC through causing particular aberrations in the genes that we studied, a conclusion in line with the one we drew after studying CRC subgroups (chapter 4). Previous research in which relations between alcohol consumption and single genetic events have been examined (case-control studies only) has yielded inconsistent results (see chapter 1 , table 4). Therefore, no clear conclusions on gene-specific effects of alcohol with regard to $C R C$ can be drawn from these studies. 
All in all, studies that have investigated molecular subgroups and single molecular events involved in CRC, including our own, have not been able to consistently demonstrate relationships between alcohol intake and specific molecular CRC pathways, and between alcohol and single molecular aberrations involved in CRC. This may imply several possible scenarios for the relationship between alcohol and CRC. In a first scenario, alcohol is related to specific events in CRC, but inconsistent findings have been observed due to methodological shortcomings of the performed studies. Perhaps the level of alcohol consumption that was examined has been too low to reveal clear associations. Also, small study populations may have hampered the detection of statistically significant associations. In a second scenario, alcohol is not related to specific molecular events or the etiological CRC pathways studied. In contrast to the often suggested mechanism in which alcohol, or rather acetaldehyde, may lead to specific mutations that in turn predispose to $C R C$, it may also be that alcohol causes general tissue damage. The accelerated rates of proliferation that follow this damage may subsequently increase the likelihood of mutations to occur and accordingly, increase the risk that cells undergo malignant transformation. In support of this alternative mechanism of cancer development, acetaldehyde has been shown to have direct toxic effects on the colorectal mucosa, inducing mucosal cell hyperregeneration $[60,61]$. Mucosal hyperregeneration in turn, is an established risk factor for CRC [62]. In addition, results from our study described in chapter 4 of this thesis suggested that alcohol was not differently related to distinct molecular subgroups of colorectal tumors which may indicate a more general mechanism of carcinogenesis.

\section{Statistical power and multiple testing}

Whereas the use of molecular endpoints in epidemiological studies on diet and cancer may offer several advantages over a classical epidemiological approach, like providing clues for unraveling underlying etiologic mechanisms, molecular epidemiology has certain limitations as well. A study on associations between the exposure factor and different molecular endpoints necessitates a large study population. After all, sufficient statistical power for each molecular subgroup should be warranted. Small sample sizes may result in unstable risk estimates and limit the number of possible subgroups to be distinguished. Moreover, small study populations are more susceptible to the adverse effects of potential sampling bias. 
It may thus be clear that molecular analyses require careful considerations and a meticulous interpretation of its results. Regardless of whether analyses were hypothesis-based, caution is warranted not to overinterpret (single) statistically significant outcomes and to take the magnitude, strength and direction of accompanying estimates into account. With regard to our own analyses, in particular those in chapters 3 through 6 , certain molecular subgroups were very small and resulted in potentially unstable risk estimates, as illustrated by relatively wide confidence intervals. We acknowledged this and focused on the directions to which the results pointed, instead of the actual magnitude of the risk estimates.

\section{IMPLICATIONS FOR PUBLIC HEALTH}

An important message from this thesis, supported by findings from other large epidemiological studies, is that relative to abstaining, a daily ingestion of three alcoholic consumptions and more is an apparent risk factor for CRC development. Whereas we lacked the power to provide statistically significant risk estimates for light to moderate consumption levels, large meta-analyses reported that consumption levels of 2 alcoholic drinks per day were already associated with an increased risk of CRC $[1,3]$. Considering that the majority of the Dutch population will classify as light to moderate drinkers, alcohol consumption may result in a substantial number of CRC diagnoses nationwide.

Unfortunately, it is not possible to accurately estimate the attributable proportion of CRC cases to alcohol consumption on a nationwide level $\left(A_{T}\right)$. Estimates are dependent on the availability of demographic statistics and figures of age-related alcohol consumption of the Dutch population. Whereas Statistics Netherlands [63] provides many statistics for a broad number of (age and sex-specific) subgroups and a various number of exposure factors, the given age categories for alcohol consumption (40-65 years and 65 and older) do not match the age range of the NLCS population (55-69 years). Since cancer incidence and alcohol consumption correlate with age, the $\mathrm{AP}_{\mathrm{T}}$ when using the data for the 40-65 year-olds may be biased by a lower risk of cancer for individuals aged 40-55 years, and by a possible underestimation of the proportion exposed to alcohol in this age group. 
The $\mathrm{AP}_{\mathrm{T}}$ can be estimated for the NLCS population though. With a proportion of the cohort exposed to alcohol of $\mathbf{0 . 7 2}$, and an RR of 1.07 for any alcohol intake versus abstaining (result not previously shown), the $\mathrm{AP}_{\mathrm{T}}$ for the cohort equals 0.05. This implies that $5 \%$ of all CRC diagnoses in the NLCS cohort might be attributable to alcohol consumption. Moreover, within the group of drinkers the percentage of CRC attributable to a high consumption of alcohol $\left(A P_{E}\right)$ can be estimated. Using a RR of 1.53 for consumers of $\geq 30.0 \mathrm{~g}$ of alcohol per day versus abstaining, the $\mathrm{AP}_{\mathrm{E}}$ equals 0.35. Thus, $35 \%$ of all CRC diagnoses among drinkers of alcohol might be attributable to a high daily alcohol consumption.

\section{Guidelines for alcohol consumption in the Netherlands}

In 2006, the Health Council of the Netherlands has published new nutritional guidelines for healthy and safe eating (Richtlijnen Goede Voeding 2006), with a better public health as their ultimate goal [64]. Consumers of alcohol were advised to moderate their daily consumption to a maximum of two standard alcoholic drinks for men and a maximum of one standard alcoholic drink for women. The advice for safe alcohol consumption from the Council is different from that of other national institutes, such as the Netherlands Nutrition Centre [65], the Netherlands Heart Foundation [66] and the Dutch Cancer Society [67]. These institutes all advice a daily maximum of three drinks for men and two drinks for women, based on international recommendations. As argued by the Dutch Cancer Society [67], these slightly higher levels of intake have consistently shown a protective effect on mortality which in turn is largely explained by an underlying protective effect on risk of cardiovascular disease.

Considering the study results in the present thesis, guidelines for safe alcohol use as stated by the Health Council of the Netherlands may seem relatively low. It is of course important not to lose sight of other alcohol-related conditions and diseases. There is evidence, showing that intakes of $10 \mathrm{~g}$ of alcohol per day (approximately one drink per day), relative to abstaining, increase the risk of breast cancer in women [68]. These arguments are also put forward by the Health Council in defense of their lower recommendations of consumption. Still, the Council's advice is preferable over that of other above mentioned Dutch institutes, "as it proposes an optimal health benefit instead of maximum health with minimal mortality risk"[64]. 
Abstainers for that matter are never advised to take up moderate alcohol consumption, which is stated by all Dutch institutions. Abstainers usually have good reasons not to drink alcohol, e.g. culture or religion, a family history of alcoholism and poor health. Next to the possible dangers of alcohol use, such as the risk of addiction and the increased likelihood of road-accidents and violence, abstainers are thus not advised to start drinking.

\section{FUTURE RESEACH}

The studies described in this thesis have contributed to the existing knowledge in the field of alcohol consumption and CRC risk. Points of attention for future research include the following.

An important issue in alcohol research concerns the assessment of alcohol consumption within the study population. Risk factors for cancer, including alcohol, are usually long-term exposures. Stable drinking habits will benefit statistical analyses and the consequent interpretation of results. Therefore, in addition to a baseline measurement of alcohol consumption it is important to gain information about stability of drinking habits. As discusses before, stable habits represent chronic exposures more closely and reduce the introduction of noise by individuals with changed drinking habits. A relatively simple question on alcohol use in the recent past (see appendix) already appeared useful in reducing misclassification of (long-term) alcohol exposure and the subsequent underestimation of CRC risk related to the use of baseline consumption levels only (see chapter 2 ). Conversely, misclassification of alcohol exposure may exaggerate possible protective effects of alcohol, such as the risk of cardiovascular diseases. Therefore, strategies to assess levels of (long-term) alcohol exposure and stability of habits deserve more attention in (future) alcohol research. Additionally, specific patterns of consumption, such as binge drinking and drinking with meals, may be worthwhile to asses and investigate with regard to CRC risk. After all, irregular consumption of large quantities of alcohol is shown to have very different health consequences compared to a regular consumption of small amounts of alcohol [21]. 
In future attempts of relating absolute levels of alcohol consumption to disease, the use of biomarkers may be an option. As for today, the availability of alcohol biomarkers is mainly limited to the field of research on alcoholism, identification of alcohol abuse and related conditions [69]. The use of acetaldehyde, as an obvious biomarker for alcohol intake, has great interest. Acetaldehyde stays free in the blood and is able to bind to hemoglobin and form stable protein-acetaldehyde adducts. Concentrations of both free and bound acetaldehyde can be measured and is known as the whole blood-associated acetaldehyde assay (WBAA) [70]. The assay is specific en sensitive and is able to provide a picture of alcohol use over time [70, 71]. The ability of the WBAA assay to measure consumption patterns over time, make it unique among the alcohol biomarkers and a useful clinical tool to, for example, monitor people in alcoholism treatment programs [69]. Whether the assay is valuable to epidemiological studies on alcohol and disease, remains to be established.

As mentioned earlier in this chapter, the incorporation of molecular endpoints in epidemiological studies may provide more and better insights into underlying mechanisms of carcinogenesis. To date, molecular studies on alcohol and CRC are scarce. Since the initiation of new large molecular epidemiological studies is a difficult and costly undertaking, it is important that existing studies seek ways to collect tumor material to assess molecular tumor characteristics. As such, the number of molecular publications can increase and meta-analyses may be performed. Other advantages of increasing amounts of molecular studies include the opportunity to perform multi-centre studies and to pool the available molecular data. Only then, study samples may be significantly large to provide clearer insights into the role of alcohol consumption in CRC development. It is important however, that there is consensus about molecular definitions of CRC subgroups. Definitions that constitute for example CIN tumors, are not yet available and still require extensive additional research $[72,73]$.

Next to molecular endpoints, the importance of genetic susceptibility of alcoholassociated CRC should not be underestimated. Genetic variations in genes may elucidate particular associations between alcohol consumption and CRC (subgroups) that otherwise would have remained unclear. Clues to the underlying etiologic mechanism of CRC development may be revealed and certain risk groups for alcohol-associated cancer may be identified. Not only polymorphic genes involved in 


\section{| Chapter 7}

the alcohol metabolism are important to consider, but also those involved in for example, the folate metabolism. Therefore, our studies and molecular studies that have already been published need to be repeated. Again, more studies and larger study samples may offer a better chance of success in unraveling the role of alcohol consumption in CRC development.

\section{CONCLUDING REMARKS}

To date, epidemiological studies have shown the existence of a relationship between alcohol consumption and CRC. The actual mechanism of carcinogenesis however, is still unclear. The incorporation of molecular tumor characteristics in epidemiological analyses - which is gaining more and more interest among studies on diet and cancer - may help to understand the fundamental biological processes and elucidate the potential role of alcohol in CRC development. However, the many molecular cancer studies conducted during the last decade have shown that elucidating cancer mechanisms is very complex and a major role seems to be granted to genetic cancer-susceptibility. In view of the rising rates of both alcohol consumption (especially amongst young people) and $\mathrm{CRC}$, there is a growing need for a better understanding of alcohol-related CRC in order to develop prevention strategies, identify potential risk groups and possibly even improve CRC treatment. 


\section{REFERENCES}

1. Longnecker, M. P., Orza, M. J., Adams, M. E., Vioque, J., and Chalmers, T. C. A metaanalysis of alcoholic beverage consumption in relation to risk of colorectal cancer. Cancer causes control, 1: 59-68, 1990.

2. Bagnardi, V., Blangiardo, M., La Vecchia, C., and Corrao, G. A meta-analysis of alcohol drinking and cancer risk. Br J Cancer, 85: 1700-1705, 2001.

3. Moskal, A., Norat, T., Ferrari, P., and Riboli, E. Alcohol intake and colorectal cancer risk: A dose-response meta-analysis of published cohort studies. Int J Cancer, 120: 664-671, 2006.

4. Cho, E., Smith-Warner, S. A., Ritz, J., van den Brandt , P. A., Colditz, G. A., Folsom, A. R., et al. Alcohol intake and colorectal cancer: a pooled analysis of 8 cohort studies. Ann Intern Med, 140: 603-613, 2004.

5. Ferrari, P., Jenab, M., Norat, T., Moskal, A., Slimani, N., Olsen, A., et al. Lifetime and baseline alcohol intake and risk of colon and rectal cancers in the European prospective investigation into cancer and nutrition (EPIC). Int J Cancer, 121: 2065-2072, 2007.

6. Chen, J., Ma, J., Stampfer, M. J., Hines, L. M., Selhub, J., and Hunter, D. J. Alcohol dehydrogenase 3 genotype is not predictive for risk of colorectal cancer. Cancer Epidemiology Biomarkers \& Prevention, 10: 1303-1304, 2001.

7. Giovannucci, E., Chen, J., Smith-Warner, S. A., Rimm, E. B., Fuchs, C. S., Palomeque, C., et al. Methylenetetrahydrofolate reductase, alcohol dehydrogenase, diet, and risk of colorectal adenomas. Cancer Epidemiol Biomarkers Prev, 12: 970-979, 2003.

8. Tiemersma, E. W., Wark, P. A., Ocke, M. C., Bunschoten, A., Otten, M. H., Kok, F. J., et al. Alcohol consumption, alcohol dehydrogenase 3 polymorphism, and colorectal adenomas. Cancer Epidemiology Biomarkers \& Prevention, 12: 419-425, 2003.

9. Willett, W. C. Implications of total energy intake for epidemioligic analyses. In: W. C. Willett and M. Stampfer (eds.), Nutritional Epidemiology, pp. 273-301. Oxford: Oxford University Press, 1990.

10. Van den Brandt, P. A., Goldbohm, R. A., van 't Veer, P., Volovics, A., Hermus, R. J., and Sturmans, F. A large-scale prospective cohort study on diet and cancer in The Netherlands. J Clin Epidemiol, 43: 285-295, 1990.

11. Dawson, D. A. Methodological issues in measuring alcohol use. Alcohol Research \& Health, 27: 18-29, 2003.

12. Midanik, L. T. Perspectives on the validity of self-reported alcohol use. $\mathrm{Br} \mathrm{J}$ Addict, 84: 1419-1423, 1989.

13. Midanik, L. T. Validity of self-reported alcohol use: a literature review and assessment. Br J Addict, 83: 1019-1030, 1988.

14. Rehm, J. Measuring quantity, frequency, and volume of drinking. Alcohol Clin Exp Res, 22: 4S-14S, 1998. 
15. Goldbohm, R. A., van den Brandt, P. A., Brants, H. A., van't Veer, P., Al, M., Sturmans, F., et al. Validation of a dietary questionnaire used in a large-scale prospective cohort study on diet and cancer. Eur J Clin Nutr, 48: 253-265, 1994.

16. Goldbohm, R. A., van 't Veer, P., van den Brandt, P. A., van 't Hof, M. A., Brants, H. A., Sturmans, F., et al. Reproducibility of a food frequency questionnaire and stability of dietary habits determined from five annually repeated measurements. Eur J Clin Nutr, 49: 420-429, 1995.

17. Kristal, A. R., Abrams, B. F., Thornquist, M. D., Disogra, L., Croyle, R. T., Shattuck, A. L., et al. Development and validation of a food use checklist for evaluation of community nutrition interventions. Am J Public Health, 80: 1318-1322, 1990.

18. Giovannucci, E., Colditz, G., Stampfer, M. J., Rimm, E. B., Litin, L., Sampson, L., et al. The assessment of alcohol consumption by a simple self-administered questionnaire. Am J Epidemiol, 133: 810-817, 1991.

19. Poikolainen, K., Vartiainen, E., and Korhonen, H. J. Alcohol intake and subjective health. Am J Epidemiol, 144: 346-350, 1996.

20. Rehm, J. Alcohol consumption and mortality. What do we know and where should we go? Addiction, 95: 989-995, 2000.

21. San Jose, B., van de Mheen, H., van Oers, J. A., Mackenbach, J. P., and Garretsen, H. F. The U-shaped curve: various health measures and alcohol drinking patterns. J Stud Alcohol, 60: 725-731, 1999.

22. Shaper, A. G. Alcohol and mortality: a review of prospective studies. Br J Addict, 85: 837-847; discussion 849-861, 1990.

23. Shaper, A. G., Wannamethee, G., and Walker, M. Alcohol and mortality in British men: explaining the U-shaped curve. Lancet, 2:1267-1273, 1988.

24. Grønbæk, M., Mortensen, E. L., Mygind, K., Andersen, A. T., Becker, U., Gluud, C., et al. Beer, wine, spirits and subjective health. J Epidemiol Community Health, 53: 721-724, 1999.

25. Tjonneland, A., Grønbæk, M., Stripp, C., and Overvad, K. Wine intake and diet in a random sample of 48763 Danish men and women. Am J Clin Nutr, 69: 49-54, 1999.

26. Le Marchand, L. Cancer preventive effects of flavonoids--a review. Biomed Pharmacother, 56: 296-301, 2002.

27. Ramos, S. Effects of dietary flavonoids on apoptotic pathways related to cancer chemoprevention. J Nutr Biochem, 18: 427-442, 2007.

28. Preussmann, R. Occurence and exposure to n-nitroso compounds and precursors. In: 0 . N. IK., V. B. RC., and M. CT. (eds.), N-Nitroso compounds: occurrence, biological effects and relevance to human cancer. Vol. 57, pp. 3-15. Lyon, France: IARC Sci Pub, 1984.

29. Willett, W. C., Howe, G. R., and Kushi, L. H. Adjustment for total energy intake in epidemiologic studies. Am J Clin Nutr, 65: 1220S-1228S; discussion 1229S-1231S, 1997.

30. Johansen, D., Andersen, P. K., Overvad, K., Jensen, G., Schnohr, P., Sørensen, T. I., et al. Energy adjustment methods applied to alcohol analyses. Alcohol, 31: 11-17, 2003. 
31. Stryker, S. J., Wolff, B. G., Culp, C. E., Libbe, S. D., Ilstrup, D. M., and MacCarty, R. L. Natural history of untreated colonic polyps. Gastroenterology, 93: 1009-1013, 1987.

32. Chen, C. D., Yen, M. F., Wang, W. M., Wong, J. M., and Chen, T. H. A case-cohort study for the disease natural history of adenoma-carcinoma and de novo carcinoma and surveillance of colon and rectum after polypectomy: implication for efficacy of colonoscopy. Br J Cancer, 88: 1866-1873, 2003.

33. Kapiteijn, E., Liefers, G. J., Los, L. C., Klein Kranenbarg, E., Hermans, J., Tollenaar, R. A. E. M., et al. Mechanisms of oncogenesis in colon versus rectal cancer. J Pathol, 195: 171178, 2001.

34. Konishi, K., Fujii, T., Boku, N., Koba, I., Ohtsu, A., Tajiri, H., et al. Clinicopathological differences between colonic and rectal carcinomas: are they based on the same mechanism of carcinogenesis? Gut, 45: 818-821, 1999.

35. Wei, E. K., Giovannucci, E., Wu, K., Rosner, B., Fuchs, C. S., Willet, W. C., et al. Comparison of risk factors for colon and rectal cancer. Int J Cancer, 108: 433-442, 2004.

36. Seitz, H. K. and Simanowski, U. A. Alcohol and Carcinogenesis. Annual Review of Nutrition, 8: 99-119, 1988.

37. Glebov, O. K., Rodriguez, L. M., Nakahara, K., Jenkins, J., Cliatt, J., Humbyrd, C. J., et al. Distinguishing right from left colon by the pattern of gene expression. Cancer Epidemiol Biomarkers Prev, 12: 755-762, 2003.

38. Corrao, G., Bagnardi, V., Zambon, A., and Arico, S. Exploring the dose-response relationship between alcohol consumption and the risk of several alcohol-related conditions: a meta-analysis. Addiction, 94: 1551-1573, 1999.

39. Seitz, H. K. and Simanowski, U. A. Alcohol and carcinogenesis. Ann Rev Nutr, 8: 99-119, 1988.

40. Arnold, C. N., Goel, A., Blum, H. E., and Boland, C. R. Molecular pathogenesis of colorectal cancer - Implications for molecular diagnosis. Cancer, 104: 2035-2047, 2005.

41. Fearon, E. R. and Vogelstein, B. A genetic model for colorectal tumorigenesis. Cell, 61: 759-767, 1990.

42. Vogelstein, B., Fearon, E. R., Hamilton, S. R., Kern, S. E., Preisinger, A. C., Leppert, M., et al. Genetic alterations during colorectal-tumor development. N Engl J Med, 319: 525$532,1988$.

43. Polakis, P. Mutations in the $A P C$ gene and their implications for protein structure and function. Curr Opin Genet Dev, 5: 66-71, 1995.

44. Miyoshi, Y., Nagase, H., Ando, H., Horii, A., Ichii, S., Nakatsuru, S., et al. Somatic mutations of the $A P C$ gene in colorectal tumors: mutation cluster region in the $A P C$ gene. Hum Mol Genet, 1: 229-233, 1992.

45. Bos, J. L. ras oncogenes in human cancer: a review. Cancer Res, 49: 4682-4689, 1989. 
46. Sieben, N. L., Roemen, G. M., Oosting, J., Fleuren, G. J., van Engeland, M., and Prat, J. Clonal analysis favours a monoclonal origin for serous borderline tumours with peritoneal implants. J Pathol, 210: 405-411, 2006.

47. Hawkins, N., Norrie, M., Cheong, K., Mokany, E., Ku, S. L., Meagher, A., et al. CpG island methylation in sporadic colorectal cancers and its relationship to microsatellite instability. Gastroenterology, 122: 1376-1387, 2002.

48. Mitchell, R. J., Farrington, S. M., Dunlop, M. G., and Campbell, H. Mismatch repair genes $h M L H 1$ and $h M S H 2$ and colorectal cancer: A HuGE review. American Journal of Epidemiology, 156: 885-902, 2002.

49. Herman, J. G., Umar, A., Polyak, K., Graff, J. R., Ahuja, N., Issa, J. P., et al. Incidence and functional consequences of $h M L H 1$ promoter hypermethylation in colorectal carcinoma. Proc Natl Acad Sci U S A, 95: 6870-6875, 1998.

50. Brink, M., de Goeij, A. F., Weijenberg, M. P., Roemen, G. M., Lentjes, M. H., Pachen, M. M., et al. K-ras oncogene mutations in sporadic colorectal cancer in The Netherlands Cohort Study. Carcinogenesis, 24: 703-710, 2003.

51. Lüchtenborg, M., Weijenberg, M. P., Roemen, G. M. J. M., Bruine de, A. P., van den Brandt, P. A., Lentjes, M. H. F. M., et al. APC mutations in sporadic colorectal carcinomas from The Netherlands Cohort Study. Carcinogenesis, 25: 1219-1226, 2004.

52. Toyota, M., Ohe-Toyota, M., Ahuja, N., and Issa, J. P. Distinct genetic profiles in colorectal tumors with or without the $\mathrm{CpG}$ island methylator phenotype. Proc Natl Acad Sci U S A, 97: 710-715, 2000.

53. van Rijnsoever, M., Grieu, F., Elsaleh, H., Joseph, D., and lacopetta, B. Characterisation of colorectal cancers showing hypermethylation at multiple CpG islands. Gut, 51: 797802, 2002.

54. Samowitz, W. S., Albertsen, H., Herrick, J., Levin, T. R., Sweeney, C., Murtaugh, M. A., et al. Evaluation of a large, population-based sample supports a CpG island methylator phenotype in colon cancer. Gastroenterology, 129: 837-845, 2005.

55. Whitehall, V. L. J., Wynter, C. V. A., Walsh, M. D., Simms, L. A., Purdie, D., Pandeya, N., et al. Morphological and molecular heterogeneity within nonmicrosatellite instability-high colorectal cancer. Cancer Research, 62: 6011-6014, 2002.

56. Liang, J. T., Huang, K. C., Cheng, Y. M., Hsu, H. C., Cheng, A. L., Hsu, C. H., et al. P53 overexpression predicts poor chemosensitivity to high-dose 5-fluorouracil plus leucovorin chemotherapy for stage IV colorectal cancers after palliative bowel resection. Int J Cancer, 97: 451-457, 2002.

57. Agrelo, R., Cheng, W. H., Setien, F., Ropero, S., Espada, J., Fraga, M. F., et al. Epigenetic inactivation of the premature aging Werner syndrome gene in human cancer. Proc Natl Acad Sci U S A, 103: 8822-8827, 2006.

58. Ogino, S., Meyerhardt, J. A., Kawasaki, T., Clark, J. W., Ryan, D. P., Kulke, M. H., et al. $\mathrm{CpG}$ island methylation, response to combination chemotherapy, and patient survival in 
advanced microsatellite stable colorectal carcinoma. Virchows Arch, 450: 529-537, 2007.

59. Jacoby, R. F., Alexander, R. J., Raicht, R. F., and Brasitus, T. A. K-ras oncogene mutations in rat colon tumors induced by $\mathrm{N}$-methyl-N-nitrosourea. Carcinogenesis, 13: 45-49, 1992.

60. Seitz, H. K., Simanowski, U. A., Garzon, F. T., Rideout, J. M., Peters, T. J., Koch, A., et al. Possible Role of Acetaldehyde in Ethanol-Related Rectal Cocarcinogenesis in the Rat. Gastroenterology, 98: 406-413, 1990.

61. Eastwood, G. L. and Trier, J. S. Epithelial cell renewal in cultured rectal biopsies in ulcerative colitis. Gastroenterology, 64: 383-390, 1973.

62. Simanowski, U. A., Homann, N., Knuhl, M., Arce, L., Waldherr, R., Conradt, C., et al. Increased rectal cell proliferation following alcohol abuse. Gut, 49: 418-422, 2001.

63. Website of Statistics Netherlands: www.cbs.nl. Accessed March, 2008.

64. Gezondheidsraad Richtlijnen Goede Voeding 2006. Den Haag 2006, publicatie nr. $2006 / 21$.

65. Website of the Netherlands Nutrition Centre: www.voedingscentrum.nl. Accessed March, 2008.

66. 66. Website of The Netherlands Heart Foundation: www.hartstichting.nl/go. Accessed march, 2008.

67. Website of the Dutch Cancer Society: www.kwfkankerbestrijding.nl. Accessed March, 2008.

68. WHO Global Status Report on Alcohol 2004. Geneva: Department of Mental Health and Substance Abuse, World Health Organisation, 2004.

69. Peterson, K. Biomarkers for alcohol use and abuse. Alcohol Res Health, 28: 30, 2004.

70. Halvorson, M. R., Campbell, J. L., Sprague, G., Slater, K., Noffsinger, J. K., and Peterson, C. M. Comparative evaluation of the clinical utility of three markers of ethanol intake: the effect of gender. Alcohol Clin Exp Res, 17: 225-229, 1993.

71. Peterson, C. M. and Polizzi, C. M. Improved method for acetaldehyde in plasma and hemoglobin-associated acetaldehyde: results in teetotalers and alcoholics reporting for treatment. Alcohol, 4: 477-480, 1987.

72. Rajagopalan, H. and Lengauer, C. CIN-ful cancers. Cancer Chemotherapy and Pharmacology, 54: S65-S68, 2004.

73. Sieber, O. M., Heinimann, K., and Tomlinson, I. P. Genomic instability--the engine of tumorigenesis? Nat Rev Cancer, 3: 701-708, 2003. 



\section{APPENDIX}

How often have you used the following beverages during the whole day?

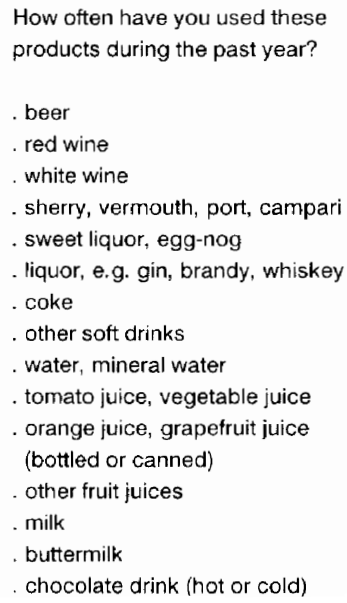

$\begin{array}{lllllll}\text { never or } & 1 x & 2-3 x & \mathbf{1 x} & \mathbf{2 - 3 x} & \mathbf{4 - 5 x} & \mathbf{6 - 7 x} \\ \text { lessthan } & \text { per } & \text { per } & \text { per } & \text { per } & \text { per } & \text { per } \\ 1 \text { x/month } & \text { mo. } & \text { mo. } & \text { week } & \text { week } & \text { week } & \text { week } \\ \square & \square & \square & \square & \square & \square & \square \\ \square & \square & \square & \square & \square & \square & \square \\ \square & \square & \square & \square & \square & \square & \square \\ \square & \square & \square & \square & \square & \square & \square \\ \square & \square & \square & \square & \square & \square & \square \\ \square & \square & \square & \square & \square & \square & \square \\ \square & \square & \square & \square & \square & \square & \square \\ \square & \square & \square & \square & \square & \square \\ \square & \square & \square & \square & \square & \square & \square \\ \square & \square & \square & \square & \square & \square & \square \\ \square & \square & \square & \square & \square & \square & \square \\ \square & \square & \square & \square & \square & \square & \square \\ \square & \square & \square & \square & \square & \square \\ \square & \square & \square & \square & \square & \square & \square\end{array}$

How much did you drink per day

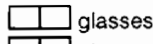

\begin{tabular}{|l|l}
\hline & glasses \\
\hline & glasses
\end{tabular} W glasses W glasses प पـ glasses $\square$ glasses 口 glasses 1 glasses $\square$ glasses W glasses $\square$ glasses ए_ glasses $\square$ glasses

Five years ago, did you use more, less or just as much of the following products as you do today?

\begin{tabular}{|c|c|c|c|c|}
\hline & $\begin{array}{l}\text { five years ago } \\
\text { more than today }\end{array}$ & $\begin{array}{l}\text { five years ago } \\
\text { less than today }\end{array}$ & $\begin{array}{l}\text { five years ago } \\
\text { as much as today }\end{array}$ & $\begin{array}{l}\text { I never } \\
\text { use this }\end{array}$ \\
\hline meat, sliced cold meat & ロ & $\square$ & ロ & $\sqsubset$ \\
\hline eggs & ロ & ロ & ロ & 口 \\
\hline raw vegetables & ロ & 口 & ロ & ש \\
\hline fruit & $\square$ & 口 & $\square$ & $\square$ \\
\hline beer & ロ & $\square$ & $\square$ & $\square$ \\
\hline other alcoholic beverages & ロ & ๑ & 口 & $\square$ \\
\hline fruit juice & 口 & ロ & 口 & 口 \\
\hline cotfee & ロ & ロ & $\square$ & $\square$ \\
\hline peanut butter & ロ & 口 & $\square$ & ص \\
\hline
\end{tabular}





\section{Summary}



Consumption of alcohol is an established risk factor for several chronic diseases including cancer. In general, cancer risk increases with the amount of alcohol consumed. To date, alcohol has convincingly been linked to cancers of the head and neck (mouth, pharynx, larynx and esophagus), stomach and breast. Large epidemiological studies have also shown a relationship between the intake of alcohol and an increased risk of colorectal cancer (CRC). Yet, the exact mechanism through which alcohol enhances this risk is still largely unknown. In addition, current knowledge is also lacking with regard to how alcohol relates to CRC risk in men and women separately, and to cancer occurrence in the distinct anatomical sublocalisations of the colorectal tract. Aiming to shed more light on these aspects and to uncover clues for the carcinogenic mechanism, we have extensively studied the effect of total habitual alcohol consumption and intake of alcoholic beverages on the risk of CRC, using data on (a) cancer occurrence according to gender and anatomical subsite, (b) the presence of single nucleotide polymorphisms in the alcohol dehydrogenase $1 C$ ( $A D H 1 C)$ gene, which is involved in the metabolism of alcohol, and (c) molecular tumor characteristics to distinguish various cancer subgroups and endpoints. In addition, we performed sensitivity analyses on a subgroup of drinkers that reported to have consumed equal amounts of alcohol five years before baseline as compared to baseline, and we studied alcohol as a potential effect-modifier.

The studies described in this thesis were performed within the ongoing Netherlands Cohort Study on diet and cancer (NLCS). The NLCS was initiated in September 1986. A total of 120,852 men and women aged 55 to 69 years, returned a selfadministered questionnaire on habitual dietary habits and alcohol consumption, life style and other risk factors for cancer. According to the case-cohort approach, a randomly drawn subcohort consisting of 5,000 men and women, is followed up biennially for vital status to estimate the accumulating person time at risk, whereas the entire cohort is followed up annually for cancer occurrence. During the present research the total follow-up time was 13.3 years. Between August 1999 and December 2001, tumor material was collected from cases that were diagnosed with CRC within the first 7.3 years of follow-up. The DNA in these samples was used for molecular characterization of the tumors. In December 2000, members of the subcohort were contacted for the collection of mouth swabs, and DNA was isolated from these swabs to enable the studying of gene-environment interactions within the NLCS. 
In the study described in chapter 2, we examined the overall associations between alcohol intake and the risk of CRC. Since we did not use molecular data, information of up to 13.3 years of follow-up was available. A habitual daily alcohol consumption of 30 grams (approximately three alcoholic drinks) or more was associated with a $30 \%$ increase in risk of CRC, when compared to abstaining. However, baseline consumption levels may be subject to misclassification of former drinkers and drinkers with changed drinking habits. This may lead to a certain level of noise in the risk estimates for disease, namely the more valid an exposure measurement, the more accurate the risk estimates. Subsequently, the analyses were restricted to a subgroup of drinkers that reported to have consumed equal amounts of alcohol five years before baseline, compared to baseline drinking levels. The reference group consisted of baseline abstainers that reported to have abstained from alcohol five years before baseline. The results now showed a $53 \%$ increase in CRC risk for consumers of $\geq 30.0$ grams of alcohol per day, indicating that information on drinking habits in the past is a valuable addition to information on baseline alcohol consumption. Although we found no evidence for a sex-specific relationship between alcohol intake and risk of $\mathrm{CRC}$, there were indications for a subsite-specific effect of alcohol. For consumers of $\geq 30.0$ grams of alcohol per day, there seemed to be a gradient of increasing risk from the proximal colon ( $29 \%$ increase in cancer risk) through the rectum (a $69 \%$ increase in cancer risk). Finally, analyses of different types of alcoholic beverages showed that CRC risk was likely to be affected by the alcohol content of the beverages, rather than by other beverage constituents.

Functional polymorphisms in genes involved in the metabolism of alcohol may underlie a potential genetic susceptibility to alcohol-related CRC. In the study described in chapter 3, we studied whether associations between alcohol and CRC risk were likely to differ according to the $A D H 1 C$ genotype. A possible indication for this was only observed among the subgroup of drinkers that reported to have consumed equal amounts of alcohol five years before baseline, compared to baseline. The highest risk of CRC was restricted to drinkers of $\geq 30.0 \mathrm{~g} / \mathrm{d}$ with the $A D H 1 C * 2 / * 2$ genotype, relative to the reference group of abstainers with the $A D H 1{ }^{* 1} / * 1$ genotype. Also, consumption of $\geq 30.0 \mathrm{~g} / \mathrm{d}$ in combination with the heterozygous $A D H 1 C * 1 / * 2$ genotype was associated with an increased risk of CRC, when compared to the reference group. Yet, the elevated risk estimates and the 
interaction term for $A D H 1 C$ genotype and alcohol intake were not statistically significant.

In order to gain further insight into the specific role of alcohol with regard to the colorectal carcinogenic mechanism, we studied three subgroups of tumors. These subgroups were based on tumors with similar molecular characteristics and may represent proxies for distinct etiological pathways (chapter 4). Although the numbers of cases in some of these subgroups were small, the results all pointed towards a positive relationship. A daily alcohol consumption of $\geq 30.0 \mathrm{~g}$ seemed associated with an increased risk of colorectal tumors characterized by (a) either a truncating $A P C$ mutation, an activating KRAS mutation or overexpression of TP53 (as a proxy for the chromosomally instable (CIN) pathway); and (b) tumors lacking expression of MLH1 (as a proxy for the microsatellite instable (MSI) pathway) and (c) tumors that did not harbor any of these aberrations (as a proxy for a pathway other than the CIN or MSI pathway). As such, alcohol may be more likely to exert an overall effect, instead of an effect limited to specific genes or molecular events.

In addition to genetic abnormalities, CRC may also be characterized by epigenetic aberrations. Therefore, we studied associations between consumption of alcohol and tumors expressing MSI and MSI-related aberrations, i.e., MLH1 hypermethylation, absence of MLH1 expression and presence of BRAF oncogene mutations (chapter 5). For these analyses the MSI status was available as assessed according to a series of pre-described MSI markers. Despite small numbers of cases, all risk estimates for high alcohol consumers, relative to abstainers, pointed towards an increased risk of CRC harboring MSI and the studied MSI-related defects. To examine the possibility that alcohol may contribute to CRC through counteracting the methyl donors folate and methionine - factors both suggested of having a protective effect against the development of CRC - we examined the modifying effect of alcohol on associations between folate and methionine and colorectal tumors harboring MSI and MSI-related aberrations. For none of the examined molecular endpoints the interaction term between alcohol and folate, and between alcohol and methionine, reached statistical significance.

Finally, we examined in chapter 6 if alcohol consumption was related to single genetic aberrations, i.e. a point mutation in the KRAS gene. We studied two hypotheses: (a) alcohol consumption may predispose to CRC by causing mutations in 
the KRAS oncogene - one of the key genes involved in the carcinogenic process and (b) beer consumption is associated with $G>A$ mutations in this gene. Compared to abstaining, a daily alcohol intake of $\geq 30.0 \mathrm{~g}$ seemed positively associated with the risk of colorectal tumors harboring a KRAS mutation. Yet, the same was true for colorectal tumors without a KRAS mutation. We did not find strong indications for a relationship between beer consumption and the risk of CRC harboring a $\mathrm{G}>\mathrm{A}$ mutation in the gene. As such, the results suggested that the induction of KRAS mutations is not a predominant mechanism in alcohol-related colorectal carcinogenesis.

In chapter 7, the main findings of the studies described in this thesis are summarized. Several aspects are discussed regarding assessment of alcohol exposure, stressing the importance of additional measurement of consumption habits in the (recent) past as a means of reducing misclassification of former drinkers. Taking into account several points of attention with regard to analyzing the effect of alcohol and alcoholic beverages, we elaborate on the use of statistical methods to analyze the effect of an alcoholic beverage independent of its alcoholic content and subsequent implications for interpretation of the results. Furthermore, the relevance of genetic polymorphisms and genetic and molecular endpoints to increase the insights into the carcinogenic mechanisms are discussed. The genetic epidemiological studies that have been performed to date, have appeared too small to yield consistent results and to allow clear conclusions on the role of alcohol in CRC. Since the initiation of new large molecular studies is very time consuming and financially unattractive, pooling of existing genetic and molecular data may be a good alternative for future analyses. Chapter 7 continues with a discussion on the implications of the study results. These results do not require a revision of our Dutch guidelines for safe alcohol use. Finally, suggestions for future research are given, and we conclude that there is a growing need for a proper understanding of alcohol-related CRC. This would be very helpful to adequately deal with the consequences of the rising rates of both alcohol consumption and CRC diagnoses. 


\section{Samenvatting}



Consumptie van alcohol is een bekende risicofactor voor verschillende chronische aandoeningen, waaronder kanker. In het algemeen neemt het risico op kanker toe naarmate de hoeveelheid alcohol die gedronken wordt toeneemt. Tegenwoordig bestaat er overtuigend bewijs dat alcohol gerelateerd is aan het optreden van hoofdhals tumoren (mond, mondholte, keelholte en slokdarm), maagkanker en borstkanker. Grote epidemiologische studies hebben aangetoond dat er ook een relatie bestaat tussen de inname van alcohol en een verhoogd risico op dikke darmkanker. Echter, het precieze mechanisme waarlangs alcohol het risico op dikke darmkanker zou verhogen is nog grotendeels onbekend. Daarnaast is ook nog niet duidelijk of de risico's op alcoholgerelateerde dikke darmkanker even groot zijn voor mannen en vrouwen, en of deze risico's onderling verschillen voor de afzonderlijke anatomisch subgebieden van de dikke darm. In een poging om meer inzicht te krijgen in de bovengenoemde aspecten en het mechanisme van carcinogenese, hebben we het effect van de totale dagelijkse alcoholconsumptie, en van de inname van alcoholische dranken, op het risico op dikke darmkanker uitvoerig onderzocht. Hierbij is gebruik gemaakt van gegevens over (a) het geslacht van de onderzoeksdeelnemers en de anatomische sublokalisatie van de tumor, (b) de aanen afwezigheid van een functioneel genetisch polymorfisme in het alcohol dehydrogenase $1 C(A D H 1 C)$ gen, dat betrokken is bij het alcohol metabolisme, en (c) moleculaire tumorkarakteristieken om verschillende tumorsubgroepen en eindpunten te kunnen onderscheiden.

De studies die in dit proefschrift zijn beschreven, zijn uitgevoerd binnen de lopende Nederlandse Cohort Studie naar voeding en kanker (NLCS). De NLCS is in september 1986 geinitieerd. In totaal hebben 120.852 mannen en vrouwen in de leeftijd van 55 tot 69 jaar, een vragenlijst retour gezonden over hun gebruikelijke eetgewoonten en alcoholconsumptie, leefstijl en andere risicofactoren voor kanker. De NLCS hanteert het zogenoemde case-cohort design. Een aselect getrokken steekproef uit het cohort, het subcohort bestaande uit 5.000 mannen en vrouwen, wordt tweejaarlijks gecontroleerd op vitale status voor een schatting van de opgebouwde persoonstijd in het cohort. Voor het hele cohort wordt jaarlijks het optreden van kanker vastgesteld. Ten tijde van het huidige onderzoek was de totale follow-upduur 13,3 jaar. Tussen augustus 1999 en december 2001 is tumormateriaal verzameld van alle dikke darmkankerpatiënten die gediagnosticeerd zijn binnen de eerste 7,3 jaar follow-up van het cohort. In het DNA uit dit tumorweefsel zijn vooraf moleculaire en genetische afwijkingen van de tumor bepaald. In december 2000 zijn de leden van 
het subcohort gevraagd om wangslijmvliesmonsters te verzamelen. Hieruit is DNA geëxtraheerd ten behoeve van onderzoek naar gen-omgevingsinteracties binnen de NLCS.

In de studie die beschreven is in hoofdstuk $\mathbf{2}$, hebben we het verband tussen alcoholinname en het risico op dikke darmkanker bestudeerd. Omdat in dit onderzoek geen gebruik is gemaakt van moleculaire data, stond ons de informatie van 13,3 jaar follow-up ter beschikking. Een gemiddelde dagelijkse alcoholinname van 30 gram (ongeveer drie alcoholische consumpties) en meer, was geassocieerd met een $30 \%$ hoger risico op dikke darmkanker ten opzichte van geheelonthouding. Echter, het indelen van de deelnemers in categorieën op grond van hun gerapporteerde alcoholinname aan het begin van de studie, kan onderhevig zijn aan misclassificatie van ex-drinkers en drinkers met veranderde drinkgewoonten. Dit kan aanleiding geven tot een zekere mate van ruis in de risicoschattingen voor ziekte. Immers hoe meer valide het blootstellingsniveau kan worden gemeten, des te accurater de uiteindelijke risicoschattingen zullen zijn. Aldus zijn de analyses vervolgens beperkt tot een subgroep van drinkers die aangegeven heeft vijf jaar voor de beginmeting vergelijkbare hoeveelheden alcohol te hebben gedronken, als ten tijde van de beginmeting. De referentie groep betrof hier de subgroep van geheelonthouders die rapporteerden dat zij zich vijf jaar voor de beginmeting ook van alcohol onthielden. De resultaten toonden nu een $53 \%$ hoger risico op dikke darmkanker voor drinkers van $\geq 30.0$ gram alcohol per dag. Het verkeerd classificeren van voormalige drinkers en drinkers met veranderde consumptiegewoonten werd geminimaliseerd waardoor een meer valide schatting van het risico op ziekte mogelijk werd. Informatie over drinkgewoonten in het verleden bleek dus een waardevolle aanvulling te zijn op gegevens over alcoholconsumptie ten tijde van de beginmeting. $\mathrm{Er}$ waren geen verdere aanwijzingen dat het verband tussen alcoholinname en het risico op dikke darmkanker geslachtsspecifiek zou zijn, al waren er wel aanwijzingen dat het verband samenhing met de anatomische sublokalisaties van de dikke darm. Voor drinkers van $\geq 30.0$ gram alcohol per dag leek het kankerrisico toe te nemen vanaf het voorste deel van de dikke darm (een $29 \%$ verhoogd risico) tot en met het rectum (een $69 \%$ verhoogd risico). Tenslotte wezen analyses van de verschillende typen alcoholische dranken erop dat hoogst waarschijnlijk de alcohol hierin het risico op dikke darmkanker verhoogt, in tegenstelling tot de overige bestanddelen van deze dranken. 
Functionele genetische polymorfismen in genen die betrokken zijn bij het alcoholmetabolisme, kunnen ten grondslag liggen aan een genetische gevoeligheid voor alcoholgerelateerde dikke darmkanker. In de studie die beschreven is in hoofdstuk 3 hebben we onderzocht of het verband tussen alcohol en dikke darmkanker verschilt al naar gelang het $A D H 1 C$ genotype. Een mogelijke indicatie hiervoor werd echter alleen gezien voor de subgroep van drinkers die aangaf vijf jaar voor de beginmeting vergelijkbare hoeveelheden alcohol te hebben gedronken als ten tijde van de beginmeting. Drinkers van $\geq 30.0$ gram alcohol per dag met het $A D H 1 C * 2 / * 2$ genotype leken het hoogste riscico op dikke darmkanker te hebben, vergeleken met de referentiegroep van geheelonthouders met het $A D H 1 C * 1 /{ }^{* 1}$ genotype. Maar ook het drinken van $\geq 30.0$ gram alcohol per dag in combinatie met het heterozygote $A D H 1 C^{*} 1 /{ }^{*} 2$ genotype was geassocieerd met een verhoogd risico op dikke darmkanker, ten opzichte van de genoemde referentiegroep. De interactieterm voor $A D H 1 C$ genotype en alcoholinname was echter niet statistisch significant.

Om meer inzicht te verkrijgen in de rol van alcohol bij de ontwikkeling van dikke darmkanker hebben we drie subgroepen van tumoren bestudeerd. Deze subgroepen zijn gevormd op basis van tumoren met gelijke moleculaire karakteristieken en kunnen mogelijk als representanten gelden voor verschillende ontstaanswijzen. Hoewel de aantallen cases in sommige subgroepen klein waren, wezen de resultaten alle in de richting van een positief verband. Een dagelijkse consumptie van $\geq 30.0$ gram alcohol was geassocieerd met een verhoogd risico op (a) dikke darmtumoren met een trunkerende $A P C$ mutatie en/of een activerende KRAS mutatie en/of overexpressie van het TP53 eiwit (als representanten voor de chromosomaal instabiele (CIN) ontstaanswijze), (b) dikke darmtumoren met een ontbrekende MLH1 expressie (als representanten voor de microsatelliet instabiele (MSI) ontstaanswijze), en (c) dikke darmtumoren zonder de bovengenoemde afwijkingen (als representanten voor een ontstaanswijze anders dan CIN en MSI) (hoofdstuk 4). Alcoholconsumptie leek dus eerder een algemeen effect te hebben op dikke darmkanker dan een effect dat beperkt was tot tumoren met specifieke moleculaire afwijkingen.

Omdat dikke darmkanker naast genetische afwijkingen ook gekenmerkt kan zijn door epigenetische abnormaliteiten, hebben we in hoofdstuk 5 relaties bestudeerd tussen alcoholconsumptie en tumoren met MSI en MSI-gerelateerde afwijkingen, te weten 
$M L H 1$ hypermethylering, afwezigheid van MLH1 expressie en aanwezigheid van BRAF oncogen mutaties. Voor deze analyses was de MSI status beschikbaar zoals bepaald aan de hand van een serie voorgeschreven MSI markers. Ondanks de kleine aantallen patiënten in sommige subgroepen wezen de risicoschattingen voor de zware alcoholdrinkers in vergelijking met geheelonthouders, in de richting van een verhoogd risico op dikke darmtumoren met MSI en de bestudeerde MSI-gerelateerde afwijkingen. Om te bestuderen of alcohol mogelijk bijdraagt aan dikke darmkanker door het tegenwerken van de methyldonoren folaat en methionine - factoren met een verondersteld beschermende werking tegen dikke darmkanker - hebben we bestudeerd of alcohol de associaties tussen folaat en methionine en dikke darmtumoren met MSI en MSI-gerelateerde afwijkingen wellicht kon modificeren. Echter, voor geen van de onderzochte moleculaire eindpunten was de interactieterm tussen alcohol en folaat, en tussen alcohol en methionine, statistisch significant.

Tenslotte is in hoofdstuk 6 onderzocht of er een verband bestond tussen alcoholinname en een enkelvoudige genetische afwijking, namelijk een puntmutatie in het KRAS gen. We hebben twee hypothesen bestudeerd: (a) alcoholinname leidt tot dikke darmkanker door het veroorzaken van mutaties in het KRAS oncogen - een van de sleutelgenen betrokken bij de ontwikkeling van dikke darmkanker - en (b) bierconsumptie is gerelateerd met $G>A$ mutaties in dit gen. Vergeleken met geheelonthouding was een dagelijkse inname van $\geq 30.0$ gram alcohol geassocieerd met het risico op dikke darmtumoren met een KRAS mutatie. Hetzelfde gold echter ook voor dikke darmtumoren zonder een KRAS mutatie. We vonden verder geen sterke aanwijzingen voor een verband tussen bierconsumptie en dikke darmtumoren met een G>A mutatie in het KRAS gen. Aldus lijken de bevindingen te suggereren dat een alcoholgerelateerde ontwikkeling van dikke darmkanker niet verloopt via het veroorzaken van (specifieke) KRAS mutaties.

In hoofdstuk 7 zijn de belangrijkste bevindingen samengevat van de studies beschreven in dit proefschrift. Verscheidene aspecten met betrekking tot het bepalen van de blootstelling aan alcohol worden besproken, waarbij het belang van navraag naar drinkgewoonten in het (nabije) verleden wordt benadukt als belangrijk middel om misclassificatie van voormalige drinkers te minimaliseren. Met het oog op het analyseren van de effecten van alcohol en alcoholische dranken, gaan we nader in op het gebruik van statistische methoden om het effect van een alcoholische drank onafhankelijk van zijn alcoholische inhoud te analyseren. De hiermee 
samenhangende implicaties voor een correcte interpretatie van de resultaten worden besproken. Vervolgens wordt het gebruik van genetische polymorfismen en moleculaire eindpunten om inzicht te verkrijgen in de verschillende carcinogene mechanismen ter discussie gesteld. De genetisch epidemiologische studies die tot op heden zijn uitgevoerd, zijn te klein gebleken om eenduidige resultaten te verkrijgen en om duidelijke conclusies te kunnen trekken omtrent de rol van alcohol in het ontstaan van dikke darmkanker. Omdat het opzetten van grote nieuwe moleculaire studies zeer tijdrovend en financieel onaantrekkelijk is, kan het samenvoegen van bestaande genetische en moleculaire data een goed alternatief bieden voor toekomstige analyses. In hoofdstuk 7 bediscussiëren we voorts de implicaties van de studieresultaten. Onze bevindingen zijn geen aanleiding om de huidige Nederlandse richtlijnen betreffende een veilig alcoholgebruik te herzien. Tenslotte geven we suggesties voor toekomstig onderzoek naar alcoholconsumptie en dikke darmkanker, waarna we eindigen met de conclusie dat er een groeiende behoefte is aan een goed inzicht in alcoholgerelateerde dikke darmkanker. Alleen dan kan beter geanticipeerd worden op de consequenties die een toename van zowel alcoholconsumptie als het aantal gevallen van dikke darmkanker met zich mee brengen. 



\section{DANKWOORD}



Zoals zo vaak het laatste half jaar, zit ik dan nu toch echt voor de laatste keer aan mijn laptop. Belandt bij die laatste paar witte pagina's bedenk ik me dat er in de afgelopen vier jaar ontzettend veel is gebeurd. Het proefschrift is een feit!

In dit dankwoord wil ik me op de eerste plaats dan ook richten tot mijn twee copromotoren Matty Weijenberg en Ton de Goeij, en mijn promotor Piet van den Brandt. Jullie boden mij de mogelijk om het tweejarig onderzoekproject, waarop ik destijds was aangesteld, tot "proefschriftwaardige" proporties uit te breiden. Ik ben jullie zeer dankbaar voor deze unieke kans en jullie vertrouwen in mij om dat ook met succes te volbrengen. Matty en Ton, ik heb enorm veel van jullie geleerd. Ik heb jullie wijze van begeleiding, met opbouwende kritiek en tactische sturing erg gewaardeerd. Onze werkoverleggen verliepen zeer prettig en ontspannen, zodat ik altijd naar mijn pc terugkeerde met het gevoel weer "back on track" te zijn. Hoe fijn ook dat de eerste 5 minuten van ieder overleg (bij benadering) gebruikt werden om elkaar even bij te kletsen over van alles en nog wat. Vergezeld van een lekker kopje koffie. Maar ehh..., hoe dronk Ton zijn koffie nu toch ook alweer? Bedankt voor alle tijd die jullie voor mij hebben vrijgemaakt, zelfs toen mijn dienstverband reeds ten einde was. Jullie zijn een super-team! Piet, jij hebt me geleerd om me efficiënt en doelgericht op alle analyses en publicaties te storten. Bedankt voor je deskundige sturing en adviezen, voor het in het oog houden van de "haalbaarheid" van praktisch alles en voor de ruimte die je me bood (letterlijk én figuurlijk) in de afrondingsfase van mijn proefschrift.

Graag wil ik Maurice Zeegers bedanken voor het mij destijds onder de aandacht brengen van de desbetreffende vacature bij Epidemiologie. Doordat jij de aio in mij wel zag, meer nog dan ikzelf, heb ik uiteindelijk ook echt gesolliciteerd. Thanks!

In diezelfde tijd waarin ik was aangesteld bij Epidemiologie, was ook Stefan de Vogel aangenomen op een project waar Matty subsidie voor had aangevraagd. Omdat onze onderzoeken nauw verbonden waren, getuige hoofdstuk 5 van dit proefschrift, was het niet meer dan logisch dat we kamergenoten zouden worden. Stefan, de interactie tussen alcohol en folaat is niet statistisch significant gebleken, maar ik zou willen stellen dat onze "interactie" dat wel was. Het standaard de draad kwijtraken na het samenstellen van een nieuwe, nog grotere, dataset voor ieder volgend artikel waarna "de aantallen" weer eens niet klopten, schept toch een band. Daarnaast kan ik ook nog opsommen: het intypen van mega-tabellen (en die 
uiteindelijk niet gebruiken in het artikel), koffie bij epi, bodemprijzen bij Paradigit, STATA, of toch liever SAS, cursus in Stockholm (Einstein's relativiteitstheorie ís te weerleggen), wintersport, SNPs (sterk geassocieerd met mega-tabellen), ..., en alle persoonlijke wel-en-wee. Ik wens je heel veel succes bij de afronding van jouw proefschrift en alle geluk straks in Noorwegen.

Manon van Engeland en Kim Wouters, jullie ben ik veel dank verschuldigd voor de grote hoeveelheid labdata die jullie hebben aangeleverd voor mijn onderzoek; Manon voor het mogelijk maken van alle lab-analyses en Kim voor de daadwerkelijke uitvoering hiervan, en de kunde en snelheid waarmee dit gebeurde... en natuurlijk niet te vergeten je stressbestendigheid. Want hoewel het analyseren van de SNPs een zeer stroeve start kende, heb je alles op alles gezet om het zo snel mogelijk voor elkaar te krijgen!

Sandra Bausch wil ik bedanken voor haar kritische blik op mijn analyses en alle nuttige opmerkingen en tips voor het schrijven en herschrijven van mijn artikelen (wat toch vaak zijn vruchten afwierp).

Al mijn (inmiddels oud-) collega's van de capaciteitsgroep Epidemiologie wil ik bedanken voor de immer prettige en collegiale sfeer. Alle mede-promovendi - reeds gepromoveerd of nog niet: Audrey, Bianca, Esther, Janneke, Jessie, John, Lore, Kim, Mirjam, Monique, Saskia, Stefan en Stephanie, het was altijd leuk om het promovendi wel-en-wee, en alles daarbuiten, met elkaar te delen. Een speciale woordje van dank wil ik uit laten gaan naar Janneke, die zich "opgeofferde" om mij te vergezellen naar 's werelds grootste congres over kanker in Los Angeles (ik was als de dood om helemaal alleen te moeten gaan). Wat we in die ene week LA en daarna in die extra week Kings Canyon National Park toch allemaal hebben meegemaakt... Gelukkig voor ons had het in ieder geval niets te maken met slangen, beren en poema's. Ik denk nog vaak met veel plezier terug aan onze vakantie, ehh congresbezoek.

Ook bij het IKL, mijn huidige werkgever, is het goed toeven dankzij leuke en betrokken collegas. Ik wil met name Miranda Dirx en Ruth Daamen bedanken voor de mogelijkheid die zij mij boden om mijn baan als epidemioloog bij het IKL te kunnen combineren met het afronden van mijn proefschrift. 
Verder dank ik de dames van mijn volleybalteam en de leden van Trimclub Kessel voor hun belangstelling voor wat-het-dan-ook-was dat ik uitvoerde daar in Mestreech. Of was het nou juist het alcoholverhaal dat de meeste belangstelling wekte?

In het rijtje van belangstellenden horen natuurlijk ook (schoon-)familie en vrienden thuis. En hoewel ik vaak heb moeten uitleggen dat promoveren en afstuderen twee héél verschillende dingen zijn, het was toch fijn dat jullie altijd even informeerden hoe het in nog in Maastricht was en of ik mijn "scriptie" al bijna af had. Grote kleine zus Vera, en (mr!) Suzan, ik ben zeer blij dat jullie beiden meteen enthousiast instemden om paranimf te worden toen ik jullie dat vroeg, zij het zonder precies te weten wat het inhield. Yes!

Frank, geheel tegen je aard in heb je - zeker dit laatste jaar - veel geduld moeten opbrengen; je zag wat vakantie-plannen en weekend-tripjes aan je neus voorbij gaan, je heb je een heel aantal weekenden zonder mij moeten vermaken, je hebt je mond wijselijk maar gehouden wanneer ik stiekem wat werk meegesmokkelde, op vakantie notabene... You're the best!

Pap en mam, ook op jullie kan ik altijd rekenen. Zie hier wat jullie stimulans om toch vooral door te blijven leren teweeg heeft gebracht. Zonder jullie steun was het me nooit gelukt. Bedankt... voor alles!!

\section{Brenda}



Curriculum vitae |

\section{CURRICULUM VITAE}





\section{ABOUT THE AUTHOR}

Brenda Bongaerts was born on September 11, 1977 in Tegelen, the Netherlands. She completed secondary school (VWO) at the Bouwens van der Boijecollege in Panningen in 1996. In the same year, she started the paramedical study Medical Imaging and Radiation Therapy (MBRT) at Fontys Hogescholen, Eindhoven. After graduating and obtaining the Bachelor degree in 2000, Brenda went on to study Biological Health Science at the Faculty of Health Sciences of Maastricht University. In addition, she followed the Epidemiology master program of the university. Subsequently, both the studies Biological Health Sciences and Epidemiology were combined into one Master thesis, entitled "The influence of birth weight on lung function in young adults". This thesis was written during an internship at the Department of Epidemiology and the Department of and Genetics and Cell Biology, section Population Genetics, in 2003. After graduating in August, Brenda was engaged as a diagnostic radiographer at the Laurentius Ziekenhuis Roermond in Roermond for almost one year, to return to Maastricht University in June 2004. She started working as a researcher with the Department of Epidemiology, on a two-year project wich was funded by the European Research Advisory Board (ERAB) and was called "Alcohol consumption and risk of genetic alterations in genes involved in colorectal cancer in the Netherlands Cohort Study on diet and cancer". The studies performed within this project, including additional research questions that Brenda worked on for another year and a half, resulted in the current thesis. Since April 2007, Brenda works as an epidemiologist at the Comprehensive Cancer Centre Limburg (IKL), to evaluate the effects of the ongoing Dutch screening programs for breast and cervical cancer. 



\section{LIST OF PUBLICATIONS}

\section{Submitted manuscripts}

Bongaerts, B.W.C., de Goeij, A.F.P.M., Wouters, K.A.D., van Engeland, M., Gottschalk, R.W.H., van Schooten, F.J., Goldbohm, R.A., van den Brandt, P.A., Weijenberg, M.P. Alcohol consumption, alcohol dehydrogenase $1 C$ (ADH1C) genotype and risk of colorectal cancer in the Netherlands Cohort Study on diet and cancer.

\section{Peer-reviewed publications}

Bongaerts, B.W.C., van den Brandt, P.A., Goldbohm, R.A., de Goeij, A.F.P.M., Weijenberg, M.P. Alcohol consumption, type of alcoholic beverage and risk of colorectal cancer at specific subsites. Int J Cancer, 2008. In press.

De Vogel, S., Bongaerts, B.W.C., Wouters, K.A.D., Kester, A.D.M., Schouten, L.J., de Goeij, A.F.P.M., de Bruine, A.P., Goldbohm, R.A., van den Brandt, P.A., van Engeland, M., Weijenberg, M.P. Associations of dietary methyl donor intake with $M L H 1$ promoter hypermethylation and related molecular phenotypes in sporadic colorectal cancer. Carcinogenesis, 2008. In press.

Bongaerts, B.W.C., de Goeij, A.F.P.M., de Vogel, S., van den Brandt, P.A., Goldbohm, R.A., Weijenberg, M.P. Alcohol consumption and distinct molecular pathways to colorectal cancer. Br J Cancer, 97: 430-434, 2007.

Bongaerts, B.W.C., de Goeij, A.F.P.M., van den Brandt, P.A., Weijenberg, M.P. Alcohol and the risk of colon and rectal cancer with mutations in the KRAS gene. Alcohol, 38: 147-154, 2006.

Bongaerts, B.W.C., Porte, L.A. Haalbaarheid van Triple-Energy Window scattercorrectie bij dual isotope single acquisitie myocardperfusie SPECT. Tijdschrift voor Nucleaire Geneeskunde, 22: 123-129, 2000.

\section{Selected abstracts}

Bongaerts, B.W.C., de Goeij, A.F.P.M., Wouters, K.A.D., van Engeland, M., Gottschalk, R.W.H., van Schooten, F.J., Goldbohm, R.A., van den Brandt, P.A., Weijenberg, M.P. 
Alcohol consumption, alcohol dehydrogenase $1 C$ (ADH1C) genotype and risk of colorectal cancer. In: Gen en Omgeving. Abstractboek WEON: \#73, 2008.

Bongaerts, B.W.C., Botterweck, A.A.M., Huveneers, J.A.M., Dirx, M.J.M. Evaluation of interval breast cancers in the Limburg screening program, the Netherlands. In: Gen en Omgeving. Abstractboek WEON: \#146, 2008.

Bongaerts, B.W.C., de Goeij, A.F.P.M., van den Brandt, P.A., Goldbohm, R.A., Weijenberg, M.P. Moderate alcohol consumption, alcoholic beverages and risk of colorectal cancer. In: Proceedings of the AACR annual meeting: \#854, 2007.

Bongaerts, B.W.C., van den Brandt, P.A., Goldbohm, R.A., de Goeij, A.F.P.M., Weijenberg, M.P. Moderate alcohol consumption, alcoholic beverages and risk of colorectal cancer. In: Methodologische uitdagingen in cohortonderzoek. Abstractboek WEON: \#26, 2007.

Bongaerts, B.W.C., de Goeij, A.F.P.M., Goldbohm, R.A., van den Brandt, P.A., Weijenberg, M.P. Alcohol consumption and distinct pathways to colorectal cancer. Eur J Epidemiol, 21(S): 48, 2006.

Bongaerts, B.W.C., de Goeij, A.F.P.M., Goldbohm, R.A., van den Brandt, P.A., Weijenberg, M.P. Associations between alcohol consumption and the risk of sporadic colorectal cancer with or without K-ras gene mutations. Alcohol Alcoholism, 4O(S1): \#285, 2006.

Bongaerts, B.W.C., de Goeij, A.F.P.M., van den Brandt, P.A., Goldbohm, R.A., Weijenberg, M.P. Associations between alcohol consumption and the risk of sporadic colorectal cancer with or without K-ras oncogene mutations. In: Preventie \& Interventie: 30e WEON Symposium, Programma en abstracts, 2 \& 3 juni2005, WICC, Wageningen. Abstractboek WEON: \#v18, 2005. 